\section{3 \\ LA-6942-MS}

informal Report $\therefore \quad$ UC.20d

lssued: Sogiembar $\$ 977$

\section{th. \\ 1546}

\title{
Cross-Section Sensitivity Analyses for a Tokamak Experimental Power Reactor
}

\author{
E. L. Simmons \\ S. A. W. Gerst \\ Dnnald J. Dudziak
}

\section{cojentific laboratory \\ of the University of California \\ LOS ALAMOS, NEW MEXICO 87545

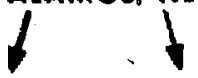

An Affirmalive Action/Equal Opportunity Employer 
Printed in the United States of America. Available from National Technical Information Service

U.S. Depurtment of Commerce

5285 Port Royal Road

Springfield, VA 22161

Price: Printed Copy $\$ 6.00$ Microfiche $\$ 3.00$

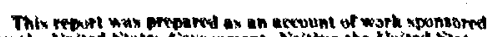

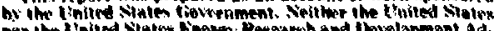

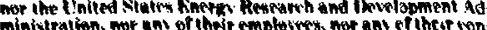

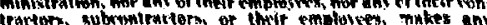

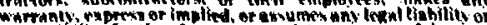

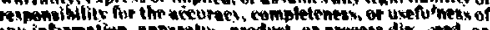

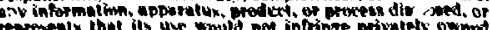
rithix. 


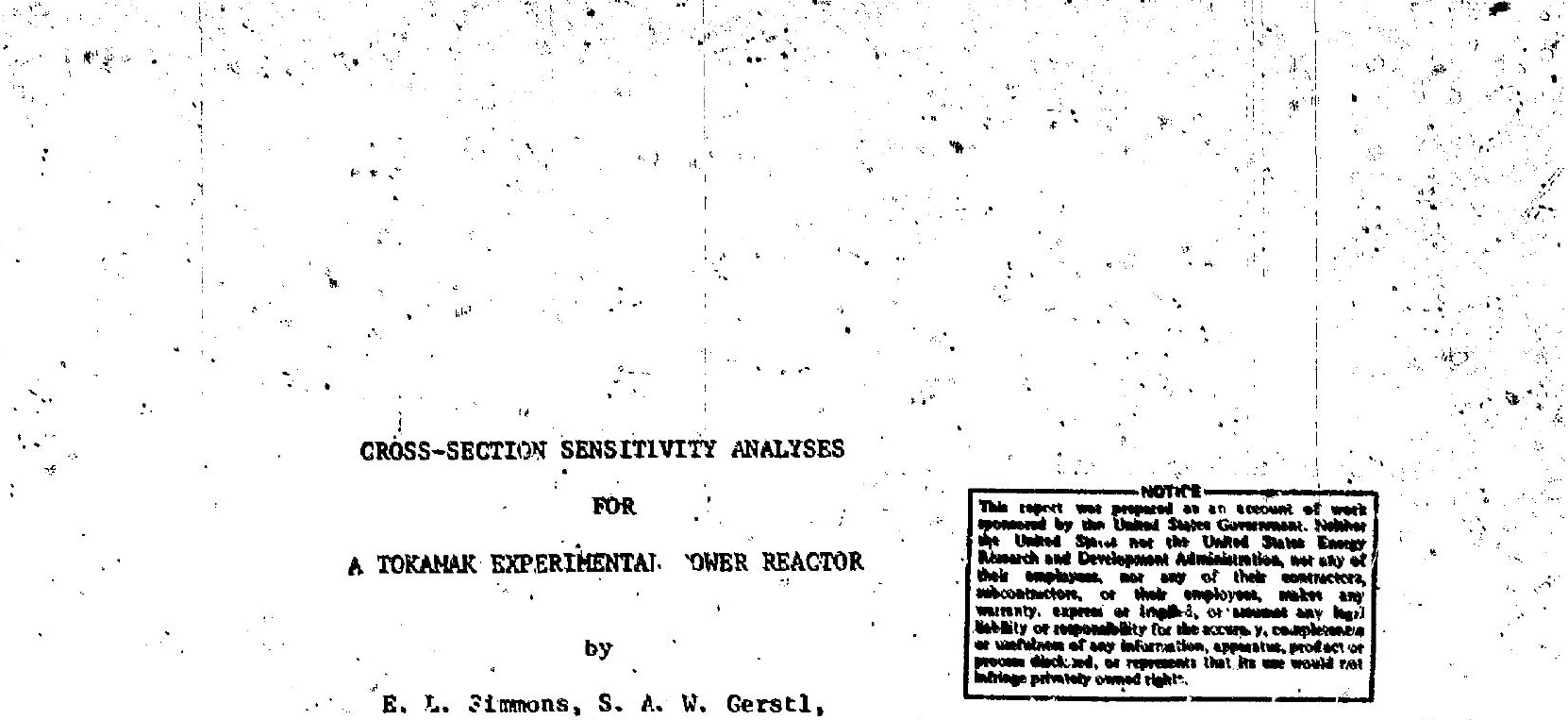
a.r Donald J. Durizlak

\begin{abstract}
The objectives of this report ware (1) to determine the sensitivity of neutronic responses in the preliminary design of the Tokamak Expeximental Power Reactor by Argonne National Laboratory, and (2) to develop the use of a neutron-gama coupled cross-section set in the calculation of cross-section sensicivity analysis. Response functions such as neutron plus gama kermi, Mylar dose, copper transmutation, copper dpa, and activation of the toraidal fleld chil dewar were investigated. Calculations revealed that the responses were most sensitive to the high-energy group cross sections of tron in the Innermost reglons containing stainlese teel. For example, both the neutron heating of che toroidal fleld coll and the activation of the torbidal fleld coil dewar show an integral sensitivity of abou': -5 with respect to the iron total cross sections. Major contributors are the scactering cross scctions of iron, with -2.7 and -4.4 for neutron liqating and activations respectively. The effects of changes in gama cross sections were generally an order of 10 lower.
\end{abstract}

\section{INYRODUCTION}

\section{A. Background}

"Cross-section sensitivicy analysis, a mechoit of determining how sensitive a calculatedintegral result is to cross-section data, has been used fin radiation shielding and tusion blanket studien: $1-4$ especinliy for designs where the use of integra? experiments is prohibitive or costly. This knowledge can provide means of sulecting areas of fu. tur = treasurement, and evaluation of cross-section dita and their consequent in:provemenc.

Vartous techniques have, been used; Including direct integral experiments, variatjunal nethods, perturbation theury, ${ }^{4}$ and differential derivation. of sensitivity. 5 Ints report wiIl be concerned with the use of the differential approach; that is, defining sensitivity functions as exact differenLlal rates of change of a talculated result with sespect to differentlal changes in cross-seistion data. Two of the Iinitations of this methud aze;
(1) this methed cannot provide an answer of how computational results compare with experinental results, and (2) the answers ubtained are very depiendent on the spectfic problem being Investigated; for example, geometrical design, sources, macertals, and response functions.

\section{B. Application of Sensitivity Analysis to an EPR As mentioned earlier, ${ }^{3}$ the Impact of changes in} crosi-section data varles not only from one reactor design to another, but also, from one integral response to anothir for the same specific design. Thus, the assessment and eviluation of crosi-section. data is very problem dependint. Since the fusion Experic. mental power Reactor (Bits) projects are at thoostage where designs are cotistrinily changing, a quentitative assessnetrt of the surrent nuclear data shuld be the. bastis for assigning pxogrimmetis prioritles for futire evaluakions and measurements of suck hatr based on a representative design which covers generic class of similar designs.

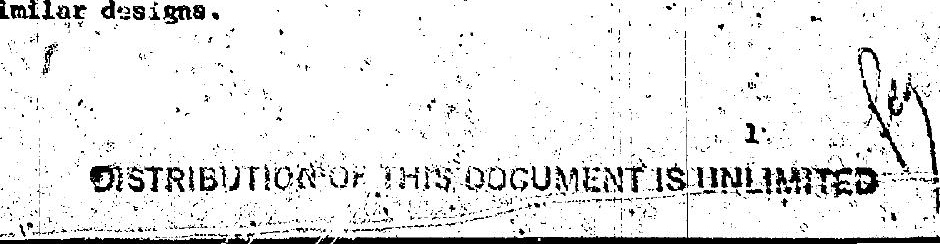


The dowiga chosen for this paper was the Tokamak - Experifentaz Power Reactor (TEPR) as conceptually. designed by irgonne National Laboratory (ANL). $6,7^{\prime}$ A full decalied description of the reactor is given in Ref. 7. However, one aspect of the method they chose to meel thezr progian objectives wha to use a staged approach. Si age I wi" basically demonstrate reactormievel plasma perfor ance, permit sensible heat extraction, and serve as a radiation test Facility. stage II will contain a cririum breeding blanket and serve as a cest facility for breeding, materials, irradiations, and yar ious otiner concepts. The research described ir. this report is limited only to the Stage 1 design.

A perspertive view of the reactor is given in Fig. 1, and a cross-sectional view of the blanket/ shleld in Fig. 2. The reactor has a flrat wall composed of 316 stainleas steel which is approximately $4 \mathrm{~cm}$.thick. The first wall is surrounded by a blanket/shield syzien. The blanket/shteld system essentially has the same shape as the D-shaped to: roidal field coll. The inmer vertical portion of the system is referred to as the Inner blanket/ shield, whereas the circular porition is the ouier blanket/shield. the inner blanket/shield has a maximum thickness of approximately $92 \mathrm{~cm}$. Its blanket port on is $32 \mathrm{~cm}$ thick and mainly composed of 316 SS. This is followed by a 1-cm-thick vacuuia and 1 , 59-cm-thick shield constructed from 316 ss laminated with $B_{4} C$. The outer blanket/shield also contains 32-ch-thick stalnless steel blanket. However, its $97-\mathrm{cm}$ shield is wainly composed of graphite and lead morcur. The blanket/nhleld system is surrounded by the $D$-shaped superconducting roroldal freld coll. The coroidal field coll will be cryogenically cooied to about 4.? $K$ and the time for anglet sooldown from room compuruture to $4.2, \mathrm{~K}$ will be approstmately two to threc months. Magnet frotection agallnst radiation heating is of ireat Importance to the duty cy-. cle and avaliablity of the reactor, heice it is a gajor concern.

As one can see, the potential paraneters for sensitivity andysis are enormous. In that the object of the prosent study is to provide basic deslgt. oriented Informetion and guidance for more detalled cross-section sersitivity analyois and uncertainty anaigsis in the Future, It was decteled to 1 imit the researeh to integral responses, that are thought to be of major Importanice. These basically pextain to the respunses related to taroidal fleld coll integrity, and activation of the coroldal. field cwil's outernosf dewar.

The nuclear heating in the magnet is important because it is relatad to (1) the total power to rui the refrigerators itilch cool the coll, and (2) the maximun allowable temperature rise in the toroldal Fleld coll (1.e., the resistivity depencience on temperature). Therefore, neutron and gama-ray heatInp in the corofdal field coll was selected as one of the reoponse functions to be investigated.

A response related to nuclear heating is the Mylar dose. The désign incorporates Mylas as tul insulation materi, i in the toroldal fleld cofl. Clearly, If the insulator tis severely damaged, the coll would have to be removed. As in consequence, the rotal dose absorbed in the Myl.ix insulation has an effect on the malntenance of tive reactor. For this reason, It was chisen us a response to be examined In our research.

Another respoile of interest is that of radiation damage in the toroidal field coll. The radiation damage mainly affects the reisistivity in the hish-conductivity numal conducting metal matrix, of a superconducting coll. In the ptestert design, copper serves is the matrix metaj. As shown in Ref:?, the displacements per atcm (dpa) in opper car be related to 1 ts saturation resistivit:' Therefore, the acrurate calculation of this response is of great concern, and the sensi-ivity of copper dpo to crosssection data will also be investigated ir this report.

The selection of copper tranimutations as response of interest was chosen because the production of impuitties in the toroidal field coil may have a significant effect on its electricai lesistivity. While Abdon stateen that this is not a sartous prob$1 \mathrm{em}$ in the particular ANt des $\$ g n$, It wruld ba Interesting to see low dzpendent it is an the cross-section data nvatiabje. The acper transmutation in the toroldal fiteld coils was chosen as the Fourth integral response to be uned in our sensitivity malysis.

Our, prosenc :esararch was abridged in that it was judged that the inner toroldal fie.ld $\cos 1$ would be exposed to a greater flux than that of the outer, and Furthermore, that the innermost portion o\% the coll would recelve the maxdmum neutron flux ef all other fortions of the lorsialal field coil. Hunce, the 
detector region, for the abuve resanses was the first (Innermost) 2.5 in of the Innel coroldal field $\operatorname{col} 1$.

The minimization of radiation-tinduced activation is an Important criterion because it is desirable to perform malutensnce and nisnor rtpatrs on the outermost components of the reactor without sequiring long shurdown periods. Thus, activatioa of the outboart coroldal fleld coll dewar is of gruat. interast. As nas been previously shown, ${ }^{3}$ the major contributurs to stainless steel activation are the where $L_{\Sigma_{1}}$ and $L_{\Sigma_{ \pm}}^{*}$ are those portions of the Boltamann forward and adjoint transport operaturs, respectlvely that contain the crous sections $\left(\Sigma_{1}^{x}\right)$.

The forward formulation ylelds the sensitivity proftle to particles of intlial energies $E_{Z}$. This can readily be seen wheu the equatinn for the sensitivity profiles is written in its analytic form.

The equation fior the forward formalism can be "written as

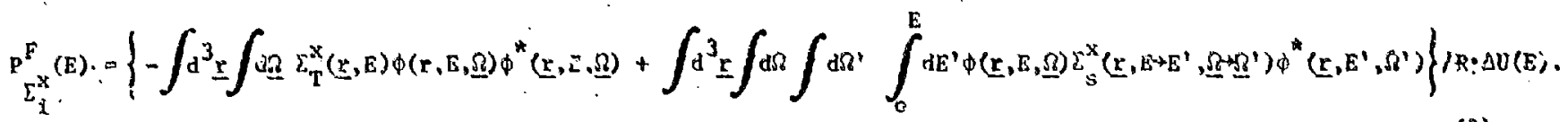

${ }^{56} \mathrm{Fe}(\mathrm{n}, \mathrm{p}){ }^{56} \mathrm{Nin}$ and ${ }^{58} \mathrm{Ni}(\mathrm{n}, \mathrm{p}){ }^{58} \mathrm{Co}$ reactions. The c: ar bination of these pror.esses, therefore, was chosen as another response to be investigated.

\section{IT. METHODOLOGY OE SENSTTIVITY ANALYSTS}

A. Gereral Theory

A relative sensitivity coeffictent called t'le sensitivity profile is defined as

$$
\sum_{i}^{x}=(\partial R / R) /\left(\partial \Sigma_{i}^{x} / \Sigma_{1}^{x}\right)
$$

where 1 is the group index of a multigroup crosssection sat $\left(\Sigma_{1}^{x}\right)$ of reaction $x$. The sonsitivity profile can be luterpreted as the fractional (percentage) chinge in the integral reaponse $R$ per fractonal (percentage) change in the cross section $\Sigma_{1}^{*}$. Various methods $1,5,8$ have been used to derive an explicit equation for the sensitivity profile. In en $h$ case, it has been shown that the adjoint flux dist-ibution $\phi^{*} 13$ needed. The detalis of the derin vations, which have been previnusly publisined, 1,5,8 will not be given here. The final results are two equations as derived frum the two transport formuletions,

$$
\mathrm{p}_{\Sigma_{1}^{*}}^{\mathrm{F}}=\frac{\left\langle\phi, L^{*} \Sigma^{\phi\rangle}\right.}{\mathrm{R}} \text { (FORNARD FORMULATION), }
$$

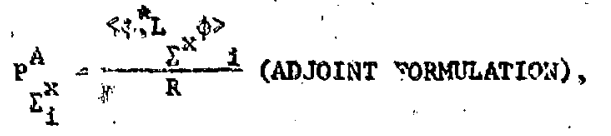

For simplicity, the above phase spaces w. 11 be denoted as follows:

$$
\begin{aligned}
& (r, E, \Omega)=(\xi) \\
& \left(r, E^{\prime}, \Omega^{\prime}\right)=\left(\xi^{\prime}\right) \text {, and } \\
& \left(r, E+E^{\prime}, \Omega+\Omega^{\prime}\right)=\left(\xi^{\prime}+\xi^{\prime}\right) .
\end{aligned}
$$

The first term in the sensitivity equation is the socalled "collision loss cerm" since any collision for reaction $x$ will remove a particle with importames of $\phi^{*}(\xi)$ from phase space $(\xi)$. The second cerm is . . "gain term", which may be interpreted as follows.

The factor $\Sigma_{s}^{*}\left(\xi+\xi^{\prime}\right) \phi^{*}\left(\xi^{\prime}\right)$ is the scatterti.s cross sectic: from (E) to (E') weighed with the Importance of the farticles born at (E'). A particle born at phase space $\left(\xi^{\prime}\right)$ has an importance $\phi^{*}\left(\xi^{\prime}\right)$. Using this to weigh the scattering cross section for particles at the initlal phase spare (E) that lea' to particles at ( $\left.\xi^{\prime}\right)$ will give what may be called an "effective" scartering rross section. That is, a scattering crnss scction that indicates how effective particles at (E) will be in contributing to the re. sponse $R$ when they reach the find phase space (E). Integrating over the final phase space wll yleld the. "total effective" scattering cross section for narti-

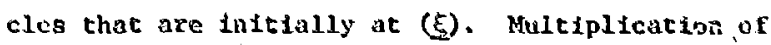
thts "effective cross section" wich the fiux at "( $\left.\xi_{2}\right)$ yields the contribution (or gain)" to the response $R$ due to particles at initial phase space ( $\xi$ ). Hence. Integration over spätıal positínon and ali angles, and summing the "Ioss" apd "gain" will produce the sensitivicy profile for reaction $x$ due to particles at the Initial energy $\mathrm{E}$. 
Dur intelal investigation has revealed that the adjolnt formalis provires the sensitivity proilie for the secondary particle energy dlatribution. A niore ietailed discussion on this aspect. Is given In a r sparate repoxt. 14

One should alio take note that due to the general defintition of the sensitivity proflle, there exists a senritivit; proftle due to changes in the response function itself, ${ }^{3}$

$$
\sum_{i}^{R}=\frac{\sum_{i}^{R}(\phi)}{H}
$$

This gives the fractional change in the integral response $R$ per fractic:s1 change in the datector response function, $\Sigma_{1}^{R}$, for group 1 .

The above discussion pertained to the sensirivity proftle as calculated by the forward and adjoint formailsms. The computational results presented 5 ihin this paper were calculatod with the forward formolism only.

Previous sensitivity analysts used $n$;utron cross-section datu not only to obtain neutron crosssection sensitivity information, but also to generate gamma-ray sourcis. These gamma-ray sources wer then used to compute the gamma-ray fluxes and crosssection sencitivily information. Thus, it required at least three ealculational steps to obtain the information desired. First the neutron transport calculations wera performed to obtain a neutron flux. Next, this neutron flux was used to generate a gamma-ray source by folding it with the gima productior. cross sections. Third, the gamme-ray sources are used to comput the gama-ray transport to obtain a gatuma-ray flux distribution hroughout the system. The use of coupled cross sections cannot only reduce the nunber of calculational steps, but also can potentially give the adted information of the sensitivity of on integral response to the gamma production cross sections. To fully understand chis, one must first understand the conscruction and composition of coupled erossisection sẹts. Once this is understood, the relationship between tha eross-section daca and sensitivity theory can read11y be seen. Therefore, a discusstion of couples cross- petion sets will be givon in the raxt section, then the theory of cross-gection sensitivicy ansiysis as periaining to eupled cross sectlons will be dartived and rolated to the data.
B. Sensittyity Anatyis is Using Coupled Cross-Section Sets

1. Structure and Composition of Coupled CrossSection Secs

An appropriate tathod to describe che structure and composition of a coupled cross-section set is to give an example. For straplicity, "the exwple wili be composed of an elght-group cross-rsection set. The first flve groups are the neutron cross sections. whlle the las; three will be gama-ray cross vections. The coupled cruss sections are usually prosented in a table, as shrion in Fig. 3. In this exniple, the first three edit posftions are absorption, flssion neutron production, and total cross sections, respectively. These are followed by the scattering cross sections. The Interesting aspect to the coupled cross-section table is that it contains the ganma production, $(n+\gamma)$, matrix in the scattering portion of the table. The scattering cross sections expressing this process are enclosed by a dashed Itne. One can then see that the potential exists to obtain pure neutron interaction calculations, pure gauma interaction calculation. "ad garma produrtion caleulatiors from a coupled cross-section set. $M$, wer, one must be very careful to properly select the crnos.sectsuns for the threr types of interactions.

In our example, the pure neutron-interaction cross-section set is contained in the flrst five columns of the matrix. The purte jamma intoraction cross-section set is contained in the upper portions of the last three columins that are not enclosed by the dashed 1ine. Finally the gamme production matrix is In the last throe energy groups and is composed of the scutterisg marix of particles inftialiy in neutren groups leading into yamma-ray groups.

Having jjentlfied the information avaliable in a couples eross-3ection set, it is possible to perform ail trree interaction calculations (pure neutron, pure gama, gama production) in one step. However; the siforthins to r-frorm the pecessary task mist have the proper linits of integration.

The derivation of the basic sensitivity profile equations have been proviousiy published $1,5.8$ and ara vell kncwn. Therofore, based on this, fact, the formulation $g^{f}$ the sensitivity proflle equations using coupled cross sections will start with the zeneral sensitivity profile equations. The three equations of cuncern are. (1) neutron interactinn equations, (1) gama intersetion equations, and (3) 
neutcron-gamme, preduct lon equations. "The formulas derived wlll ise the forward calculetional method only: anc araty'tcal and discrete-ordi lates forms shall be givinn.

The general sensitivity proftle equation calculated by the forward method wae previousiy shown. as:
- Interaction, Bamma Interaction, and neutren-zamm: production, the demominator is assumed to be 1itugrated over all phase space, and will be denoted by R. The explicit analytic and discrete ordinates forms of the sensitivity profilt equations will now be given.

2. Neutron Interaction Equattons a. Analyescal equation for neutron inter-

The sensitivity priftle for the raction cross scction $\Sigma^{x}$ for pure neutron inceractions is as follows:

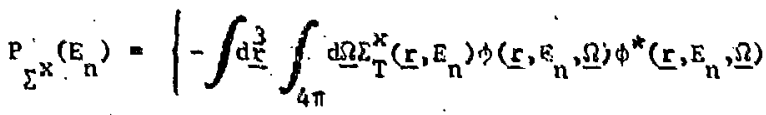

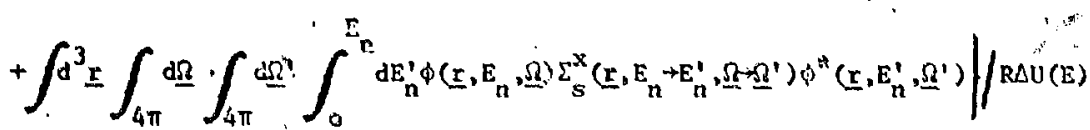

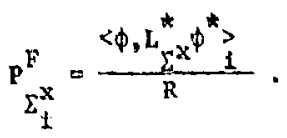

The adjoint operator, $\mathrm{L}_{\Sigma^{*}}^{*}$, can be written as

$$
L_{\Sigma^{x}}^{*}=-\Sigma_{T}^{x}(\underline{r}, E)+\int_{4 \pi} d \Omega^{\prime} \int_{0}^{E} d^{\prime} \Sigma_{S}^{x}\left(\underline{x}, E^{\prime}+E^{\prime}, \underline{\Omega} \rightarrow \underline{\Omega}^{\prime}\right) .
$$

where $E_{n}=$ Initial neutron energy and $E_{n}^{\prime}=$ final neutron energy. This equation expresses the crosssection sensitivity for neutron interactions at energy $E_{n}$. The first termi. is the coll1sion loss of neutrons at that energy. The energy integration in the second term is over all final neutron energles $E_{n}^{\prime}$ due to downscatter, and therefors is the contribution which veutrons of initial enersy $E_{n}$ w11l make when they rexich the final neutron energies $E_{n}^{\prime}$. The

The sensitivity profile equation [Eq. (1)] can then be written explfelts: as

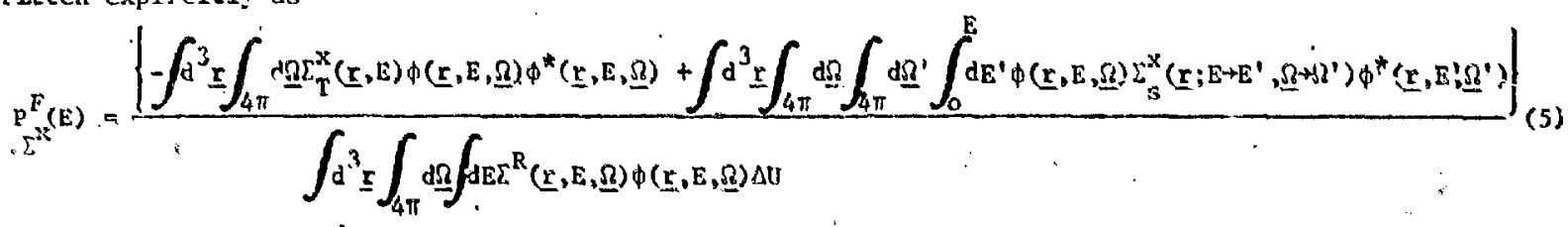

of main cencern in creating sensitivity proffles for coupled cross-section sets are the limits on the energy integrals of the basic equation. Ler us first examine the denoutinator of the equation. This facm cor tis the total integral response of interest. There are no problems with the exergy limits here, because (depending upon the response) both veutron end gamma-rays may contribute to the rosponse. Ia the event that only neucrons are responslble for the Iintegral response, the response function, $\Sigma^{R}(\underline{r}, E, \Omega)$, is automaticaliy saero for the gamma en-. ergies. In all future derivations fot neutron equation is thus limited to neutrons as being the primary and secondary particles. This is the standard equation for a pure neutron cross-section set (1.e., for neutron interactions only).

The usual practice is to represent the double

. differential stattering criss-section $\chi_{s}$ by a Legendre Polynomial expansion:

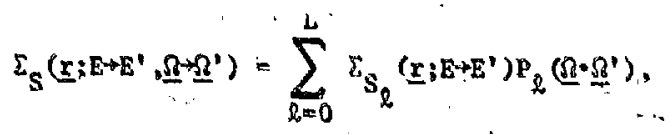


where

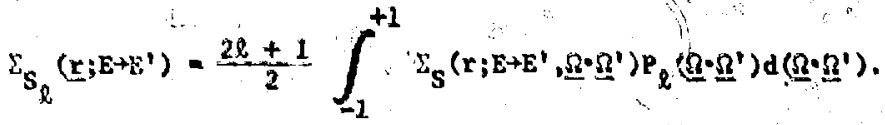

It can be shown that

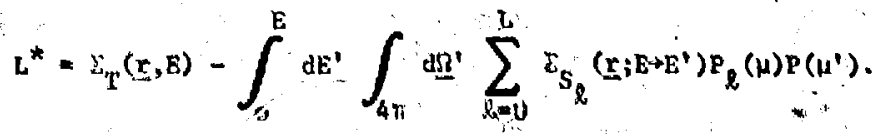

placing this substitution trio sq, (4) yields

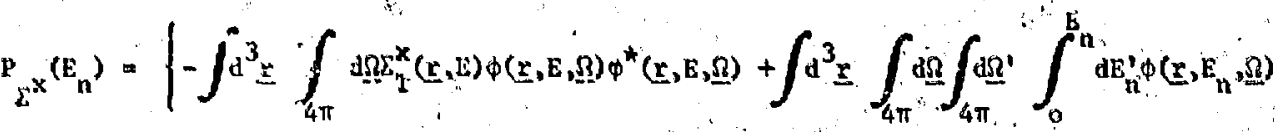

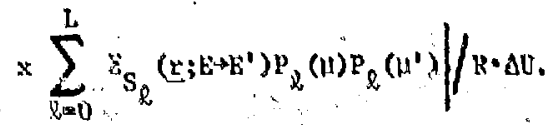

b. Multigroup Discrete Ordinates Equation For Neutron Interactions

Equation (5) cam be represented in the multigroup disescte ordinates $\left(S_{N}\right)$ for for compatibility wi th numerical evaluations. For simplicity, this form shall be written in one-dimensional plane geonetry. As given in Ref. 8, the following reprosentations hold for $s_{N}$ calculations:

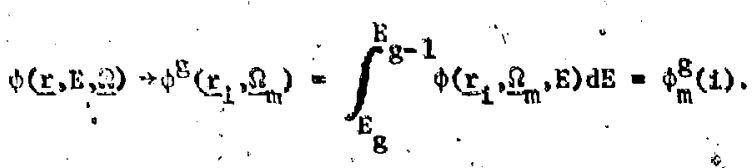

Similarly,

$$
P_{2 x}(E)+P_{E x}^{8}
$$

$$
\begin{aligned}
& \phi^{*}(\mathbf{r}, E, \Omega) \rightarrow \phi_{m}^{* g}(1) \\
& \Sigma^{R}(r, B, 3)+2_{n}^{R}(1) \\
& \Sigma_{\eta^{\prime}}^{\mathrm{x}}(\mathrm{P}, \mathrm{E})+\Sigma_{\mathrm{T}}^{\mathrm{xg}}(1)
\end{aligned}
$$

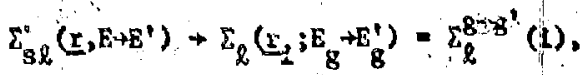

also for any function $F$ :

$$
\int_{g}^{\infty} E(E) d E+\sum_{g=1}^{G} \int_{E}^{E-1} F(B) d E=\sum_{g}^{G} F^{8}
$$

$$
\begin{aligned}
& \int_{4 \pi} F(\Omega) d \Omega+\sum_{m=1}^{M} F\left(\Omega_{m}\right) \cdot \Delta \Omega_{m}+\sum_{m=1}^{M} F_{m}
\end{aligned}
$$

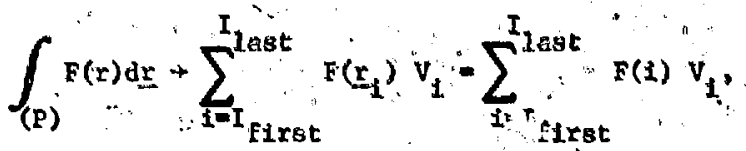

where $V_{1}=$ volume of spatial Interval $L_{i} I_{\text {fIrst }}=$ first triterval of zone containing the coss sections of interest; $I_{\text {last }}$ last interval of sou containing the cross sections of interest: $F(t)$ = average value of function $F(r)$ in interval $1 ; \omega_{m}=$ quadrature weight of $s_{n}$ angular representation.

The denominator of Eq. (7) who originally written In its explicit form in Eq. (5) as

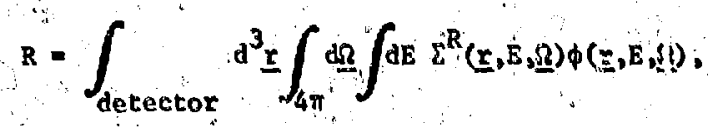

and substitution of the above discret-ordilates representations leads to

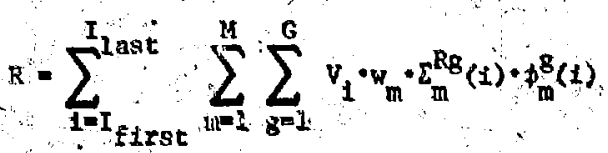


where $\$=$ tocal numbar of dirsctions; $G=$ total number of energy groups (neutron + galuma). Note that this representution of $R$ is comon in all the sensitivity equations of interest. Also, the forward flux, $\phi$, and adjoint flux, $\phi^{*}$, can be expanded In terms of Legendre polymonilals:

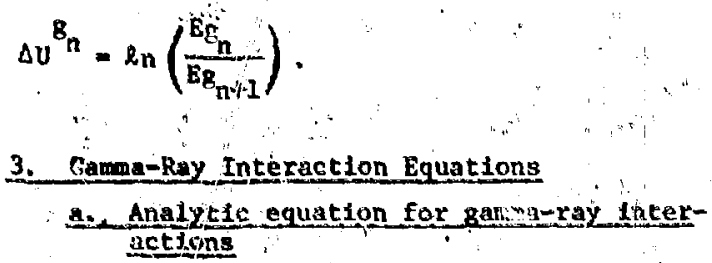

The gamma-ray sensitivity function is similar to that of neutcons except that only pure, gantu-ray Interactions atu considered:

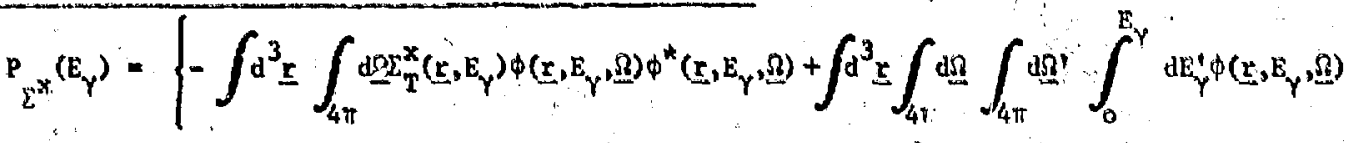

$$
\begin{aligned}
& \left.\Sigma_{s}^{x}\left(\varepsilon ; E_{\gamma}+E_{\gamma}^{\prime}, \Omega+\Omega^{\prime}\right) \phi^{*}\left(r, E_{\gamma}^{\prime}, \Omega^{\prime}\right)\right) / R A U\left(E_{\gamma}\right)
\end{aligned}
$$$$
\phi(r, \underline{z}, E)=\sum_{l=0}^{l} \frac{2 \ell+i}{4 \pi} \phi_{l}(\underline{r}, E) g_{\ell}(\mu) \text {. }
$$

Thls equation gives the sensityyty of the integral response $k$ to cross-section data at gamna energy $F_{\gamma}$, (1.c., a.sansitivity proftle fo" gamm iviteractions only). The first term is the collision ioss term for gammu rays.' The second torm is the contribution from gamne rays of energy $\mathrm{E}_{\gamma}$ to the inteigral respense R.

\section{b. Multigroup discrete urdinges equation for gammi Interactions}

The derfuation of the alscrete ordinates formulation for the gamma-ray crosisection sensitivity proftie equation is similar to that of the neutron cross-section sensitivity proflle derivation. "It ,

for slab geonatry.

How, Introducing the discrete-ordinates reprem sentation into $E q_{i}^{\prime}$ (7) and rearranging the triple sumation one has

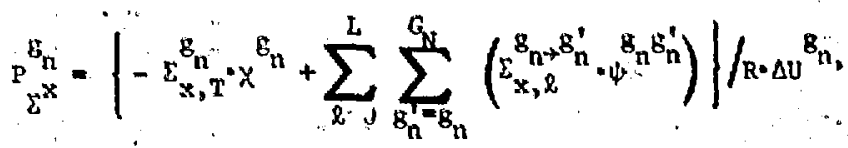

where $\varepsilon_{x, t}^{8_{n}}=$ total cress section for reaction $x$ in neutron group $E_{n}$.

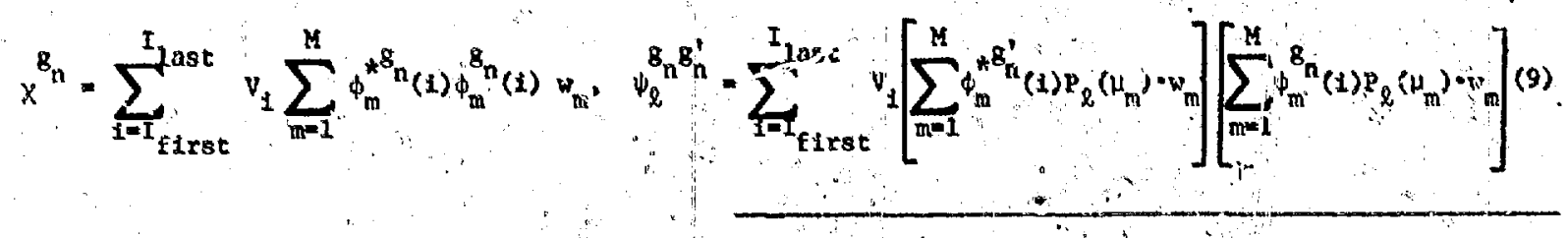

$\varepsilon^{B_{n} \cdot B_{n}^{\prime}}$ lown scattering cross aection of reaction $x$ going froin neutron group $g_{n}$ to reutron group $g_{n}^{\prime}, G_{n}$ total number of neutron groups. can be easily shown that the diserete-ordinates formulation for gamma-ravinteractions is 


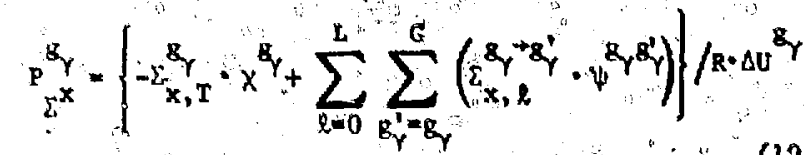

$$
\begin{aligned}
& \Sigma_{X, T}^{B_{Y}}=\text { total ctoss section for reaction } x \text { in } \\
& \text { Bana group } \mathrm{j}^{\circ} \text {. } \\
& \Delta u^{B}=\ln \left(\frac{E_{g}}{E\left(g_{\gamma}+1\right)}\right) \text {. }
\end{aligned}
$$

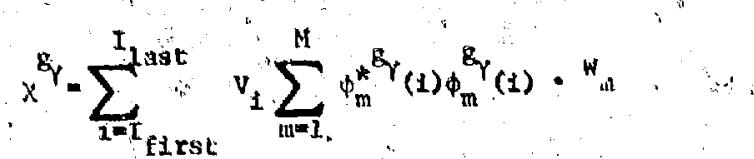

$$
\begin{aligned}
& \mathrm{q}_{\gamma} \mathrm{g}_{y}^{\prime}=\sum_{i=1}^{I \text { first }} v_{1}\left[\sum_{m=1}^{M} \phi_{m}^{*} \gamma_{(1) p_{l}\left(\mu_{n l}\right)} \vdots w_{m}\right] \\
& x\left[\sum_{m=1}^{M} \phi_{m}^{2}(1) p_{l}\left(\mu_{m}\right) \cdot w_{m}\right]
\end{aligned}
$$

\section{Gamma Production Equations \\ a. Snalytical equation for the sensitivity to gamma production cross sectlons}

As mentioned earliez, past pròcedure invölved using the neutron fluxes to obtain a source for the gamma-ray transport calculation. The neutron and gamma fluxes were then employed in the calculation of separite neutron interaction and gamma-ray interaction senstivity analyses, respectively-; the above procedure can be circumvented by the use of coupled cross-section secs. Using coupled crosssection sers also provides the additional aspect of finding the sensitivity to gaxana production cross sections;.".

The derivation of the analytical gatma-production sensitivity profile equation can better be comprehended if one observes varlous characteristics of the coupled cross-section set structure. Referring to the example in lig. 3 , one can see that the gama production-natrix (encircied with dasisd ines) Is embedded thto the scattering cross section matrix In the guma-energy group tolumns. However, note the dashed section in FIB. 3 does not inctude the gamp-gama acitertitis cross sections. The result being that these scattering cross sections describe only neutron interactions that lead to the production of gamma rays.

Whth the above statements kept In und, it is now possible. to generate the ganms-ray production: sensttivily. The gamma production process wili be hereafter denoted by the symbol $(n, w)$, which includes only gamnia-ray production by sutasns. The basic Censitivy profile equation, Eq, (5), applies for this reaction except that the so-called collision. loss term is excluded. The reason for this can be explatned as follows:

The colitston loss term th the equation theans that a neutron is lost from phese space $\left(\xi_{n}\right)$. This loss of a neution will, however, somettmes produce gemma rays.

The generation of photon production cross geetions is described in Refs. 9 \& 10. The important point to note is that in the centinuum case the photon production cross section $\sigma_{k}^{\gamma}(\varepsilon)$ is calculated by 9

$$
\sigma_{k}^{\gamma}(E)=\int_{0}^{E^{M} M x} \frac{d \sigma^{\gamma}}{d E_{\gamma}}\left(E^{\gamma}+B_{\gamma}\right) d E_{\gamma}
$$

whare

$$
\begin{aligned}
& B_{Y}=\text { photon enargy... } \\
& \text { E noutrón energy } \\
& \begin{aligned}
-\frac{d \sigma_{k}^{\gamma}}{d E}\left(E-E_{\gamma}\right)= & \text { absolute pioton energy distribution, } \\
& \text { e.g., In b/ov. }
\end{aligned}
\end{aligned}
$$

Also, the energy distribution of the photons can be uritten as

$$
\frac{d \sigma_{k}^{\gamma}}{d E_{\gamma}}\left(E+E_{\gamma}\right)=\sigma_{k}^{\gamma}(z) f_{k}\left(E^{+}+E_{\gamma}\right)
$$

where

$$
\begin{aligned}
& \int_{0}^{E^{M a x}} f_{k}\left(z+E_{\gamma}\right) d E_{\gamma}=1 \\
& \mathrm{~F}_{k}\left(\mathrm{E}_{\mathrm{E}}\right)=\text { numalized energy dittribution. }
\end{aligned}
$$

The multiplictty or yield, $y_{k}(E)$, of gammas is defined as 


$$
y_{k}(E) \frac{\sigma_{l k}^{\gamma}(E)}{\sigma(E)}
$$

Where $\sigma(E)$ is the neutron inturaction cross section. for the production of gamma rays. As one can see, the gamas production cross section tnvolves a generally nonunit multiplfity, $y_{k}(\mathrm{e})$, and is not realiy a neutron interaction cross section 1 in the same sonse as the other transport crosis suctions. This means that a neutron in phase space $\left(E_{\mathrm{n}}\right)$ can produce a multiple of gammias in $\left(\xi_{\gamma}^{p}\right)$. As a result of this multiplicity, little mianing can* be al:tached to the collision loss term. Another argument for the exclusion of the loss term is that the gamal productiran by $\left(n^{2}+\gamma\right)$ processes cam be only a sotired (i.e., a contrtbutor to the response of interest). For exisuple, tif the response of interest is nuclear heating one sam clearly see that an inerease in the gamma production cross section can only incease the response, not decreuse It. The loss term would invo'? ve the summation of the diagenal elements for the same neutron groups in the (n'p) portion of the crosssection matrix (sea Hitg. 3). Now, the process of $\left(n, n^{\prime} \gamma\right)$, for example, is noe only included in the photon production cross section, but is also included In the neutron scatterimg cross sections. Stmilarly, the $(n, \gamma)$ prucess is included in both the pheton production matrix as well as the neutron abserption and total cross sections. Hence, the loss of a neutron from phase space $\left(\xi_{n}\right)$ by the ganma production process tis included to the neutron intoraction sensitivity calculations as a collision loss tern. consequentiy, thi giamia production cross section can only be a positive coutribucor, (1.e., can never further decroase the response). Based on this reasuntng, there tis no edllision loss tern fn the (n+p) sensitivity proflle equation. Bused upon the above discussion, the analytical sensitivity profile cquacton for the gatuna production eross section tes isy the evaluator. The above equation can therefore provide juidance to the evaluator as to how much an arre $E$, In his normalization cair affect the incegral. response. There are certain IImitaticas th the applicabllity of the dove equition whteh shall be diseussed later in this paper.

\section{$\therefore$. \\ b. Mul+turoup discrete ordinates equation for the senstervity fo (n-m) production cross sections}

The derivation of Eq. (1i) in discrete ordinutes formulation is sinitar to the gat in terms of the pure neutron, finteraction and pure gama interaction equations. The only difference sppears in the limits of the group summation:

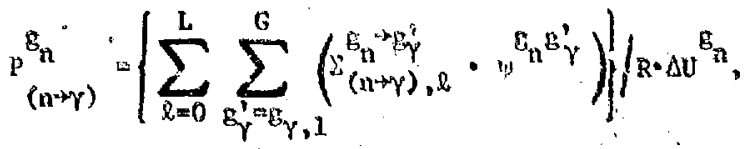

where

$B_{n}+B^{\prime} \gamma$
$\left(n^{2} \gamma\right), l$ scattering cross section for a neutron bt energy group $B_{n}$ to gamna-energ group bi:

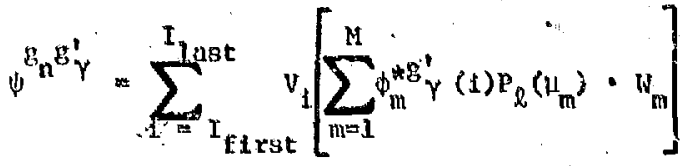

$$
\begin{aligned}
& x\left[\sum_{m=1}^{N} s_{m}^{s_{n}}(1) P_{l}\left(\mu_{n}\right) \cdot w_{n}\right]
\end{aligned}
$$

$$
\begin{aligned}
& 0 \text { - total nuaber of groups (neutron + gamma) } \\
& B_{\gamma, 1}=\text { first gumma encrgy group } \\
& \Delta y^{\mathrm{G}}-\ln \left(\frac{\mathrm{E}_{\mathrm{B}}}{\mathrm{E}_{\mathrm{g}+1}}\right)
\end{aligned}
$$

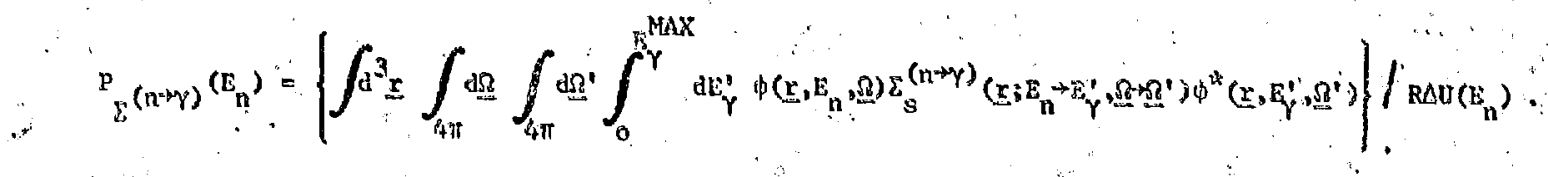

Rhis states the sensitivity of the total responsti $R$ to the $(n+y)$ cross section.: An uncertainty in (n+y) cross sections" may be due in part to the formaldat"tion or the gama yiela taposed on the exoss section
Note that the sumation is over dit gatma energy groups"; that "is, from the first ganma energy group 
G, to $G$. For example, in the cross-section set in Fig. 3, the sumation would be from $8,1=6$ to B.last $=6=8$.

5. Diffirulties in the Use of comoste TransDort Cross-Section Ser

The ideal use of sensitivity profile equations incorporates only partal cross sections. This leads to straightfondra Interptetations of tha culculated results. However, die to the nonavailability of complete patial cross scction sets, the use of tzansport cross sections such as used in DTF, ANISN, ect, have been employed in cross-section sensicivity malysis calculations. These are composite cross sections and present problems in data manipulation and interpretacion.

Thi interpretation ef cross-section sensitivity results for the absorption cross section of a DTF diata set is complicated by the fact that the $(0,2 n)$ reaction has been incorporated as a nebucive absocption. It the $(n, 2 n)$ cross section is geeater than real absarption in a group; then the result is a negative absorption cross section. Consequenty. cuution must be taken when intexpreting sensitivity. profiles for sach absorption eross sections because chese are resily composite, not partial, eresesection sensitivizy profiles.

Results of sensitivity calculations for meutron scitccring cross sections as represented in composite cransport cross-secticr sets, such as DTH data sets. are aifficult to inturpet. These cross suethans are composed of partiall cross sactions sum as $(n, n)$, $\left(n, n^{*} y\right),\left(n, n^{*} \mathbb{p}\right),\left(n, n^{\prime}\right)$, etc.; that is; a sum of al. scattering interactions in which a secondary Misutron is one of the resultant particles. As was strom in Sec. II.B.3.a, the incluston of $\left(m, n^{\prime} y\right)$ th the newron scatering natrix was one reason for the elimination of the loss tem in the $(n+p)$ sensitiv1. profile equation. There is no direct information on the true partial scattering cross sections that compose the transport scattering cross sections.

Finally, the $(n, \gamma)$ production cross sections are also composite cross sectlone, They Inelude all reactons that lead to gamma-ray production such as ? $(n, \gamma),\left(m, n^{\prime} \gamma\right), A\left(n, n^{\prime}\right) B^{*}$ where $B^{*}+q+\gamma$, etc. Irformation on tie partial noutron cross sections that lead to ganma production cannot be directly obtakned. Auso, mostly the cross-section evaluator is devtied this information and anst consequently considel the tocal of ali sam producing reactions eimultanenusly The composite structure of the transpoit eross see tion sets dictates that the $(n-\gamma)$ cross section be treated as an entity in icself.

III. CONPUTATIOHAL MDELS, CODSS, AND DATA

\section{A. Ceometric Models}

Figure 2 illustrates the cross-sectional view of tive blanket/shield systen of the LPR. The reasons for tholce ồ materials and design are given in Refs, $6=7$. For transport calculational purposes, two models were chosen. The first represented the Inier bianket/shield along cut $A-C$ of Fig. 2 ; the other represented tive outer blankef/shield alonst cut E-E. The reasons for the cholce of these cuts are also explained in Ref. 7.

Because of the large radii of the blanke/shield systems, it was concluded that representing the in one-dimensional slab geometry would produce negligible errors in the resulting sensitivicy inlurtatian. A confiemation of this conclusion can be found in Rof. 15 where nunerical comparisons of slab-geonetry results with those from equivalent cylindrical calculations are given. Figures 4 and 5 show a schenatic layout of the slab models for inner and outer blanket/shield systems, respectively, vore detall of the material' compositions of eaci region is given in Rer. 6. DrF-IV ${ }^{11}$, was employed to calculate the forward and adjoint fluxes. Calculations were made in the $P_{3}-S_{8}$ approximation to assure reasonable accuracy at deep penetration. 15 The transport ctoss sections were a 42 -group coupled cross-section sea. 16 the first 36 groups contain the neutron Interaction data, whereas the last 12 groups contain photon information.

B. Resporse Eunctions and Acioint Sour ins

The response functions chosen for this research were (1) neutron plus gama kerma (2) Mylar dose, (3) copper transmutation, (4) copper fpm, and (5) activation of TFE dewar swerounding the outen tianket/shleld. The neutron plus gamma kexma factors were generated by the HAck cude. ${ }^{12}$ The materiais under consideration for nuclear heating were those contained in the first 2 ch of the Tre; nanely, stalniess steel components; copper, niobium, titanium, and the liquid helium coolant. The resultant composite mulcigroup response function is plotted in Fig. 6 . 
Figure ils istrates the mulcigroup response funetion for Mylar dose. This was obtained by converting the neutron plus gama kema for its min consticuerts (asrber, oxysen, ahd hydrogen) ince the proper units ef $\left(a y-c a^{2} /\right.$ particle) Copper transautaiton and copper dpa response functions are lllustrated in Eigs. 8 and 9, respectively. As stated earlier, the" main ecntribucors to the activation in stair.less steel are the ${ }^{56} \mathrm{Fe}(\mathrm{n}, \mathrm{p})^{56}$ th and ${ }^{58} \mathrm{Ni}(\mathrm{a}, \mathrm{p})^{58}$ co processes. 3 The composite response fumction is shown rig. 10.

These response functions were used as. sources in the DrF-IV adjoint txansjort saluulations and also as the resporise functions for the eross-section sensitivicy calculations performed by SRNSTT-10. ${ }^{13}$

\section{COMPUATIONAI, RESULTS AND ANALYSIS}

The wain objective of the presen. researcli is to provide the necessiry data for future cross-section error analyses: The selection of cross sections that should undergo the error evaluations can be made by examining their effectis on the rusponsas of interest. The sechnique of exantwation enployed veilizes the integral sensitivitles. Nathematicalny; the integral sensitivity is an integration of sensitivity profile over all energies, -

$$
s_{g^{x}}=\int \mathrm{ate}{ }_{5^{x}}^{(\mathrm{s})}
$$

where $s{ }^{x}$ is the notation that will be used for the integraf sensitivity to all cross sections describing reaction $x$.

As was previously stated, the sensitivity profile expresses the fractional (percentage) change in the response due to a Exational (percentage) change in the rross-section $\Sigma_{i}$ "The sensitivity proflle is a function of energy, E; hence, an integration over the energy will yiela the cotal sensicivity. It is often convenient to thtnk of tha incegral sepsitivity as being the pecentage change In the response due to a $1 \%$ increase In all errisssections $2^{2}$

The FPR design chosen consists of many materials which in turn wily leat to an cnorwous set of ikrosssinctan sonsitivities. Therefore, method of iselectins the more mportant cross sections is nejeded in orter to limit the research project to manageable proportions: As was seen in See, III, B, all the response functions considered for the inner blanker/ shield studies are high-energy peaked. This means that the senstituity profiles for the same cross sections but different response functions are expected to be similar shape sines all responses are localized in the cirst 2 en of the torotdal Field coil. Based upon this, it was decided to pick the response of nucleax heating to determin Which spatial zone has the greatest integral sensitivity for a partieular material mixture." Aftexwards, that zole wili be used in the sensitivity salculetions ror the remalining responses.

There is significant amount of staìless steel in the inmer blanket/shield; consequently, it was " declded that this materin be constidered first in the calculations. The shield portion of the inner blanket/shield also contains $B_{4} C_{i}$ and, due to the fant that ${ }^{10} \mathrm{~B}$ is a strong absorber of thermal neutrons, $B_{4} C_{\text {was }}$ whosen as the next mixture for sensitivicy calculations, The last mixture considered reprasented the somponents of the first $2 \mathrm{~cm}$ of the toroidal field coil Itself because it semed desirable to know how it affects the responses.

The materias mixtures used in the activation sensitivity analysis were the same as those mentioned above, except $B_{4} c$ was deleted since it $t 5$ absent in the outer blanket/shield. The material mixtures of lead mortar and graphite were consilered in addition due to their albundance in the system.

\section{A. Nuelesx Heating In TFC}

The response sunsitivity protile, $p_{R^{R}}^{(E)}$, for nuclear heating, is.shown in Figs, 11 and 12, Figure 11 idustrates the sensitivity of the nuclear heating due to neutron interactions; and Fig, 12 shows the sensitivity due to gamm-ray interactions, it should be noted that the integral sensitivitief for heating, $S_{S^{2}}$ are 0.109 and 0.891 For the neutron and gaina portions, respectiveiy... This indicates, that the majority of the heating is due to gamm rays: How ever, the transport of gamas in the TrC raroly exceeds distances of $2 \mathrm{~cm}$, hence, the majority of the gamma rays created within the first 2.5 ch of the topeidal fiald coil are also absorbed in that negion.

It is interesting that a.peak occurs at the $1-$ $\mathrm{HeV}$ eacrgy region in the neutron profile. Instght of how this peak is generated can be obtained as fallows.

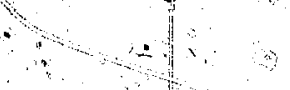


A major contribtitor to the transport of neusrons is the iron stainless sted due to the large about present in the design. Examination of the tot 1 ctoss section of Iron (Aig 13) reveals that the probatility of interaction is keduced in the 1-NeV energy regicn. Hence, neutrons that inelastisaly scatcer into this energy region have a 1ow probability to interact with iron atoms of the steel. The result is that there is a streaning of 1-iteV neutrois, throughout the blanket/shield and these neutrons ape abundanily present when entering the toroidal field coll. This is reflected by the flus plot at thi fixst interval in the TFC (FIg. 14).

1. ifuclear Heiring Sensteivicy to stainles: Steel (SS) Cross Sections

The Elrse step of our pronedure called for us to determine which component of the stainless steel mixcures gives the highest integral sensitivity and In which zóne this occurs. Tie neutron integral sensitivitics for nuelear heating by mixture conponents and zone axe given in Table $I$. As It can be scen, the element that has the greatest effect is Irzm in the reglons 8-8; for the gama internction sensitivities it is irsn in zone 16 (Table II). The dighest neutron 'sensicivity is approximately an oraex of magnitude greater than the highest sensitivity. Thus, anes 6-8 were chosen as the region for additional, more detalled sensitivity studies. - Msso, based upon these results, we decided too use zones $5-8$ to calculate the sensicivities due to stain ss sted components for the remaining response functions. Table III shows that the nuelear heatang in the inner TFG is most sensitive to the scattering cross sections of iroa in zones 6-8. The neutron sensitivity profiles for the various cross sections of iron in that region are given in Eigs. 15-20.

Figure 15 illustrates the profile for the absorption cross section (a pure loss term). Notice that in the two highest energy groups, the sensitivity is positive. This is due to thit use of a composite cross-section set. As was eirplained fan Sec." Ir. 4 , the $(n, 2 n)$ reaction is addel to the absorption cross sections as i negative ibsorption. Hence, if this pseudoabsorption cross pection 15 inegative, the sensitivity will be posilive.

The scattering eross section's loss-texm portion of the sensitivity proftle is shoin In Fig. 16, the the total cross section's loss-term sensitiv"ty profile is show In FiB. 17, and the gain cexa frow all scattering interactions is iluotrated In. kig. 18. Addition of gains and losses results in nat sensitivity profiles for the stattering and total cross sections, FIgs, 19 and 20 , respectiyely. . In eachalase the highest sensitivity appears in the upper etergy groups, thus llilustrating that the exps sections pertuining to the kigh-arergy neutrou sntexactions are nost important. Also the cross sections in the 3 - MeV region have a significant effect on the nuclear hearing in the TFC due to the spectrum peak discussed carlier (spectral straming).

The sersitivity profilc for the gamma production cross sections in iron is shown in Fig. 21. The nost important gamma production cross sections are those in the highest energy group: There is also a peik around $1 \mathrm{keV}$. These eross sections are important because the response function has a peak at approximately $1 \mathrm{keV}$ which leads to an increase in heating at that energy (see Fig. 6).

The ganma-ray interaction sensitivity prof:les for absorption, scattering, and totnl 108 torts are given .In 1.gs. $22-24$, respectively. The gain term is show in Fig. 25. The net sensitivity profiles For the pure gama-ray' seattering cross sections (Fig. 26) and for the famma-ray istal interaction. cross section's (Fig, 27), both show that the most important cross sections aze those in the upper encrgies. This is understandable because ganma rays of lower energy will never reach the TFG unless they ace produced there. "All sensitivities to gamma-xay cross sections, however, are much lower (about an oxder of magnitude) than those for the neutron interaction cross sections. "

2. Nuclear Heacing Sensitivicy to Bac Crosa Sections

Boron carbide appears in several regions of the shield portion of the Inner blanket/shield. Tierefore, the procedure for determining the material component and zone location that yjelds the greatest Integral sensitivity was repeated for ali $\mathrm{B}_{4} \mathrm{C}$ zones. $A$ comparison of Tables $V$ and $V I$ shows that If heatIng is most sensitive to the neutron interactions with ${ }^{10} \mathrm{~B}$ in zone 17. Afian, the neutron total integral sensitivity sumped over all domponents and all zones) is greater than that for ganas by a factor of approxituately 10. The result is that 
zone 17 was chosen for the additional sensitivity calculations to $\mathrm{B}_{4} \mathrm{C}$ for the remaining response functions. Examination of Table $Y$ shows that the sensitivity to ${ }^{10} \mathrm{~B}$ monotonically increases from the inhoard $B_{4} C$ rogions to the outboard $B_{4} C$ region: whereas; the scnsitivity, to carboi increases up to region 15 and then drofir slightly for region 17.: These effects are due to the comptition between the processes of thermalization and absoxption in $\mathrm{B}_{4} \mathrm{C}$. The aisorption-process always tohinates, . and in region 17 the neutrons have been thomalized to the point that thay are preferably absorbed by ${ }^{10} \mathrm{~B}$, rather than scattered by carbon; the result is a decrease In the sensitivity to carbon.

The neutron and gama-ray interactions integral sensitivities for the absorption, seattering, is al, ind $(n+\gamma)$ cross sections of ${ }^{\prime 10}$ are shown in Tables VII and VIII. The associated sensitivity profiles for these cross sections are shown in Figs. 28-31. Again TFC nuclear heating is most senaltive to the high-energy neutrons interactions with peaks at 14 MeV and azound $1 \mathrm{MeV}$ of equal magnicude. The gamiaray interaetions sensitivities are greatest for gamma interactions at high gamma eneriy also.

\section{Nuclear Heating Sensitivity to TFC}

The effert of eross sections in the first interval of che ThC (the respouse region itself) is also.of interest. Tuble IX ilJustrates the integral sensitivities to totol cross sutions of the TFC components for neutron interactions and gama interactions. Clearly, as one might suspect from the re-." sponse intagrul seisitivity, the total nuelear heating is moro sensitive to gamma-ray interactions. . The copper cross sections displuy the largest sensitivity. Integral sensitivities to the cross sec"Lians of absurption, seattering, total, and (n-p) reactions loe copper are given in Tables $\mathrm{X}$ and $\mathrm{XI}$ for neutron and gummo-ray interactions, respect:lvely. The gamala production cross section shows the largest net affect. The sensftivity profiles for these cross sections are given in Figs. $32-36$.

\section{B. Copper Transmutation in Inner TEC}

Copper is the stabilizing material conducter in the coroidal field coil, and tts transmutation to other elements introduces undesirable impurities in the magnet whicli impair the electric conductivity. Therefore, knowledge of the copper transmutation rates, and its sensitivity to nuelear cross-sention data dis important.

The copper transmutation crosersection sensitivity study was performed selecting as perturbed regtons zomes 6-8 for the stainless steel cormonents, rone 17 For the $\mathrm{B}_{4} \mathrm{C}$ components, and tha first $2 \mathrm{~cm}$ of the TFC for the MFC components. These regions were chusen becalse of the results obtained in the nuclear beatins study. Figure 37 illustrates the stensitivity profile for the response function itself. The large peak in the $1-10-k e V$ region is manly: tue to the peak of the response function itself in this encrgy region (see Fig. B).

1. Sensitivity of the Copper Transmutation In the Innex TFC to Stainless stecl Coinponents

The integral sensivivities of the stainless steel components in zones 608 for copper transmutation is given in Table XII. Transmutation is independent of gamumray incesactions, henee, the sensituvity to gimma-ray cross sections is zero. Again, Iron is the component whose cross seations has the greatest sensitivity and from Table XIIJ, it appears that the scattering cross section is the predominant contributor to this integral sensitivity, The net eensitiviny profiles for the scattering and tatal cross sectlons are shown in Figs, 38 and 39. Both sensitivity profiles are highly peaked at $14 \mathrm{MeV}$. Also, there exist the 1 - keV peak that is charactaristic to this destgn.

2. Sensitivity of Copper Transmutation in the Inner THC to B4C Compenerits.

Table xIV shows that ${ }^{0}$ cross sectlons have the highest integral sensitivity: Tablo XV Hives the partial and net integral sensitivities for this isotope. The absorption eross section clearly has the laygest net effect on copper transwutation. The physical exolanation of this was discussed in Sec. IV.A.2. Net and total suiduluty profiles for the scattering and total cross sections of 10 are shown In Figs. 40 and 41 , whlle Fig. 42 11lustrates the absorption sensitivity profile.

3. Sensitivity of Copper Transmutation in the Eirst Interval of the Inner TFC to $T F$. Components

The Integral sensitivities of copper transmutation to the various toruldal field cost material components are shown in Table XVI. As in the case of nuclear heating, coppex cross sections cause the 
freatest senstifiviy, to copper pransmutation. rable 7VII shows that the assorption cross section is the main contributor to the net Integral sensitivity. Fígures 43 and 44 are the sensitivity profiles for copper transmutation to the net-neutron scattering cross section and net total nentron cross section of copper, respectively. Figure 45 shows how srinsitive copper transmutation is to the absorption cróss section. Figures $4-45$, teveal a change in $s i g r$ in the "sensitivity profile as the neutron scattering eross section caises a decrease in copper transmutation at high neutron energies and an increase at lower heutron energies.: The $(n, 2 n)$ process with copper is the only contributing scatitering ceaction to cu transmutation. However, at energies $z 10 \mathrm{MeV}$ the $(n, 2 \mathrm{n})$ and inelastic seatcering tend to scatcer nevtron bulow the $(n, 2 n)$ threshold. Vence, the sensitivity profile is negative is the neutrons are further seatcered down in en rgy, the radlative capture by copper tends to dominate, which will hucrease the "transmutation. Therefore, the sensttivity profile has a positive nature." at approximately $1 \mathrm{keV}$, the cransmutation process begins to sompete uith the radiat fve capture reactions of the diron and niobium that are also contained in the toroidal ficed coil. The iron and niobium reactions dominacic and cause :' the sensitivity proflle to tum negative again. Figure 44 roitcrates, the above statements. The net neutron total cross-bection sensitivity profile reflects the fact that at approwimately $10^{5} \mathrm{eV}$, the $(n, \gamma)$ reaction with copper causes the profile to be positive; and, at approxinately $1 c^{3}$ ev the $(n, y)$ reaction mith: Iron and niobium causas neutrons not to be avallable for thi cransmutaction process, $1, e$, negative sensitivity"profile. "Furiher proof ean be seen in the partial absorption ctoss-section profile of copper (Fig. 45). The copper is not absorbing neutrons due to the niobtum and iron; however, care nust be taken when incerpreting the dats at approximately 14 tev. As stated in Sec. II, B.5, the $(n, 2 n)$ reaction is considered negative absorption. And since at approximately $14 \mathrm{MeV}$, the $(n, 2 n)$ reaction has a nontrivial cross section (approxinately 1.56), the serittivity profile at those points is postthe.

\section{Copper apa in the Inner TFC}

The resistivity of the nomal (stabilizing) conductor can be related to the displacements per atom In that material. 7 Consequently, the sensitivity of calculated copper dpa is shown th Fig, 46. There is no gama-ray interaction dependence in this response, thercrore the neution integral sensitivity for the response fuirition is equal to one. The figure shows tite characteristic approximately $1-\mathrm{MeV}$ peak and an addtional significant sousitivity at high neutron energies.

\section{Sersitivity of Copper DPA to SS Cross Sectlons in Regions :5-8}

Tuble XVIII shows that the iron cross sections ccuse the greatest effect in the sensitivity of copper Apa. 'Table XIX shows the scatcering cross sections have a major payt in this effect." The relevant partial and net sensitivity profiles are shown in Figs. 47 and 48 . These sensitivity profiles show a large dependence on high-energy cross sections, as would be expected. The peak at approximately I Ney is due to a conibination of slight increase in 1-kev neutrons (see FIg. 11 ) and the response function still being significant at that energy:

\section{Sensitivity of Copper DPA to BfC Cross Sections in 2one 17 \\ The copper dpa is most sensitive to the ${ }^{10_{B}}$} cross sections. The sensitivity profiles (Figs. 49 and 50 ) also show a high energy dependence and the 1-Mev peak.

\section{Sensitivity of Copper DPA to TFC Cross Sections}

Table XXI points out that the copper DPA is mos: sensitive to the copper cross sections as compared to all other cross sections in the TFC, whereas Table XXIII isolutes the partial cross section of scattering as being the largest contributorm. The sensitivity proftles of copper dps vo copper net scattering and net total cross sections are given In, FIgs: 51 and 52, "respectively. All sensitivities, however, are much smaller than previously calculated sensitlvities to cross sections in other zones.

D. Mylar Dose Sensitivity

The vylar dose is the energy absorption by the insulation material, taken here as a radiuttion damage indieator. If this material is severely damaged, the entire TFG coll woult have to be removed, which in turn will require revetur shut down. It is inportant, therefore, to predtct the gaximum dose to Hylar reliably and to identify its main contributors and its sensitivities to nuclear cross sections. The Integral response sensitivity for the fysar dose is approximately 0.96 for neutron interactichs and 
approximately 0.04 for the gamm-risy interactions. The higher dependence on the neutron response function is reflected in $\mathrm{Fig}$. 7. The neutron response sensitivity profile is shown in FIg. 53. The characteristic 1-HeV peak in the neutron sensitjvity profile shows the strong dependence on high energy gamma-ray interactions (FIg. 54) but is In magni-. : tude much smaliex than the sensitivities to neutron Interactions.

\section{Sensitivity of Mylar Dose to SS Cross Sections in Zones 6-8}

The strong dependence of Nylar dose on neutron interactions leads to a sígnificant sensitivicy to neutron Intaraction cross sections, as can be seen wheh Tables XXIV and XXV are compared. The most sensitive contributor to this response, is again, iton. The partial and net integral seisitivities are shown in : sbles XXVI and XXVII for neutron interactions and gafima Interactions, respectively. The major contributor is the scattering cross section. Proflles of Mylar dose sensitivity to Iron seattering and total' eross sections In Tables XXVI and XXVII are ${ }^{*}$ iven ix Figs. 55-58.

\section{Sensitivity of Mylar Dose to Bur Cross Sections in Zono 17}

A comparisen between Tables XVIII and XXIX shows that the gimma-ray interäctions cause very little effect in the, response of Mylur dose. The major contributors to these sensitivities are the neutron inveractions wit: ${ }^{10} \mathrm{~B}$. The partial and net integral sensitivities for thes element are shown in Tables $\mathrm{XXX}$ and $\mathrm{XxN}$. It is interesting to note that the net nieutron scittering and absorption sensitivities are about equal. The efscic seattering cross sections for $10_{B}$ increases with decreusing neucron enargy and so there seems to be a compatition between nizutron absorption and scattering. The amma-ray interaction cross sections have negligible sensitivities, The sensitivity proilies for Mylix dose to 10. neucron scatterfing and total cross secu lons aré shown in Figs. 59 and 60. The cross-section sensilivities are mainiy in the bigh-energy region and the $\infty$ 1-MeV region.

\section{Sensituluty of Hyl ar Dose to TFC Crosis sections in First interval of TFC}

Al1 integral sensitivities are almost ndgliglbly small. The copper cross fections show the relatively highest sensitivities in both the netcron and gamis Interactions (Tables XxxII and XxxIII). Tables XXXIV and XXXV Indicate that the major sensitivity is due to the total cross section for neurrons, and the scattering cross sections of copper for gammays, respectivaly. The proftles of Nylar dose sensitiv1ty to copper scattering and total cross sections are 11 lustrated In Flgs. 61 and 62 , respectively. Again the revelation of sensitivity profile sign changes occur. Figures 61 and 62 suggese the noutrons scatcered from the higher groups that were considered lost, as far as copper transmutation was concerned (see SaC. IV.B.3), appear now is positive sensitivity for Mylar dose. As tha noutrons are scatterad below approximately $3 \mathrm{NeV}$, the copper transmutation process becomes the dominant reaction, hence, the sensitivity profile shanges signs.

The gainma sensit tvity profiles for gaima acatier and the gama total cross sections in copper (Figs.:" 63 and 64) show that Mylar dose is thosk sensitive to the cross section data in the 1-10-HeV range.

\section{E. Outer Tocoidal Field Coll Dewar Activetion}

The sensitivity profile of the stainless steel activation in the toroidal field coll dowar (region 40 in Fig. 5j is 1llustrated in F48. 65. As was. shown in FIg. 10, the response function has its greatest value at high neutron energies. Consequently, the high-energy neutruns will have a more Important role in the activation of the dewar. The history of the flux shape can be seen as follows. FIgure 66 shows the flux at the iast Interval of the lead moxtar in region 22 of Fig. 5. There is a slight bulld-up of flux at approximacely 1 MeV, but a decrease in flux with energy thitenfter. The 1-Mr: peak becomes more nottcegble in this stainless sreel zone 23 of Fig. 5. This is shown th Fig. $h$ ?. Whan the flux spectrum In FIg, 67 is compared with the Iron total cross section in Fig. 13, the shape of the flux appears to bo due to the Iron? in stainless steel. As before, there is the characteristic I-MeV peak due to the window in the iron cross section at that energy. The smoothness of the fux in Ftg, 66 has given way to slight peaks at a $1 \mathrm{kt}, 100 \mathrm{eV}$, and $\approx 3 \mathrm{eV}$. These peaks may be ilue to the desrease In the Iron cross section at thosy energies (sege Fig. 13). The peait that should appiar at energies lightly greater than $10 \mathrm{keV}$ is pertially hiduen by the 1-KeV peak.

broceding thithe vacuum regtion 39 (FIg. 68) shows that she 1-HeV peak has becone more predominant 
due to the interactions wth the $44 \pi$ by voling stainless steel in the TFC. Figure 69 show the flux at the region of interest, 1.e., thr trc dewas. While a major portion of the neutrons are In the energy region of $100 \mathrm{KaV}$ to $1 \mathrm{kN}$, there a relatively sfgnificant arount of neutrons at $234 \mathrm{Mev}$. Hence. when the flux and the respone lustion are folded rogether, the sensttlvity profile is high-energy peaked and decreases with decreasing energy.

\section{TrC Dewar Actiyation Sengit tulty Due co}

The integral sensitivities for the response of toroldal field cotl dewar actliation due to stainlnss stcel pross sections are sinown in Table XXXVI. phe taile indicates that the response $1 \mathrm{~s}$ most senstcive to the tron cross sections in the inbourd stainlass steel regions. This is to be expected In that the Iron is the wost abunciant eomponent in stainless steel und the interaction of the more important highenergy neutrois is grestest in the Innernost stainlestz steel restions. Table XXXVII shows the partial and net treegral senstelvities for the iron component. The scattering Interactions play the more Important role. Figure 70 is the sensitivity proflle for the Fe cotal eross bection. "There is a large sensitivity of activation to the high-energy cross sections of tron. Figure 71 reinforces the fact that the major contributor of the eross-section sensitivitics ure the seuttering eross sections of sron. Note that in both Figs, 70 and 71 there 1 is the characteististe 1-kov peak.

\section{THC Dewar Activation Sensitivity bue to Graphite Cross Sections}

The outer blanket/shield contains, a Bruphtte moderator in zones 11-13 of Fig, 5, The Braphite consisti of $-99 \%$ by weight of carbon and $1 \%$ by weight of bocon. The previous ealculations pertaining to $B_{4} C$ cross sactions have indicated a competition between the absorption of neatrons by boron and the scattering of neutrons by carbon. . In that the moderacion of neutrons could be Impoxtant to the activation" of the TFC dewar, it was declded to InvestiBate the sensitivity of the TFC activation to the cross sections of tise graphite moderator.

Table XXXVII reveals that the activation is more senstive to the curbon cross section and as expected, the scatcering cross suction ts the major contributor (Table $x \times x I X)$. The scatering cross-

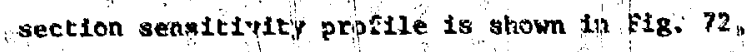
whereas the total seasitivity profile ls lllustrated in Fig. 73. In both res, the high-enepgy neutron crass dections yield thi most pensitivith.

\section{TFC Dewar Activation Sensitivity to Lead Mortar Cross Sections}

The outer blanket/shteld corteatns a stgnjficant amount of lead twortax (see. Fig, 5): The neittar has components such as hyorroger $(\approx 1,8 \% / w)$, lead $(\sim, 80 \% / w)$, carbon (o $11 \% / w)$ ete. It was suspected that these components may have a significant effeet in the ac"tlvation due to tha amount of lead mortar present in the design: Therefore, it was desired to determine which component had the most effect on the activation, and to what extent. Table XL brings forth the fact that the hydrogen cross sectien has a slightly higher effect on the activation than the lead eross section. This is interesting in that the activation is morc sensitive to the $1.8 \% / \mathrm{w}$ hydrogen than to the the mafo component lead $(80 \% / \omega)$. Table XLI sliows that it is the scattering properties of hydrogen that eause this to be so. Figure 74 is the sensitivity profilf of the TrC dewar activation to the hydrogen scattoring cross section. Close examination of Fig. 74 shows that the sensitivity is positive at "o $\mathrm{HeV}$. and negative elsewhere. When this data is oompared with the sensitivity profile for the carbon scattering cross section, the answar for the cliange in sign appears to be the following. The nevtrons that are seattered by hydrogen and earbon in the 8 -kev energy region downscutter to energies where there is a tendancy for the neutrons not to undergo absorption by the slobtum, copper; or fron in the regions that "follow. Table XIII gives rough estimaten of the major absorption and elast1c seattering cross sections for neutron energy of $\sim 3 \mathrm{MeV}$. As can be seen at that energy, the absorption processes will be lower than the elastic scattering, hence, the neutir is are avallable for furcher transport to the TFC dewar: At lower energles, particularly, $-1 \mathrm{keV}$ the bsorptive processes begin to overcome the scattering processes. As a result, the sensitivity profile tums negative again. Figure 76 shows the TFC dewar activation 'sensitivity to the net neutron total srous section of hydrogen. The activation has, a sensitivity of $\sim 10 \%$ to the hydrogen crosps sections at $14 \mathrm{MeV}$. 


\section{TFC Defar Aativation Sensitivity to TFC Component Fross Sections}

As was shown earlier in this sectton, the cowponents of the IFC, particularily copper, greatiy drfected. the shape of the flux spectrum. As a result, It was felt that the components of the TFC coil (in zones 31-34 of FIy. 5) may have some bearing on the integral reșult of the dewar activatinit. These were investigated with the Integral results": listed In Table XiII. The integral, sensitivity due to all components is a heaithy $-11.9 \%$. The copper and iron cross sections showed the greatest sensitivities: with the former dominating. Azain the scattering cross section is the mujor contributor to copper's effect on the dewar activation. The high-energy peaked sensitivity profiles of TWC dewar activition to the copper scactering and total cross sections are shown in Figs, 77 and 78 , respectively. The change in $81 \mathrm{gn}$ is due to the fact that the elastic soattering cross section of copper has the tall end of 1 ts resonance region at $-1 \mathrm{MeV}$. Therefore, the probability of seattering neutrons to the TFC dewar is greater, und leading to a positive sensitivity. "At energies greater than $~ 2 \mathrm{MeV}$, the elast1e cross. section of copper dęcreases withqut further resonunces, and this leads to a decrease in the probabllity of scattor Therefore, the sensitivity profile is negative for these energies.

\section{v. CONCLUSIONS}

There are several pojnts of Inicrest as a result of the investigations carried out in this researth.. The first is that the design as proposed in Refs. $6-7$ tends to have a draxactertstic of a streamig of 1-MeV neutrons through most of the blanket. It is felt that this is the cinsequence of the fron in the large anounts of stainless steel contained in the present design.

The second point pertains to the data obtained. All the sensitivity proftles rovealed that the responses investigated were basically more sensitive to tha 4 -Mè cross sections; and, that the 1-HeV entrgy range played an important role for the present EPR design. The TFC nuclear heating was dominated by the neutron interactions, and the gaitma Inteructions showed sensitivities of approximately a magnicude of 10 lower. The coll heating had a sensitivity of $-7 \%$ per $1 \%$ change in the stainless stecl cross sections for the total amount of stain less steel contalned tr. the blanket. Iroth was the major contributor to this. The $\mathrm{B}_{4} \mathrm{C}$ cress sections caused a sensitivity in the nuclear heating of the: TFC of -22 ger $1 \%$ change In cross section and was $v$ mainly due to the absorption of thermalized neutrons by $10 \mathrm{~A}$. The components of the TF itself showed lower

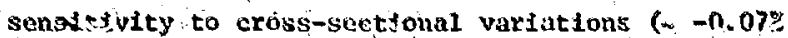
for neutrons and $-0.3 \%$ for gunma rays), with copper being the major contributor.

Copper trunsmutation sensitivity to the innermost stainless steel rugions' cross seetions was a $-4 \pi$, with tron as the mafor contributor. While $\mathrm{B}$ of the $\mathrm{H}_{4} \mathrm{C}$ was the main cross-8ection Information that caused a total sensitivity of $--1.1 \%$ and as in the heating, the copper triansmutation sensitivity to the TFG conponents was the smallest $(\sim-0.08 \%)$ and eopper eross sections being the greatest cuuse. Alșo, the highenergy neutrons will be Inelastically scattered to energies where they will net the undergo the $(\mathrm{m}, 2 \mathrm{n})$ process nor be captured by copper. Further downcus:texing will show a pastlive sensitivity of copper transmutation die to the dominance of radiative cap:" ture, by copper. Furthermore, competition between absorption by copper and radiative capture by nioblum and iron will again cause a negative response in sensitivity at $-1 \mathrm{KeV}$.

Copper dpa. followed the same trend as the two previously mentioned studies: The iron of stainless steel caused the most sensitive response, whlle $10_{B}$ and sopper followed in order.

As expecied, the Mjate case followe closely with the TrC nuclear heating results. The Iron in the innermost stainless steel regions was the nain contributor to the stainless steel integral neutron sensitivity of $\sim-4 \% ; 10_{B}$ was the main reason for the total neutron integral senstitivity of $\sim-0.7 \%$ in the $\mathrm{B}_{4} \mathrm{C}$ region; copper cross sections caused a large portion of the total $-0.07 \%$ sensitivity to eome about due to TFG components.

The activation of the rFC dewar had higher senstivilies than the previously mentioned studies, although the prime contributor in this easa was the coppert In the TFC. The stainless steel regions of the outiox blanket/shield sliowed a total sensiteivity of $-1 \% 5 \%$, the Braphite regions $-2.4 \%$, the lead mortar reglons (with the hydrogen cross sections 
dominating) at approximately" -7.57 and the TFC

components at anproximately $-11.9 \%$.

Thus It appears that the major concern for the innox blanket/shield in the jun cross sections, aid theimajor concern for the outer blanket/ahield 'TFC's dewar activation is the copper cross sections. In both cases, the energy ragions of concern were the 14-MeV and 1-MeV reglons.

The last point to be made pertains to the use of coupled cross-section sats for cross section sensitivity aralyses. Their use facilitates matters" greatly, provided that care Is taken with not only the computer algorithms used, but also wth the interpretation of the various components of the dif* ferential method equations. The use of composite transport cross-section sets presenti problems in data manipulation and intorpretation. The researcher must realize the structure and composition if these types of cross-section sets and lend grat care in the illterpretation of the results. Once this hurdle is overeome, the methods amployed in this paper should provide a most helpful and expedienc procedura of obtaining eross-section sensitivity data:

NOTE: Comments to computer plotted sensitivity profiles (Figs, 11-78). The sonsitivity profiles. should be interpreted in the following manner. Bach point of the graph repkesents the sensltivity of the response of concern for a particular energy iroup. Tic group structure cali be found In.Ref. 16. The periods represent a positive sensttivity and the ashes correspond to a.ne;ative sensitivity. Each symbol is locited on the upper bound of its respective energy group.

\section{REFERBNCES}

I. D. E. Bartine, E. M, Oblow, and F, R. Mynat, "Radiation-Transport Eross-Section Senattivity Analysis - A General Approxch I1lustrated for a Thermonuclear Source in ALr," Nuel. Sel. Eng. 55, 147 (1974).

2, D. E. Birtine, R. G, Alsmiliex, Jr, E. M. "Oblow, and F. R. Mynat, "Cross-Section SensiHivity of Breading Ratio in a Fusion-Reactor Blatket," Nucl. Se1. Bng, 53, 304 (1974).

3. S. A. W. Gerstl, Donald J. Dudriai, and D. W. Muir, "Cross-Section Sensitjuity and Uucertainty "Analys is with Application to a Fusion Reactor," Nuel. Se1. Eng. 53,137 (1977):

4. S. A. W. Gerst1, "Blanket Destgn and Gross-Sèction Sensitivity Dalculations Based on Pertufbation Methrde," Proc. First Topieal Neeting on
Technology of Controzled Nuel. Fuston (San Diego, CA, Apr \pm 1 (6-18, 2974), CONF-740402-12, p. 336 .

5. B. H. Oblow, "Seirativity Thenry From a Differential Viewpoint, it Nucl. Sel. Eng. 59, 187 (1976).

6. V. 1. Maron1, Editor, "Review of Tokamak Livperimental Power Redictor Stikiles at the Argonne National Laboratory," Argonne Nat Lonal Laboratory (1976).

7. M. A. Abdou, "Nuclear Design of the Blanket/ Shield systems for a To'vamak Experimental Power Reactor," Nucl: Tech. 29, 7 (1976).

8. S. A. W." Gersti, "The Application of Perturbation Methods to Shicld and Blanket Design Sensitivity Analysis," Argonne National Labo.. ratory report AP/GTR/TM-28 (1974).

9." "Donald J. Dudziak, Editor, "ENDF Formats and Procedures for Plioton Production and Interaction Data," Ios Alamos Scientffic Iaberatory report LA-4549, ENDF-102; Rev, Vol, II (1971).

10. D. J. Judziak, R. E. Seamon, and D. V. Susco, "LAPHANC: A $\mathbf{P}_{0}$ Mulcigroup Photon-Production Matrix and Source Code for ENDF," Los Alamos Sejentifle Laboratory report LA-4750-MS (Jarimary 1972).

il. k. D. Lathecp, "DTF-IV, a FoRTRAN-IV Program for Solving the Multigroup Transport: Equation with Anisotropic Scattering," Los Alamos Setientific tuboratory report LA-3373 (1965).

12. M. A. Abrou and C. W. Maynard, "MACK: A Program to Calculate Neutron Energy Rel,ease Rarameters ant Multigroup Neutron Reacticns Crnss Sections from ENDF/B," Trans. Am. Nucl. Soc. 16, 129. (1973).

13. S. A. W. Gerst1, "SENSIT-1D, A FORTRAN" code to Perform Cross-section and Design Sensitivity Analyses in one-Dimensioral Geometries," Ios Alamos seientific Laboratory report. (to be published).

14. S. A. W. Gerst1, "Sensitivity Profiles for Secondary Energy and Angular Distributions," Fifth Internal Conf, on Reactor Shielding, (Knoxville, Fonnessee; Apri1 18-22, 1977).

1\%. E. L. Simmons, D. J. Dudziak, and S. A. W. Cerstl. "Nuclear Design Sensitivity Analysis. for a Fuston Reactor," Nucl. Technol. 34,138 (August 2977)..

16. H. A. Sandmeter, G. E. Hansen, R. E. Seamañ, T. J. Hirons, and A. H. Mastugll, "Coupled Neutron-Gama Multiginup-Wiltisable Cross Sections for 29 Materlals Pertitient to Nuclear Weapons Effeet Calculations Generated by LASL/ TD Division "L Los Alamos Scientifie Laboratory. report LA-5137 (1974). 


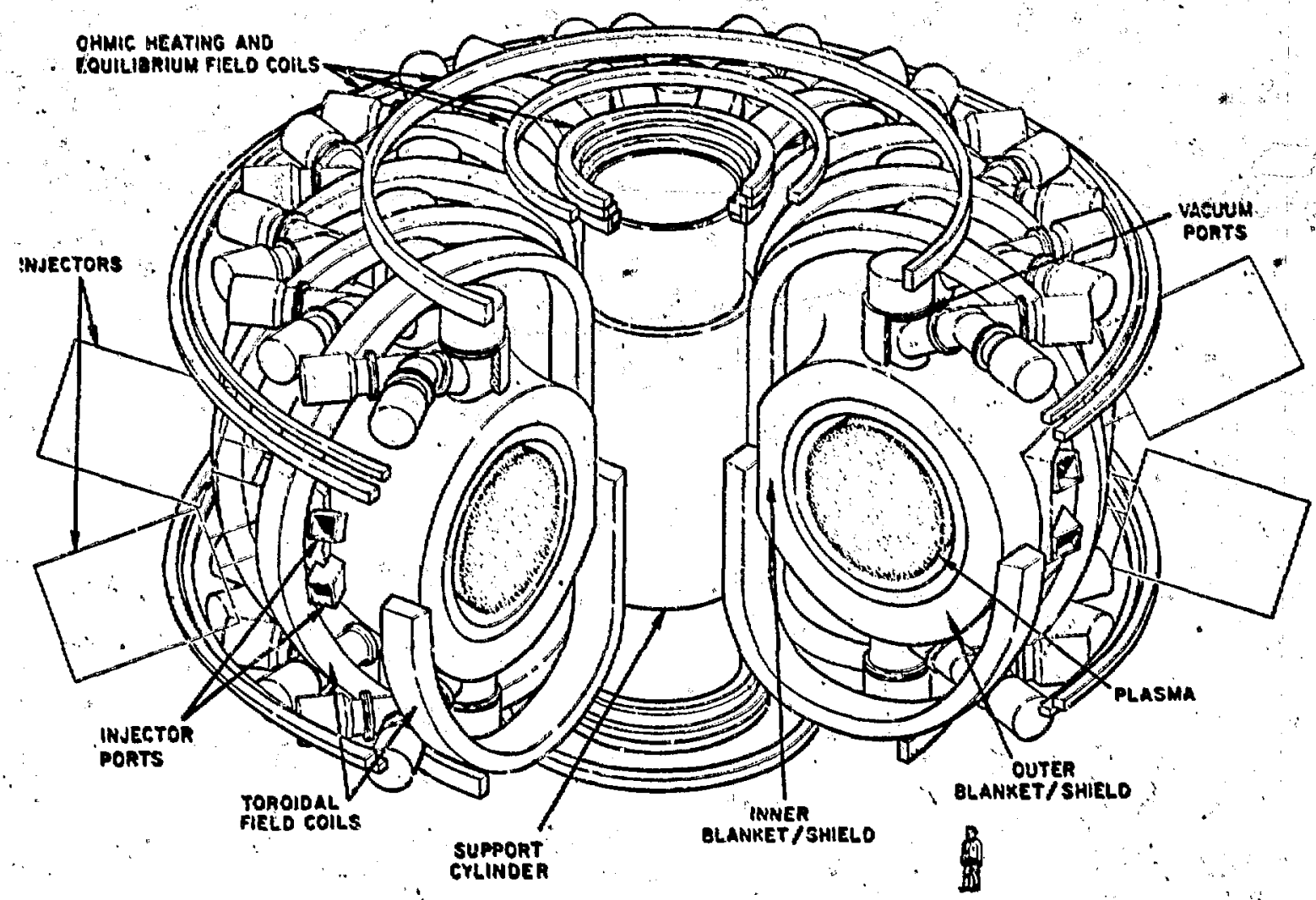

Fig. 1. Schematle view of the Argonne Natlonal Labotatory Tokamak:"
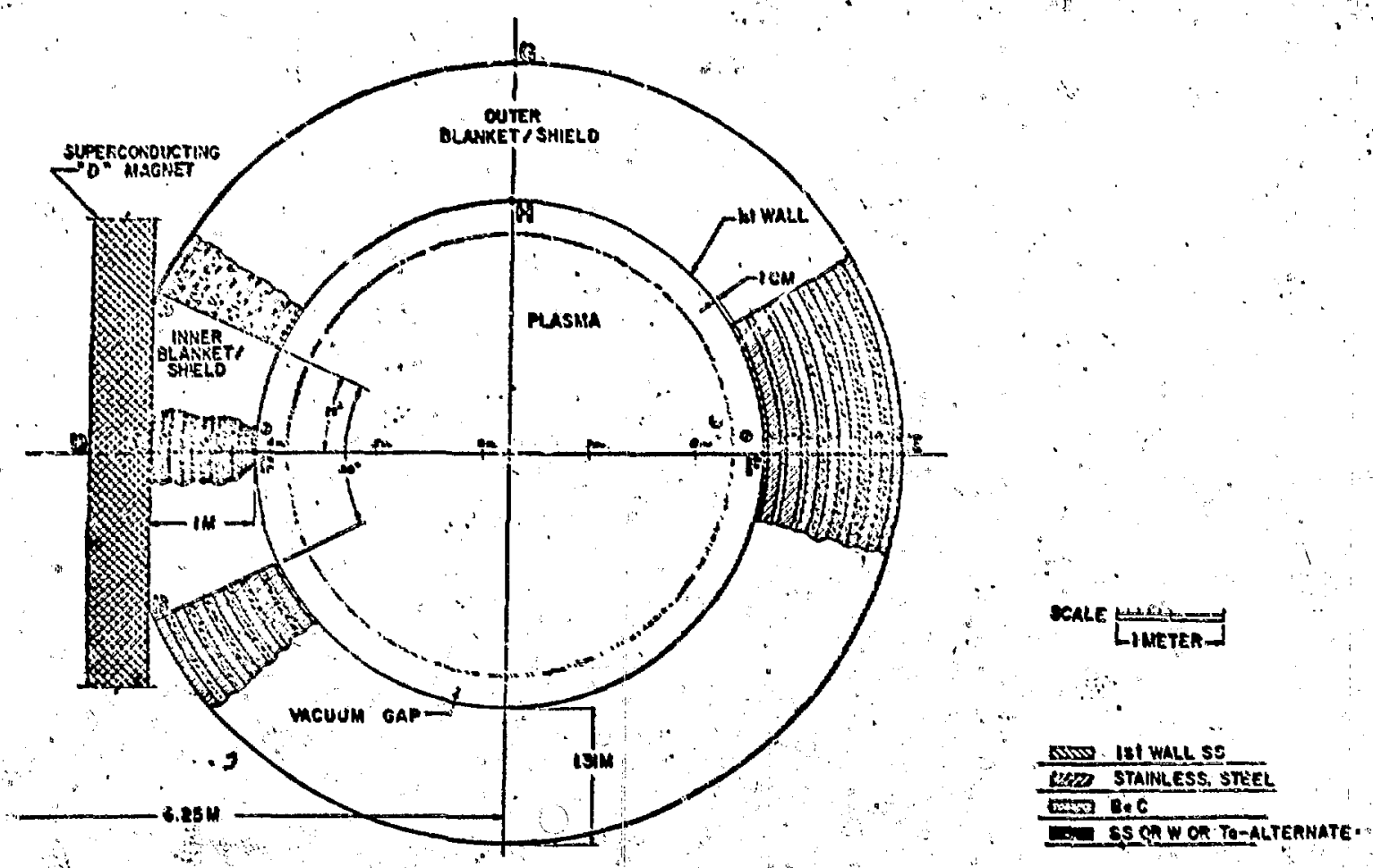

IfB. 2. ANL-TEPR blahket/shleld vertical sectlon view. 


\begin{tabular}{|c|c|c|c|c|c|c|c|c|}
\hline $\begin{array}{l}\text { EOIT } \\
\text { POSITION }\end{array}$ & 1 & 2 & 3 & 4 & 5 & 6 & 7 & 8 \\
\hline 1 & $\sigma_{a}^{\prime}$ & $\sigma_{\dot{a}}^{2}$ & $\sigma_{0}^{3}$ & $\sigma_{0}^{4}$ & $\sigma_{0}^{5}$ & $\sigma_{0}^{6}$ & $\sigma_{0}^{7}$ & $\sigma_{0}^{8}$ \\
\hline 2 & $\nu \sigma_{f}^{\prime}$ & $\nu \sigma_{f}^{2}$ & $\nu \dot{\sigma}_{f}^{3}$ & $\nu \hat{\sigma}_{t}^{4}$ & $\nu \sigma_{f}^{5}$ & 0 & 0 & 0 \\
\hline 3 & $\sigma_{t}^{\prime}$ & $\sigma_{t}^{2}$ & $\sigma_{t}^{3}$ & $\sigma_{t}^{4}$ & $\sigma_{t}^{5}$ & $\sigma_{t}^{6}$ & $\sigma_{t}^{7}$ & $\sigma_{t}^{8}$ \\
\hline 4 & $\sigma^{1-1}$ & $\sigma^{2-2}$ & $\sigma^{3 \rightarrow 3}$ & $\sigma^{4-4}$ & $\sigma^{5-5}$ & $\sigma^{6 \rightarrow 6}$ & $\sigma^{7-7}$ & $\sigma^{8-8}$ \\
\hline 5 & 0 & $\sigma^{1-2}$ & $\sigma^{2-3}$ & $\sigma^{3-4}$ & $\sigma^{4-3}$ & $\bar{\sigma}^{5-6}$ & $\sigma^{6-7}$ & $\sigma^{7-8}$ \\
\hline 6 & 0 & 0 & $\sigma^{1-3}$ & $\sigma^{2-4}$ & $a^{3-3}$ & $\sigma^{4-6}$ & $\bar{\sigma}^{5-7}$ & $\sigma^{6 \rightarrow 8}$ \\
\hline 7 & 0 & $\therefore 0$ & 0 & $\sigma^{1-4}$ & $\sigma^{2-5}$ & $\sigma^{3-6}$ & $\sigma^{4-7}$ & $\sigma^{5-8}$ \\
\hline 8 & 0 & 0 & 0 & 0 & $\sigma^{1-5}$ & $\sigma^{2-6}$ & $\sigma^{3-7}$ & $\sigma^{4-8}$ \\
\hline 9 & 0 & 0 & 0 & 0 & 0 & $\sigma^{1-6}$ & $\sigma^{2-7}$ & $\sigma^{3-8}$ \\
\hline 10 & 0 & 0 & 0 & 0 & 0 & 0 & $\sigma^{-7}$ & $\sigma^{2-8}$ \\
\hline 011 & 0 & 0 & 0 & 0 & $0^{\circ}$ & 0 & $-Q$ & $\sigma^{\prime-}$ \\
\hline
\end{tabular}

Fig. 3. Neutron-gawe coupled cross-section table with five neutron groups and three gaveta groups. Note: (nitr) production matrix is enclosed with - 


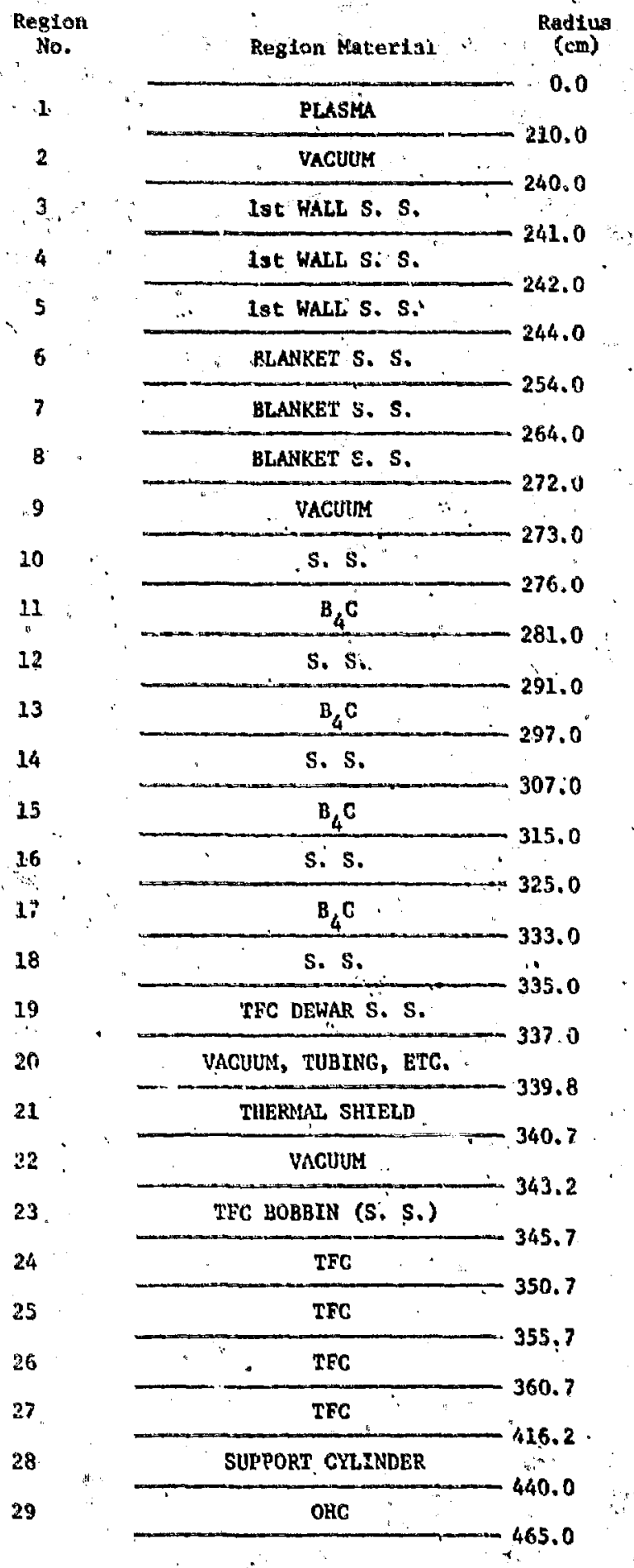

FIB. 4. One-dimenstonal model of Inner b.lanket/ shield of EPR.

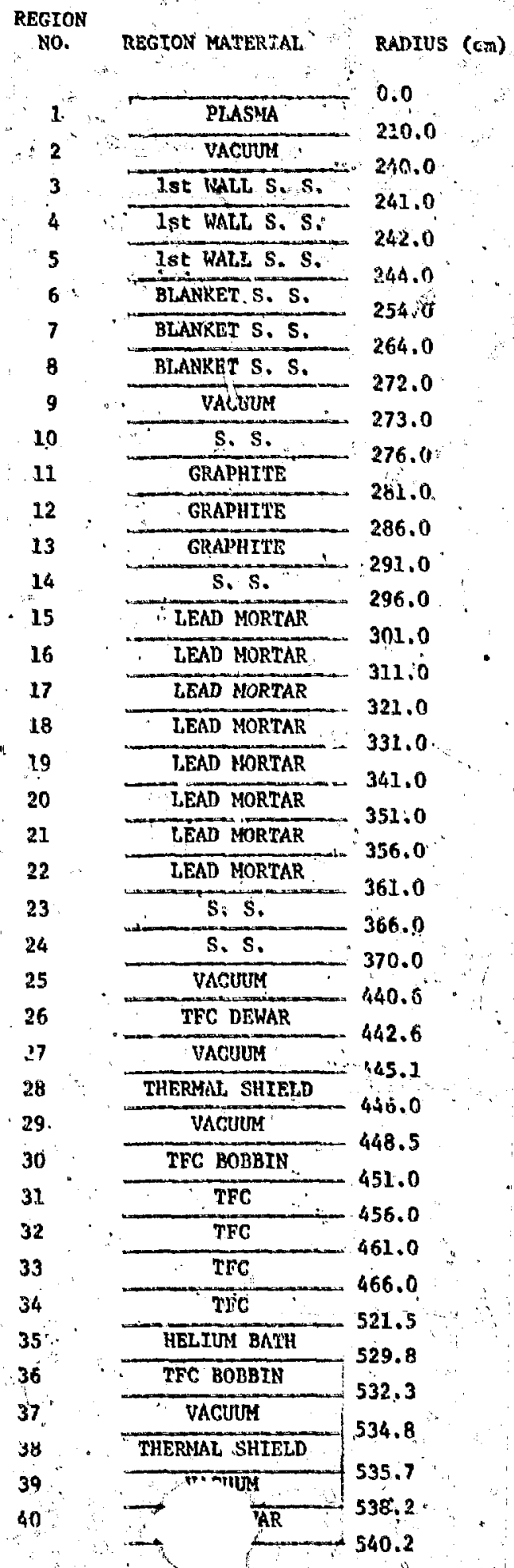

Fi8. 5. One-dimensional model of outer blanket/ sinield of EPR. 


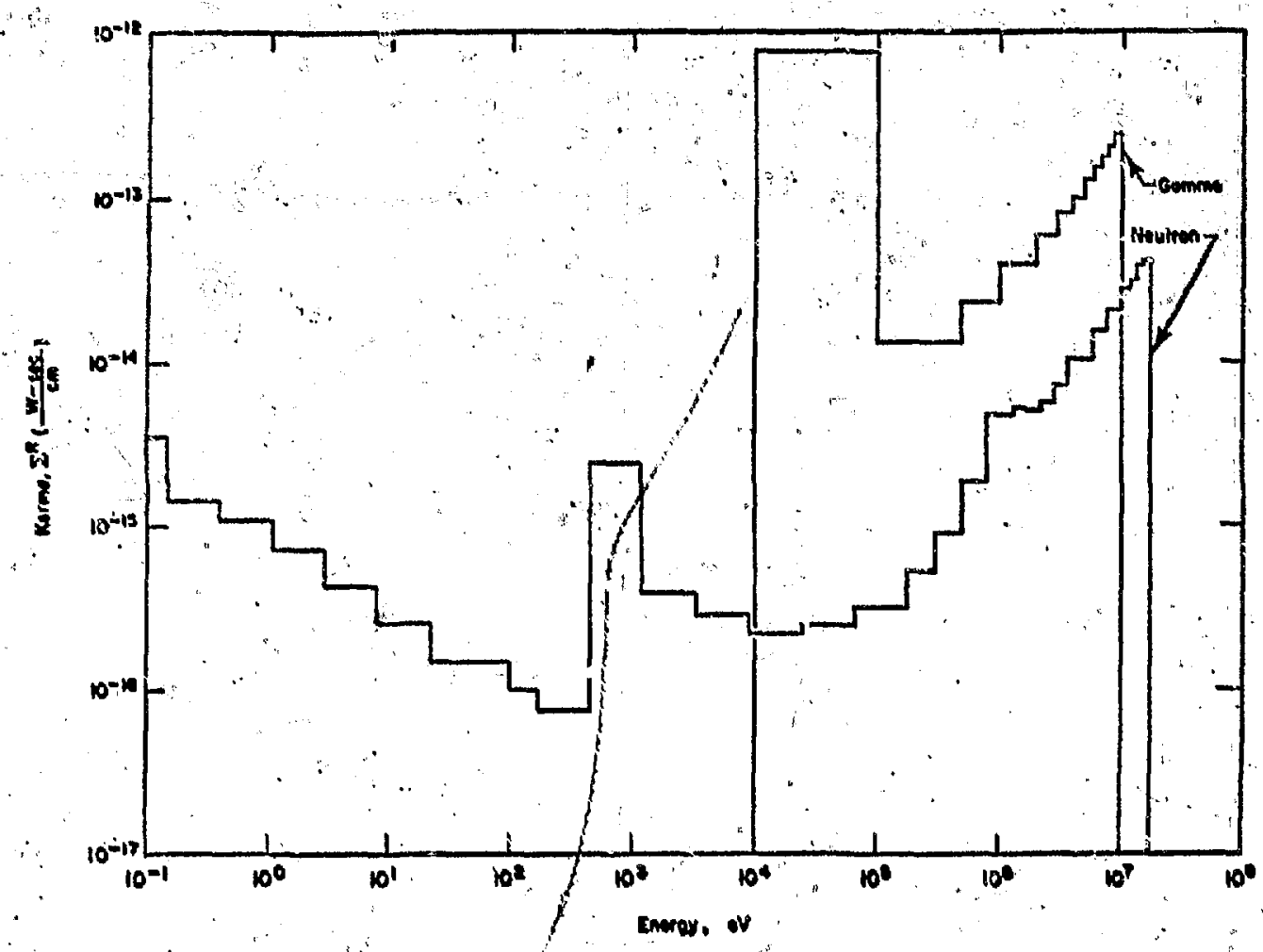

F1G: 6. Neutror and gamma kezmi response funetions.

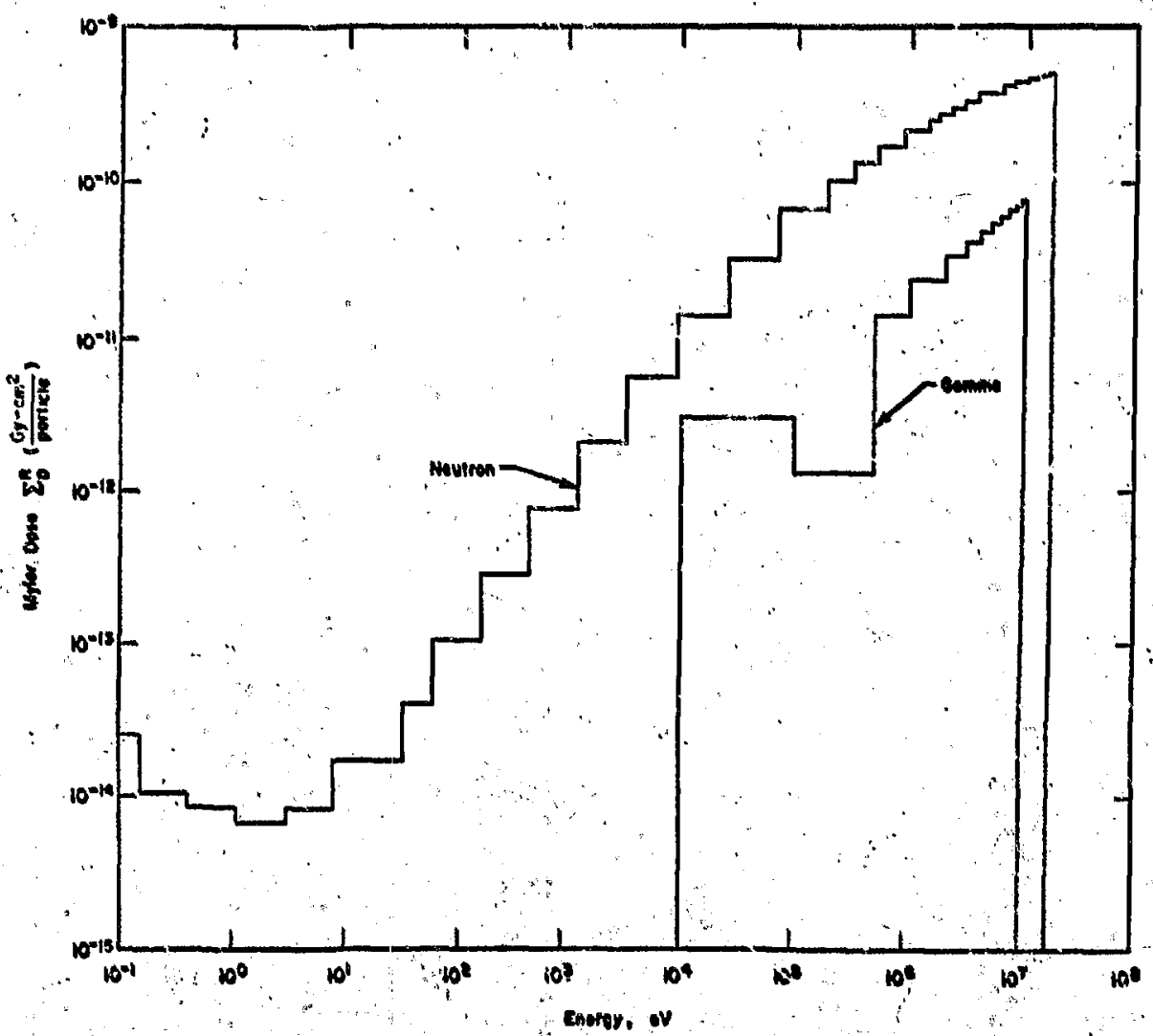

Fig. 7. Neutron and Bamma Mylar dose response iunctions., 


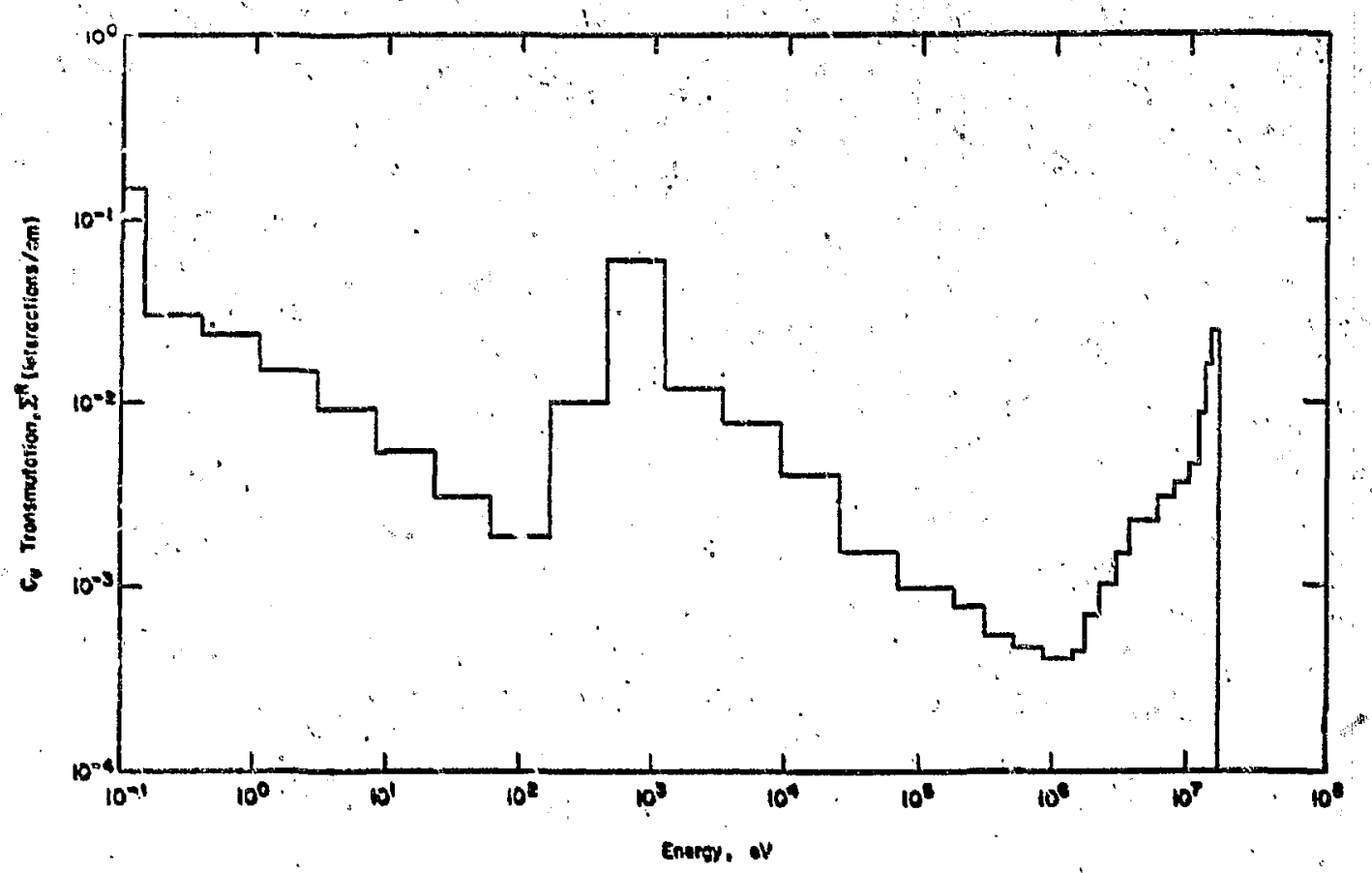

Fig. 8. Gu transmutation rusponse function.

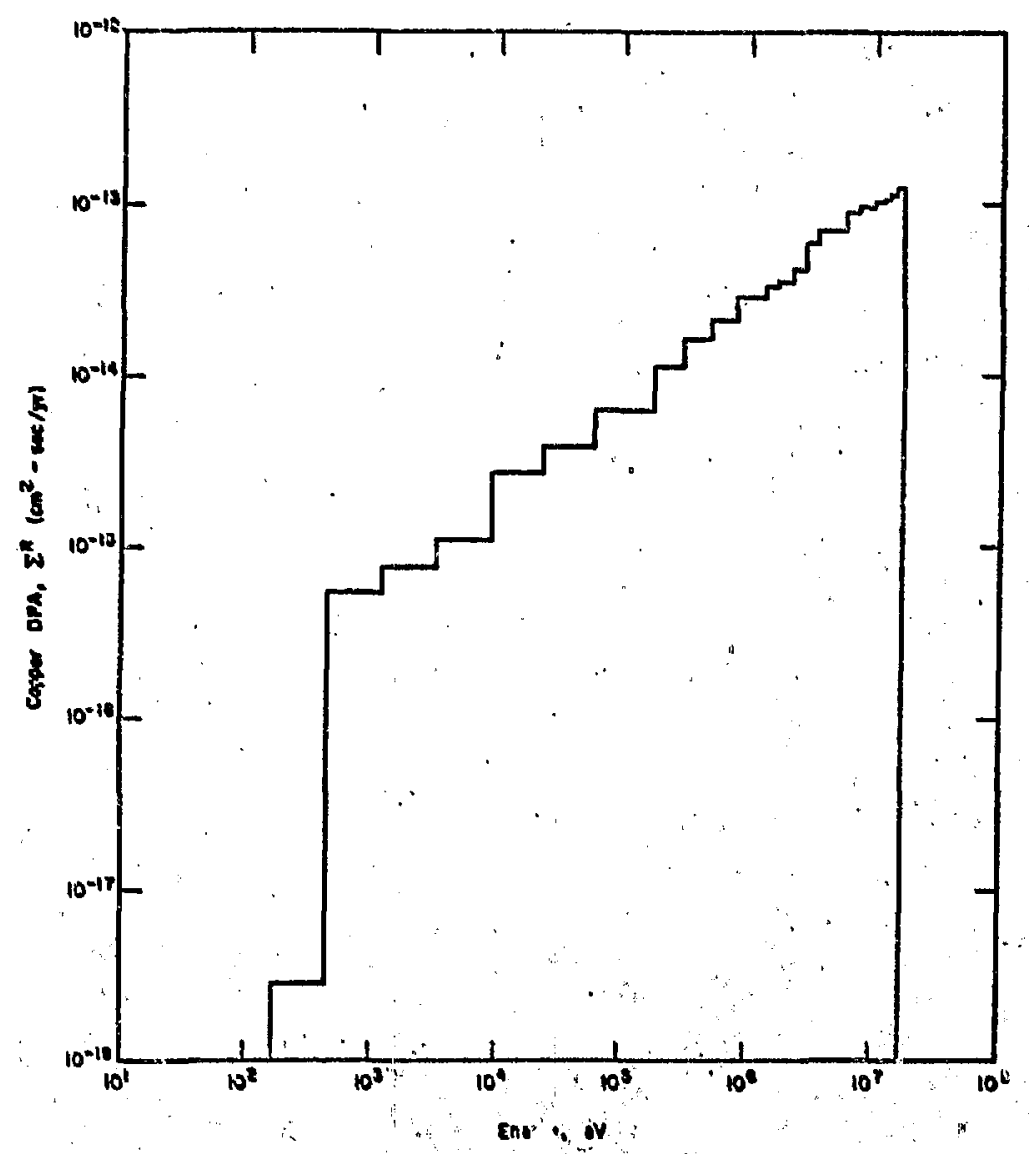

Fig. 9. Cu DPA respónse function. 


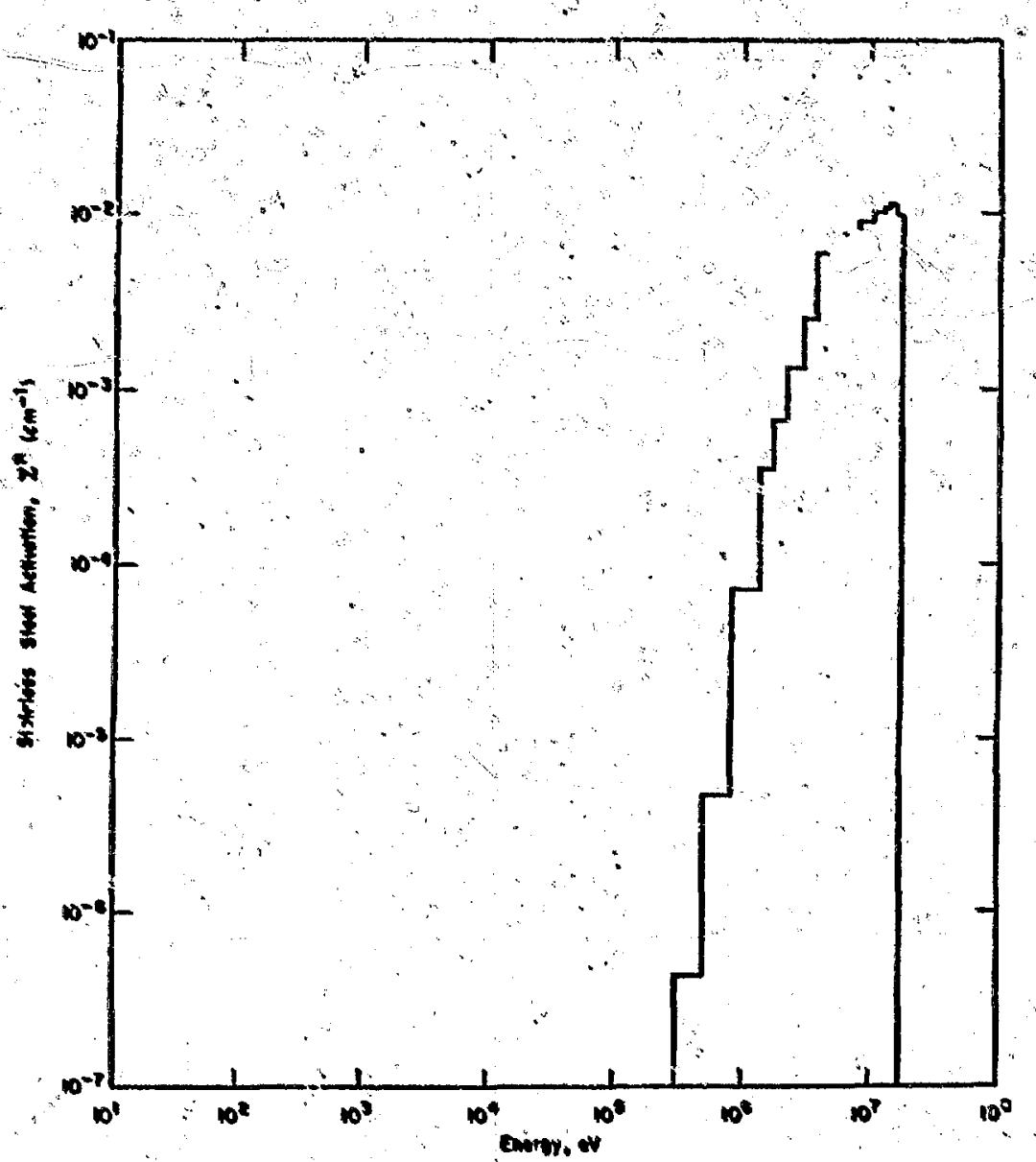

Fig. 10: Stainiess steel activation response function.

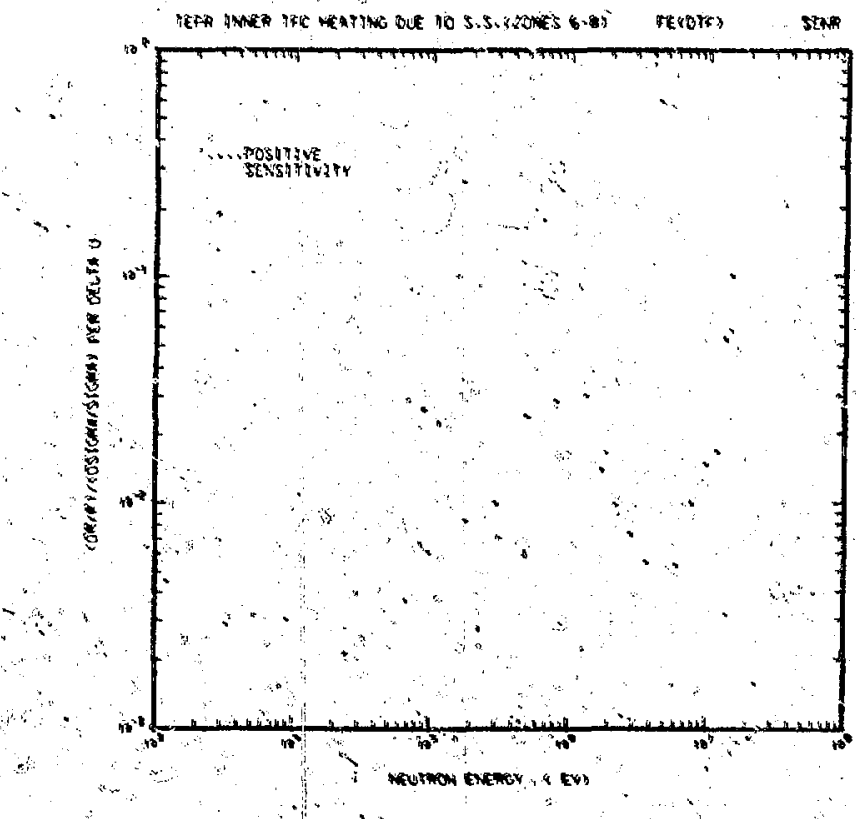

Fig. 11. Neutron sensicivity of nuclear heating in Inner TFG to Fe in zones 6-8. Net for response tunctiou. 


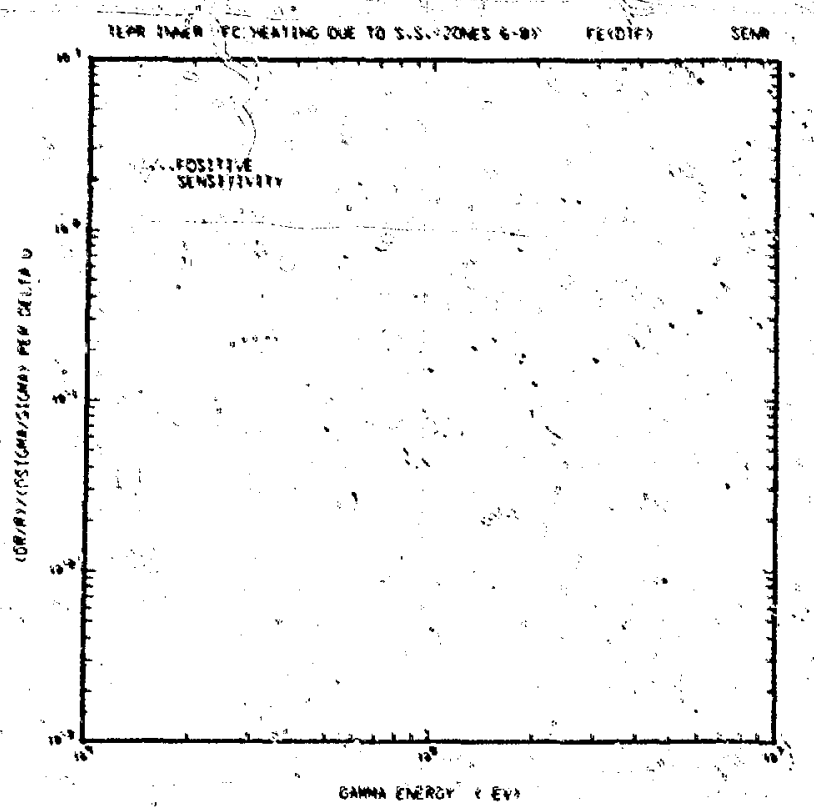

Fig. 12. Gana sensitivity of nuclear hating in the inner TFC to Fe in zones 6 -8. Net for tesponse function.

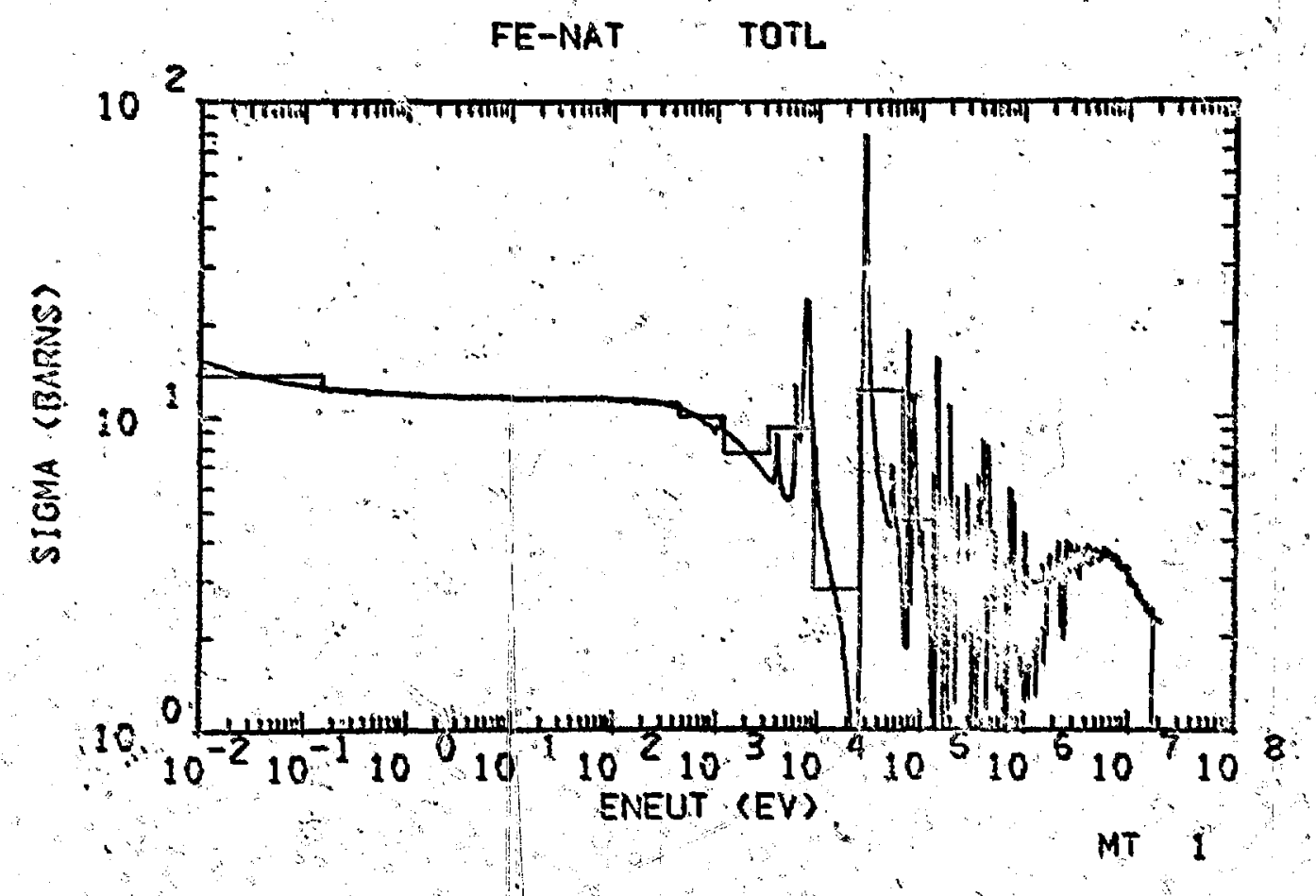

F18. 13. Fe total eross sention. 


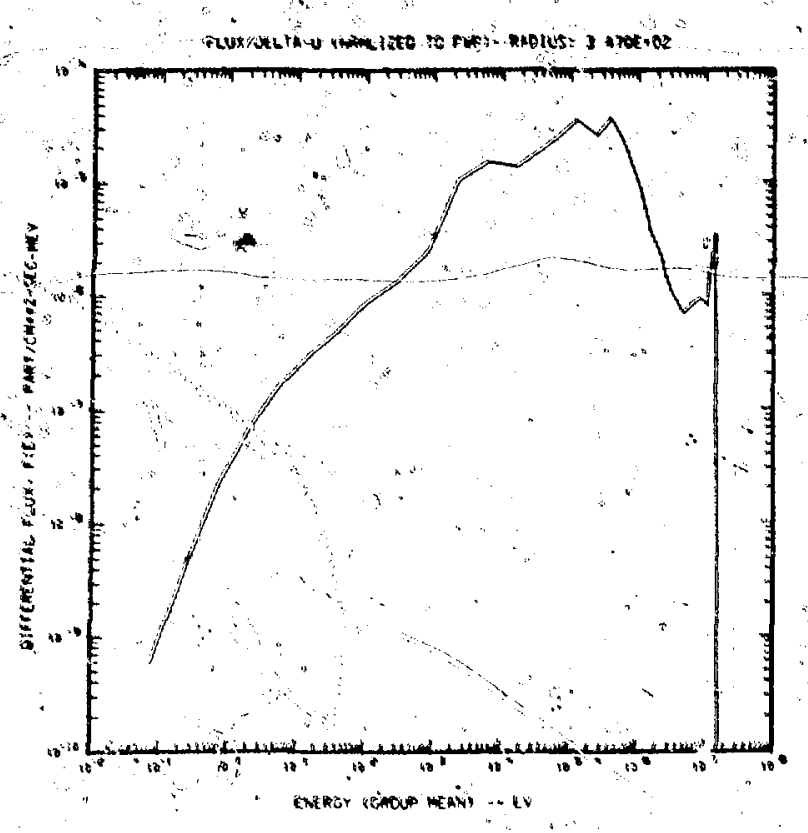

Fig. 14. Mux at the first intervel in the TFC.

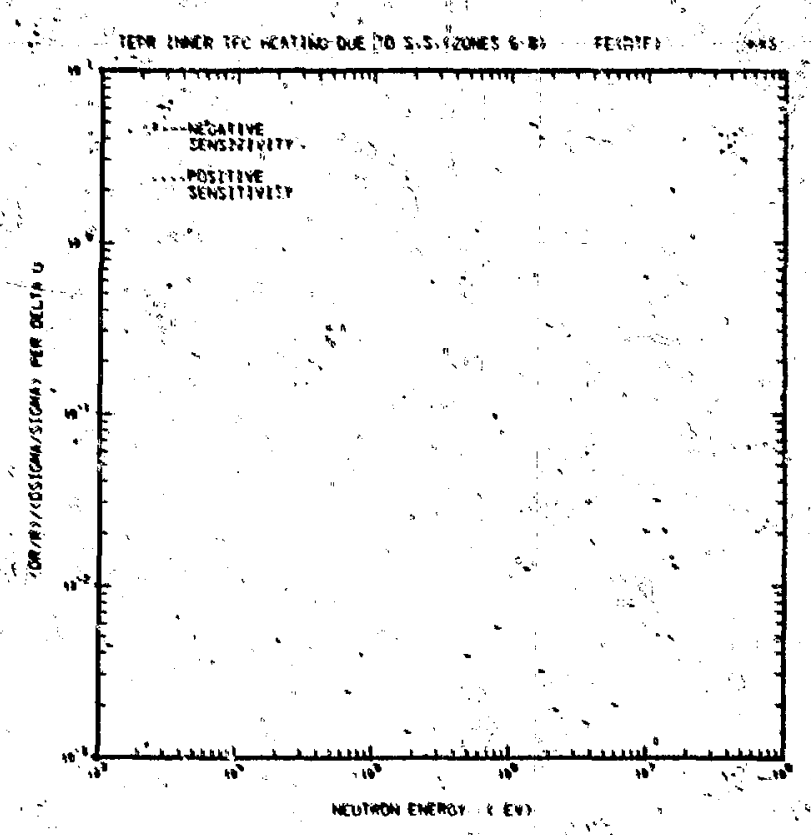

F18. 15. Sensitivity of nuclear heating in inner TFC to $F e$ in zones 6-8. Neutron absorption cross section, pure loss term.

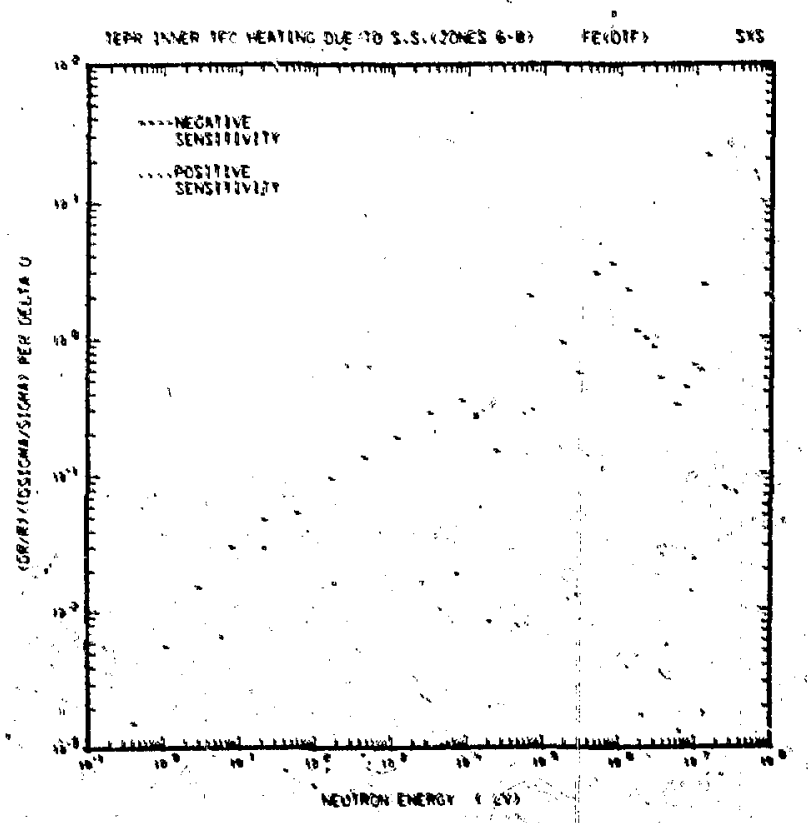

Fig. 16. Sensitivity of nuclear besting in innex TFC to In yones $6-8$. Nectron scattaring, cross section, loss term only.

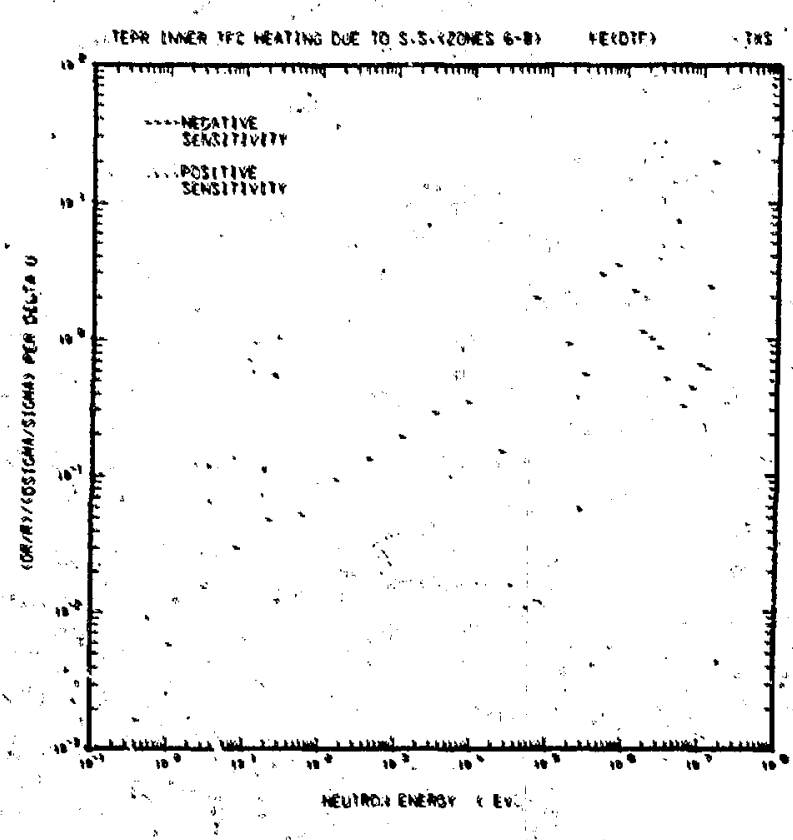

Fig. 17. Sensitivity of nuclear heating in inner TF́ to Fe in zones $6-8$. Neutron total cross section. Pure loss term. 


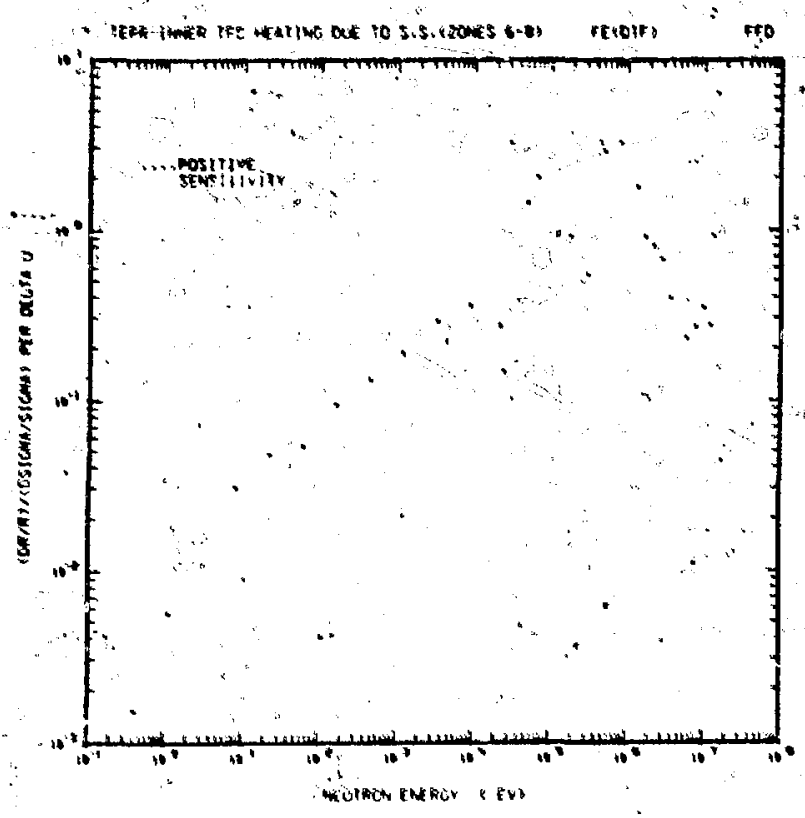

Fig, 18. Sonsitivity of nuclear leating in Inner TFG to Fe in zones 6-8. Neutron gain term oniy:

$y^{*}$

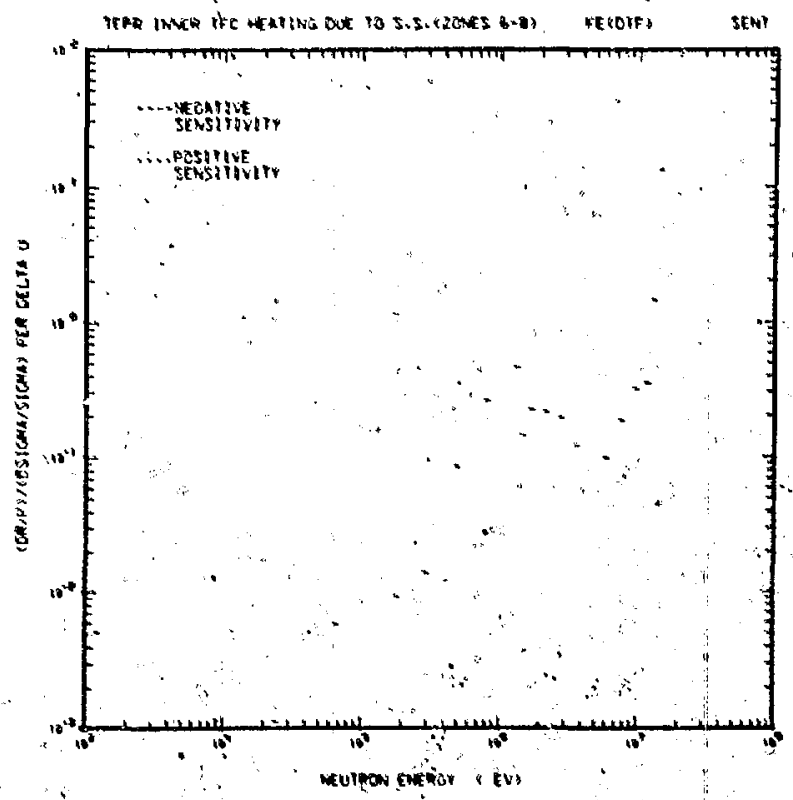

F18. 20. Senstivicy of nuclear heating in inner TFC to Fe in zones 6-8. Net nuturon totel cross stetion.

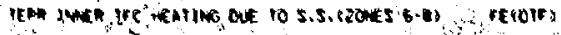

sw

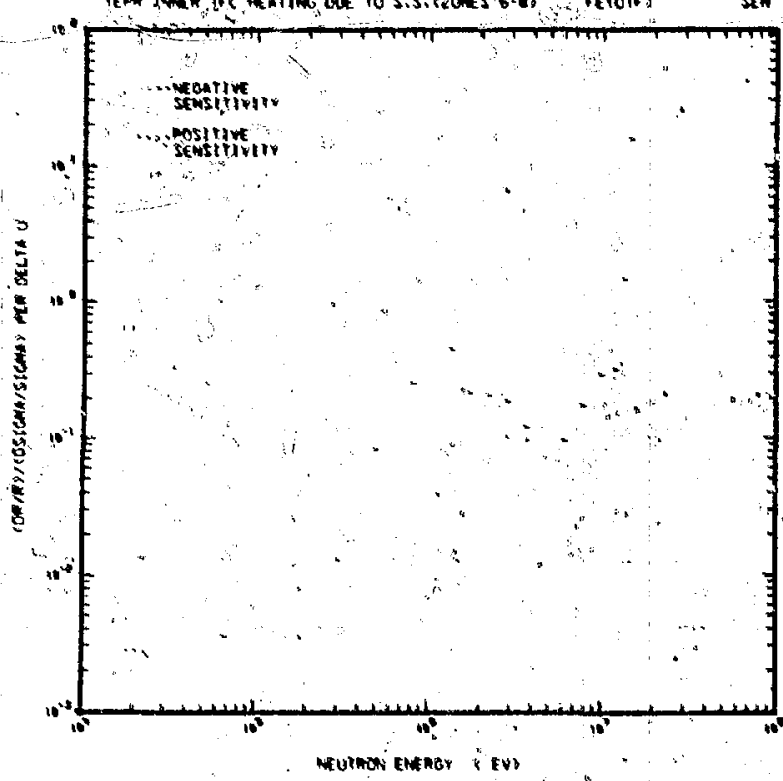

Fig. 19. Sensitivity of nuclear hesting "in inier TFG to Fe In zonys 6-8. Net neutron scuttering cross section.

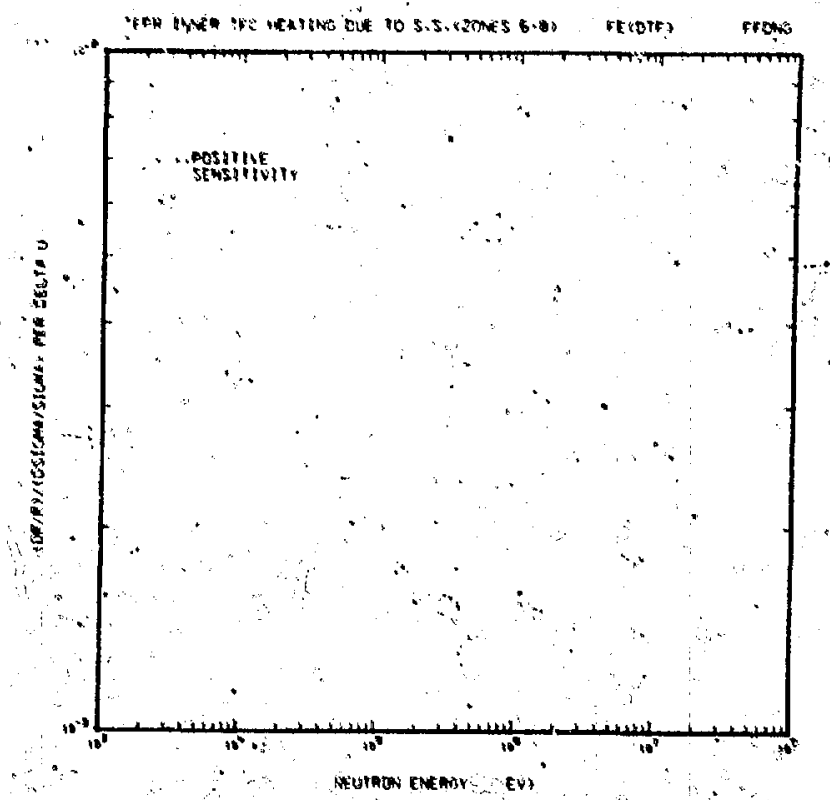

Fig. 21. Sensitivity of nucleer heating in Inner TFC to Fe in zones $6-8$. - tama producition cross-section gain term only. 


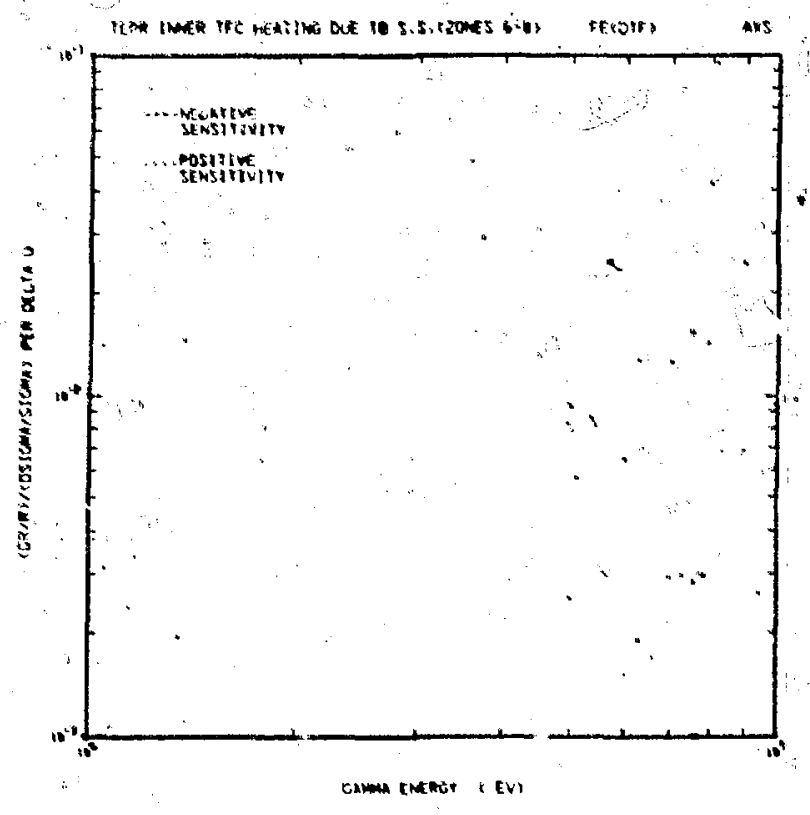

Eig. 22. Sensttivity of uuclear heating in inner TEC to Fe In zones 6-8. Gamm absorption cross section, pure loss term.

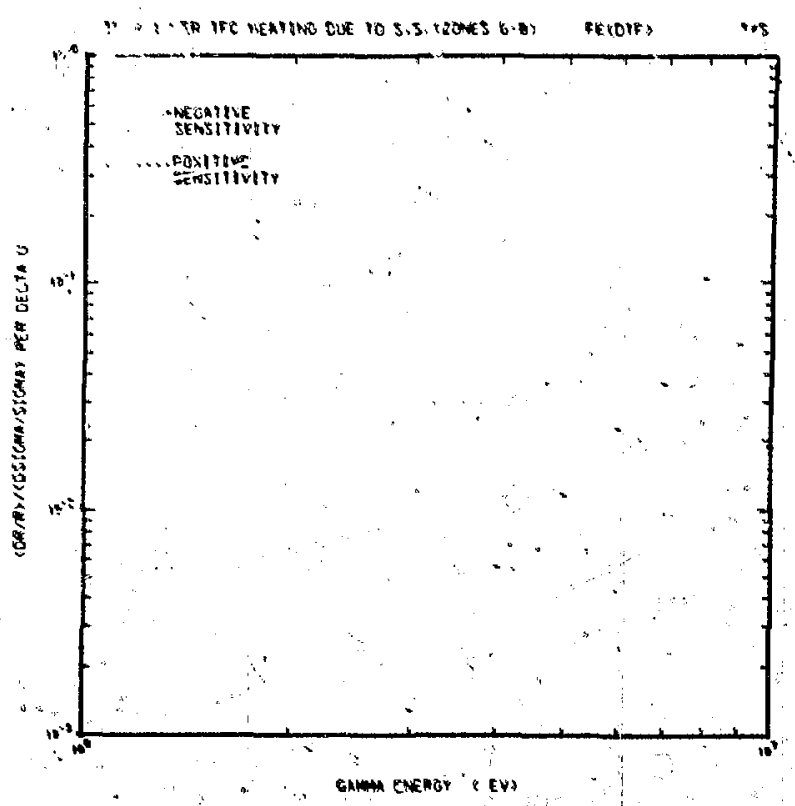

F1g. 24. Sensitivity of nuclear heating in inner. TFC to Fe in zones 6-8., Gam total eross section. pure loss term.

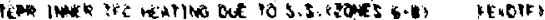
sus

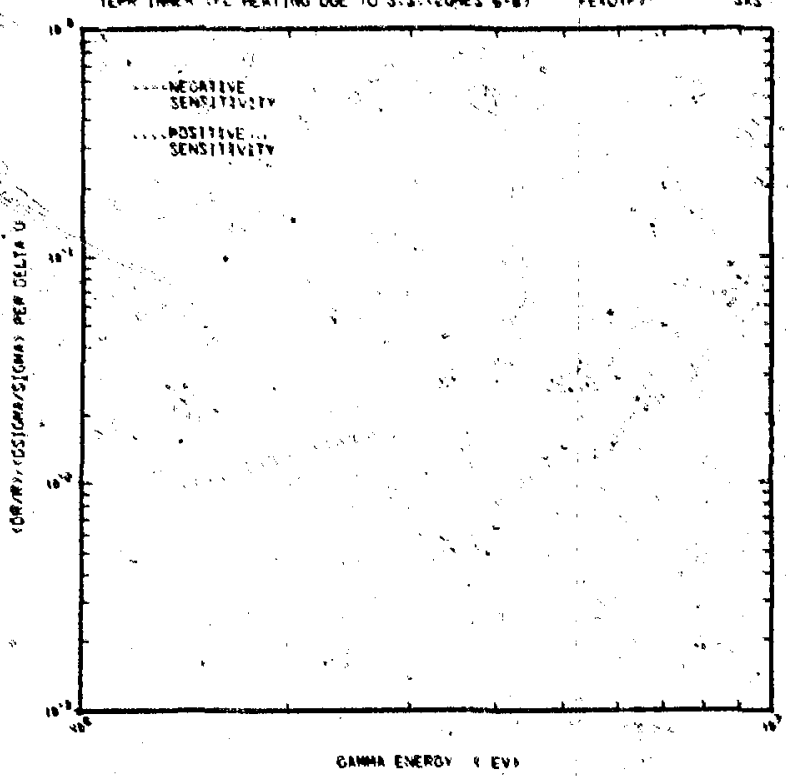

Fig. Sis; Sensitivity of nuelear heasing in Inner TFC to Fe in zones 6-8. Gama scatturimg cross section, loss term pnly."

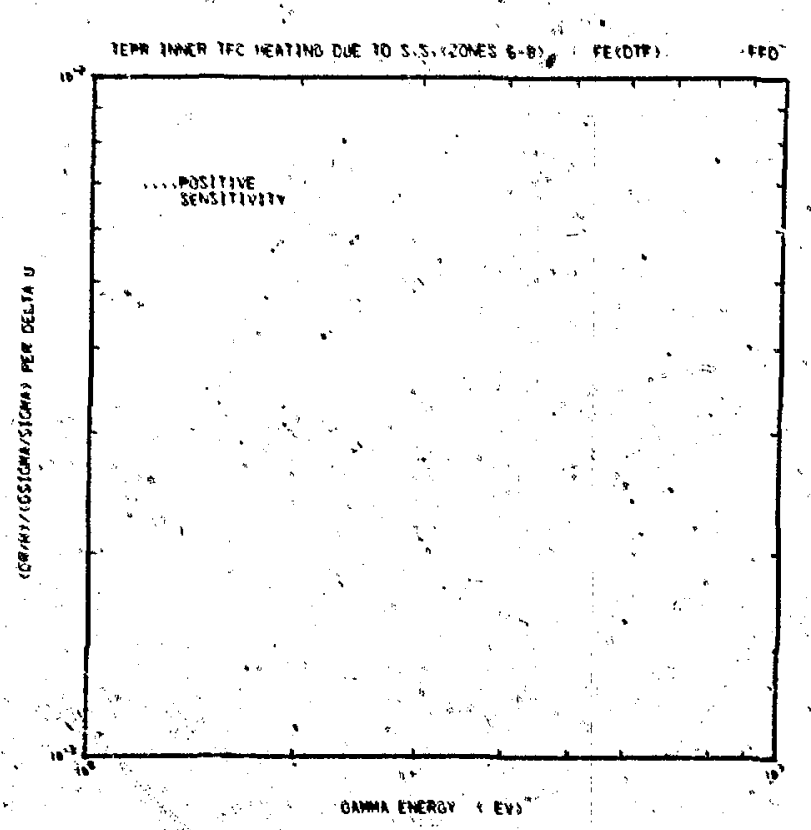

Fig. 25. Sensitivity of nuclear heating in inner TFC: to Fe in zones 6-8. Gamitia gain terw only. 


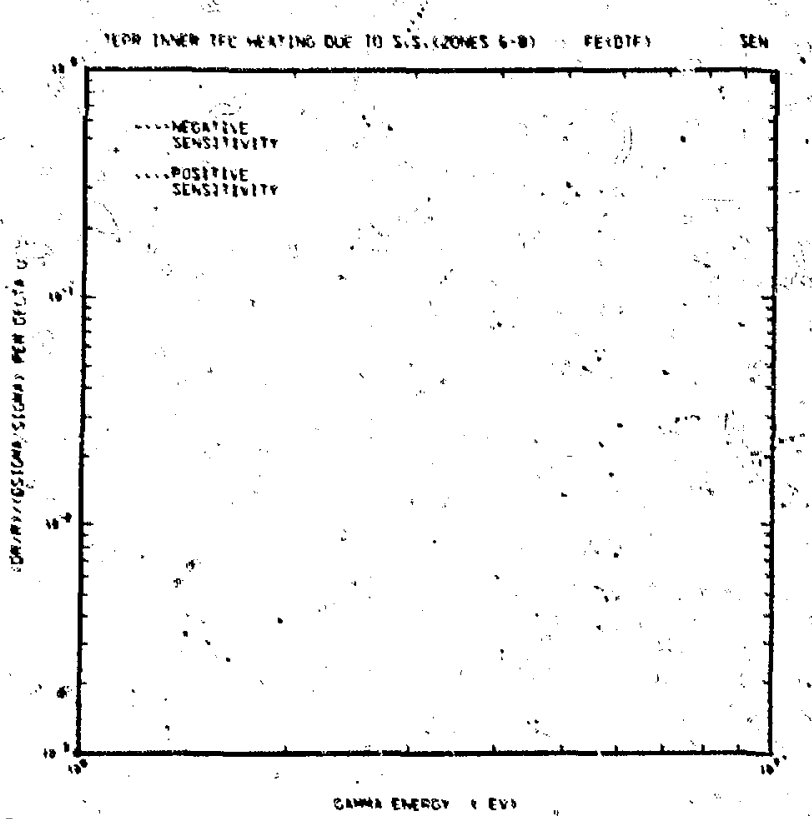

Fis. 26. Sensiti.ity of nuelear heoting in inner TFC to the in zones 6-8. Net gamma scatiering cross section.

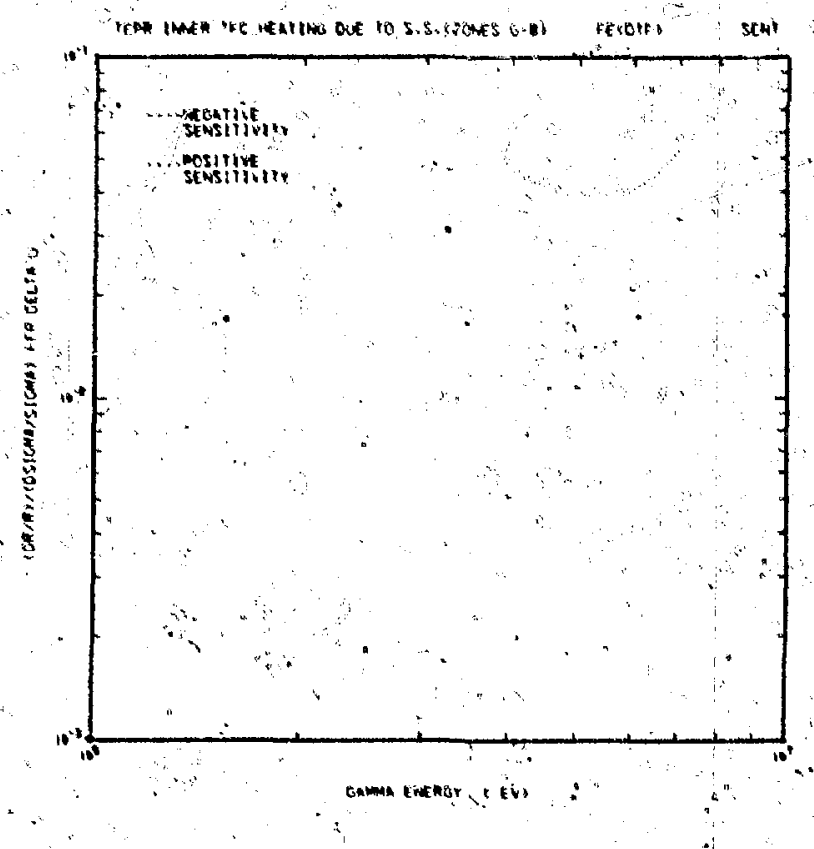

F1g. 27. Senstulvity of nuclear heating in inner TFC tu' Fe in zones 6-8, Net gamma total cross section.

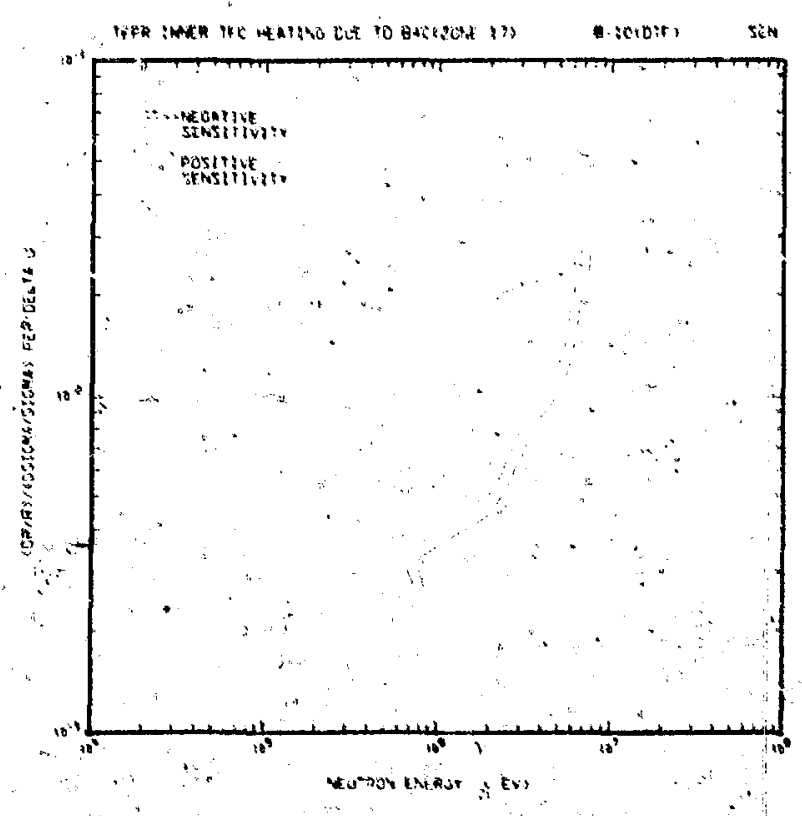

Fig. 28. Senstelyty of nuclear heac1ng in inner TFC to $10_{B}$ in zone 17 . Net neutron scattering cross section.

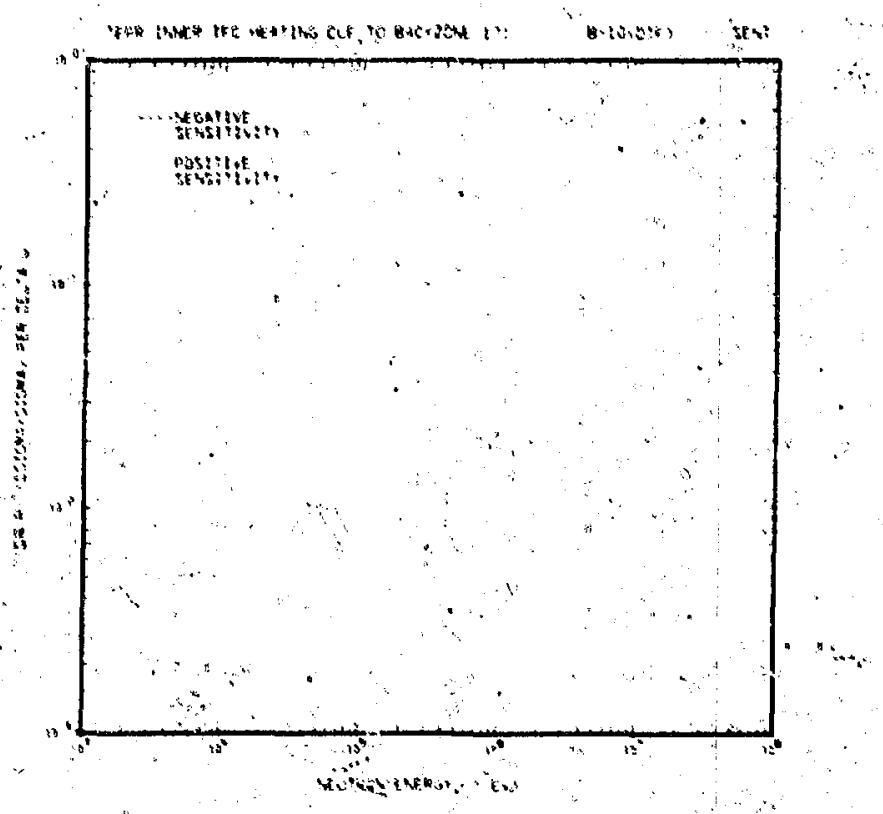

Fig. 29. SensitIyity of nuclear heating in innex TFC to $\mathrm{IO}_{\mathrm{B}}$ In zone 17 . Net neutron total cross section. 


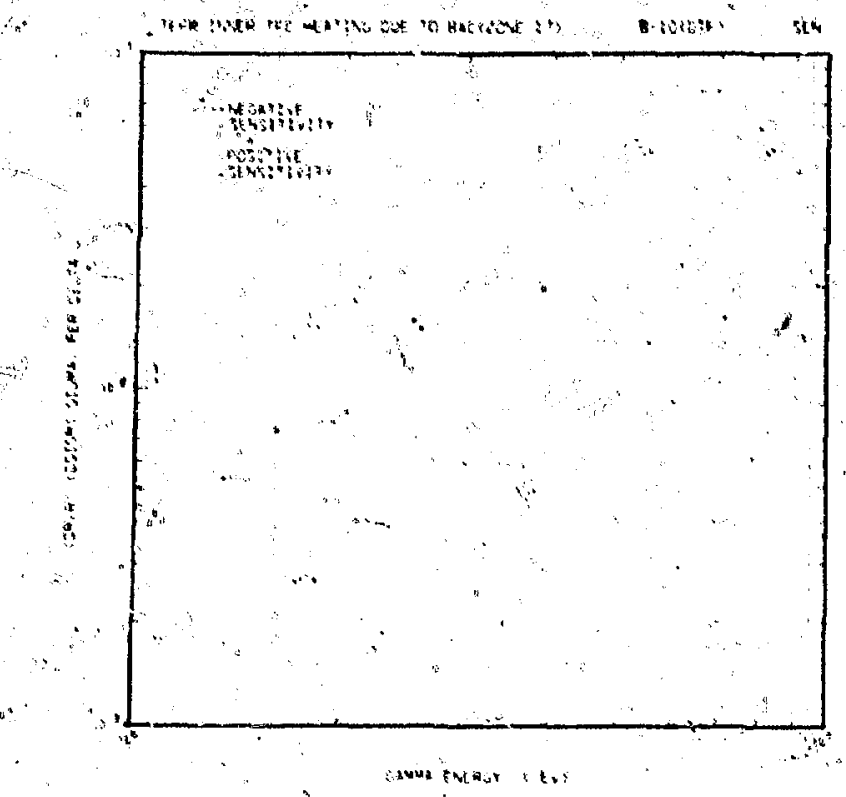

Fig. 30. Sensitivity of nuclear heating in inner TFC to $10_{B}$ in zone 17 . Net gamma scattering $\operatorname{cros} n$ section.

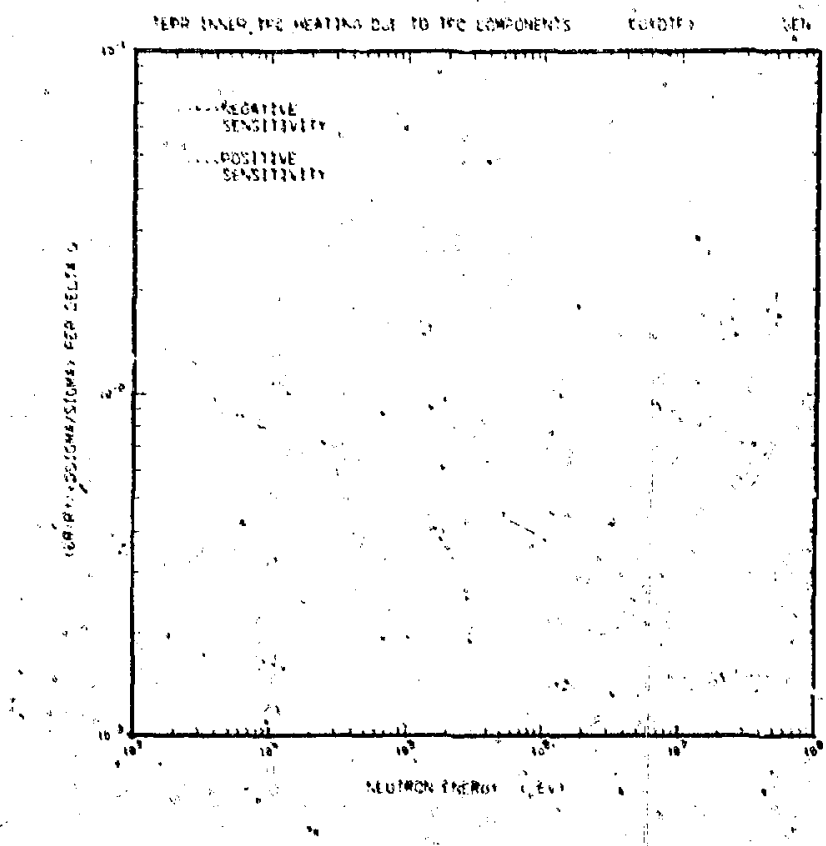

FIg. 32. Sensitivity of nuclear heating in Innex TFC to $\mathrm{Cu}$ in TFC. Net neutrion scattoring eross section.

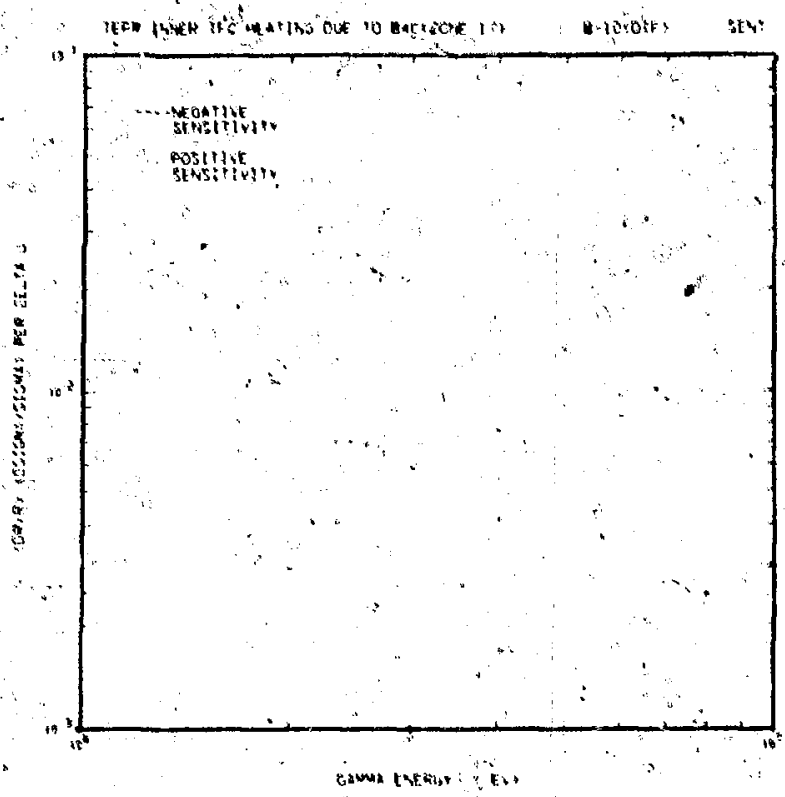

Fig. 31. Sensitivity of nuciear heating in inner TFC to $10_{\mathrm{B}}$ in zone 16 . Net gamma total cross section.

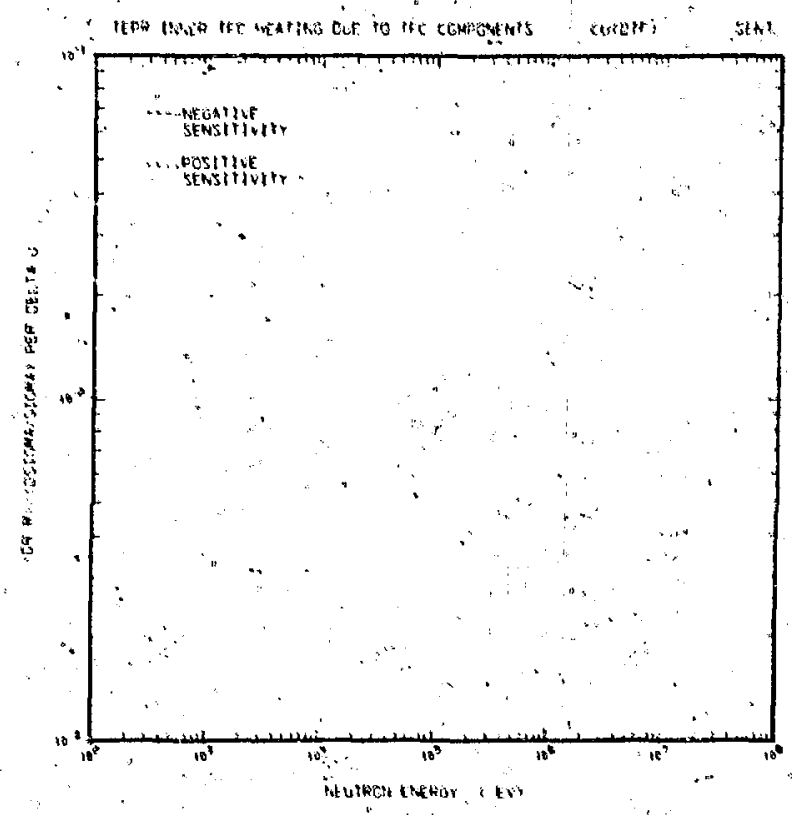

FEg. 33. Sensitivity of nuclear heating in inner IFC to $\mathrm{Cu}$ In TFC. Net neutron total cross section. 


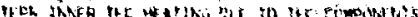

\section{Newing}

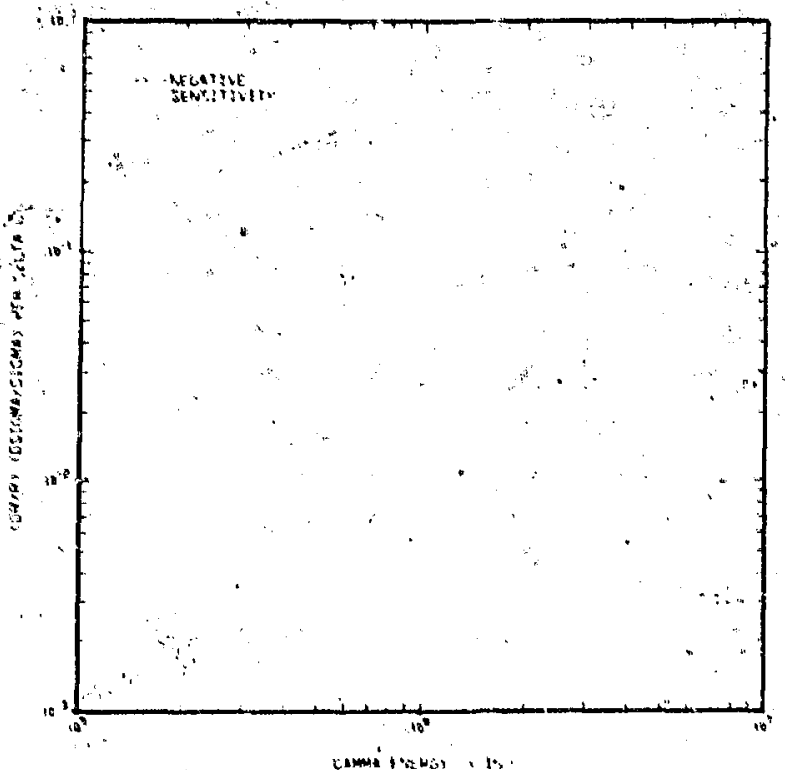

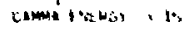

Hig, 34. Sensitivity of nuelear heating in inner TFC to Cu in TFC. Net gasma scattering cross section.

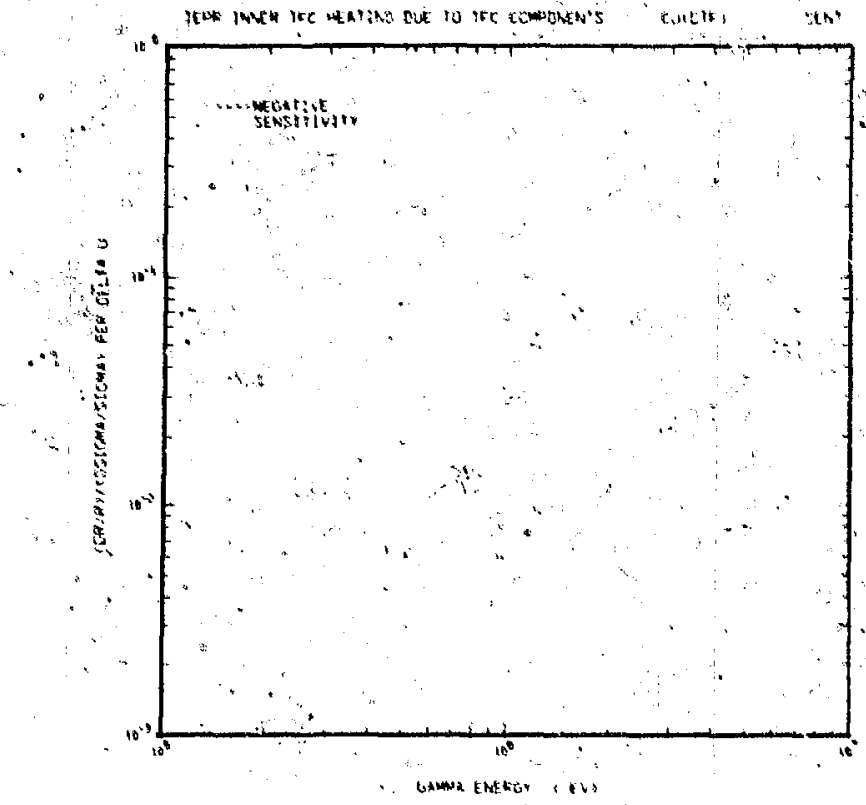

Fig. 35. Sensitivity of nuclear heating in inner TFC to $\mathrm{Cu}$ in TFC. Net gama total crose section.

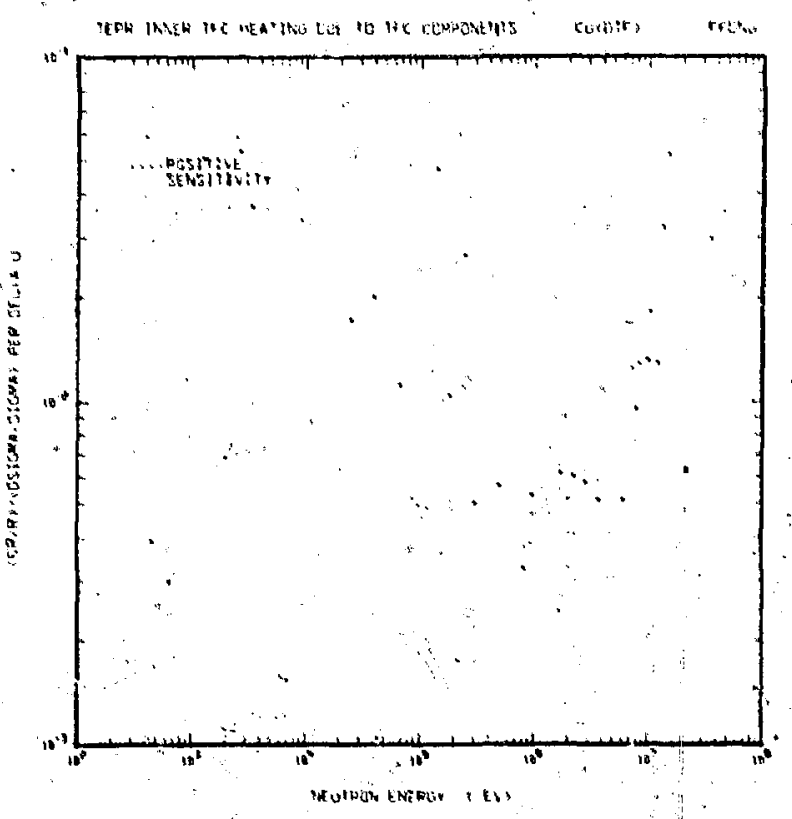

'F18. 36." "Sensitivity of nuclear heating in inner TFC to cut in TFC. Gamma production cross section, gain cerm only.

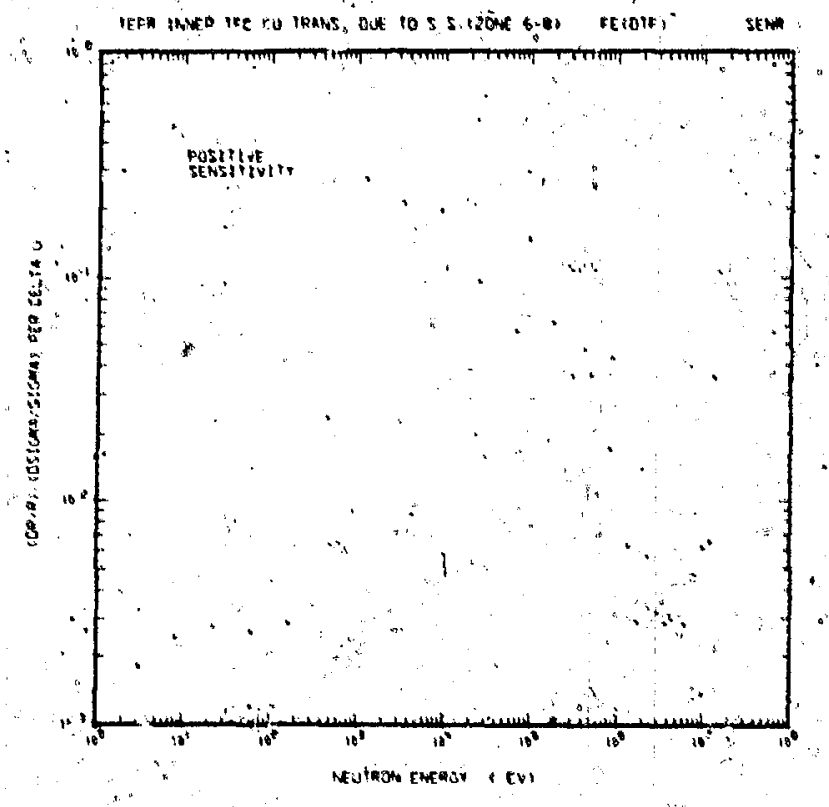

$\beta^{2}$

F1B. 37. Sensiclivity of cu transmutation in inner TFC to Fe -in zones 6-8. Nec. response funation. 


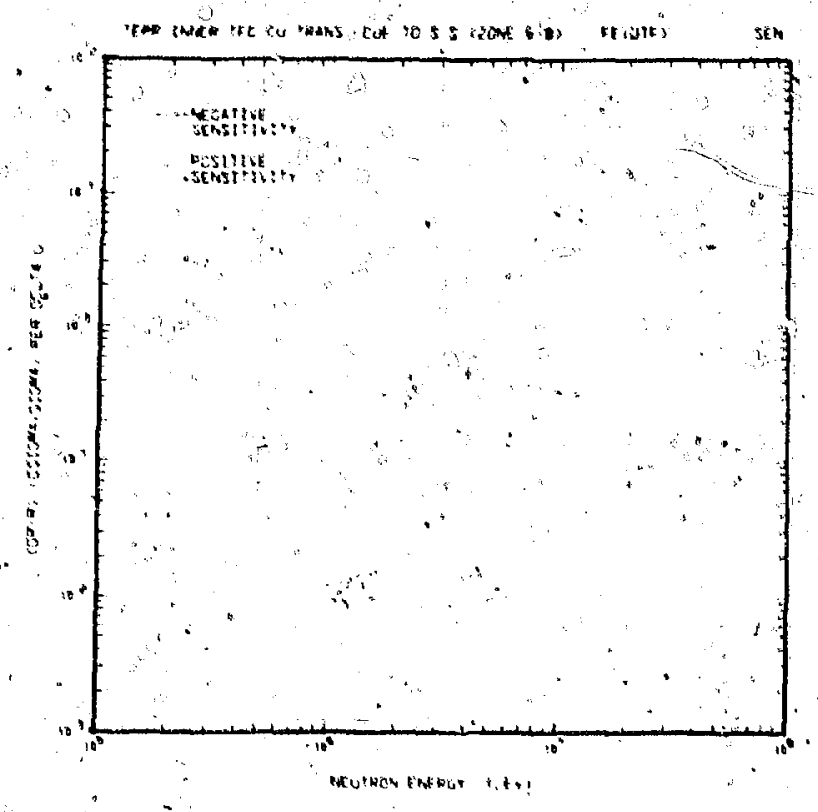

Fig. 38. Sensitivity of Cu transmutation in inner inf G to Fe in zones 6-8, Net neutron scaterfug toss section. .

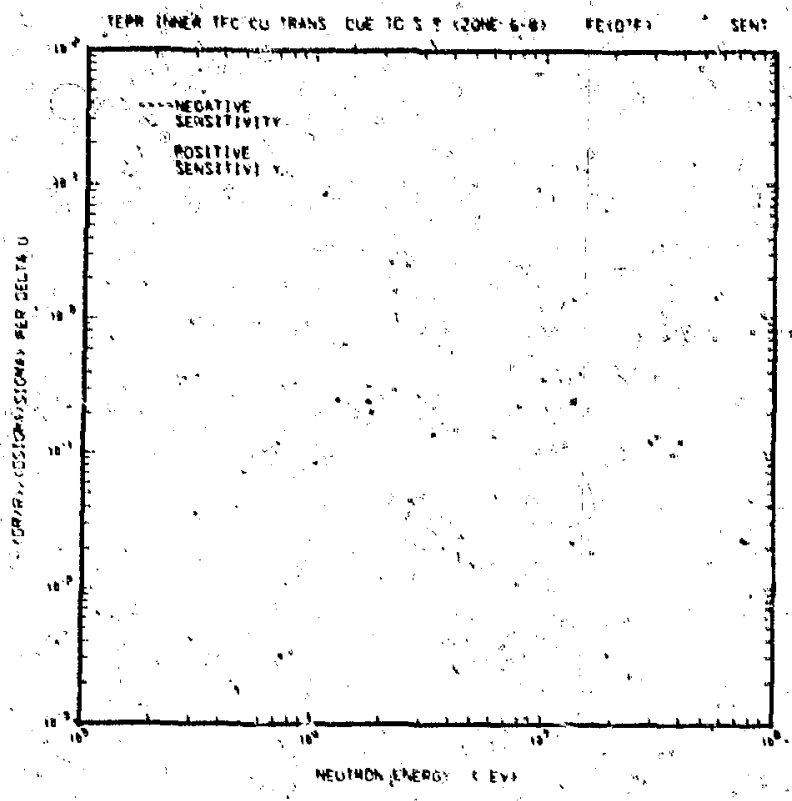

Fig. 39. Sensitivity of Gu transmutation in Inner TFC to $F C$ in zones 6-8. Net neutron total cross section.

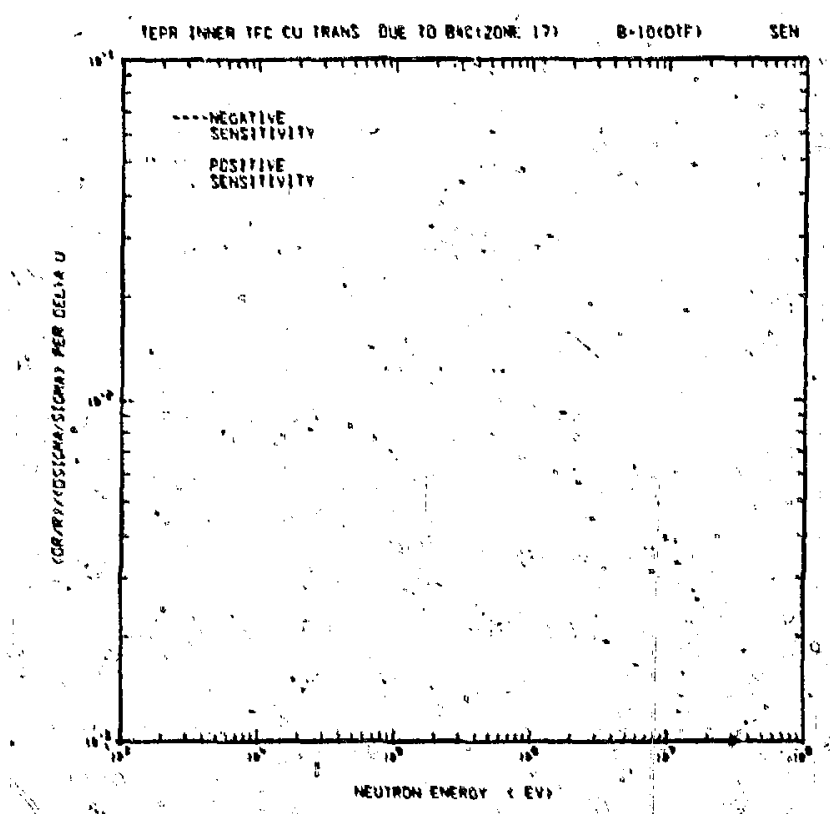

Fig. 40. Sênaltiyty of gu transmutation in inner. TFC to $10_{B}$ in zone 17 . Net neutron. - scattering cross section.

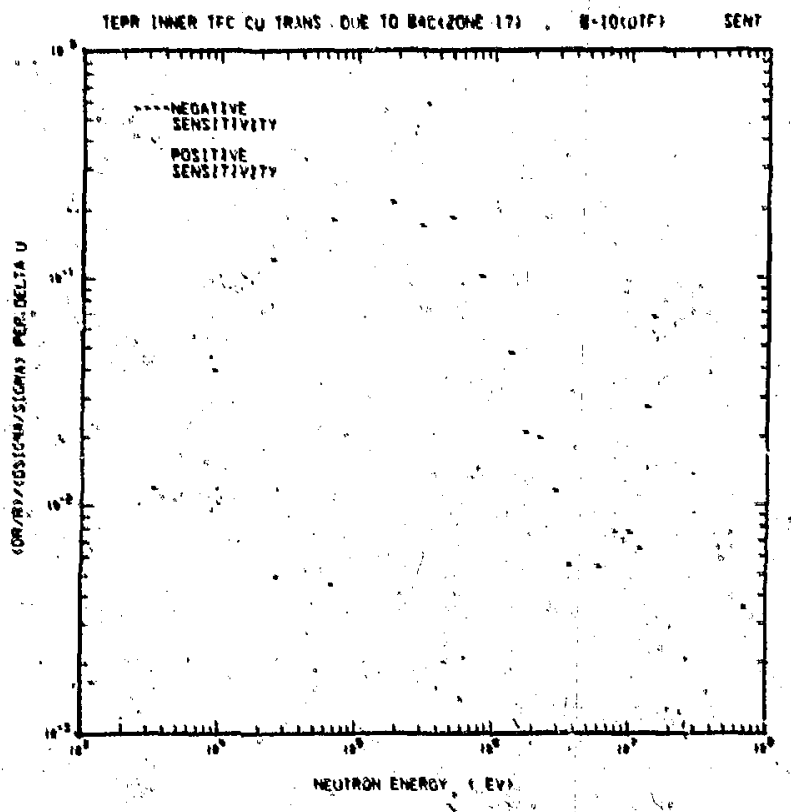

Fig. 41. Sensitivity of Cu transmutation in shiner. TFC to $10_{B}$ in zone 17 . Net neutron total cross section.

52 


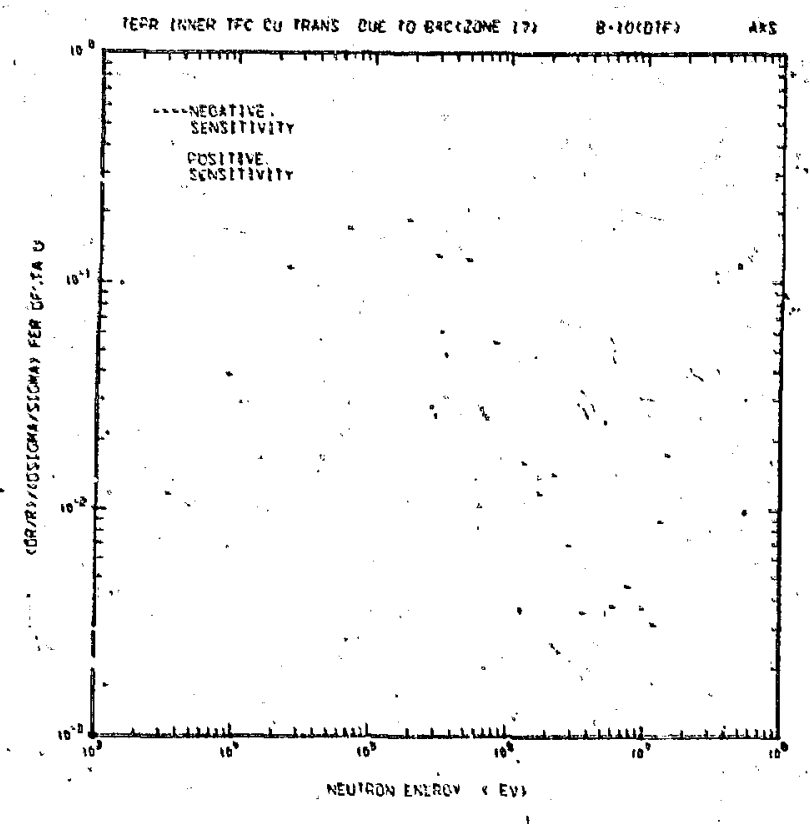

FIB. 42. "Sengtetvity of Inner IFC Gu transmutation to $10_{B}$ in zone 17 . Neutron absorption cross section, pure 1038 terth.

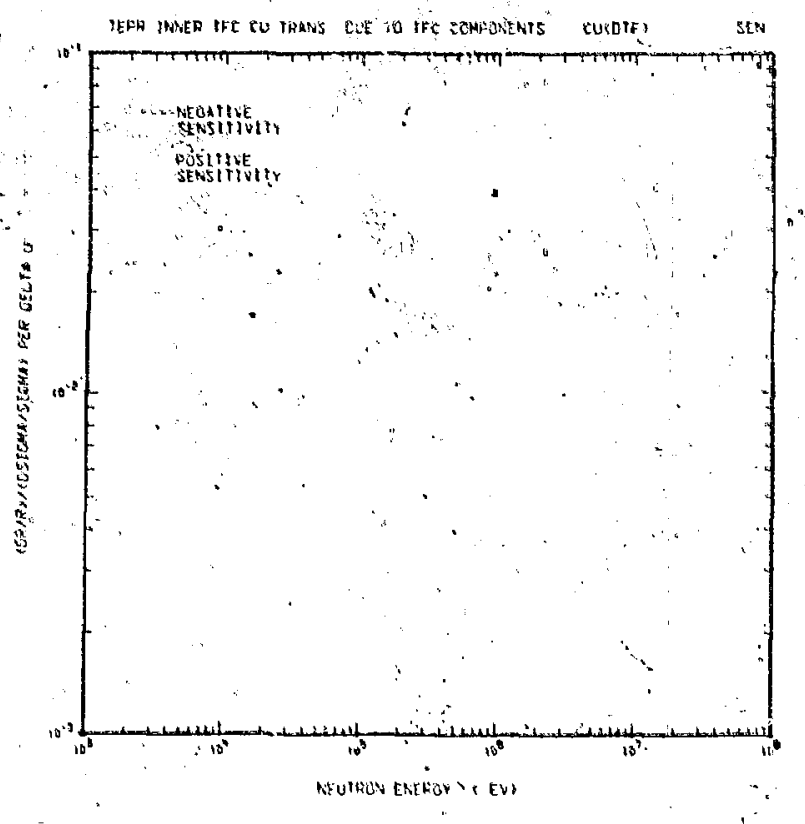

Fig. 43. Sensitivity of Cu transmutation in inner THC to Cu in THC. Net neutron scattering eross section.

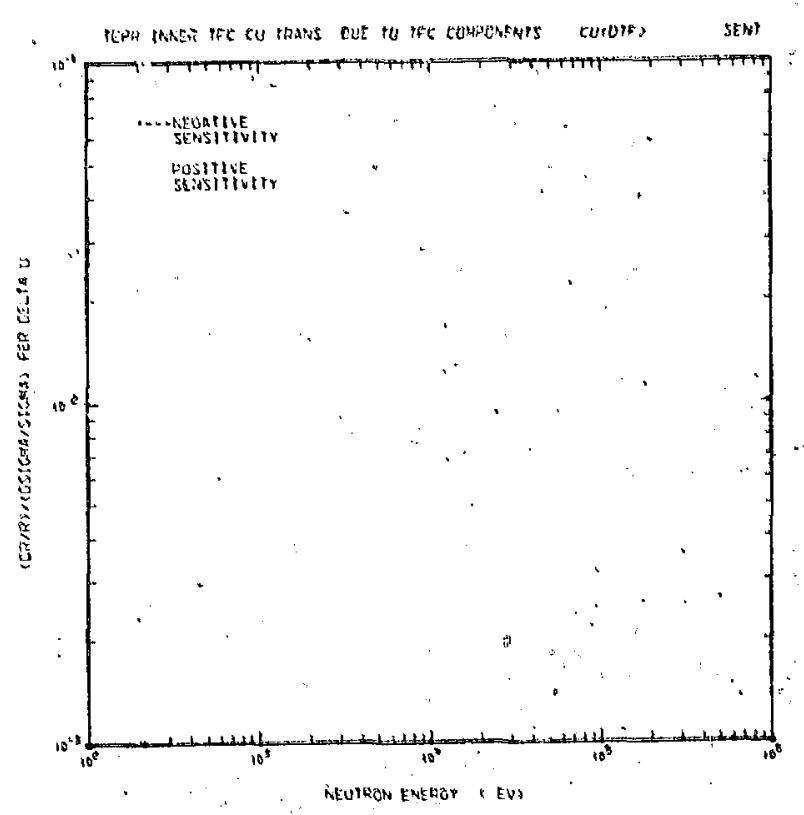

Fis. 44. Sensitivicy of vil tansmutation in liner TFG to Gu In TEG. Net noutron total eross rection.

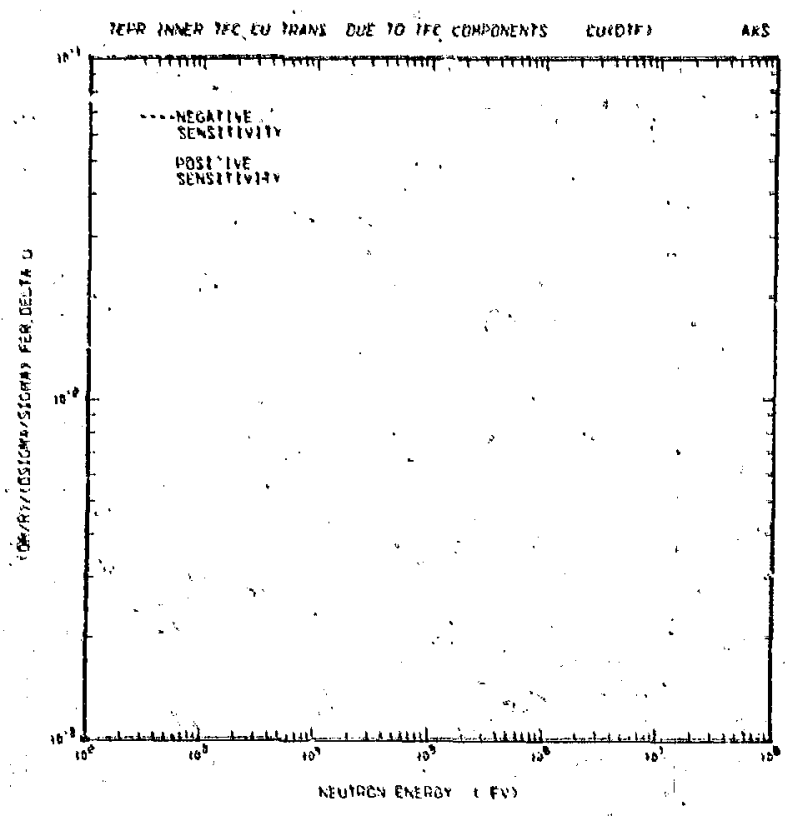

B18. 45. Sensitivity of Inner TFG Cu transmutation to. cu in TRC. Neutron absorption cross section. puic loss term. 


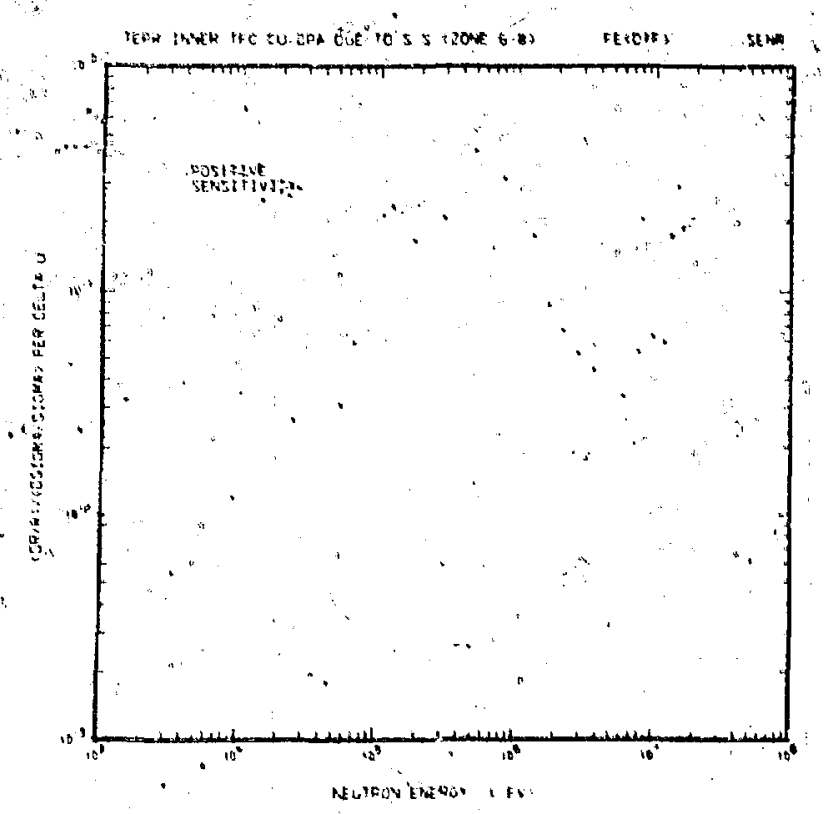

F18. 46. 'Sensiturity of Cu dpa in Inmer TFC to Fe Iu zonos 6-8. Net response function.

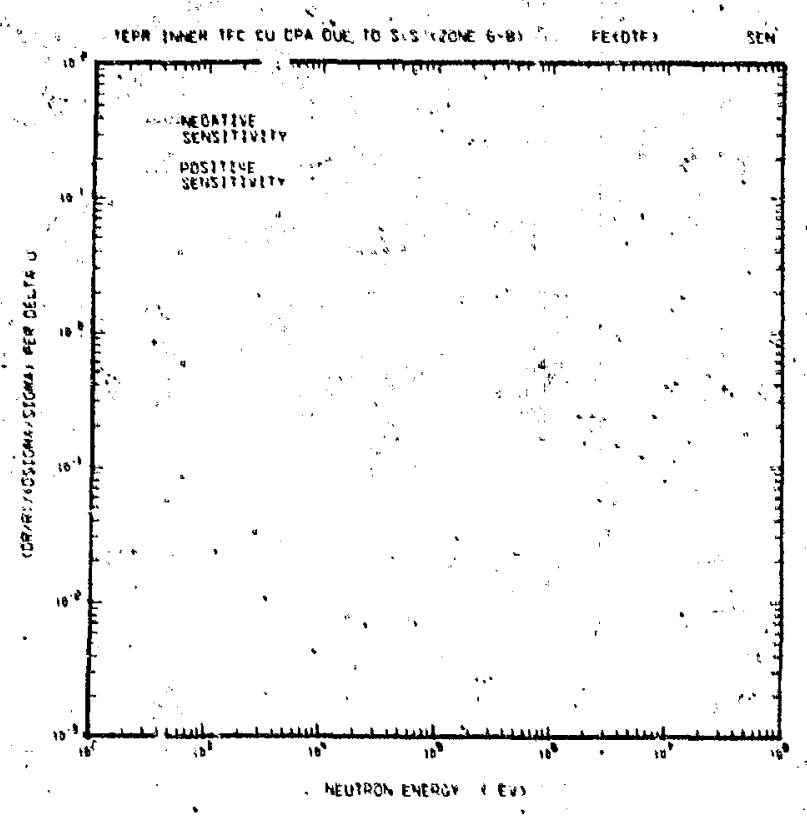

Fig. 47. Sensitivity of Cu dpa in Inner TFC to Fe In zones 6-8." Net neutxon scatcering cross "section.

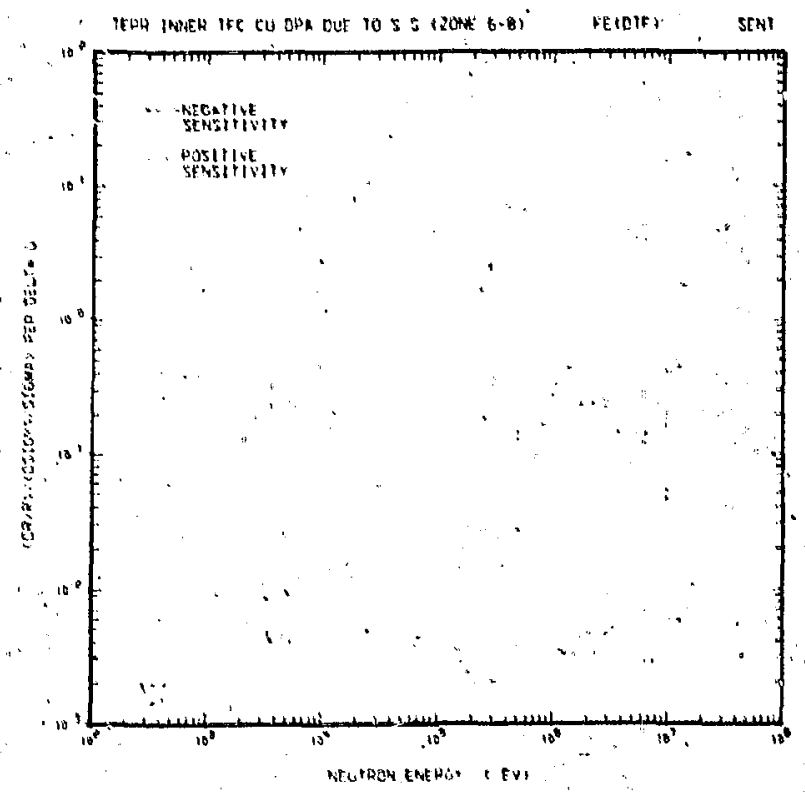

Fig. 48. Sensitivity of Gu dpa in inner IFC to te in zones 6-8, Net neutron total crosi: "section.

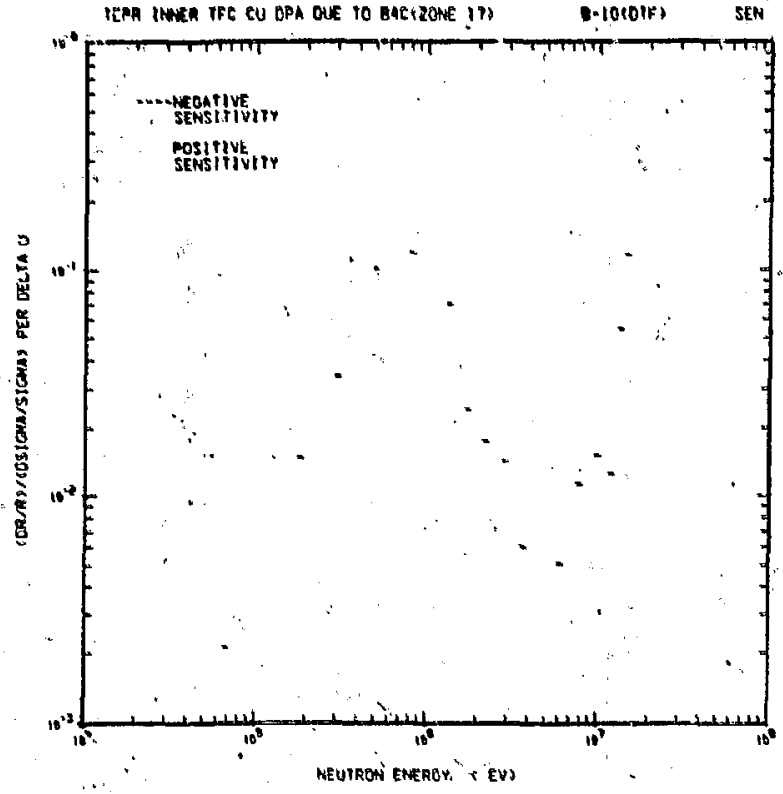

Fig. 49. Sensitivity of Cu dpa in Inner TFC to $10_{B}$ in zone 17: Net neutrón scattering cross section. 


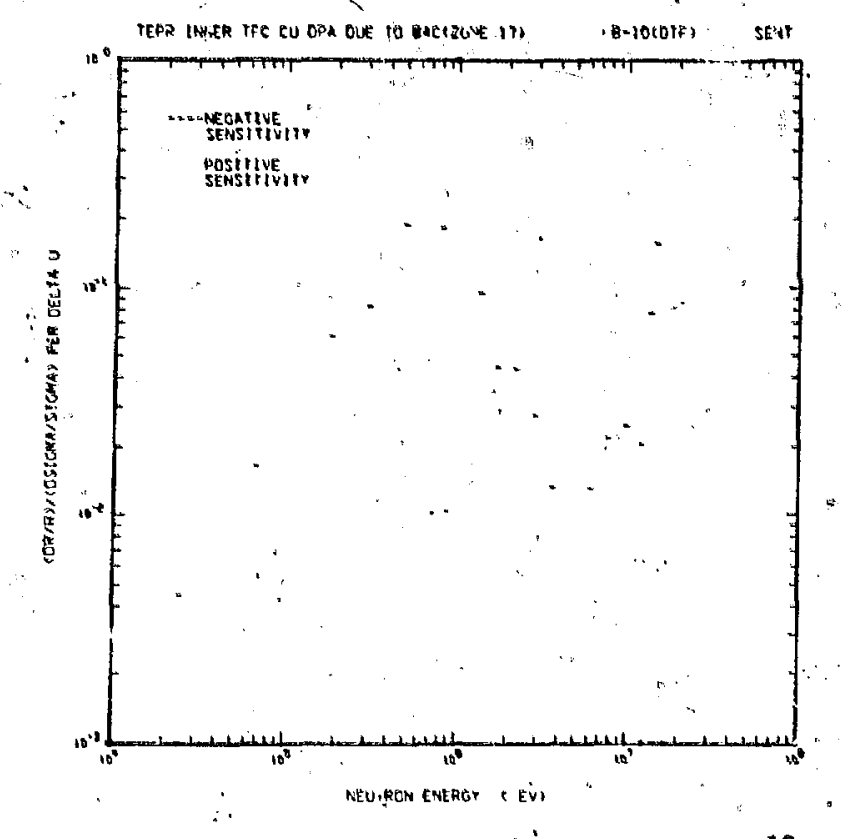

FIS, 50. Senstalieity of Cu ripa in inner TFG to 10 in zone 17. Net neutron total cross section.

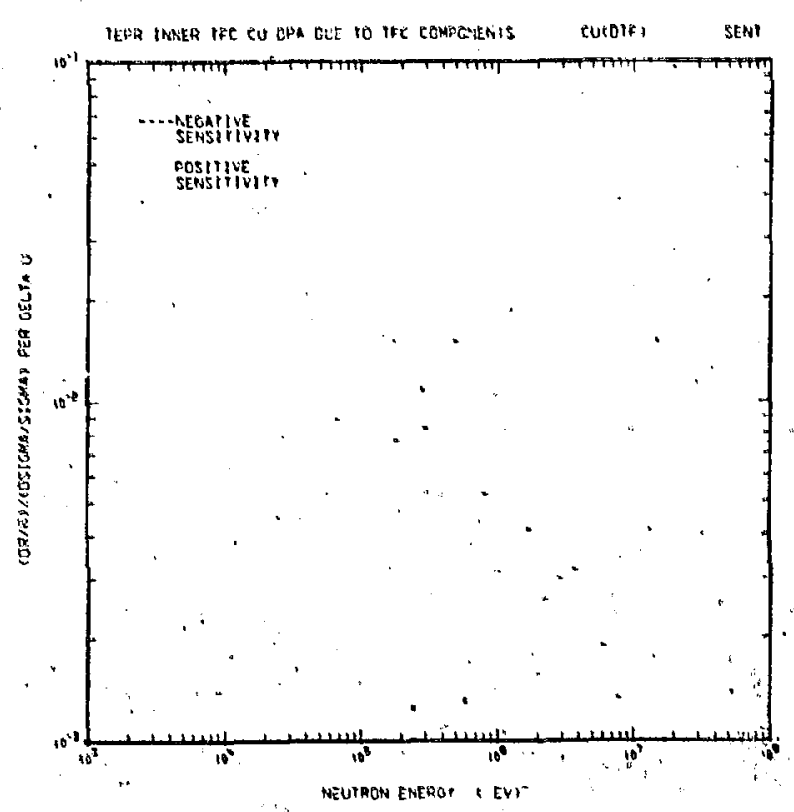

Fig. 52. Sensitivity of Gu dpa in inner TFC to Cu In TFC. ' Net neutron total cross section.

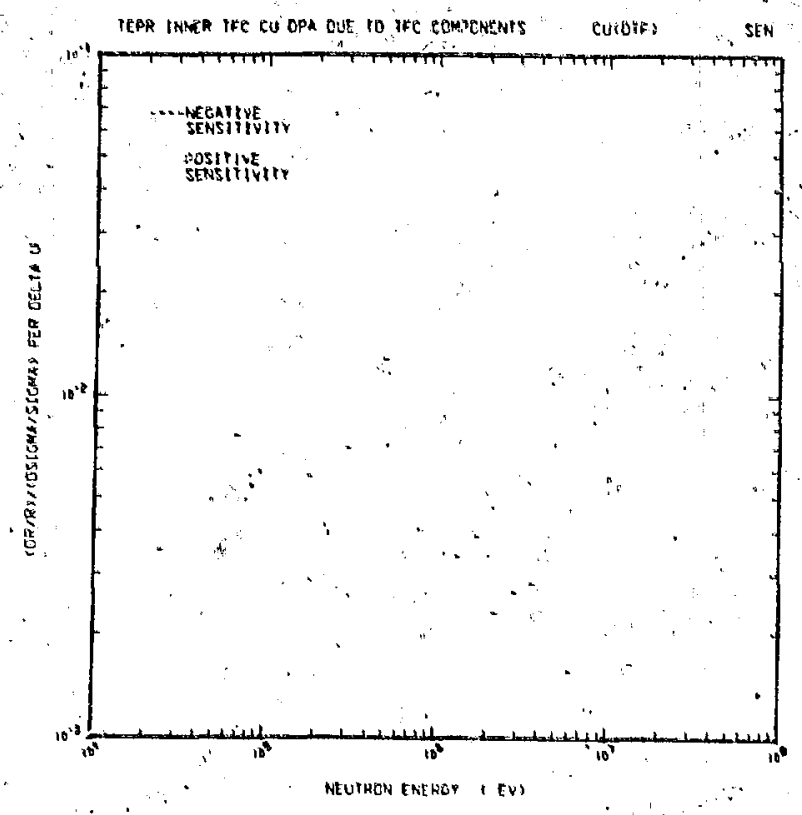

Fig. 51. Sensitivity of Cu dpa di innet TLC to Cu In TFC. Net neutron scattering cross section.

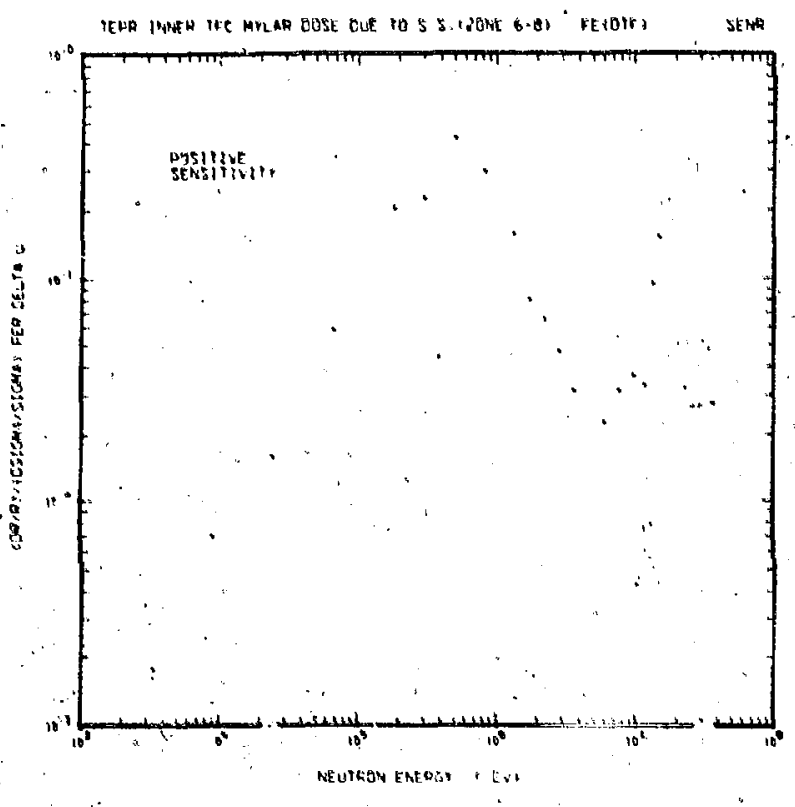

Fig. 53. Sensitluity of Mylar dose in Inner TAC to Te 1 in colles 6-8. Net rasponse functinn. 


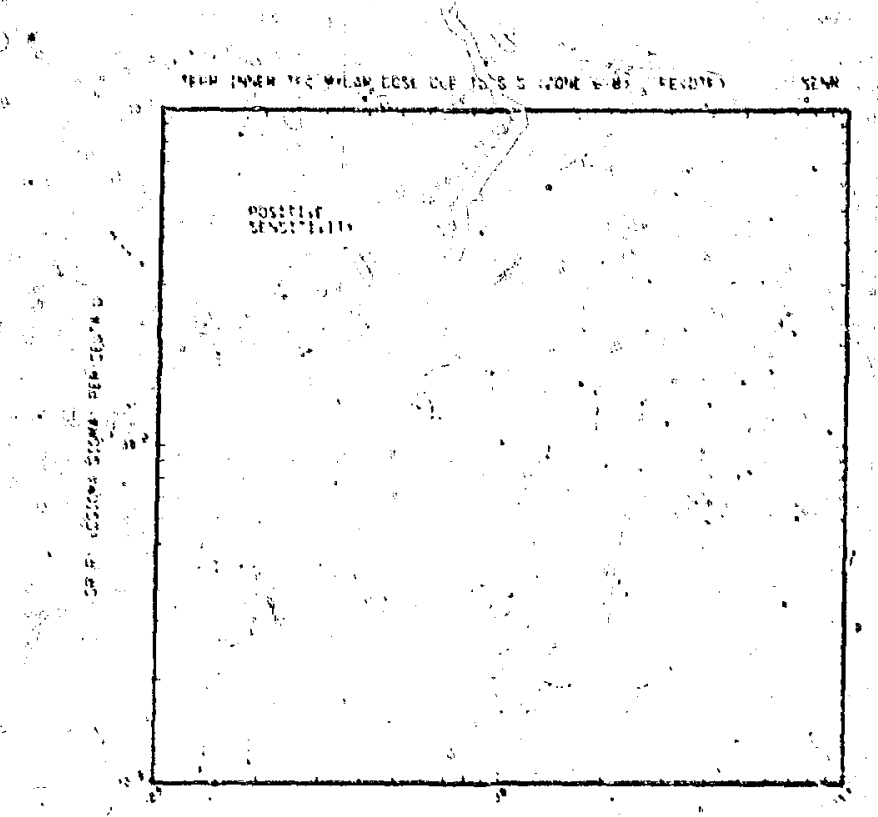

$\therefore$

Fig. 54. Seusitivity of Myla: dose in Inner TFC, to Fo it zones $6-8$. Net responge function.

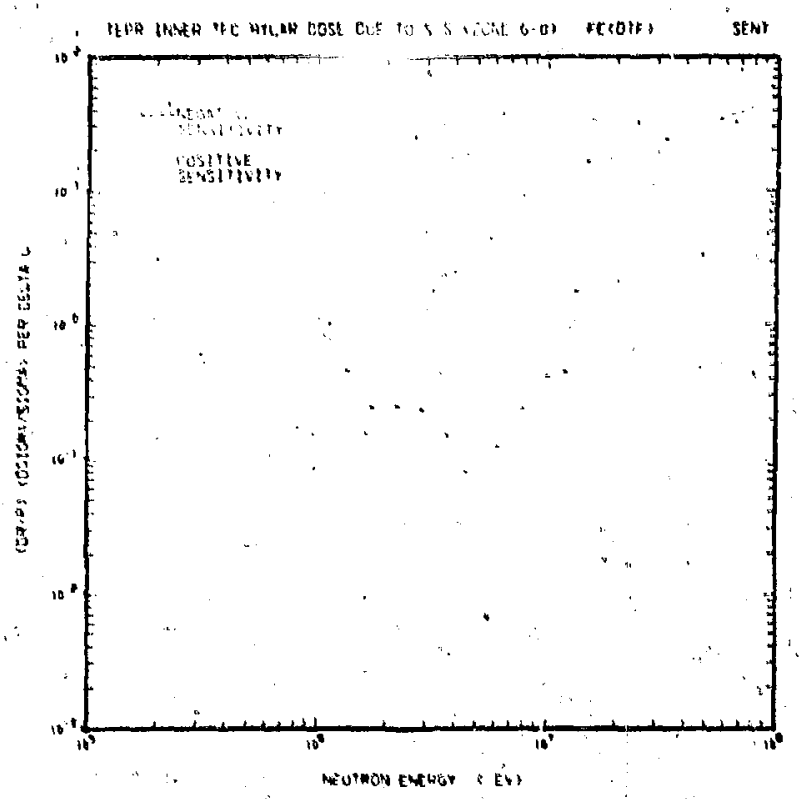

F1g. 56. Sensitivity of Mylar dose In thner TFC to Ve in. zones 6-8. Net neitron" total crose section.

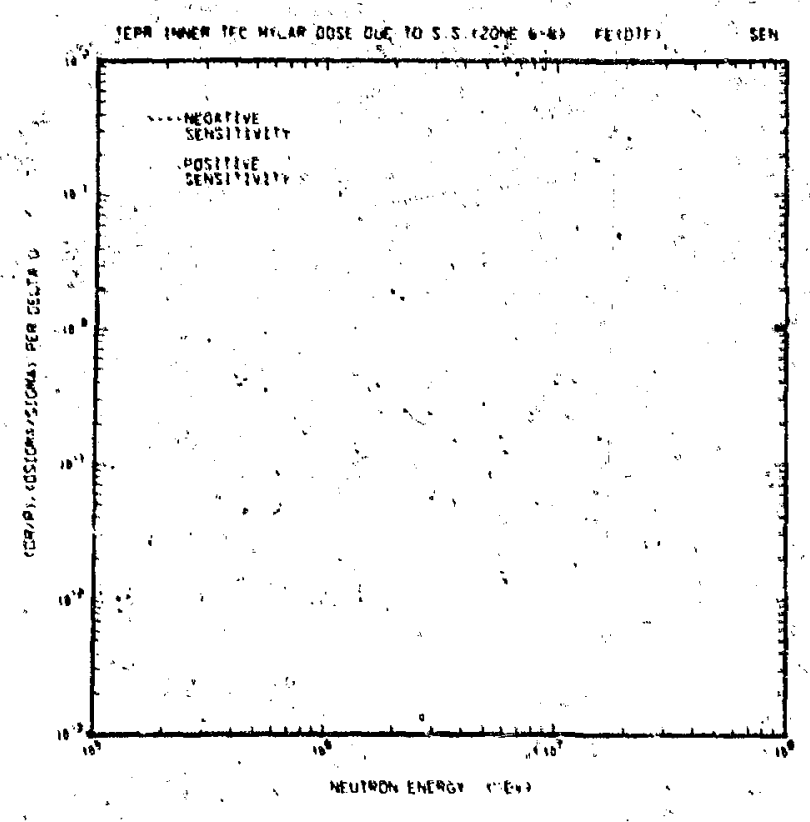

Fis. 55. Senstetvity of Mylar dose In Inner TFC to Fo it sones $6-8$. Net neutron scattering sLues section.

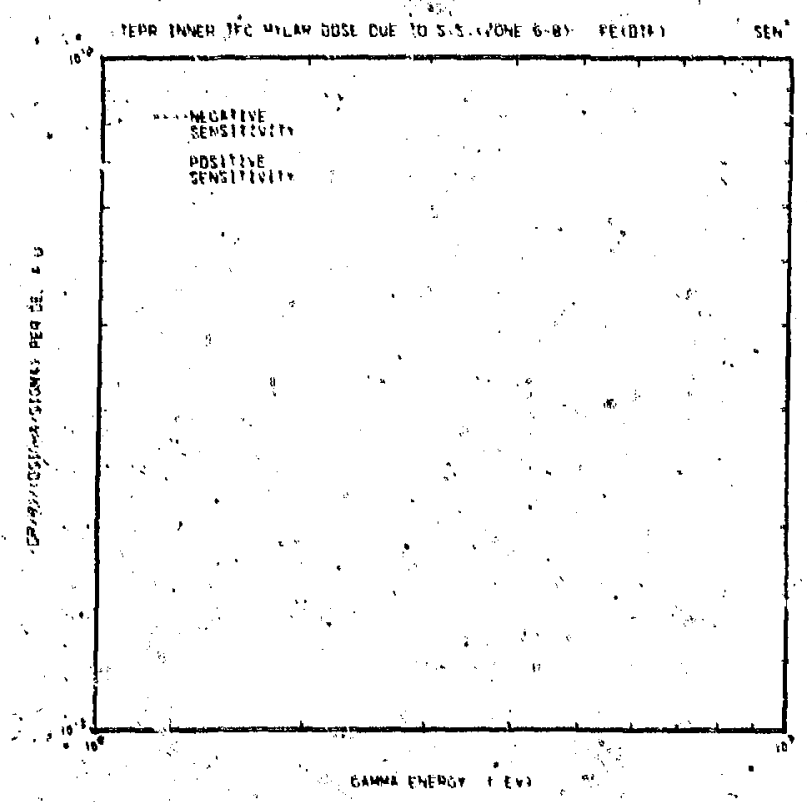

F18. 57. Sensitivity of Mylar dose in Inner TFC to Fe in zones 6-8. Net gamma seattering eross section. 


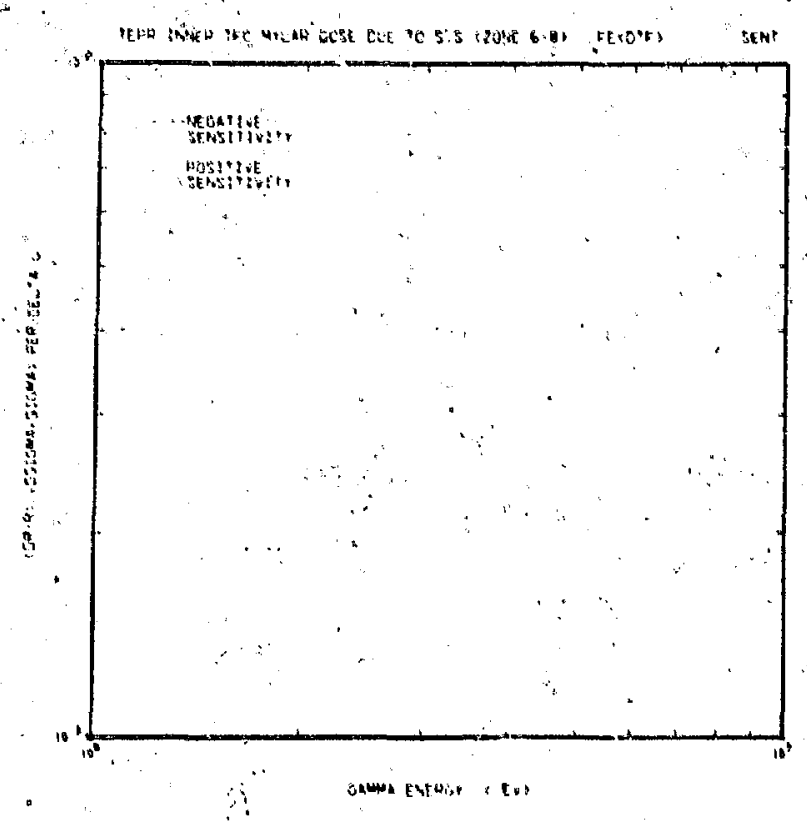

F1g. 58. Senstivity of Mylar tose in Inner TFC to Fe in zones $6-8$. Net gumma total cross section.

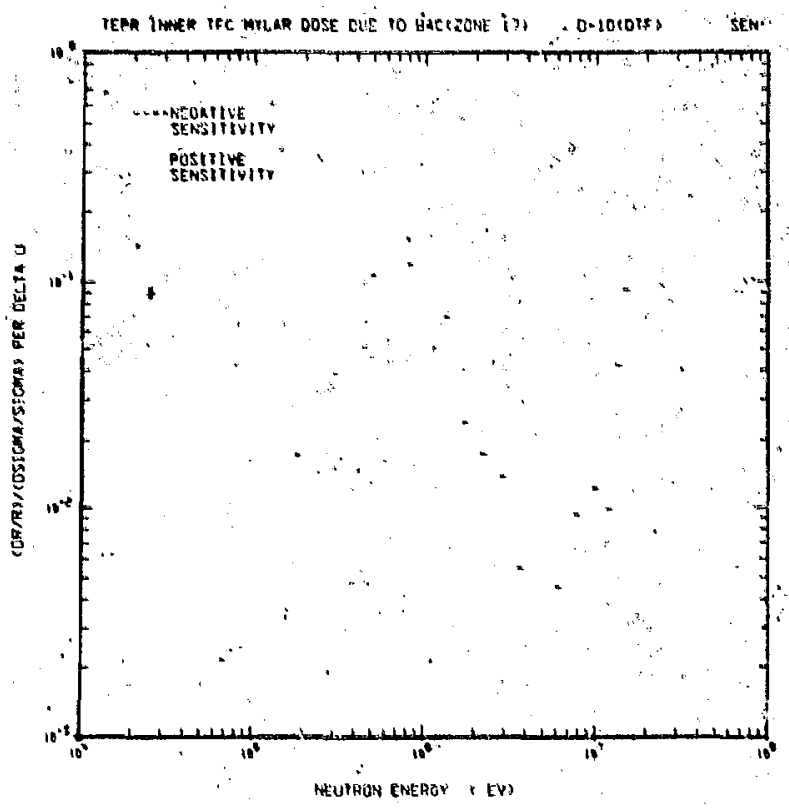

Hig. 59. Senslelvity of Mylar dose in Inner TFC to 10 $B$ in zone 17. Nat neutron sciatering cross seetion.

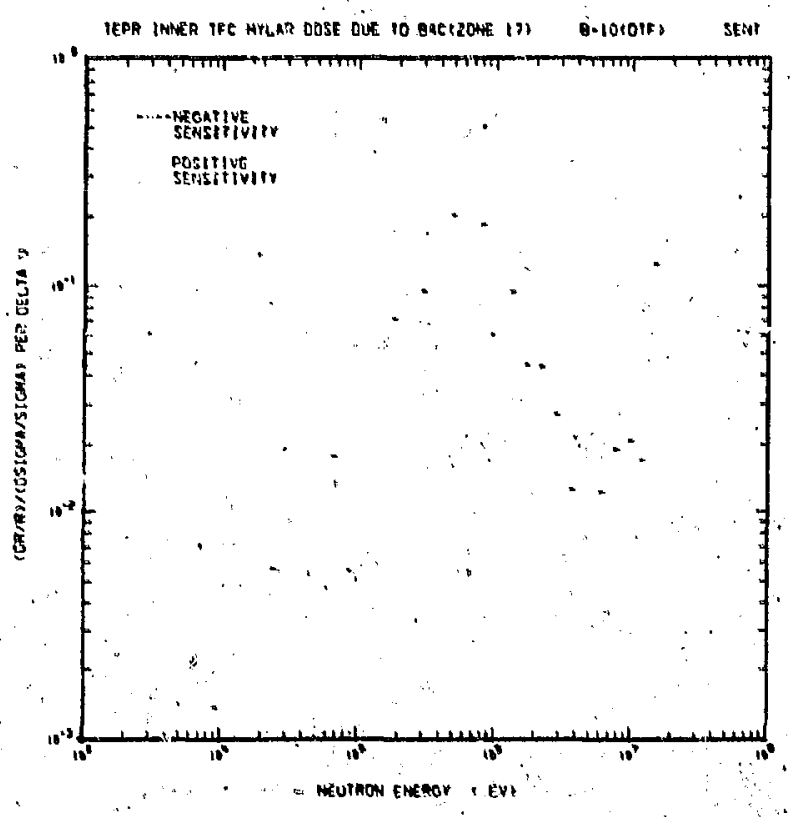

Fig. 60. Sensitivity of Mylar dose in inner TRC to $10_{B}$ in zoue 17. Net neutron total ciross section:

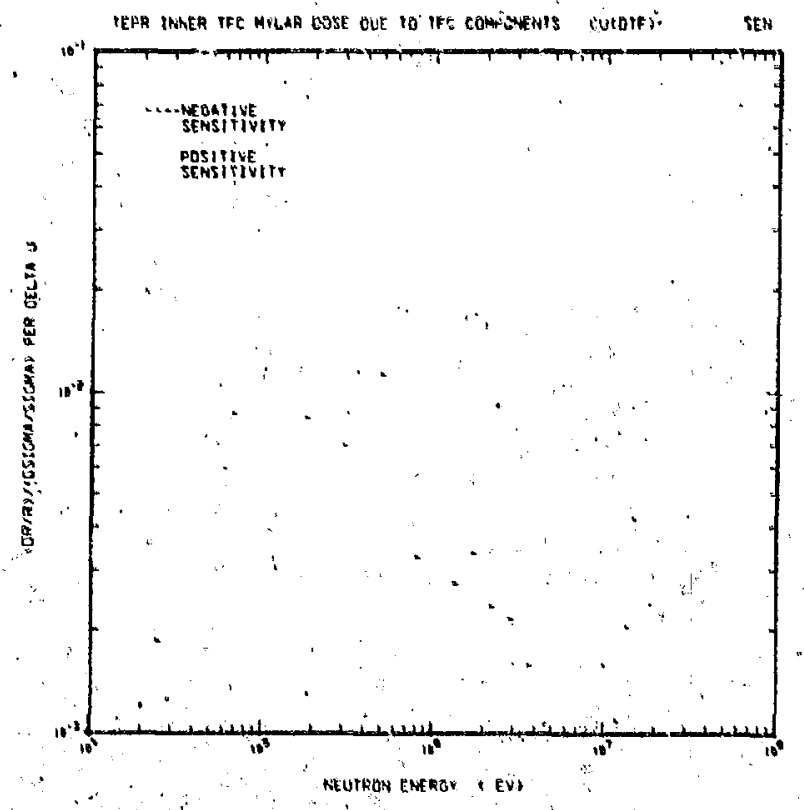

Fig. 61. Senstrivtty of Myitar dose in inier TFC to Cu In TFC. Nat neitron sertering cross section. 


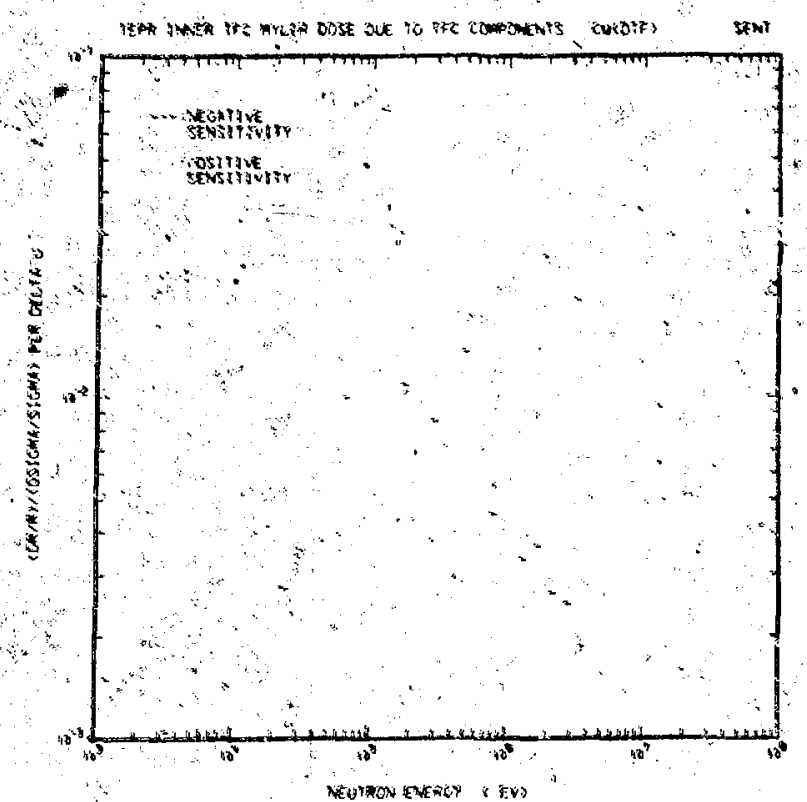

Fig. 62:" Sensitivity of vylar dose in inner TrC to Gu in TrC, Net neutron tatal eross section.

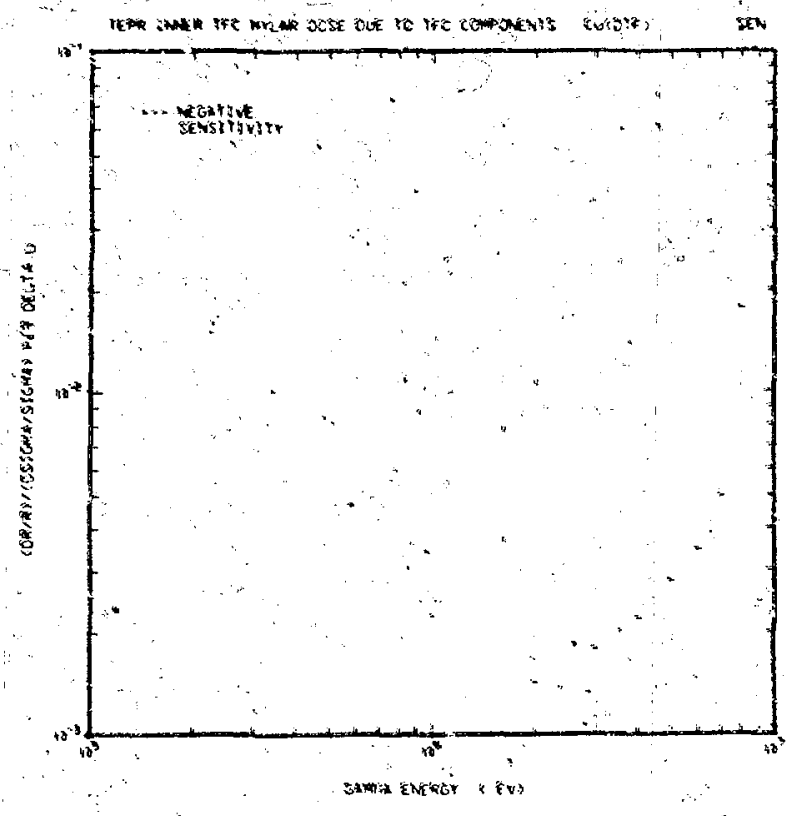

Fig. 63. Sensitivity of iylar dose in inner trc to Cu in TEC: Net gamma scattering cxoss section.

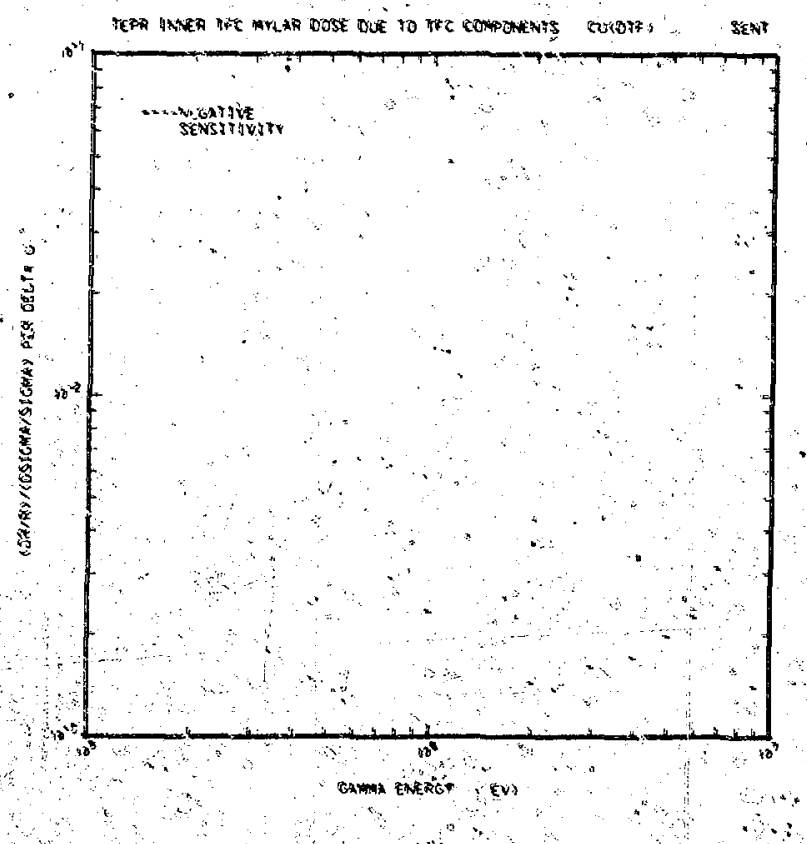

18. 64. Sensitivity of dylar dose in inner TrC to Gu in TrC. Net gaima total cross. section.

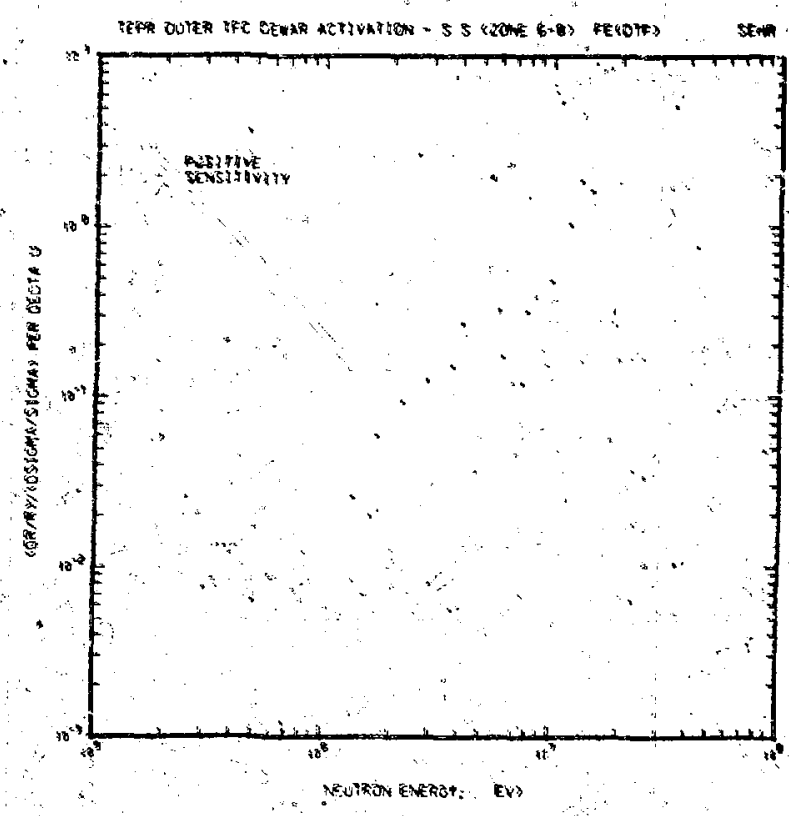

Fig. 65. Sensi tvity of TFG dewar activation to Fe in zones 6-8. Net response function. 


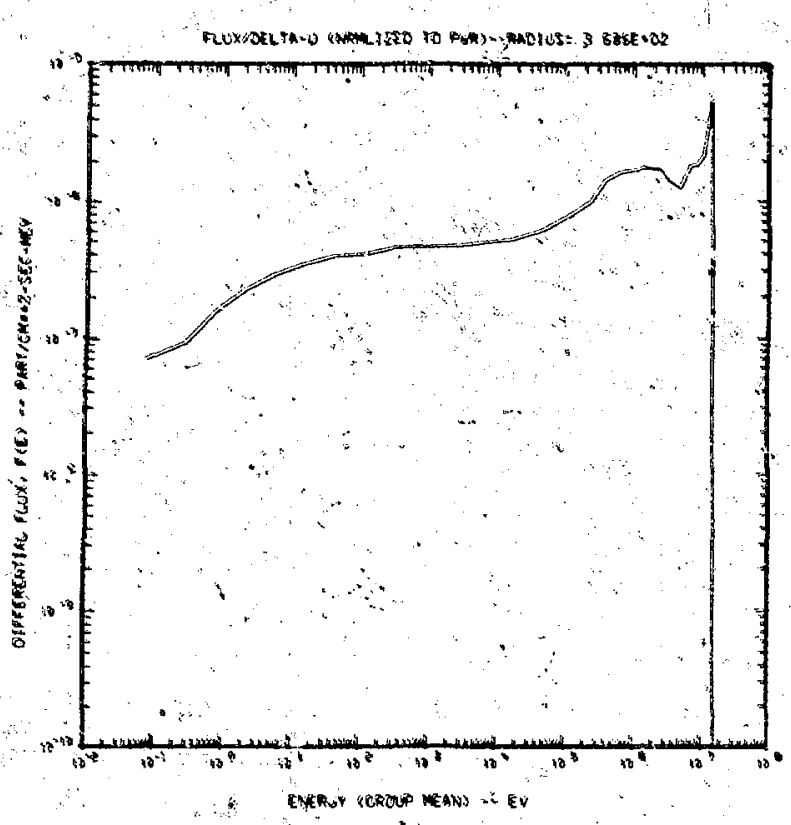

Fig. 66. Neutron flux spectrum in last interval of lead mortin (mone 22) in outer blanket/ shield.

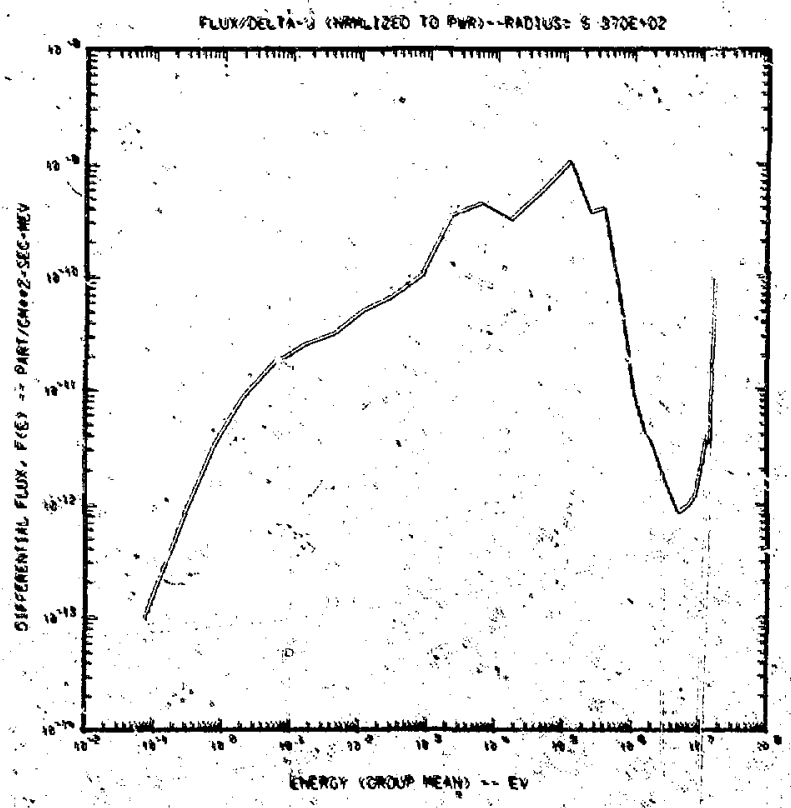

Fig. 68. Neutron tlux apectrum in vacuum (tone 23) of outer blanket/shield.

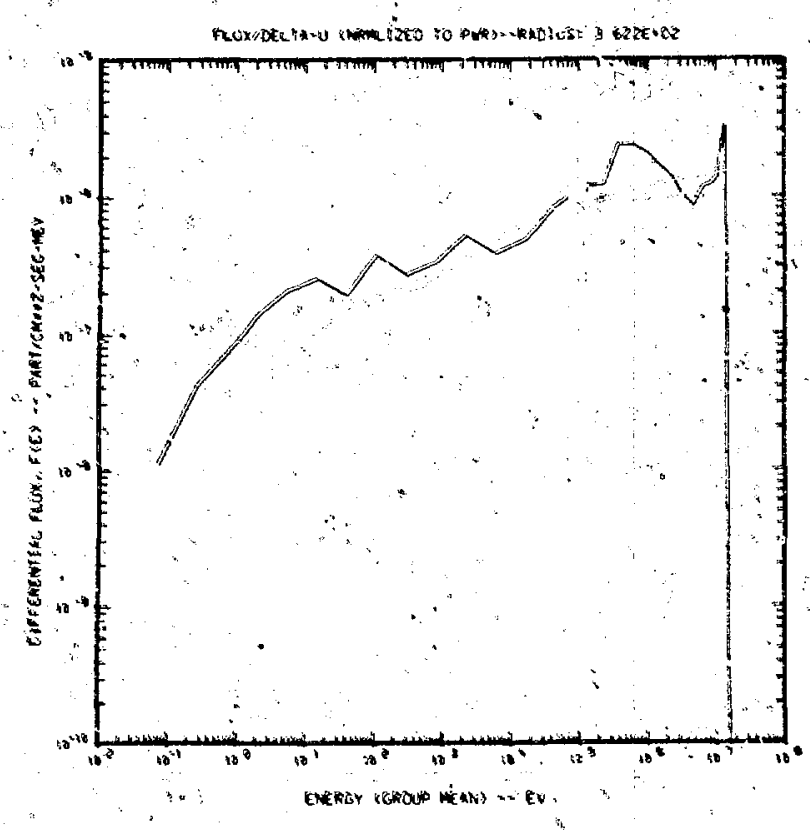

Fis. 67. Neutron flux spectrum in stainless steel (rone 23) in outer blanket shield.

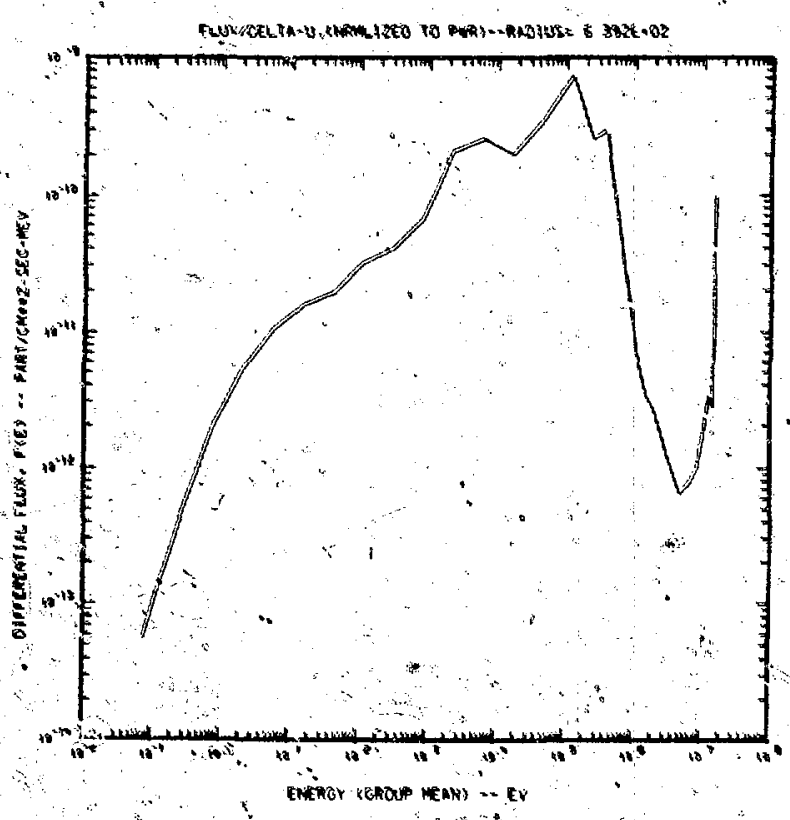

Fig. (S. Neutron fuux spectrum on TFC dewar (zone 40) of outer blanket/shield, 


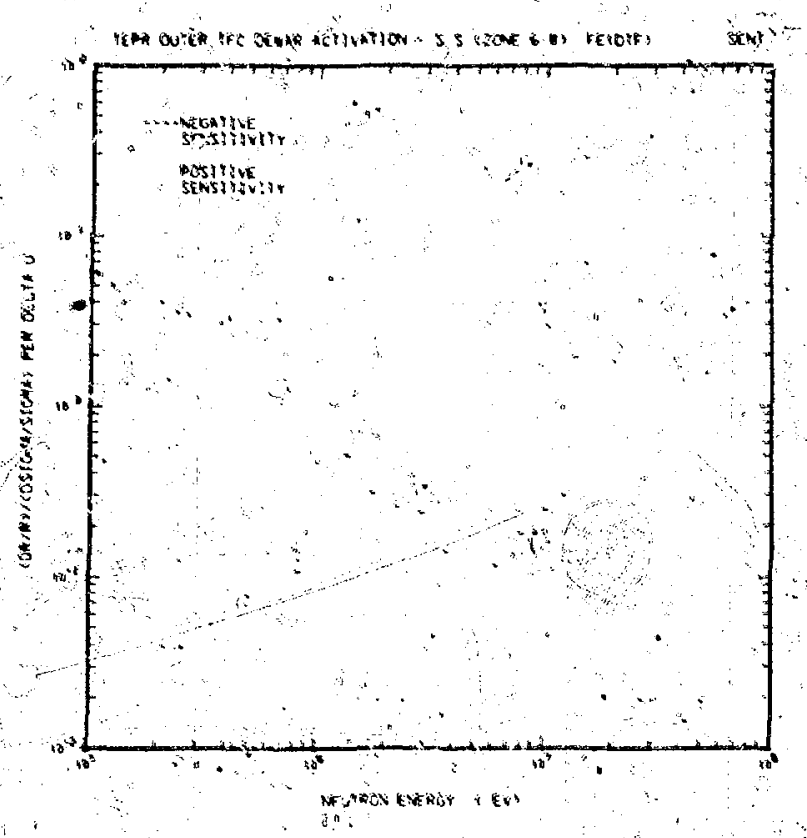

Fig. 70. Sensitivicy of, TFG dewar activation to Fe in tones 6-8. Net neutron total crosis section.

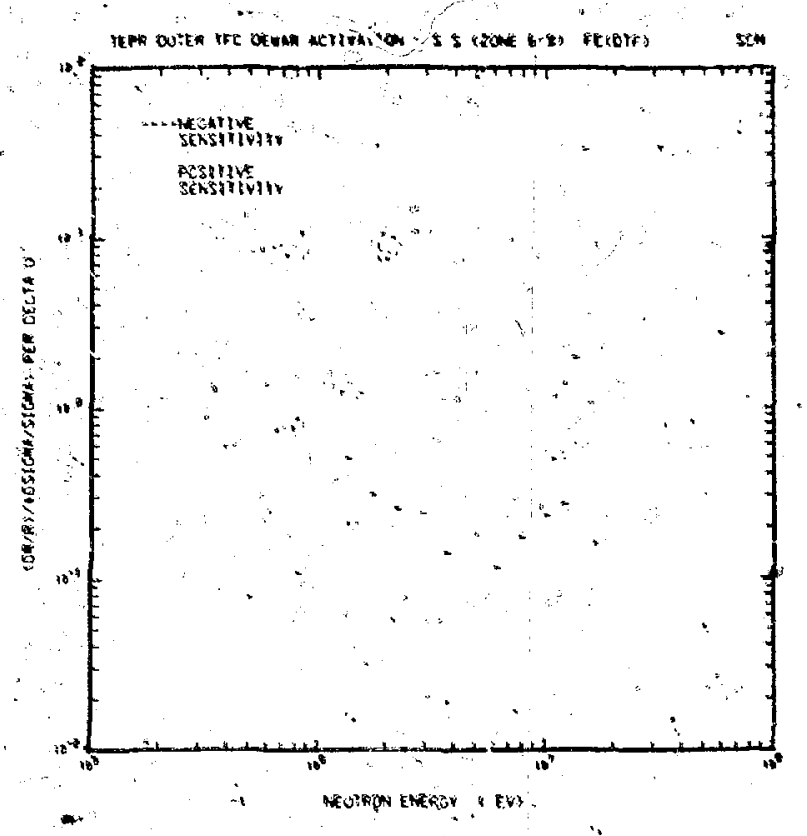

Fig. 71. Senstcivity of TFC dewar activation to Fe in zones 6-8. Net neutron scattering eross section.

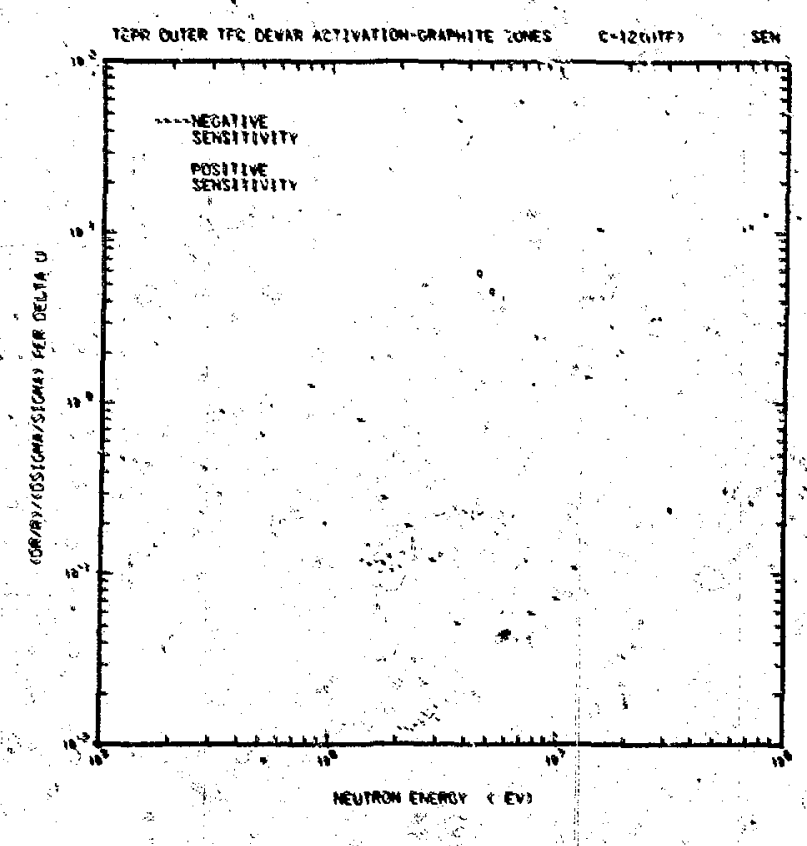

18. 72. Sensitivity of TfC dewer activation to ${ }^{12} \mathrm{C}$ in graphite cones. Net neutron scattering ernes section.

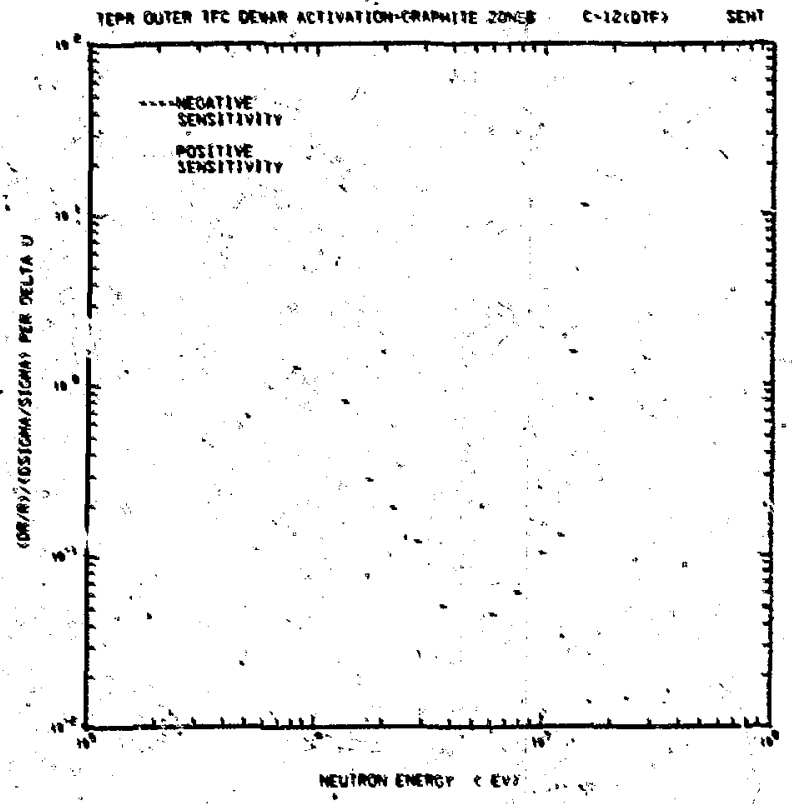

FIg. 73. Sensitivity of TFC devar actruation to ${ }^{12} \mathrm{C}$ in graphite zones. Net aeutron total cross section. 


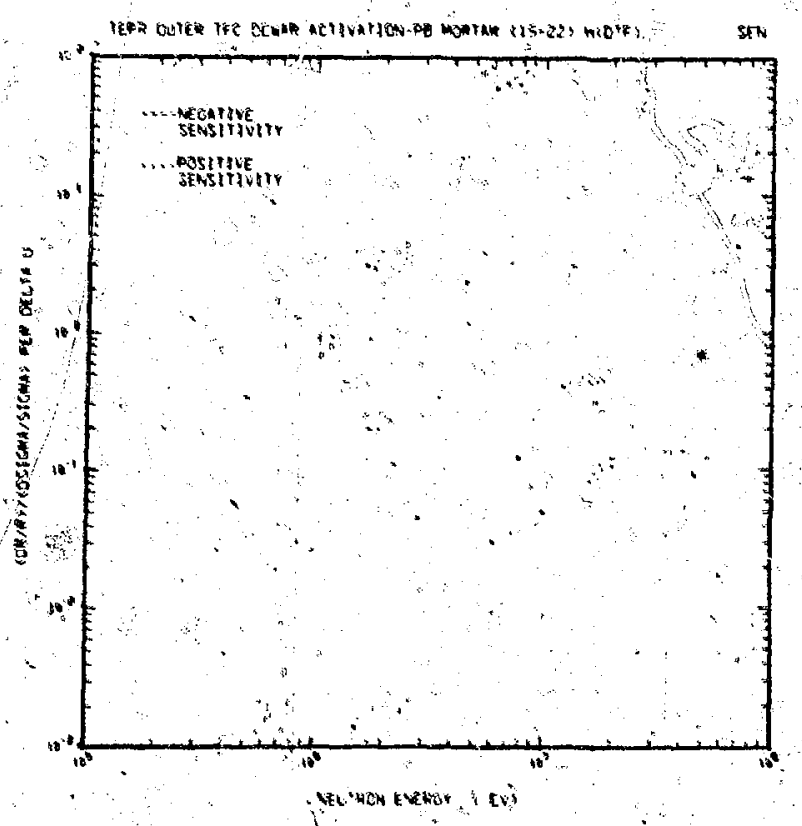

Fig. 74. Sensitivity of TFC dewar" activation to H in zones 15-22. Net neutron scattering cross section.

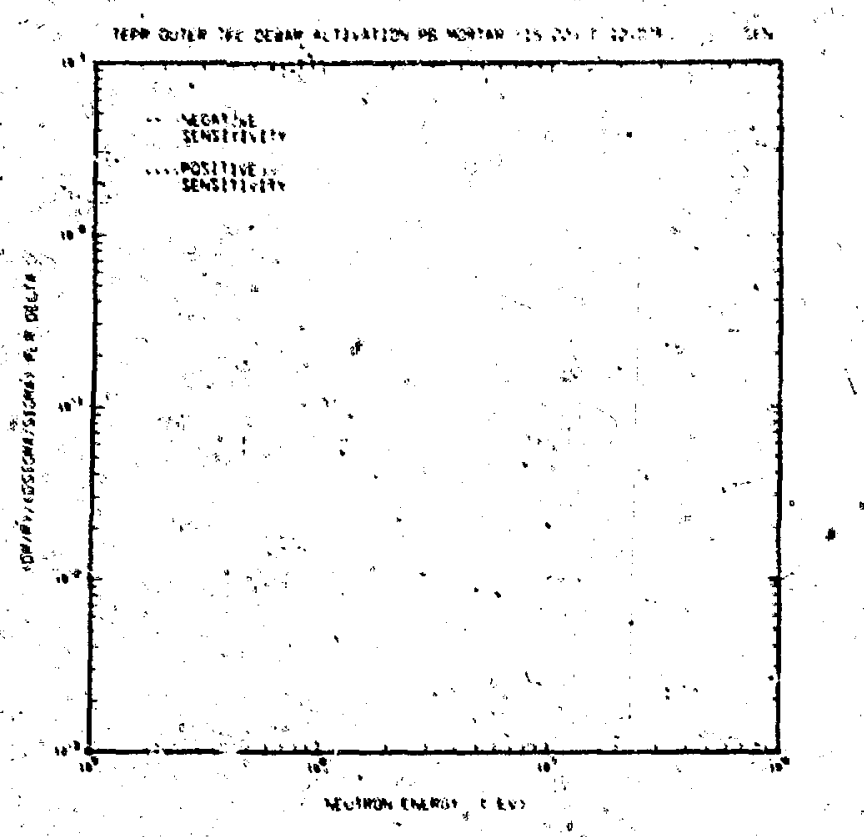

Fig. 75. Sensitivity of TFC dewar activation to ${ }^{12} \mathrm{C}$ in zones 15-22. Net neutron scattering cross section.

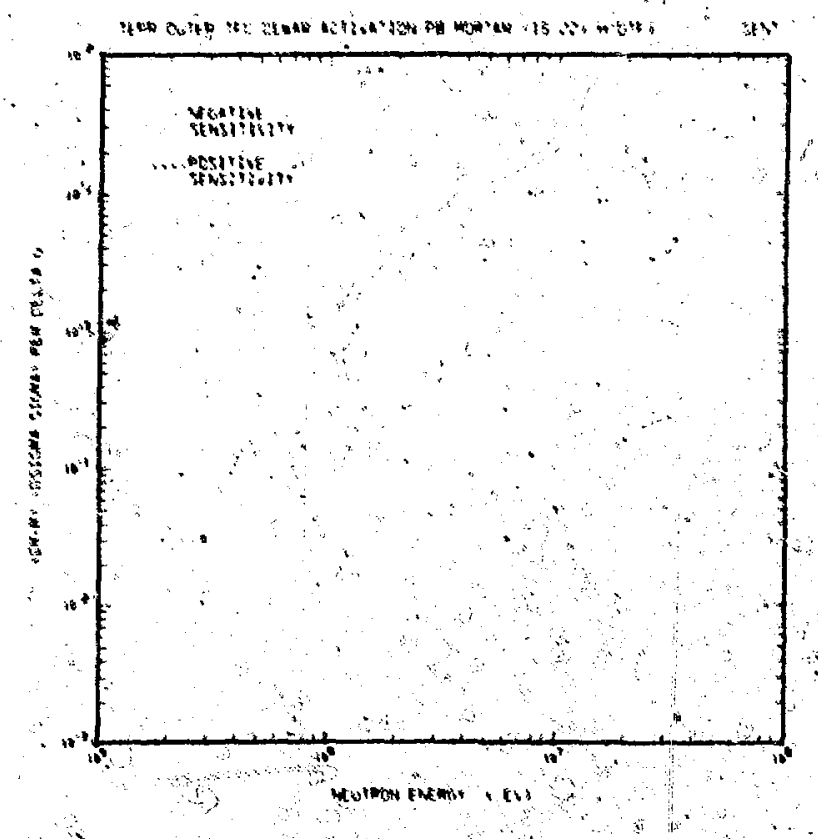

Fig. 76. Sensitivity of ThC dewar activation to in zones 15-22. Net neutron tot 1 cross section.

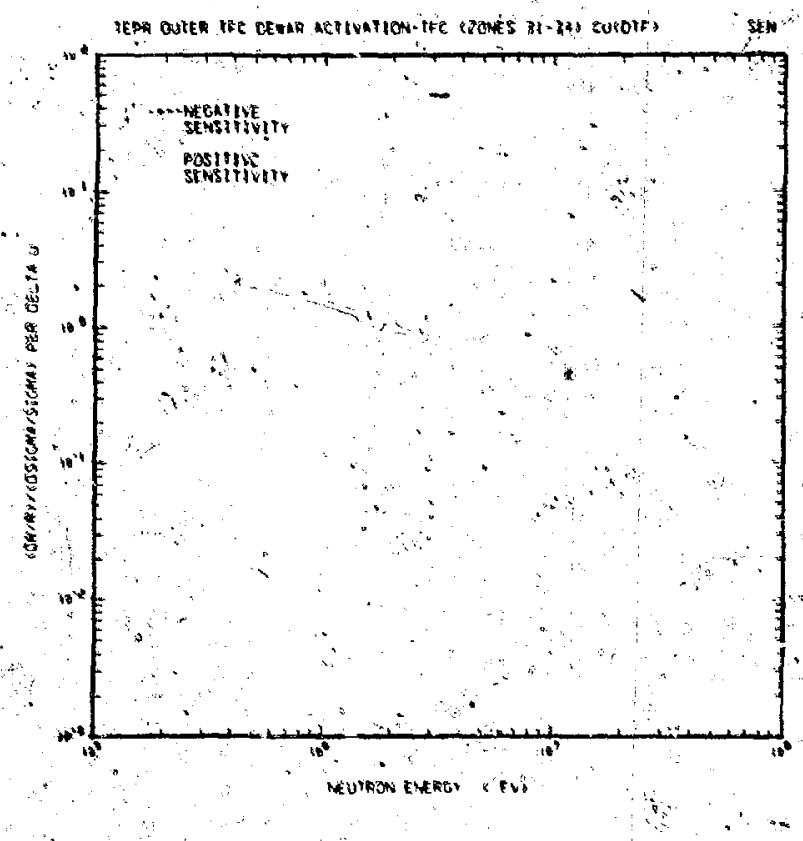

Fig. 77. Sensitivity of TFC dewar activation to $\mathrm{Cu}$ In zones $31-34$. Net neutron scattering cross section.

41 


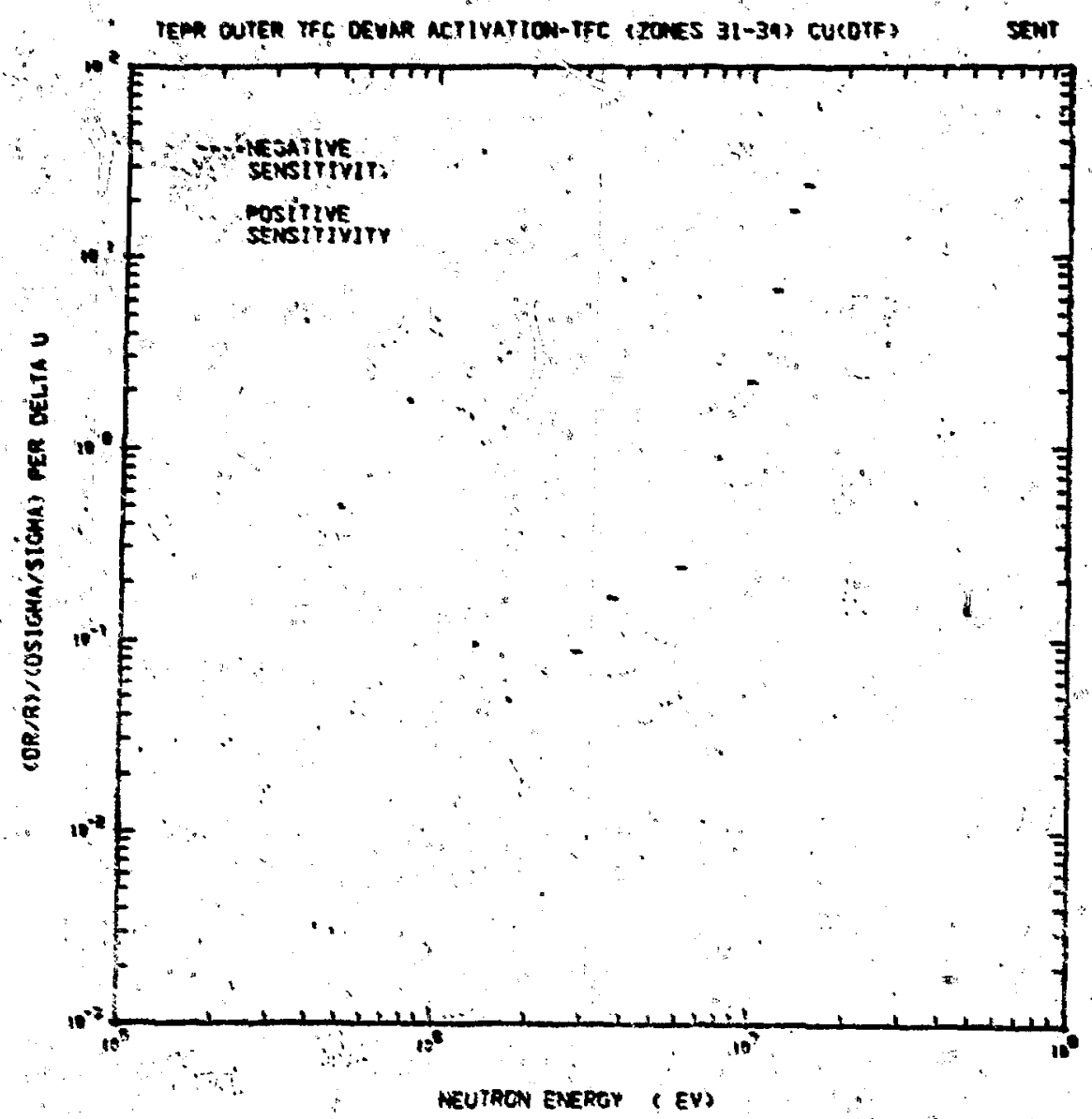

Fia. 78. Sensitivity analysis of TFC dewar activation to cu tin zones 32-34. Net neutron total cross seetion.

TABLE I

NEUTRON INTEGRAL SENSSTTIVITY, $s_{\Sigma_{T}}$, BOR THE SENSITIVITY OF

IWNER TTC NUCLEAR HEATING TO TOTAL NEUTROA

CROSS SECTIONS OF STAINLESS STEEL COMPONENTS

\section{Component}

Cr

in

Fe

NI.

Mo

Tota1

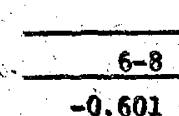

$6-8$

$-0,203$

$-2.480$

$-0.526$

$-0.091$

$-\frac{-3,801}{-601}$
Zone

14

$-0.188$

$-0.031$

$-0.034$

$-0.868$

$-0.182$

$-0.033$

$-1.329$
$\$ 0.767$

$-0.164$

$-0,030$

$-1,180$

$\begin{array}{cc}16 & \frac{23}{-0.150} \\ -0.026 & -0.014 \\ -0.602 & -0.005 \\ -0.140 & -0.058 \\ -0.024 & -0.010 \\ \therefore-0.942 & -0.008 \\ - & -0.095\end{array}$

Total

$-1.168$

$-0,202$

$-4.775$

$-1.032$

$-0,187$

$-7.374$ 
TABLE II

GANGA INTEGRAL SGNSITIVIT, $s_{\Sigma_{T}}$, FOR THE SSNSITIPITY OF INNER TFC NUCLEAR HEATING MO TOTAL GANA CROSS

SECTIONS OF STAINLESS STEEL CONHONENTS

\begin{tabular}{|c|c|c|c|c|c|c|}
\hline Component & -5 & • & & Zone. & & 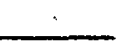 \\
\hline 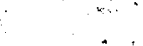 & $6-8$ & 12 & $\therefore$ & $14^{\circ}$ & 16 & $23^{\circ}$ \\
\hline $\mathrm{Cr}$ & -0.008 & $-0,023$ & $\therefore$ & -0.041 & -0.067 & -0.042 \\
\hline Min & $=0: 001^{\prime \prime}$ & -0.003 & & -0.006 & -0.009 & -0.006 \\
\hline $\mathrm{Fe}$ & -0.034 & -0.099 & $\therefore$ & -0.174 & -0.282 & -0.181 \\
\hline $\mathrm{NI}$ & -0.007 & -0.022 & & -0.038 & -0.062 & $=0.040$ \\
\hline No & -0.001 & $=0.004$ & & -0.007 & -0.011 & -0.009 \\
\hline Total & -0.051 & -0.151 & & -0.266 & $-0,431$ & -0.278 \\
\hline
\end{tabular}

$\operatorname{Total}$

$-0.183$

$-0.026$

$-0.771$

$-0.170$

$-0.034$

$-1.184$

TABLE III

PARTIAL AND NET NEUTRON INTEGRAL SENSITIVITIES OF THE INIER TFC NUCLEAR HEATING TO THE Fe COMPONENT

IN STAINLESS STEEL REGION 6-8,

Neutron Cross Section, $\Sigma_{x}$

$5_{a}$

s

$s_{T}$

$\Sigma(n+y)$
Interral Loss Term

0,175

$-12.98$

$-12.81$

$\therefore-$

\section{Integrai Gain Term}

10.33

10.33

0.014
Integral Net, $S_{E}$

0.175

$-2.65$

$-2.48$

0.014

TABLE IV

PARTIAL AND NET GAMRA-RAY INTEGRAL SENSITIVITIES OF THE IMNER TFC NUCLEAR HEATING TO THE Fe COMPONENT

\section{IN STAINLESS STEEL RBGION - 6-8}

Gamma Cross Section, $\Sigma_{x}$

$\mathrm{s}$

$\Sigma_{\mathbf{T}}$
Integral Loss Tern 0.013

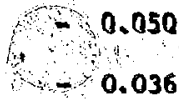

\section{Integrel Gain Term}

$\therefore$

0.002

0.002
Integral Net, $s_{\varepsilon}$ 0.013

$-0.047$

$-0.034$ 


\section{TABLE V}

NEUTRON INTEGRAL SENSITIVITY, $s_{s_{T}}$, FOR THE SENSITIVITY OF

INNER TFC NUCLEAR HEATING TO THE TOTAL NEUTRON

CROSS SECTIONS OF $B_{4} C$ COKPONEXTS

Copponent

$10_{B}$

C

Total

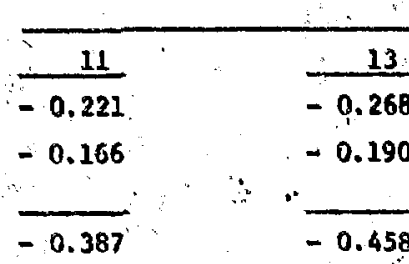

Tone

$\begin{array}{ll}\frac{15}{-0.375} & \frac{17}{-0.543} \\ -0.243 & =0.196 \\ -0.618 & \frac{-}{-0.739}\end{array}$

Total

$-1.409$

$-0.796$

$-2.20$

TABLE VI

GANA-RAY INTECRAL SENSITIUITY, $s_{E_{T}}$, FOR THE SENSITIVITY OF INNER TFC, NUGLEAR HEATING TO THE TOTAL GAMLLA-RAY CROSS SECPIONS OF B, O COAPONENTS

Component

Zone

Total
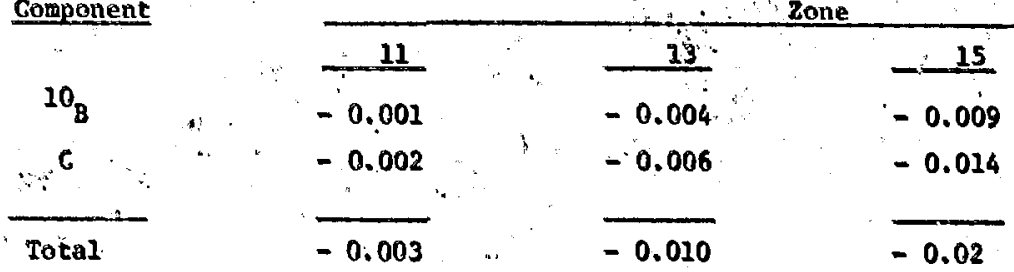
17

TABLE VII

PARTIAL AND NST NEUTRON INTEGRAL SENSITIVITIES OF THE INNER TFC 'NUCLEAR HEATING TO THE

${ }^{10}$ COMPONENT IN $B_{4}$ C REGION 17

Cross Section, $\Sigma$

$\Gamma_{\text {a }}$

$s_{S}$

$\varepsilon_{T}$

$\stackrel{\Sigma}{\Sigma}(n+\gamma)$
Integral Loss Term

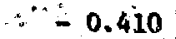

$-0.813$

$\therefore-1.224$

$-1$
Integra1 Guin Term

$$
\therefore \quad 0.681
$$

0.681

0.000

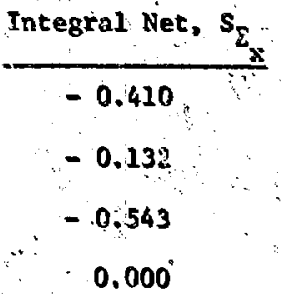


TABLE VIII

PAR:IAL AND NET GAMA-RAY INTEGRAL SENSITIVITIES OF THE INNER TFC NUCLEAR HBATING TO THE ${ }^{10}$ COMPONENT IN B $\mathrm{C}_{4}$ RECION 17

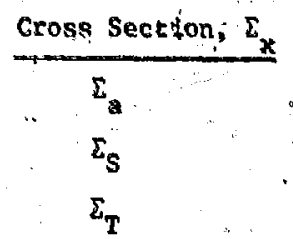
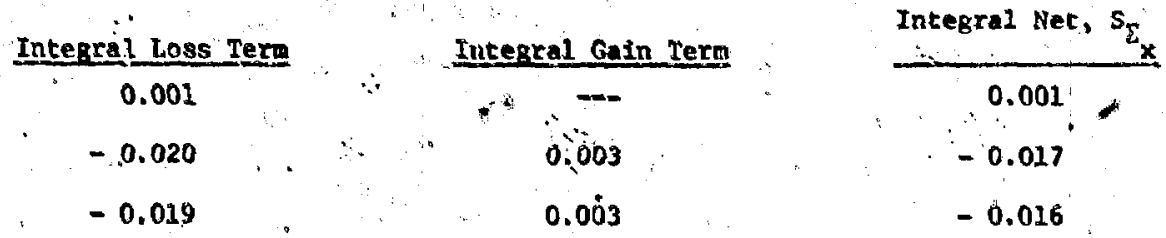

TABLE IX

NEUTRON AND GANAA-RAY INTEGRAL SENSITIVITIES, $s_{\Sigma_{\mathrm{p}}}$, OF THE TFG NUCLEAR HEATING TO THE TOTAL CROSS SECIIONS OF ALL CONSTITUENTS IN THE TEC

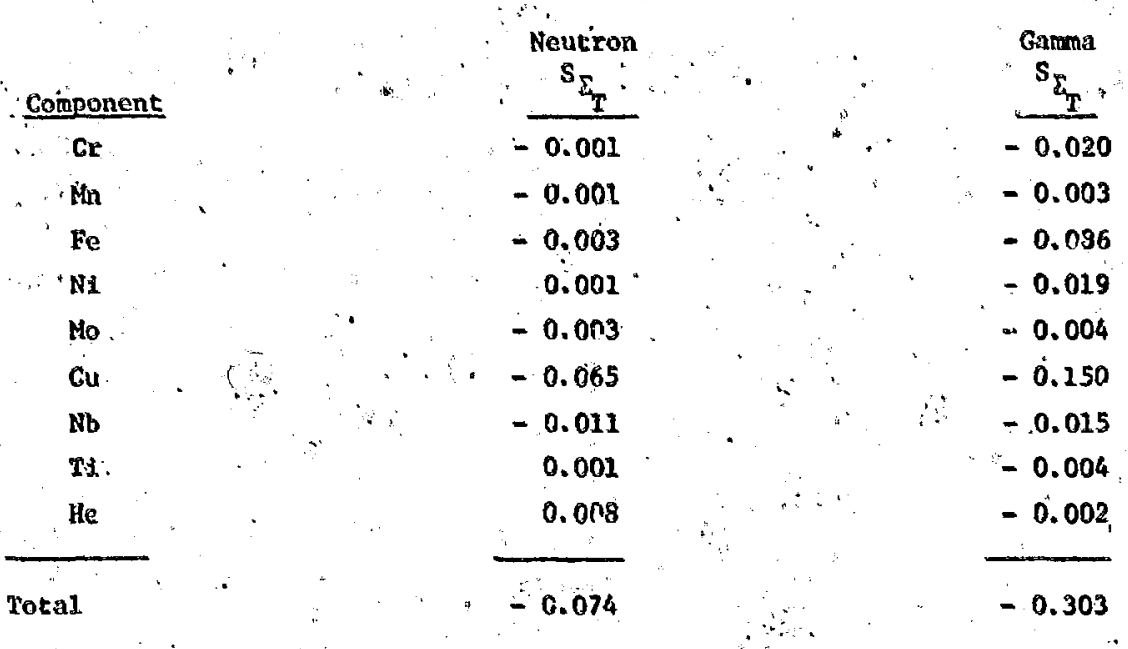

TABLE $x$

PARTIAL AND NET NEUTRON INTEGRAI SENSITIVITIES OF THE : INNER TFC NUCLEAR HEATTNG TO GU GROSS SECTIONS:

Neutron Croes Section, $\Sigma_{\mathrm{x}}$

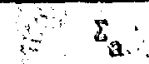

$\mathbf{S}$

$\Sigma_{\mathbf{T}}$

$\varepsilon(n+\gamma)$

\section{Integral Loss Term}

$-0.081$

$-4.708$

$-4.789$

0.201
Intescal Gain Term

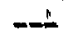

4.724

4. 724

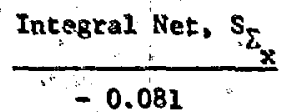

0.016

0.065

0.201 
PARTIAL AND RET GAMA-RAY INTEGRAL SENSITIUITIES OF THE INNGR TFC NUCLEAR HEATING TO Cu CRNSS SECTIONS."

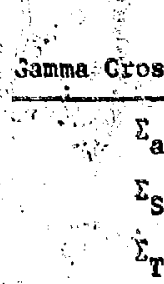

Integral Lo88 Term

0.015

Integral Gain Term

$-0.365$

0,200

$=0.350$

0.200

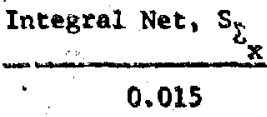

$-0.165$

$-0.150$

TABLE XII

NEUTRON INTECRAL SENSITIVIVIES, $s_{\Sigma_{T}}$, OF THE INNER

TFC COPPER TRANSMUTATION 'TO THE TOTAL

NEUTRON CROSS SECTIONS OF 55 CONPONENTS IN ZONES 6-8

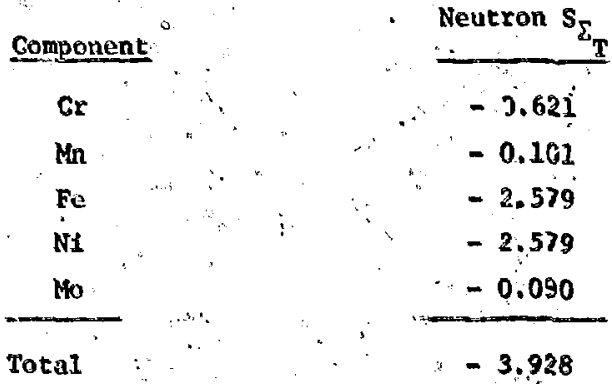

TABLE XIII

PARTTAL AND NET INTEGRAL SENSITIVITIES OE THE INNER TRC COPPER TRANSMUTATION TO CROSS SECTIONS

OF. THE-Fe CONDONENT; IN STAINLESS STEEL REGIONS 6-8

Neucron Cross Section, $\Sigma_{\mathrm{x}}$

$\Sigma_{\mathrm{a}}$
$\Sigma_{\mathrm{S}}$
$\Sigma_{\mathrm{T}}$

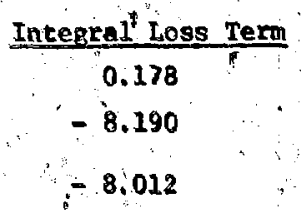

\section{'TABLE' XIV}

NEUTRON INTEGRAL SENSITIVITY, $s_{\Sigma_{T}}$, OF THE INNER TEC ROPPER TRANSMUTATION TO THE TOTAL CROSS SECTIONS OF $\mathrm{B}_{4} \mathrm{C}$ IN ZONE 17
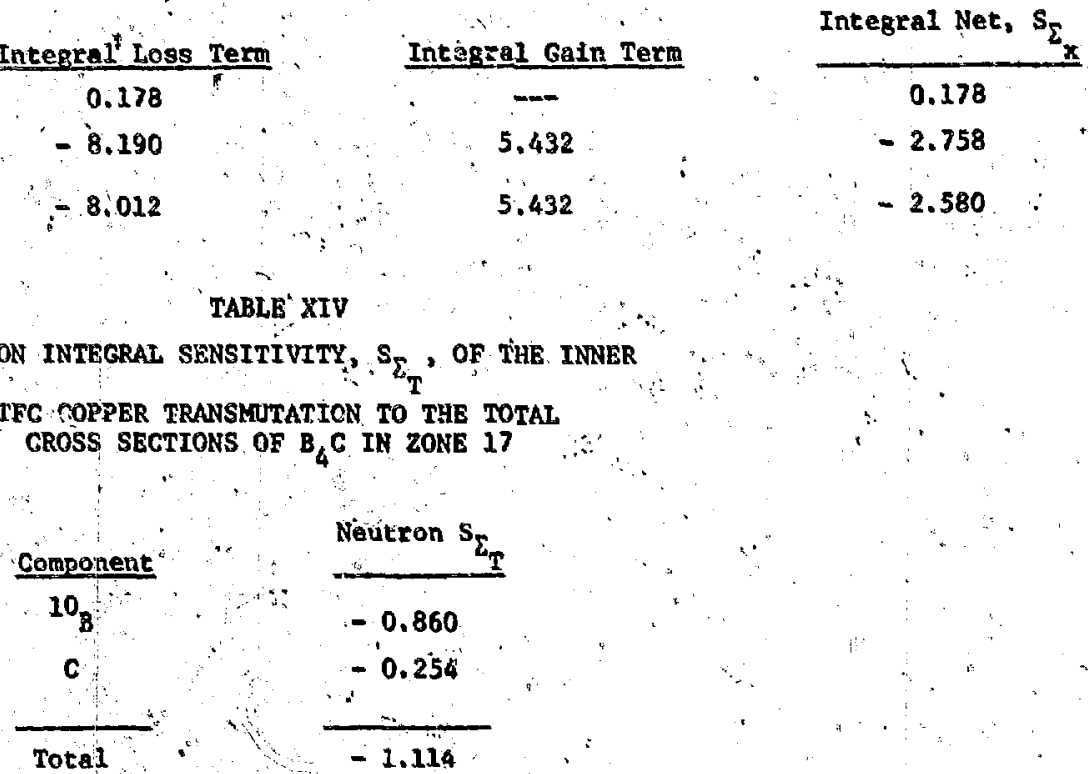
TALE XV

PARTIAL AND NET NEURRON INTEGRAL SENSITIVITIBS OF THE INNLR TFC COPPER TRANSMUIATIOH TO

$10_{B}$ CROSS SEGTIONS IN ${ }_{4} \mathrm{C}$ ZONE 17
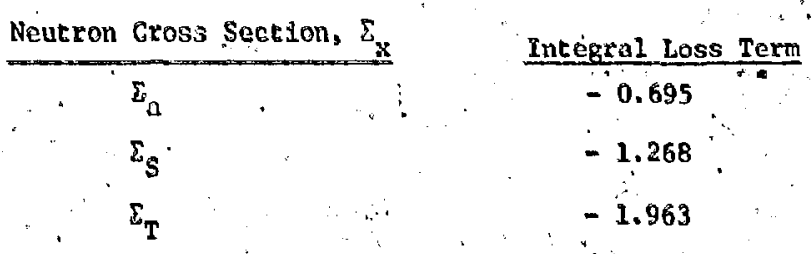

Integral Gain Term

1.103

Integral Net, $s_{g_{x}}$

$-0.695$

$-0.165$

1.103

$-0.860$

TABLE XVI

NEUTRON INTEGRAL SENSITIVITIES, $s_{\Sigma_{T}}$ : FOR TFC COPPER TRANSMUTATION SENSITIUITY TO CHANGES IN TEG GROSS SECTIONS

COMPONEN'

\begin{tabular}{l} 
Cr' \\
In \\
Fe \\
$\mathrm{NI}$ \\
No \\
$\mathrm{Gu}$ \\
$\mathrm{Nb}$ \\
$\mathrm{TI}$ \\
$\mathrm{He}$ \\
\hline TOTAl.
\end{tabular}

NEUTRON :

0.003

$-0.001$

0.008

0.009

$-0.005$

$-0.108$

$-0.023$

0.005

0.034

\section{TABLE XVIT}

RARTIAL AND NET NEUTRON INTEGRAI SENSITIVITIES OF THE INNER TFC COPPER TRANSMUTATION TO GHANGES IN CU CROSS SECTIONS

Neutron Cross Section, $\Sigma_{\mathrm{x}}$

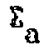

$\Sigma_{\mathrm{S}}$

$\Sigma_{\mathbf{T}}$

\section{Integral Loss Term}

$-0.189^{\circ}$

$-9.502$

$-9.691$
Integral Gain Term

.483

9.583

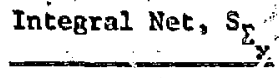

$-0.189$

0.081

$-0.108$ 
"TABLE XVIII

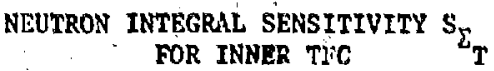

COPPER DPA DUE TO CHANGES IN SS CROSS SECIIONS

IN ZONES 6-8

Componeat

cr

Mn

Fe

N1

Ho

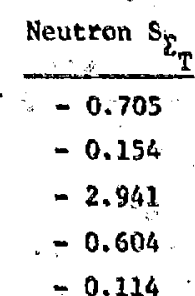

TABISE XIX

PARTIAL AND NET NEUTRON TNTEGRAL SENSITIVITIES FOR INNER TFG GOPPER DPA TO. Fe GRUSS SECTIONS IN SS ZONES 6-8

$\frac{\text { Integral Loss Term }}{0.183}$
-26.20
-26.02

\section{Integral Gain Term}

23.08

23.08
Integral Net

0.183

$-3.12$

$-2.94$

TABLE XX

NEUTRON INTEGRAL SENSITIVITY $S_{\Sigma_{T}}$ FOR
COPPER DPA SENSITIVITY DUE TO $\mathrm{B}_{4} \mathrm{C}$ CROSS SECTIONS IN ZONE 17

Component

$10_{\mathrm{B}}$

C

Total

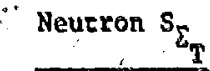

$-0.436$

$-0.290$

$-0.726$ 
TABLE XXI

PARTTAL AND NET NBUTRON INTEGRAL SENSITIVITIES FOR COPPER DRA DUE TO ClaNGES IN ${ }^{10}$ B CROSS SECTTONS IN zONE 17

Neutron Cross Sections; $E_{x}$ $\Sigma_{a}$ $\varepsilon_{\mathrm{S}}$ $\Sigma_{\mathrm{T}}$
Integral Loss Term

$-0.210$

$-0.830$

$-1: 040$

\section{Integrai Gain Term}

0.604

0.604

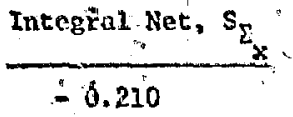

$-0.226$

$-0.436$

\section{TABLE XXII}

NEUTRON INTEGRAL SENSITIVITIES $s_{\Sigma_{T}}$ FOR
COPPER DPA SENSITIVITY

DUE TO TFC CROSS SECTIONS IN FIRST INTERVAL OF TFC

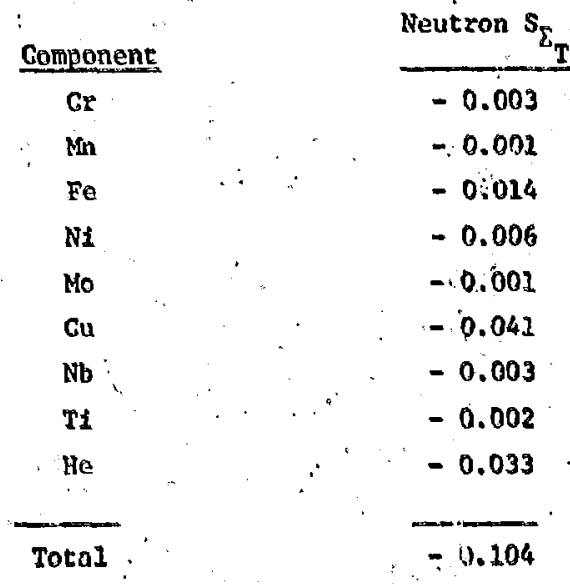

TABLI XXIII

PARTIAL AND NET NEITRON INTEGTLL SENSITIVITIES FOR COPPER DPA 'DUE TO GU CROSS SECTIONS IN FTRST 1NTERVAL OF TFC

Neutron Cross Section, $\Sigma_{\mathrm{a}}$ $\Sigma_{\mathrm{S}}$

$\varepsilon_{T}$
Incegral Loss Term

$-0.006$

$-1.856$

$-1.862$
Integral Gain Term

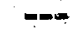

1.821

1:821
Interral Net

$-0.006$

$-0.035$

$-0.041$ 
TABLE XXIV

NEUTRON INTEGRAL SENSITIVITY $s_{\Sigma_{T}}$ FOR DUE TO GIIANGES IN SS CROSS SECTIONS IN ZONES 6-8
TABLE XXY GAMA INTEGRAL SENSITIVITY $s_{\mathrm{K}}$ FOR
WYLAR DOSE SENSITIVITY DUL' TO CHANGES IN SS CROSS SECTIONS:IN ZONES 6-8
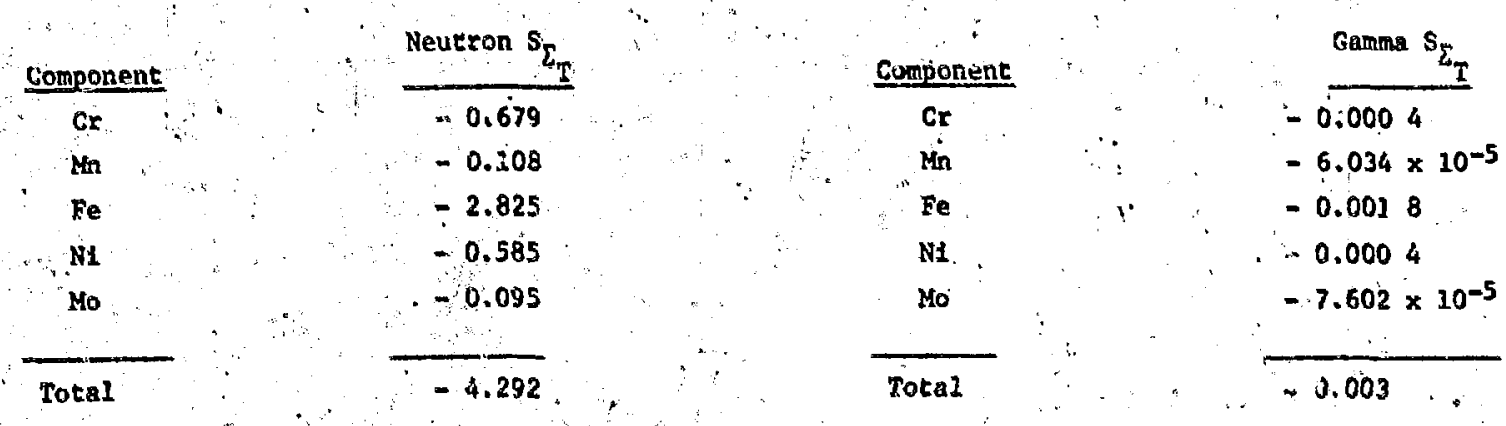

TABLE XXVI

PARTIAL AND NET NEUTRON INTEGRAL SENSITIVITIES FOR MYLAR DOSE DUF TO CHANGES IN Fe CROSS SECTIONS IN ZONES 6-8.

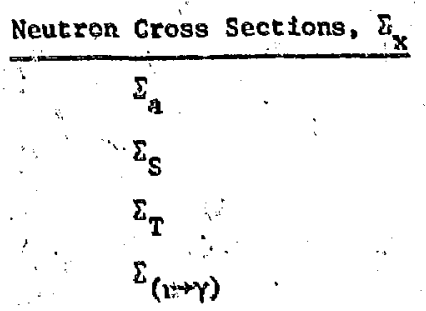

$\frac{\text { Integral Loss Texm }}{0.227}$
$\therefore-6.792$
$\therefore-6.565$
-

Integra: Gain Term

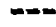

3.740

3.740

0.0007
Integral Net

$-3.052$

$-2.825$

0.0007

TABLE XXVII

PARTIAL AND NET GAMM INTEGRAL SENSITIVITIES FOR MNLAR DOSE DUE TO CHANGES IN Fe CROSS SECTIONS IN ZONRS 6-8

Gama Uross Sections, $\Sigma_{x}$

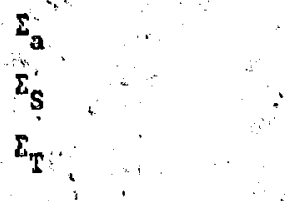

Integre1 Loss Term

0.0007

$-0.002 \cdot 6$

$-0.0019^{\circ}$
Intercal Gain tern.

0.0002

0.0001
Interral Net

0.0007

$-0.0025$

$-0.0018$ 
MABLE XXVIII

NBUTRON INTEGRAL SENSITIVITY $S_{\Sigma_{1}}$ FOA
MUAR DOSE SENSITIVITY DUE TO CHANGES IN $\mathrm{B}_{4} \mathrm{C}$ CROSS SECTIONS IN ZONE 17,
TABLE: $X X I X$

GALAS INTEGRAL SENSITIVITY $S_{\text {E }}$ FOR MYLAR DOSE SENSITIVITY $T$

DUE TO CHANGES IN $\mathrm{B}_{4} \mathrm{C}$ CROSG SECTIGNS IN ZONE 17
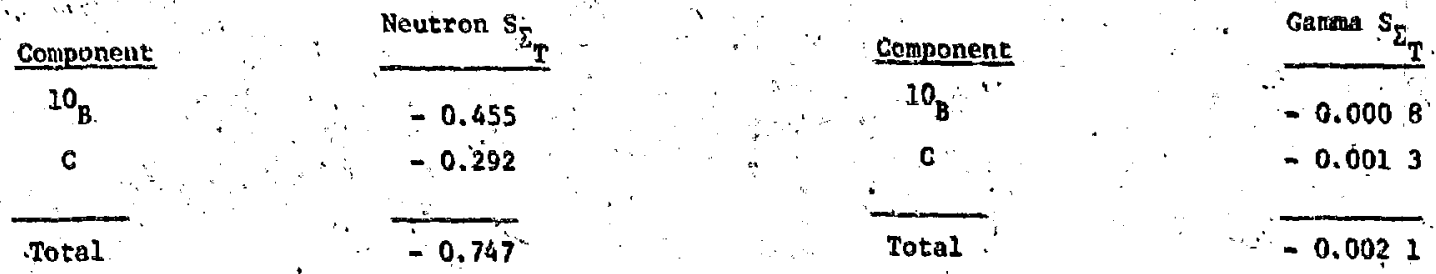

TABLE XXX

PARTIAT AND NET NEUTRON INTEGRAL SENSITIUITIES FOR MYLAR DOSE DUE TO ${ }^{10} \mathrm{~B}$ COMPONENT TN $\mathrm{B}_{4} \mathrm{C}$ 2ONE 17

Neutron Cross Sactions, $\Sigma_{x}$

$\Sigma_{\mathbf{a}}$

$\Sigma_{\mathrm{s}}$

$\Sigma_{T}$

$\Sigma(n-\gamma)$
Integral Loss Term

$-0.228$

$-0.872$

$-1.100$

$-\infty$

\section{Integral Gain Term}

0.645

0.645

$1.323 \times 10^{-5}$
Integral Net $s_{\Sigma}$

$-0.228$

$-0.227$

$=0.455$

$1.923 \times 10^{-5}$

TABLE XXXI

PARTIAJ AND NET GAMA INTEGRAL SENSITIVITIES FOR MYLAR DOSE DUE TO ${ }^{10} B$ COMPONENT IN B $C$ ZONE 3 ?

Gamma Cross Sections, $\Sigma_{\mathbf{x}}$ $\Sigma_{\mathrm{a}}$.

Integra1 Loss Term

$\Sigma_{\mathbf{S}}$

$\Sigma_{m}$ $5.402 \times 10^{-5}$

Integsal Gain Term

$\therefore 1.011 \times 10^{-3}$

$-9.569 \times 10-4$

$1.378 \times 10^{-4}$

$1.378 \times 10^{-4}$
IntegraI Net $s_{z}$

$5.402 \times 10^{-5}$
$=8.732 \times 10^{-4}$

$-8.191 \times 10^{-4}$ 


\section{$\because$ TABLL XXXII}

NEURON INTEGRAL SENSITIVITY $\dot{S}_{\Sigma_{T}}$ FOR TO CROSS SECTIONS IN FIRST INTERVAL TFG

\section{Component}

$\mathrm{cr}$.

Min

Fe

Nì

No

$\mathrm{Cu}$

$\mathrm{Nb}$

$\mathrm{Ti}$

He

Toral

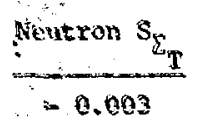

$-0.001$

$-0.012$

$-0.006$

$-8.309 \times 10^{-4}$

$=0.043$

$-0.003$

$-0.002$

$=0.003$

$-0.074$
TABLE XXXII

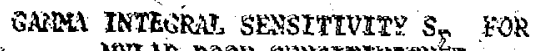
MYMAE DOSE SENSTTUVITY

TO CROSS SECTIONS IN FIRST INTERVAL OF TEC

$$
\begin{aligned}
& \frac{\sigma_{1}}{-0.001} \\
& =1.515 \times 10^{-4} \\
& =0.004 \\
& =9.354 \times 10^{-4} \\
& -1.59 \times 10^{-4} \\
& =0.007 \\
& =5.841 \times 10^{-4} \\
& -2.439 \times 10^{-4} \\
& =1.167 \times 10^{-4} \\
& -0.014
\end{aligned}
$$

Neucron Gross Section, $\varepsilon_{x}$

$\begin{array}{lll}\Sigma_{3} & & \ddots \\ \Sigma_{S} & & \\ \Sigma_{T} & \\ \Sigma_{(3 i-\gamma)} & \end{array}$

\section{Integral Loss Tern}

$-0.010$

$-2.037$

$-2.047$

$-\infty$

\section{Integral Gain Term}

-r.

2.004.

2.00 年

0.009
Integral Net, $s_{\Sigma_{\mathrm{X}}}$

$$
-0.010
$$

$-0.033$

$-0.043$

0.009
Banta Gross Section, $\Sigma_{x}$

$\Sigma_{\mathrm{a}}$
$\Sigma_{\mathrm{g}}$
$\Sigma_{\mathrm{T}}$

Integrai Loss Tem

$$
0.002
$$

$-0.015$

0.013
Integrai Gain Tern

0.006

0.006
Integral Net. $s_{E_{x}}$

0.002

$-0.009$

$-0.007$ 
TABLE XOXVT

NEUTRON INTEGAL SENSITIVIT, $s_{T_{T}}$, FOR ACTIVATION OF TFC DSWAR DUE TO s. S. CROSS SECTION.
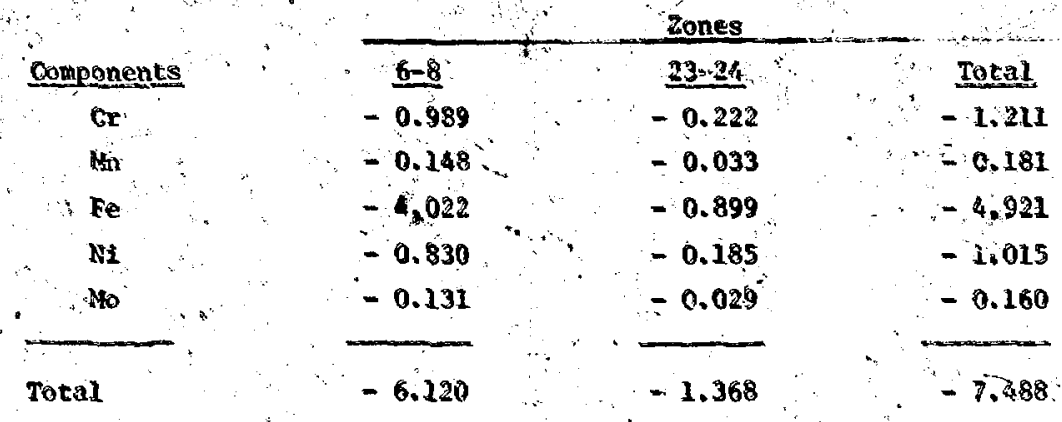

TABLE XXXVII

PARTIAL AND MBI NETIRON INEERAL SENSITIVITIES FOR TFC DEWAR ACTIVATION DUB TO Fe IN REGTON $6-8$
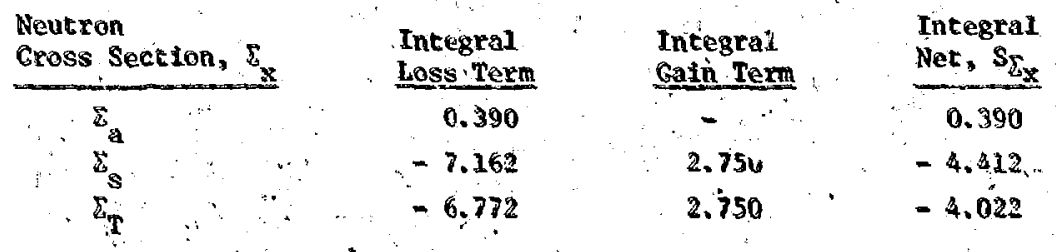

TABLE XXXVIII

NUUTON INTEGRAL SENSITIVITY, $s_{z_{2}}$, WOR AGTTUATION OF TFC DEWAR DUE TO GRAPHTTE CROSS SECTTONS IN ZONES 1]-13
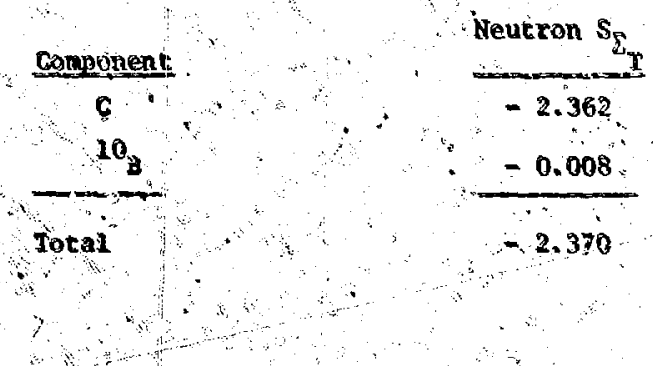


\section{- TABLE XOXIX}

PARTIAL ND NET NEUTRON INTEGRAL SENSITIVITIES FOR TEC DETRR ACEIVATION DUE TO C IN REGION 11-13

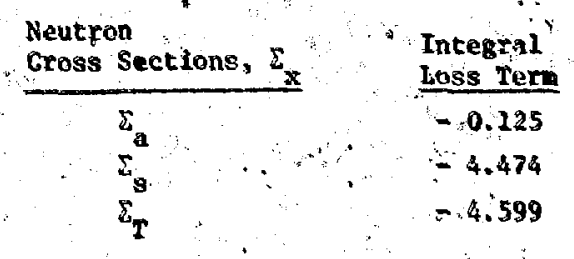

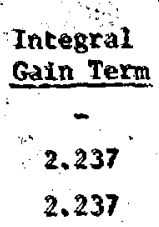

Integral Net, $\mathbf{S}_{\Sigma_{\mathrm{X}}}$

$-2.125$

$-2.237$

$-2.362$

TABLE XL.

NEUTRON, INTEGRAL SENSITIVIT, $s_{T}$, FCR ACTIVATION OF IFG DEWAR DUE TO LEAD NORTAR CRJSS SECTIONS IN ZONES 15-23.

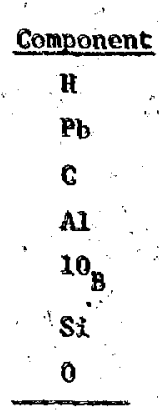

$\operatorname{Tota} 1$

$$
\begin{aligned}
& \text { Neutron } s_{\Sigma_{T}} \\
& \text { - } 2.721 \\
& \therefore 2.405 \\
& -1.563 \\
& -0.019 \\
& -0.039 \\
& -0.378 \\
& -0.565 \\
& -7.490
\end{aligned}
$$

TABLE XLI

EARTIAL ALD NET MEUTRON INTEGRAL SENSITIVITIES FOR TTG DEWAR ACTIVATION DUE TO H IN RBGIONS 15-22
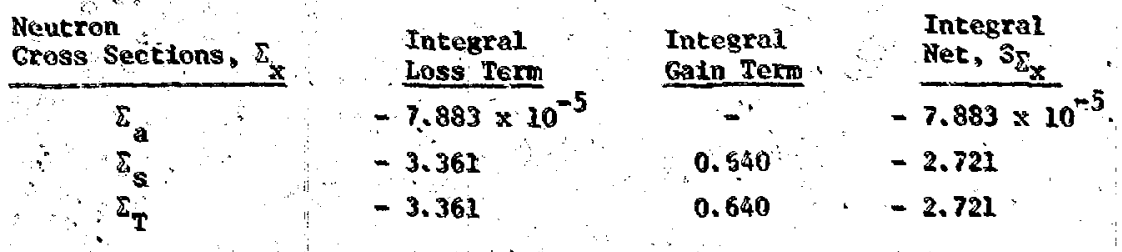
AJSORPPITON AND BLASTIC SCATTERING CROSS SEGTIONS FOR $\mathrm{Nb}, \mathrm{Cu}$; Fe AT - $3 \mathrm{MeV}$.

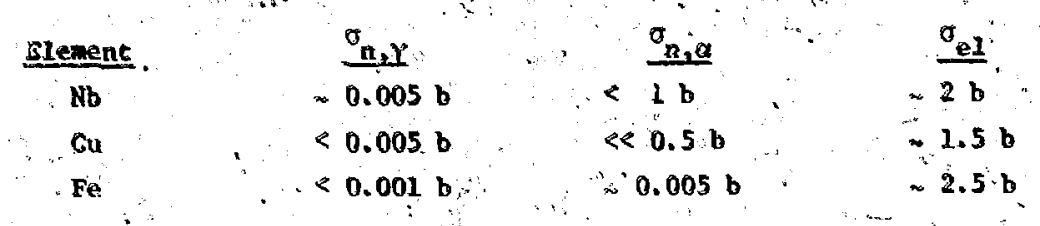

TABLE XILIII

NEUTRON INIEGRAL SENSITIVITY, $s_{S_{T}}$, FOR ACTIVATION,OF

IFC DEWAR DUE TO TFG GROSS SECTYONS. IN ZONES $31-34$

\section{Comporents}

\begin{tabular}{c}
$\mathrm{Gr}$ \\
$\mathrm{Hu}$ \\
$\mathrm{Fe}$ \\
$\mathrm{NI}$ \\
$\mathrm{Cu}$ \\
$\mathrm{Nb}$ \\
$\mathrm{Ti}$ \\
$\mathrm{He}$ \\
\hline Total
\end{tabular}

$\therefore$ TABLE XLIV.
Neutrẹn $\mathrm{s}$

$$
-0.866
$$

$-0.37$

$=3.634$

-0.745 .

$-0.095$

$-5.716$

$-0.315$

$-0.233$

$=0.156$

$-11,897$

\footnotetext{
$\because \quad$ EARTIAI AND NET REUTRON INTEGRAL SEŇSITIVITIES FOR TIC DEWAR aGTIVATION DUE TO GU IN TFC REGTONS 31-34
}
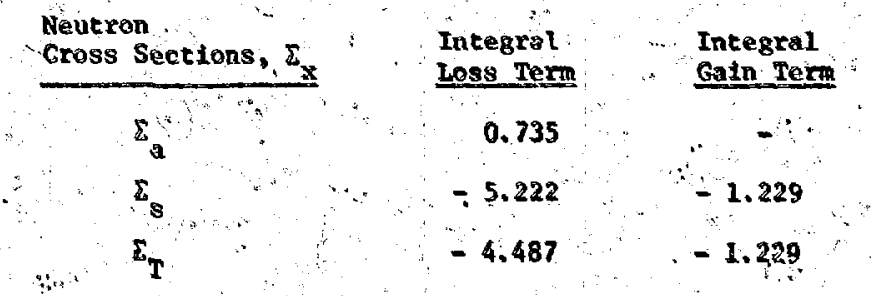

Integral

Net: $5 z_{x}$

0.735

$-1.229$

0.735

$-5.222$

$-1.229$

$-6.451$

$-4,487$

$-5.716$ 
This section will peftain to the general scheme of alculation using the cross-section senisitivity profile equations. The principle equations of incer, est are those for the sensitivity profiles for neutron Interactlons [Eq. (8)], ganma-ray intertetiens [Bq: (10)], and photon productlon [Bq. (12;].

* $\therefore$ When using coupled cross-section sets, the obfeet is to perform all computations in one computer run. Thts will require caution in the limits of. energy group summations. A few algerithms will be given to show the IImits" of the sumations, but the discussion will be limited to cross-section sensitivity calculations and the aspects of how the lim1 is of sumution are chosen and manipulated. Other capabilities of SENSIT-1D, such as design sensitivity and error nnalyses will not be discussed. Hore details of how these calculations ate pesformed are given in Ref. 13.

Fig. A-1 shows the logic of that portion of the main program where decisions for the calculation of profiles are greatly dependent upon the strueture of the eross-seetion set. It must be noted that previous subprograth have read in and stored the fluxer $\dot{\phi} \phi *$, and have calculated and stored $\varphi^{88^{\prime}}$ as well as $X^{g}, R$, and $\Delta U^{g}$.

The Eollowing explanation of the FoRTRA parameters will be useful th furthex discusstons:

$I C N=$ the total number of energy groups (neutron + gamma)

Iritl - the final energy to be used in a sumat ion ${ }^{\mathrm{r}}$ over energies

$J 1$ = the initial enerby to be used in $A$ +... sunmation over energies

NCoupL = a parametor that is 0 for noneoupled cross-section sets, and is equal to the number of neutron groups for coupled cross-section sets

NPERYs - number of isotopes whose crciss sections are considerad perturbed

NXS - Integer that allows all perturbed isotopes to be considered.

A bricf explanation of the overall viev as shiwn in Fie. A-1 is that the proftam iverforms two steps of operations per Isotope, MAs: The first step is to calculate the neutron Interaction sensitivity profiles while the secand step is to perforal the ganaray interaction profites. The gama production calculetions are performed in the former operational step. When the noutron calculations are made, $J 1$ is equal to 1 and IGM 1 is equal to NCOUPL (thie number of neutron groups) if it is a coupied eross-section set. If noc, then $\mathrm{J} 1=1$ and IGMl = IGM for a noncoupled cross-section set. During this phase it also calculates the (n-ip) results. After the neutron caleulations are made and plotted, the prograp then goes to the gama-ray energy groups with $\mathfrak{J}=$ NCOUPL+1 and IGM * IGM (1.e., the energy group of the firgt ganma group and the final energy group). After the gammray intersiction calculations are made, the program cheeks to see if all the perturbed cross sections have been accounted for, If not, it goes to the next material and reselats the neutron and gamma-ray calcuIational procedures over again. A better understandIng can be obtained if one observes some pertinent algorithms in the subroutines SUB6 and SIJB8.

\section{ALCORITHMS IN SUB6 FOR COUPLED CROSS-SECTION SETS}

The subroutine SUB6' ealculates the erost-seetion rerms used in perturbation applieations, that

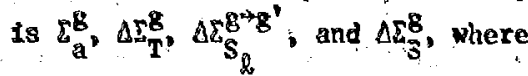

$$
\begin{aligned}
& \Delta \Sigma_{T}^{\mathrm{g}}=\bar{\Sigma}_{\mathrm{T}}^{\mathrm{g}}-\vec{\Sigma}_{\mathrm{T}}^{\mathrm{B}} \\
& \Delta \Sigma_{S_{\ell}}^{8+g^{\prime}}=\Sigma_{S_{\ell}}^{g^{-1} g^{\prime}}=\Sigma_{S_{\ell}}^{g^{8}+g^{\prime}} \\
& \Delta \Sigma_{s}^{B}=\Sigma_{s}^{g}-\Sigma_{s}^{8} .
\end{aligned}
$$

The barred cross seftions are the reference cross sections, and the others are the perturbed cross sections. These cross-section differences are needed in design sensitivity anslysis using perturbation theory. However, since we are interested here only in cross-section sensitivity analysis, only one set of eross sections is needed, $(1 . e, \bar{\Sigma} \equiv 0)$. The algorithm that calculates $\Delta \Sigma_{T}^{8}$. and $\Sigma^{8} 13^{2}$ is follows:

DO $40 \mathrm{G}=1$, IGH

$\left.\operatorname{DST}(G)^{2}=x S^{(G, I H T}, 1\right)-X S B A R(G, \operatorname{IHT}, 1)$ 
$\operatorname{AXS}(G)=\operatorname{sX}\left(\theta_{;}\right.$IHA, 1$)$

$40^{\circ}$ CONTINUE

where

DST $(G)=$ the total cross-section difference, $\Delta \mathrm{z}_{\mathrm{T}}^{\mathrm{g}}$

IHT = edit position af total cross section in cross-section tables

$X S(G, I A T, 1)=$ perturbed cross secțion in energy group 8 , edit position IHT, and Legendxe order 0 , 1.e.: $\Sigma_{T}$

XSBAR $(G, I H T, 1)=$ referenee cross section In energy gioup $g$, edit position IHT, and Legendre order 0 , ....

Axs(G) = absctption cross section, $\Sigma_{\mathrm{g}}^{\mathrm{g}}$ XS $(6, I H A, 1)=$ cross section tin energy group $\mathrm{gi}$, at the absorption crosssection edit position, IHA, and Lagendre order $0,1 . e .$. s.

In the case of cross-section sensitivity analysis XSBAR(G,IHT, 1$)=0$ for all of and all IHT.

The total scattering cross sections, $\Sigma_{T} \mathrm{Sg}$, are also caleulated for later use in sensitivity proflie computations. This usually Involves suming over diagonal elepents in the scattering matrix. However, When coupled cross-section sets are beting used, caution is warranted over the limits of summation. For the pure neutron interactions the sum should bo chity over the neutroti groups, and the gama-ray interas: tions sumation shouid be oniy over the gamma-xay groups. As an example, the cross-section table, in:Fig. 3 shows that the sum should only, be over the neutróngroups 1 to 5 per neutrón group. SImilarly, the sun of the gamma-ray diagonals should be only over the groups 6-8 per gamma-ray group. An algorithm that accomplishes this is:

$$
\begin{aligned}
& \text { DO } 60=1, \text { IGH } \\
& \text { SXS(G) }=0.0
\end{aligned}
$$

DO $50 \mathrm{GP}=\mathrm{G}, \mathrm{IGN}$

$I=I \hat{T}+G F-G+1$

50 ax8 $(G)=\operatorname{SXS}(G)+X S(G P, I, 1)$

60 CONTINUE

IE (NCOUPL, BQ, O) 60 TO 200
Do $2046=1,104$

204 SXSNG(G) $=0.0$

NG1 - NCOUPL+1

Do $200, G=1$, NCOUPI.

DO $201 \mathrm{GP}=$ NGI, IGA

$I=I+T+G P-G+1$

201 SXSNG(G) = SXSNG(G) + XS(GD,I, I)

sXs (G) - sXs(o) - JAsNG(G)

200 CONTINUE

" s

where

$\because \quad$ SXs(G) = total seattering iross seetion for group $\mathrm{g}, \mathrm{sg}_{\mathrm{g}} \mathrm{Sg}$

Sx $(G P, \ldots, 1)=$ eross section nt group $\mathrm{Cr}_{2}$ ent posttion I, and Legendre tirdex 1

SXSNG(G) - rotal scattering cross section from neutron group $G$ into oil gama

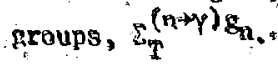

The do-loop on 60 performs the summition ziong. the diagonal seattering, cross" sections for groups (neutron + gamma rsy) tc abtatn the total scattering for each group f. This would, ordinarily be correet for noncoupled cross-section sets; however, the next do-loops make corrections if a coupled cross-section set is used. Bssentially, that happens is that the algorith suis over the diagonal elements of the $\left(n^{-h}\right)$ matrix for each neutron group $s$ and subtracts the result from the previously calculated total seattering cross section. For Instance, in our 8group coupled cross-section example, the program would sun ali the scattering eross sections over the diagonal for each group (1.e,, from groups 1 to 8 for each group g). It then sums over the diagonal of the (n-p) matrix for each neutron sroup 1 to 5 and subtracts that from the previousiy calculated total eross sections for neutron group 1 to 5 . The result is the same as if the neutron totil seattering cross section were sumed over the diagonals from groups 1 to 5. Note that the gamma-ray total scattering cross sections remain unchanged. The calculation of $\Delta \Sigma_{S_{R}}^{g+g^{\prime}}$ is given below:
$10030 \mathrm{G}=1, I G M$
DO $30 \mathrm{GP}=\mathrm{G}, 1 \mathrm{BA}$
$\mathrm{K}-\mathrm{thT+Qj- \textrm {e } + 1}$
, bo $30 \mathrm{~L}=1$, LL. 
$30 \operatorname{DSLED}(G, G P, L)=\operatorname{XS}(G, K, L)-X \operatorname{XSAR}(G P, K, L)$

where

$\begin{aligned} \text { DSLFD }(G, G P, L)= & \text { the scatering cross section } \\ & \text { from group } G \text { to } G P \text { for } \\ & \text { Iegendre order } t, \Delta E_{S}^{g} \rightarrow B_{B}\end{aligned}$

$L L=$ maximum Lëgendre order, $l_{\max }+1$

XS $(G P, K, I)=$ perturbed cross section at energy sroup GP, edit posicton $k$, and Legendre order $L_{1}$. $\Sigma_{S}^{8+g}$

XSBAR $(G P, K, L)=$ reference tross section at onergy Broup GP, edit position $K$, and Legendre otder $L$. $\bar{\Sigma}_{S_{\ell}}^{8 \rightarrow B^{\prime \prime}}$

AII reference cross sections are zero for crosssection sensitivicy analysis.

II. ALGORITHMS IN SUH8 FOR COUPLED CROSS-SECTION SETS

This subroutine evaluates the senstivity profile equations. Equations (8), (10); and (12) are being computed for the total cross sections, the absurption cross sections, the scactering cross sections, and the photon production cross sections. As the explanation of Fig. A-1 Indicates, the subroutine SUB8 is subjeat to two phases of calculations. The first is the neutron interactions calculations and the second 19 the gamma-ray interactions calculations. The values for the group limits, Jl and IMl play an important role in this subrouitine. The parameters. $X^{8}, \psi^{88^{8}} R_{3}$ and $\Delta U^{8}$ are calculated in other subroutines. 13 Hence, having calculated the macroscople cross-section terms in SUB6, the program has if the data needed to compute the sensitivity profiles.

Av calculaion of $\sum_{l=0}^{L} \sum_{g=g}^{G}\left(\sum_{\ell}^{x+8} \psi_{l}^{88}\right)$

The following alforithm calculites the gain term of the sensitivity profile equation.

10060 6-J1, IGMI

$F F D^{\prime}(G)=0.0$

DO $50 \mathrm{~L}=1, \mathrm{LL}$

DO, $50 \cdot \mathrm{GP}=\mathrm{G}, \mathrm{ICM}$

50 FED (G) FFD(G) + DLSFD(G,GP, L $) \pitchfork P E I(d, G P, L)$ 60 CONTINUE were 5

$$
\begin{aligned}
& \text { FFD (G) = gain term at energy } 6, \sum_{l=0}^{L} \sum_{g^{l}=8}^{G} \\
& \left(\Sigma^{\mathrm{xg}+8^{+}} \cdot \psi_{\ell^{8}}^{88^{\prime}}\right) \\
& \operatorname{PST}(G, G P, L)=4_{8}^{B 8}
\end{aligned}
$$

The values of $\mathfrak{J}$ and IGMl vary according to the calculational phase. In the neutron interactiox ealculations $\mathrm{Jl}$ has the value of 1 (the first neutron group) and IGNi has the value of NCoupl (the last neutron group). Whereas in the ganmaray-calculational phase, ji has the value of NCouplt1 (the first Gamma-ray group) and IGMi is equal to IGL (the last. gamma-ray group). Hence, the program computes the gáin term for neutron or gamma-ray interactions depending upon the phase of computation.

B. Galculation of $-\Sigma_{T}^{x 8}, x^{8}$ and Sensitivity Profile

The'next step is to determine the collision loss term, and add it to the gain term to form the sensitivity profiles:

DO 2 G-J1, IGM

FFD $(G)=F F D(G) /(I 1 P H I * D E L U(G))$

AXS (G) $=-(\operatorname{AXS}(0) * C H I(G)) /(\operatorname{IPHI} * \operatorname{DELU}(G))$

SXS (G) $=-($ SXS (G)*CHI (G)) / (IIPHI*DELU(G))

$\operatorname{DST}(G)=-(\operatorname{DST}(G) * C H I(G)) /($ I1PHI*DELU(G))

$\operatorname{SEN}(G)=\operatorname{SXS+VED}(G)$

$\operatorname{SENT}(G)=\operatorname{DST}(G)+F F D(G)$

SABS - SABS+AXS (G) *DELU(G)

SSCAT $=$ SSCAT+SXS (G) *DELU(G)

STOT $=$ STOT+DST (G) *DELTI(G)

SFFD - SFFD+FFD (G) $\star D E L U(G)$

SSEN = SSEN+SSEN (G) $A D E L U(G)$

SSENT - SSENT+SENTIG) *DELU(G)

2 contrinus

where.

IIPHI integrated response, $R$

DELU(G) = the lethargy Interval per group, $\Delta v^{8}$ GHI (G) $=x^{8}$

SEN(G) = sensitivity proflle for scatcering cross sections

SENT(G) sensitivity profile for total cross $\therefore$ sections

SABS = Integral sebistivity for absorption cross sections

sSCAT - Integral sensttivity for scattering cross sections, los's term onl: 
STOr = integral sensitivity for cotal cross sections, $10 \mathrm{ss}$ term only

SFED Integral sensitivity from the gain term only

$$
\rightarrow \text { a }
$$

SSEN = integra sensitivity for net sensitivity proflie with scattering interactions as onily lasses

SSENT - Integral sensitivity for net sensitivity profile with total ecoss-section losses.

Here we create the loss terms due to absorption, scattering, and total eross seetions by dividing by $\left(R \cdot \Delta U^{\delta}\right)$ and after dividing the gain term by $\left(R^{2}\right.$ * $\left.\Delta U^{B}\right)$ we add them to get $P^{B}{ }^{*}$ We also sum over a11 groups 8 to obtain an integrated sensitivity. $S$. Note that the role of $J 1$ and IGLI is the same as In Sec, II A; above.

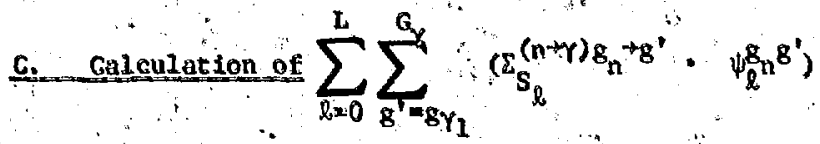

and Sensttivity profiles for the (n+p) Production Cross Sections

The calculational procedure for the gain term and sensitivity profile for the gamma-ray'production cross seetions is the same as in Sec: II.B, above. Lowever, the Ifmits of sutwition are different and must be chosen carefully. Thls is illugtrated in the following algorithm.

IF(J1.NE.1) 60 TO 800 NG1 = NCOUPL+1

$\therefore$ DO 802 G=J1, 1 GM1. FFDNG(G) $=0.0$
DO $802 \mathrm{~L}-1, \mathrm{LL}$

DO 802 GP $=\mathrm{NG1}, 1 \mathrm{GM}$

8Q2 FFDNG(G) $=$ FFDNG $(G)+D S L F D(G, G P, L) * P S I(G, G P, L)$

SFFDNG $=0.0$

DO 804 G-J1, IGM

FFDNG $(G)=\operatorname{FENG}(G) /($ IIFHI $*$ DELU $(G))$

804 SFFDNG - SFFDNG+FFNG(G)*DELU(G)

$\$ 00$ CCNTINUE

where:

FFDNG(G) - gatn term for $(n+p)$ prodtict in, $\therefore$

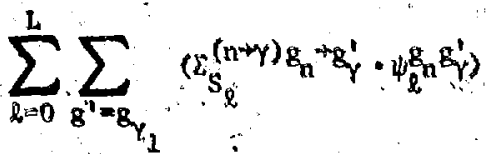

$$
\begin{aligned}
& \text { SFFDNC = integrated sensitivity for }(n+\gamma)
\end{aligned}
$$

The procedure is self-explanatory. Note that the computation "is nade only when $J 1$ is equal to 1 (1.e., during the neutron interaction calsulations). Also observe the Initial energy groups, $G$, in the scattering process are only the neutron groups (1 to NCOUPL) and the final energy groups, $G P$, are the gamma-ray groups (NCOUPL+1 to IGM). The result of this algorithm is thit.the cross-section aensitivity due to the $(n+y)$ production eross sections is obtalned for each neutron group.

\section{APPENDIX B \\ PARTIAL CROSS-SECTION SENSITIVITY PROEILES}

This appendix was included in order tô provide" the reader with plots of the various dross section sensitivity profiles that were obtained by sENSIT-1D. The reader will be able to understand which partial cross-section sensitivity is being plotted by lookIng at the top right-hand side of the graph This
- vomencluture of the various partial cross sections can bo understood by reviewing Appendix A. The plots are the partial eross sections for th major contributors to the various detector responses and are 11 sted as the contributor appeared in the papèr. 


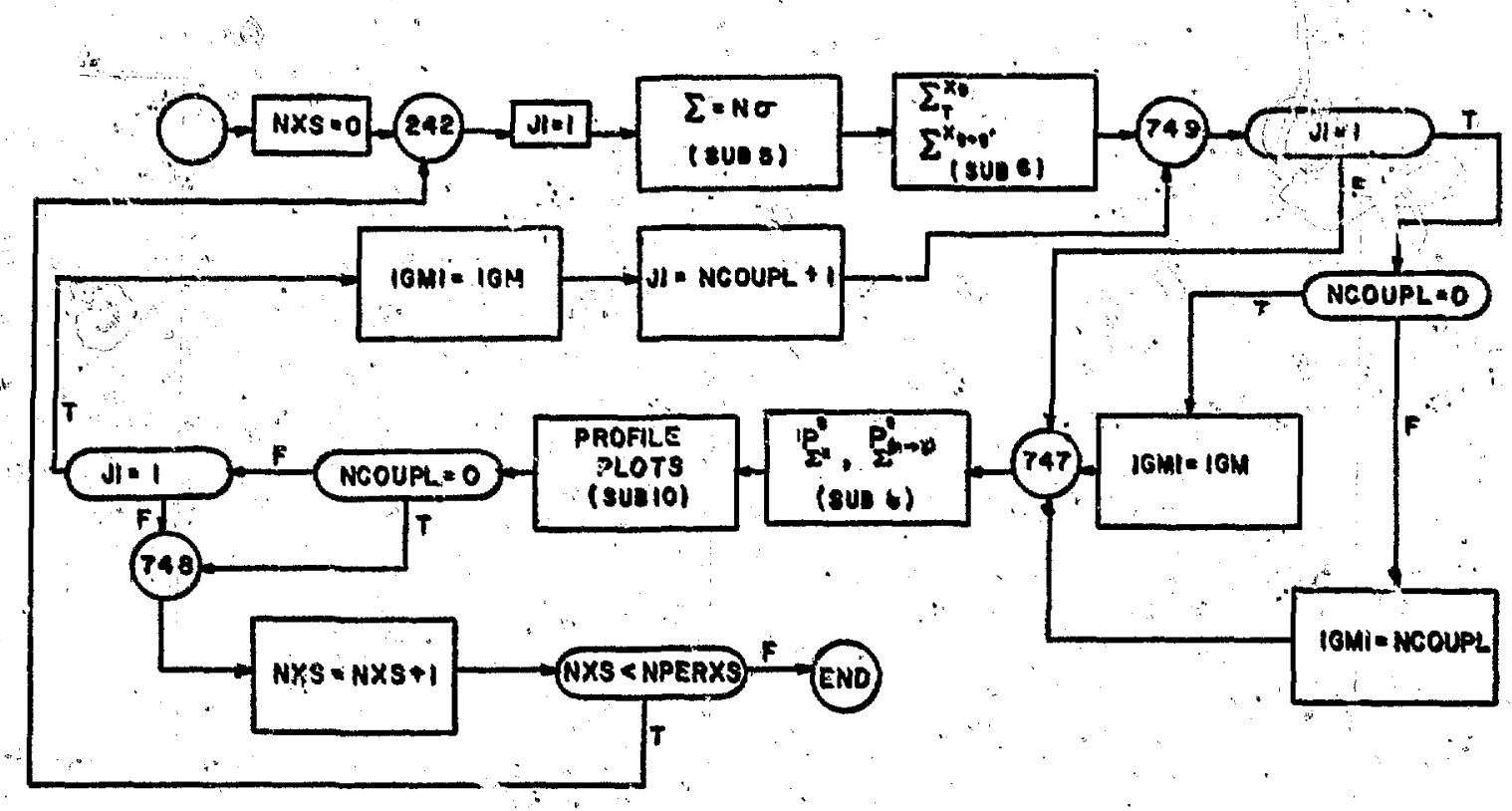

Fig. A-I. Simplifled flow diagram of SENSIT-1D calculations of aensitivity proftles using counled crosssection sets.

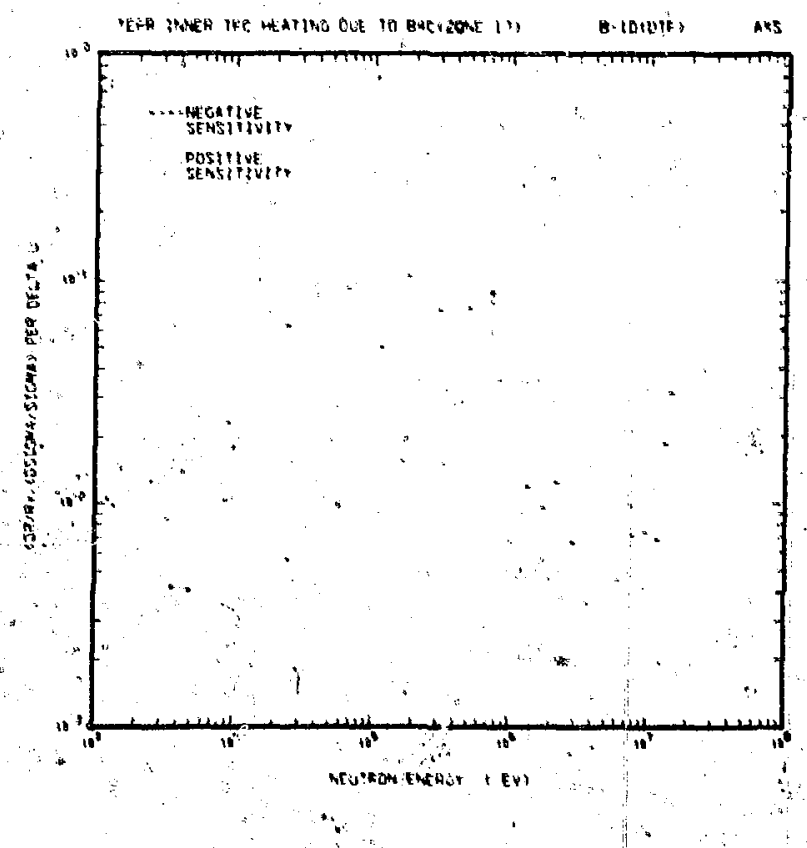

Fig, B-I. Sensitivity of Inner TFC Heating to $10_{B}$ in zone 17. Neutron absorption cross section, fure loss term.

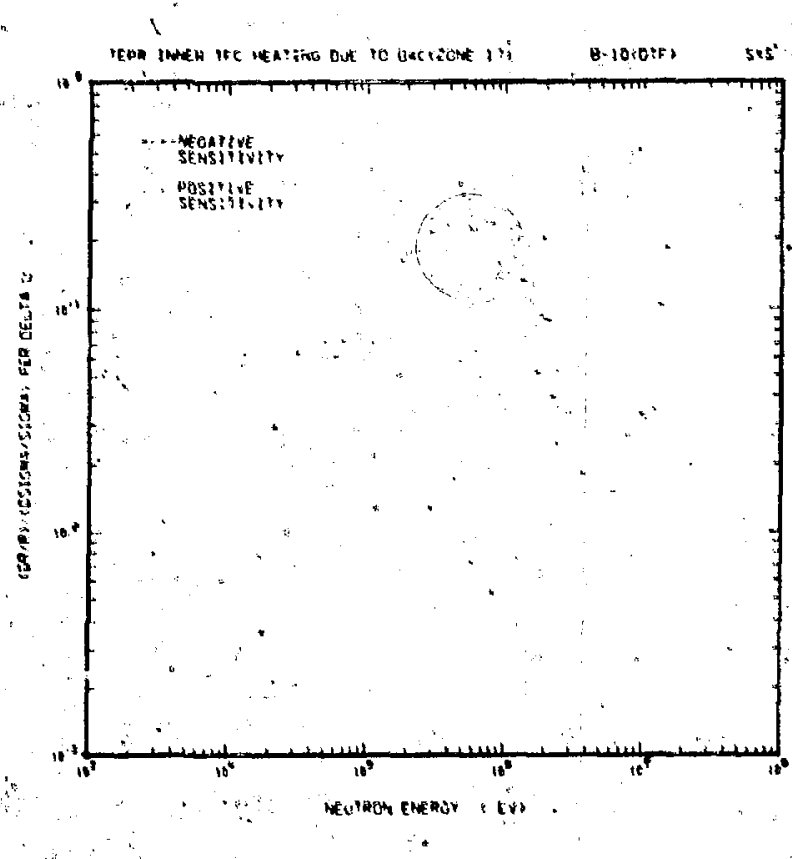

Fig. B-II. Sensitivity of fnner TFC heating to $10_{B}$ In zone 17. Neutrón scattering eross section, loss term only. 


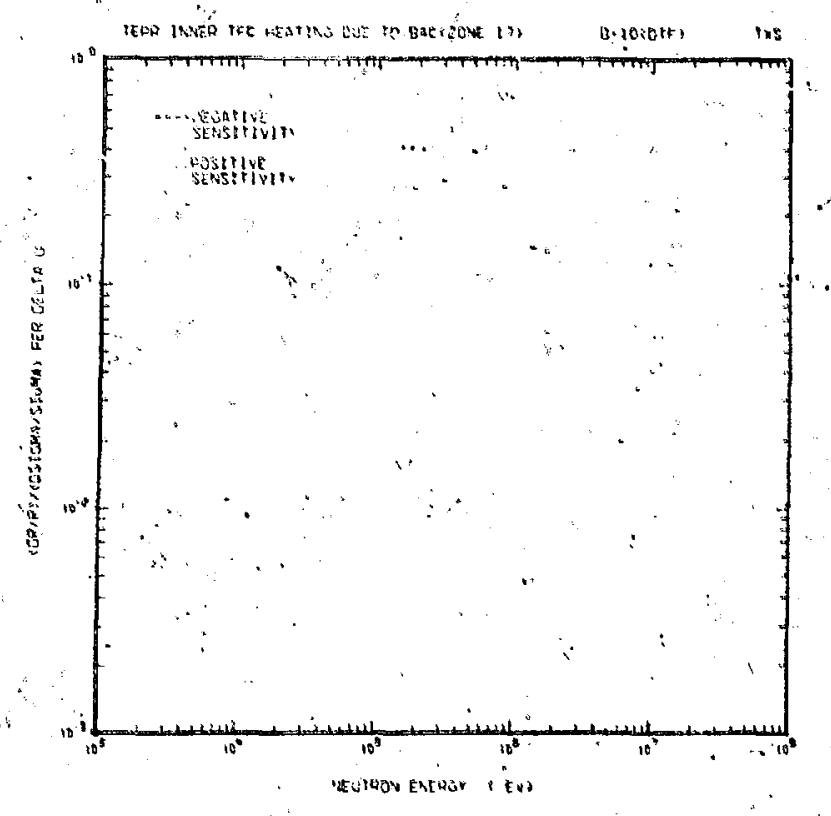

FIg. B-LIL.: Sensitivity of inner TFC heating to $10_{B}$ in zone 17. Neutron total eross section, pure loss term.

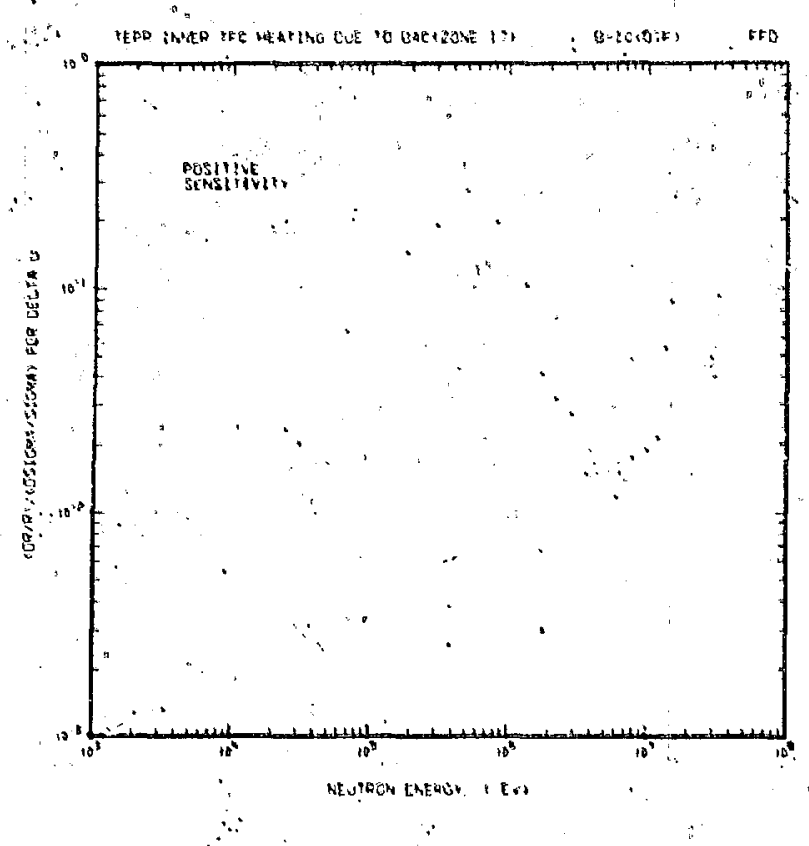

Fig. B-IV, Sensitivity of Inner PFC heating to $10_{B}$ Neutron gain terin only.

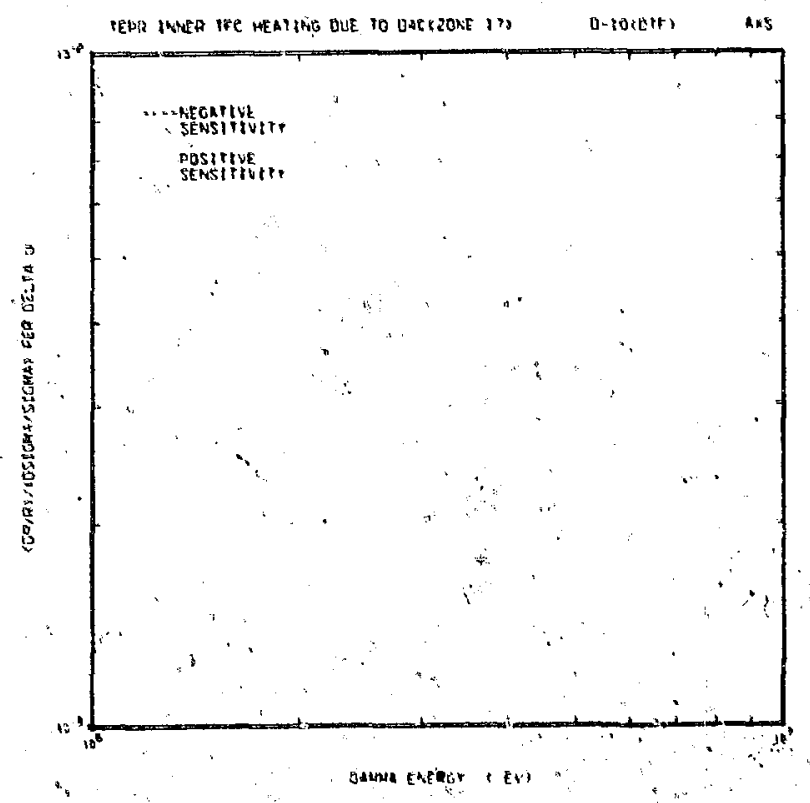

Fis. B-V. Sensitivity of ineer TFC heatsing to $10_{B}$ in zone 17. Gamma absorption cross section, pire loss terni:

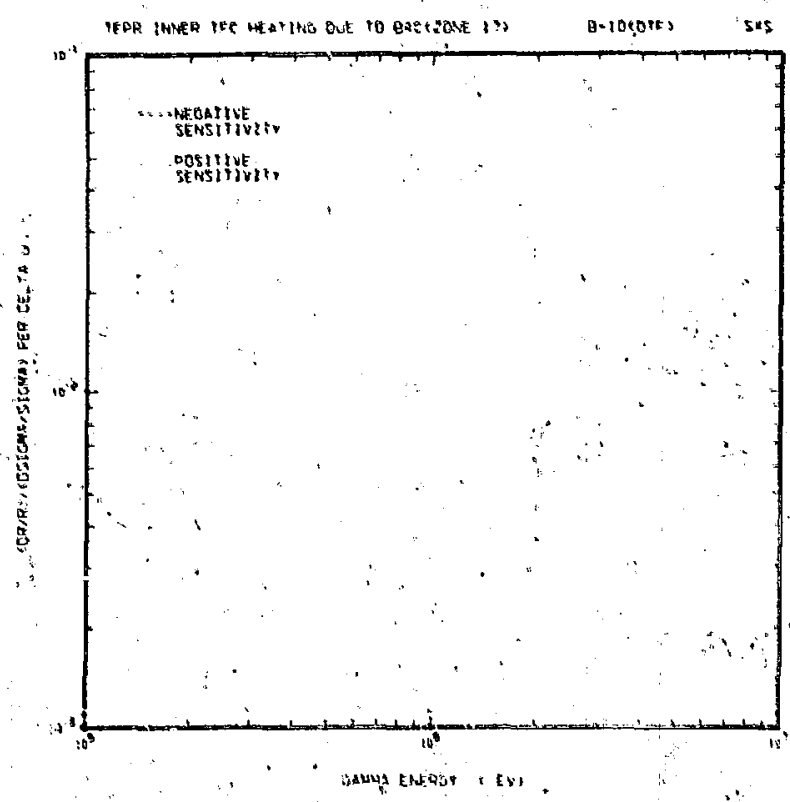

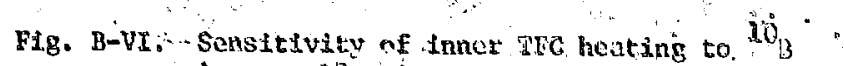
In zone 17. Gama seattering eross sections, lose teit on $1 \mathrm{y}$. 


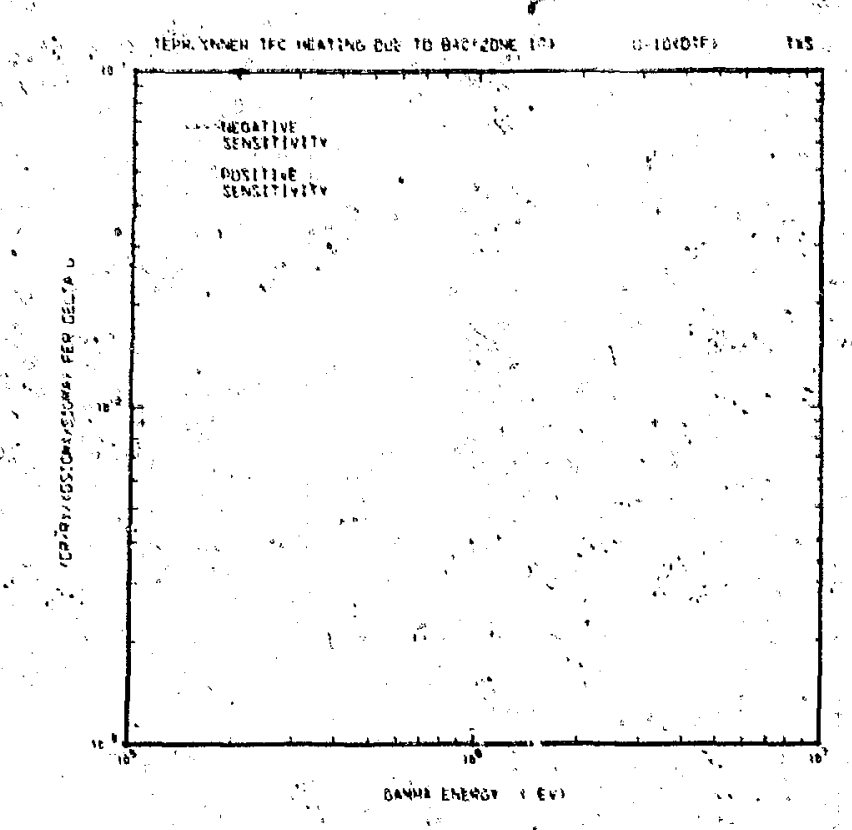

Fig. B-VII. Sensitivity of inner TFC heating to $10_{1}$ In zonè 17. Gama total cross section; pure 10 so cerm.

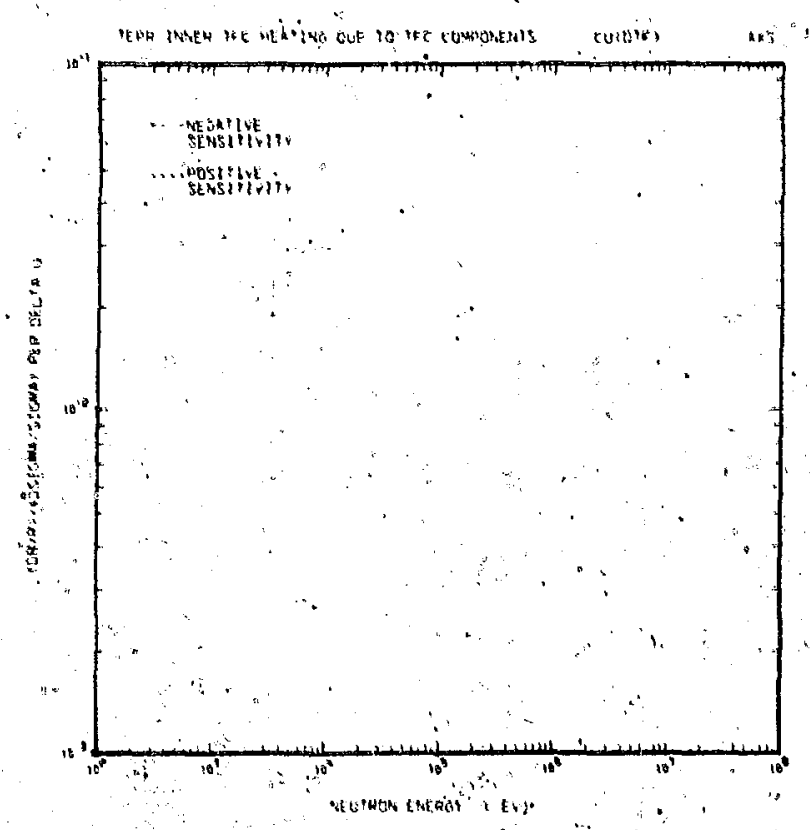

Fig. B-IX. "Sensitivity of Inner TFC heating to cu in TFC. Neutron absorption cross section, pure loss teril.

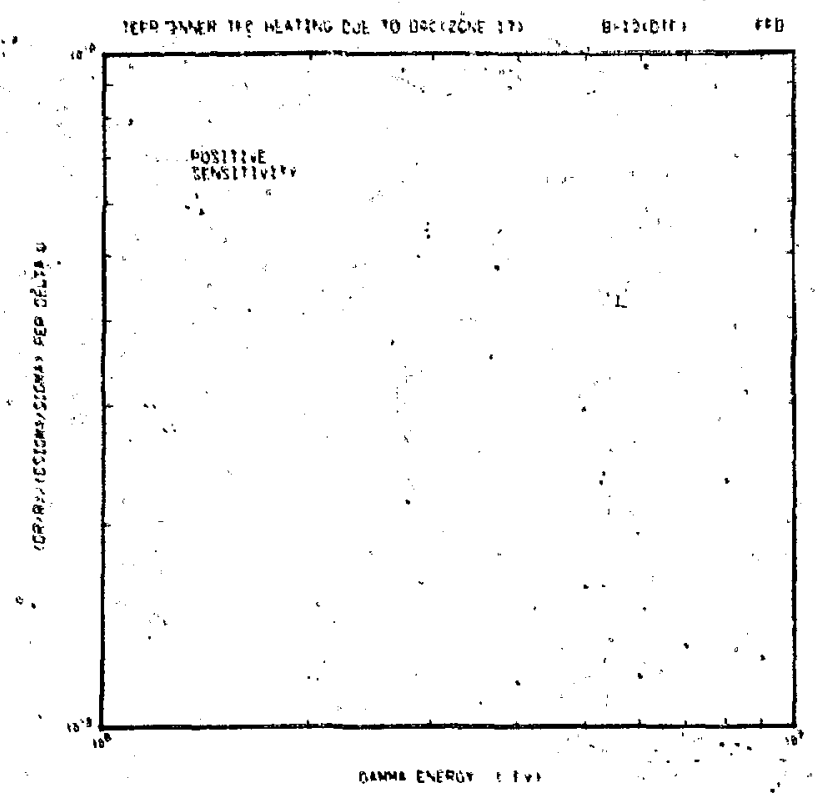

Fig. B-VIII. Sensitivity of inner TFC heatifg to $10_{B}$ In zone 17. Gamma gain term only.

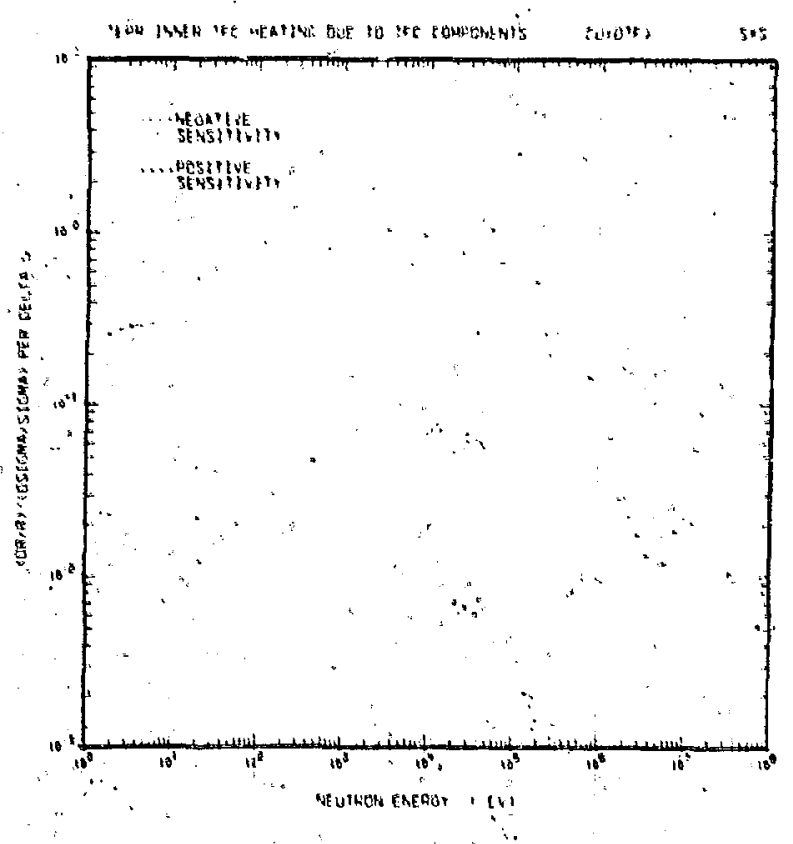

Fig. B-X. Sensitivity of inner TFC heating to su In TFG. Neutron scattexing eross section, 108 s term only. 


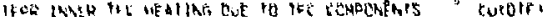

trts

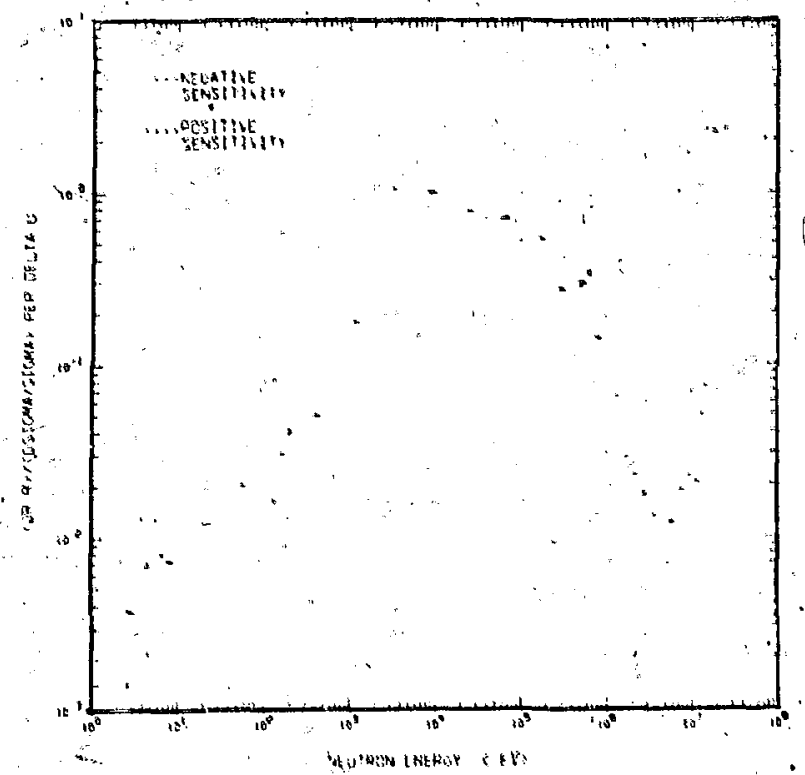

FIg. B-XI. Sensitivity of inner TFC heating to Cu In. TFC. Neutron tatal cross seectots, pure 109 term.

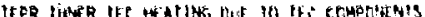

Listert

$t i$

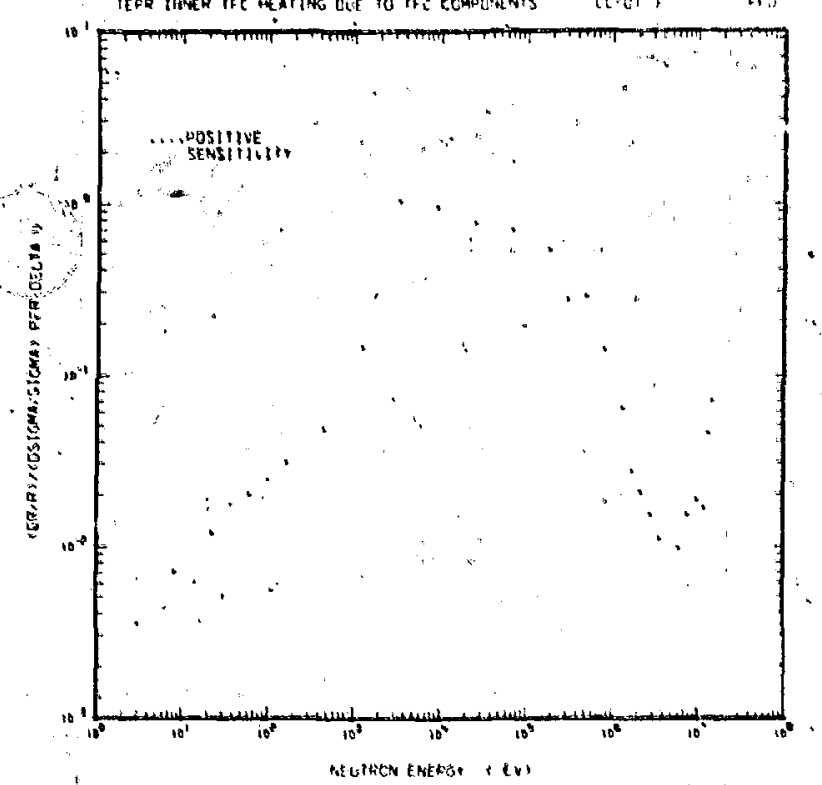

Fig. B-XII. Sensitivity of inner FFC heating to Cu In TFC. Neutron gain term, only.

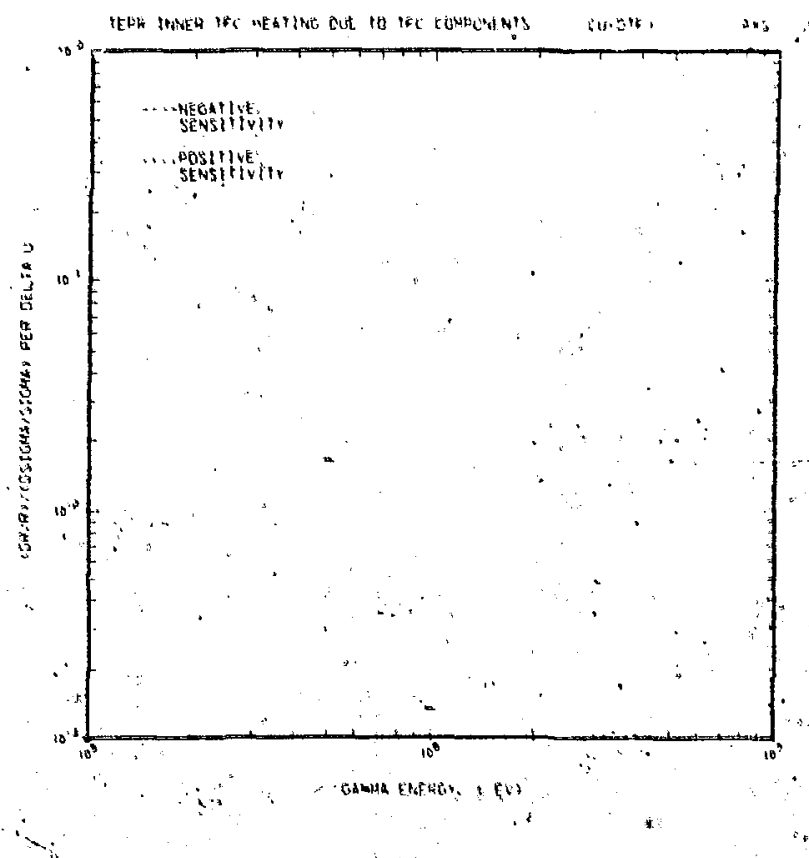

Fig. B-XIXI. Sensitivity of Innex TFC heating to $\mathrm{cu}$ in TFC. Gamma abcorption cross section, pure loss term.

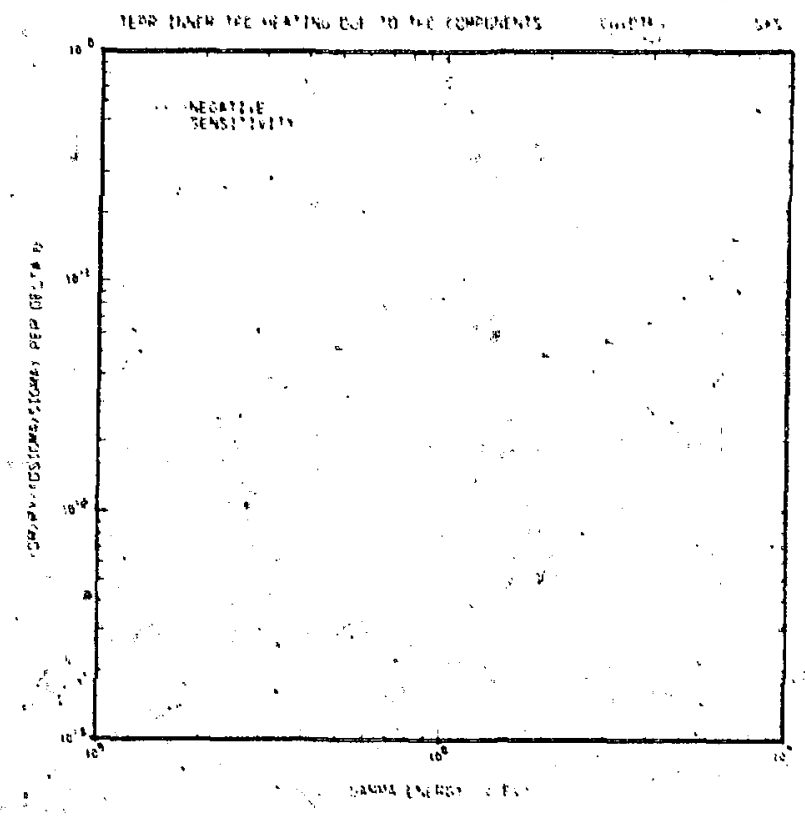

Fig. B-XIV. "sensitivity of Inner TFG hearing to is in TFC. Binma, seattering cross section, loss term oniy. 


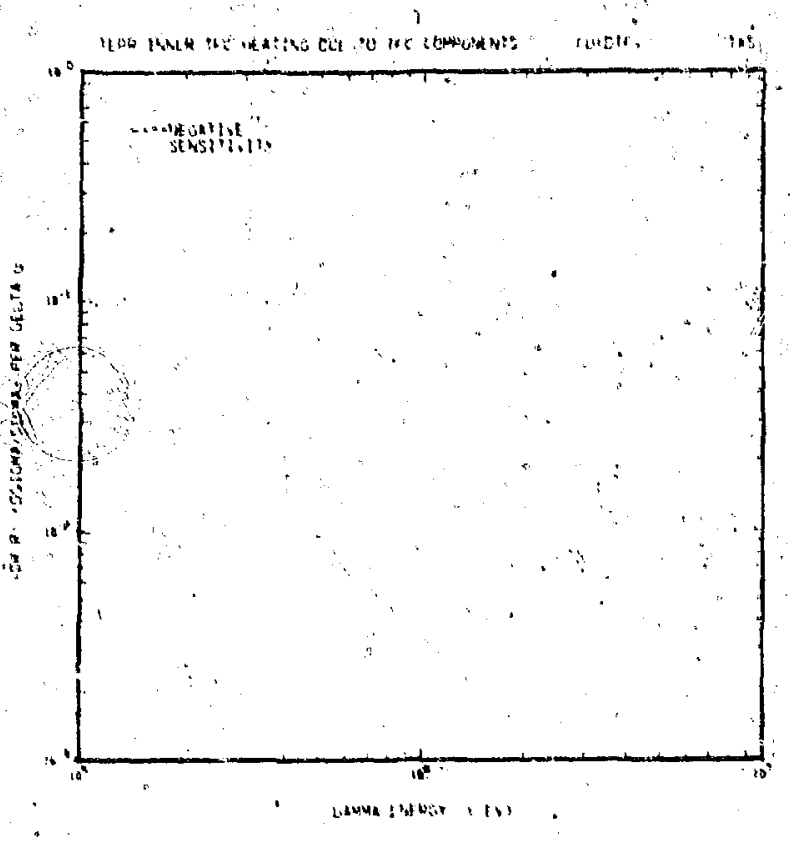

Fig. B-XV. Sensitivity of Inner TFC hearing to. Cu In TFG. Gamma total cross section. pure loss term.

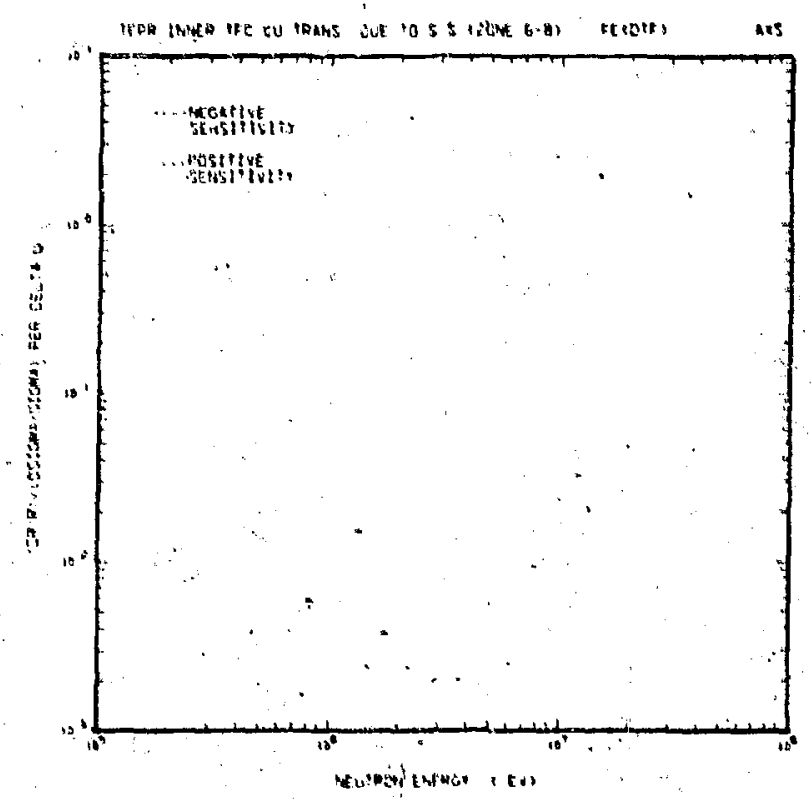

EIg. B-XVII. Senstttvity of Inner TFC Gu transmuration to $\mathrm{Fe}$ in zones $6=8$. Neutron absorption cross section, pure loss term.

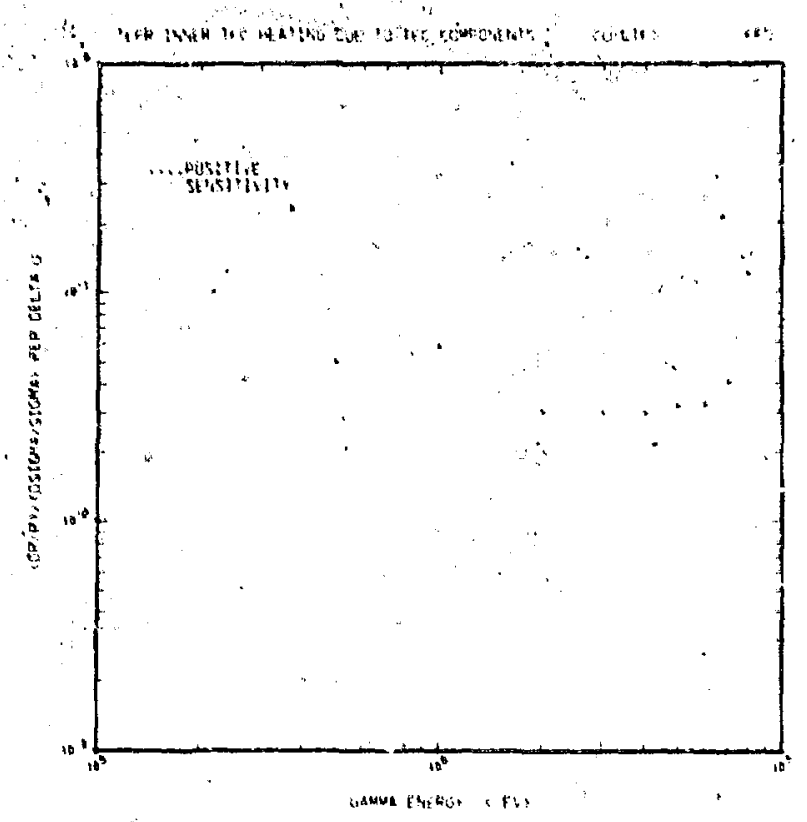

Fi.g. B-XVI. Sensitivity of inner TFC henting to Cu in TFC. Gainna saiti term only.

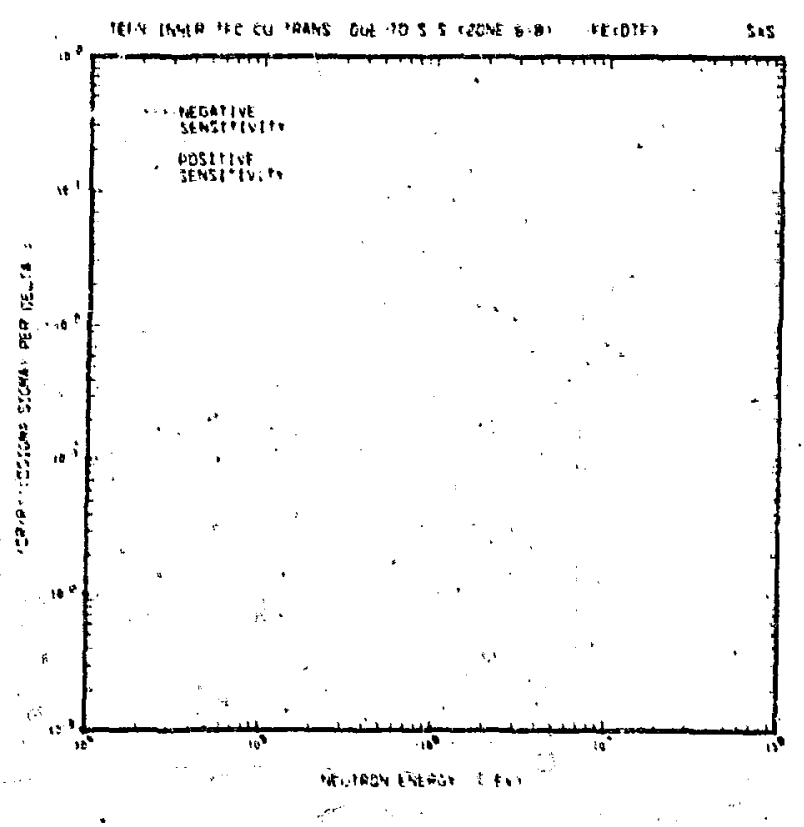

Fis. B-xVIIr, Sessitivity of Enner THC Gu tranciutation to Fe in zones 6-8. Neutron scattering cross section, loss term only. 


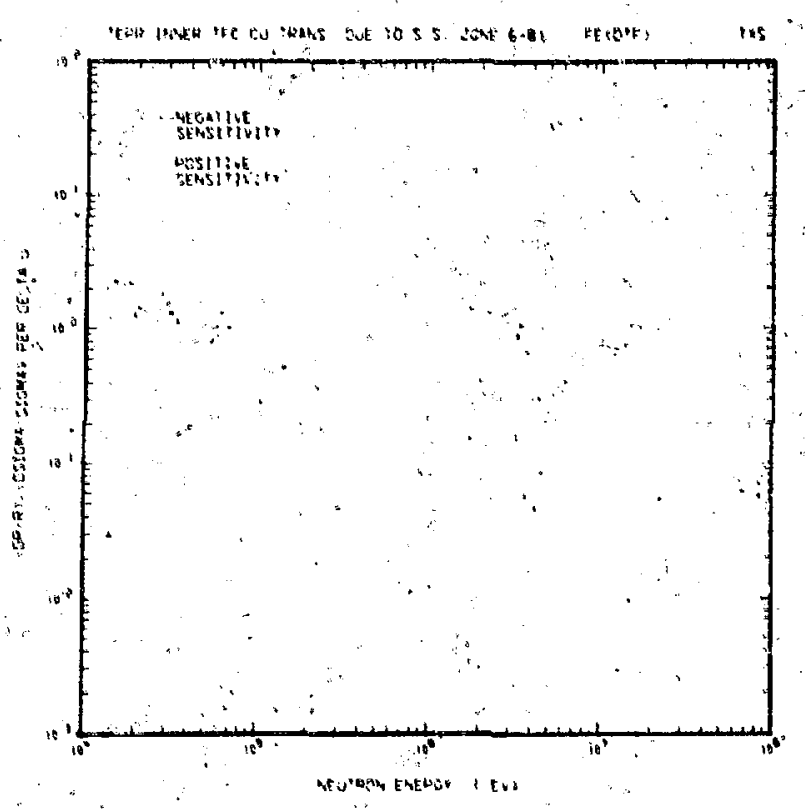

FIg. B-XIX. Sensitivity of inner TFC Cu transmutation to Fe in zemes 6-8. Neutron tocul cross section, pure loss terin.

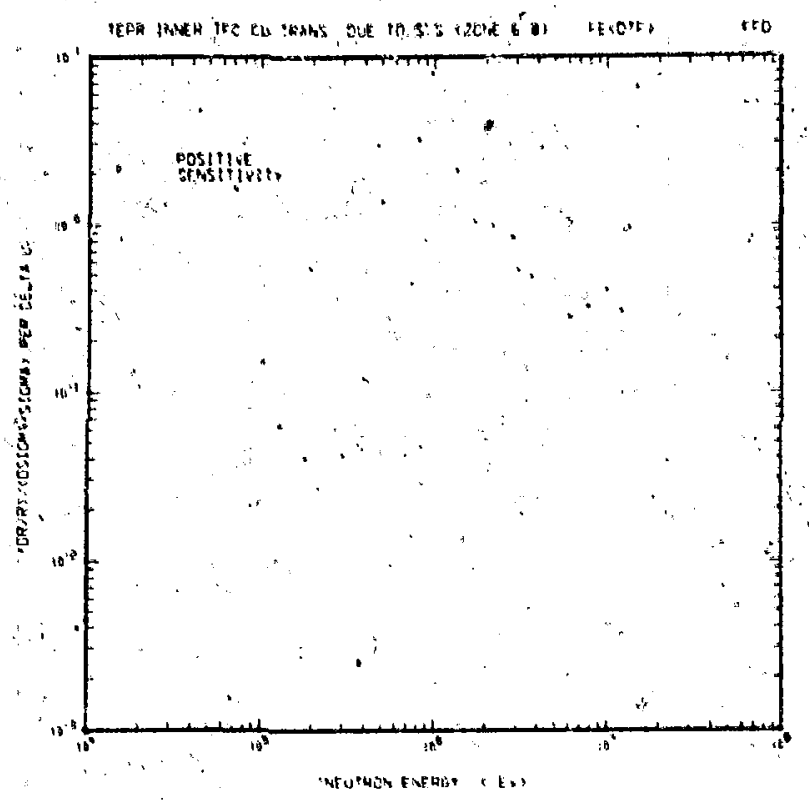

Fig. 8-XX. Sensitivity ö Inner. TFC Gu transirutatinn to Fe in zones 608: Neutron gatn term on.1y.

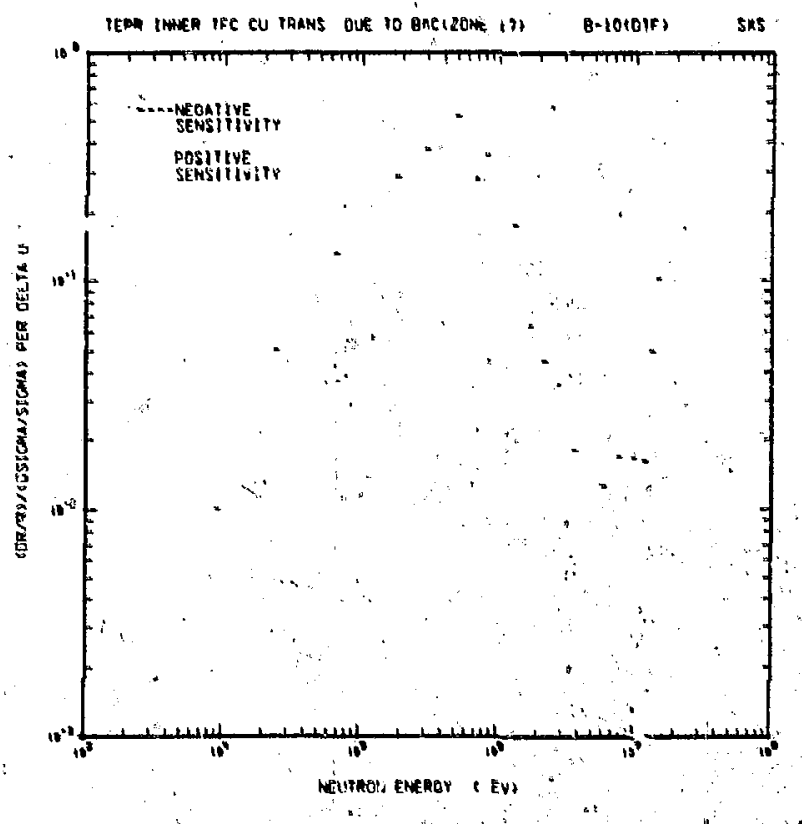

Fig. B-XXI. Sensitivity of Inner TFC Ca eransmutation to $10_{B}$ in zone 17 Neutron total cross section, pure loss term.

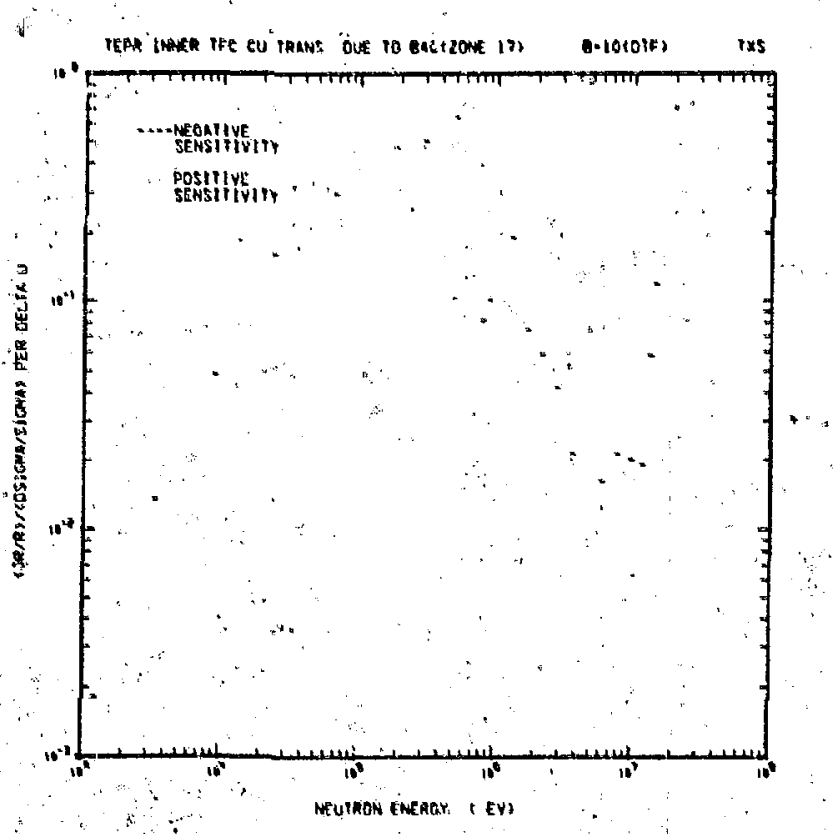

F1g. F-XXII. Senstetvity of Inner TFC Gu tronstnutation to $10_{\mathrm{B}}$ in zone 17 . Neutron total cross section, pure loss term. 


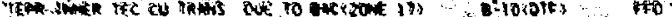

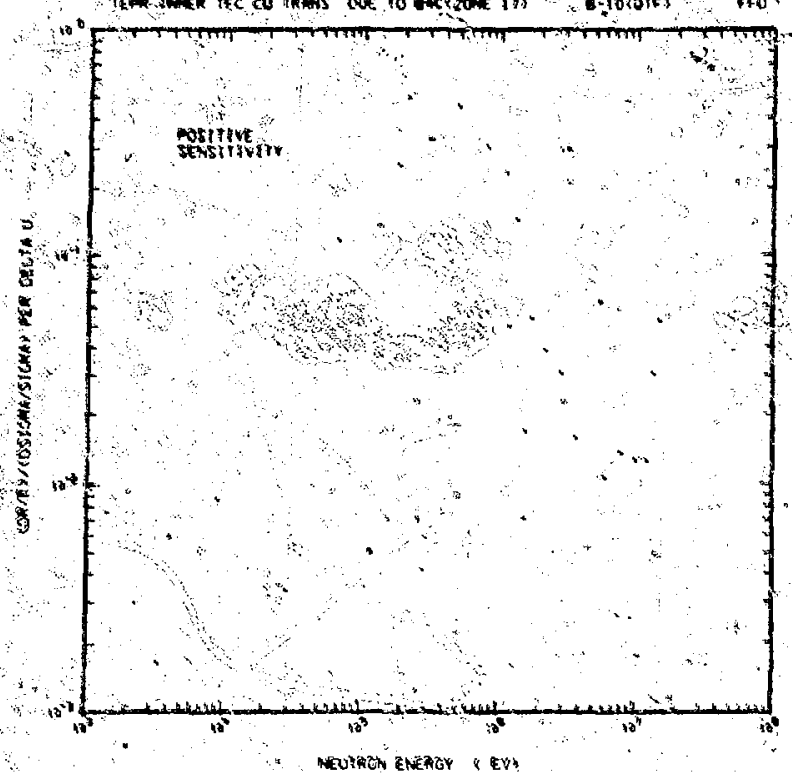

Nig. B-XXIXI. Sensitivity of triner tFC ou transmutation to $10 \mathrm{H}$ in wone 17 . Neutran gain terin enly.

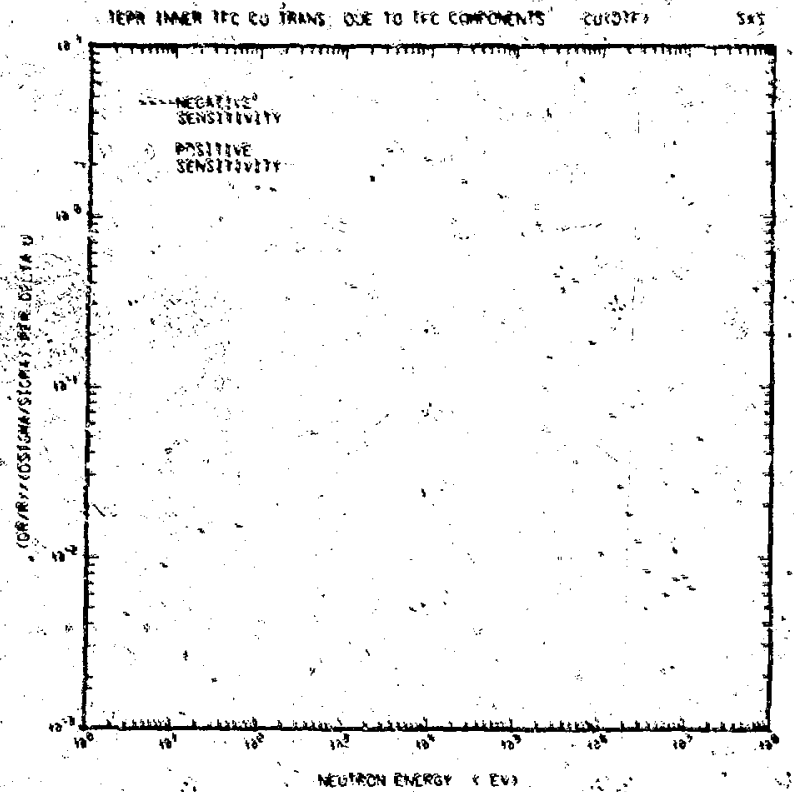

Fig. B-XXIV. Sensitivity of inner TFC Gu transmutation to Gu in TFG. Neutron seatcering eross section, loss tekm only:

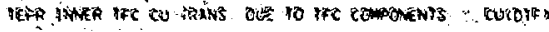

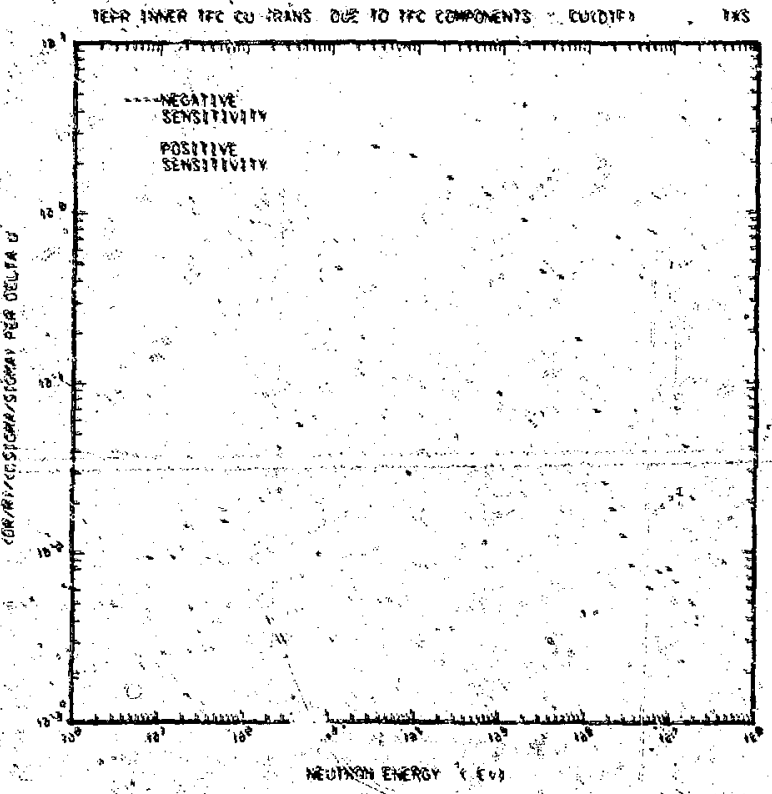

Fig. B-Xxv. Sensieiviey of Imer Tre Gu transnutaHon to ou do TFo. Neutron tetal eross sectlon, pure loss torat

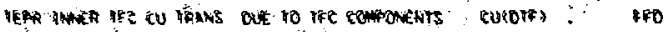

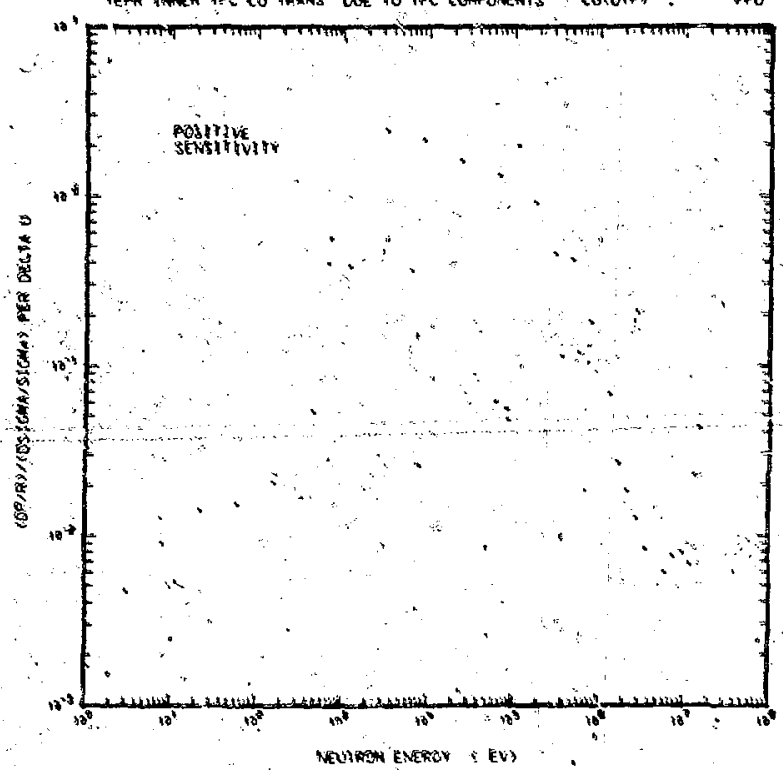

Fig. 3-XXVI. Sensitivity of Inner TFC Cu exansmitation to ou In TFG. Neutron gain ters only. 


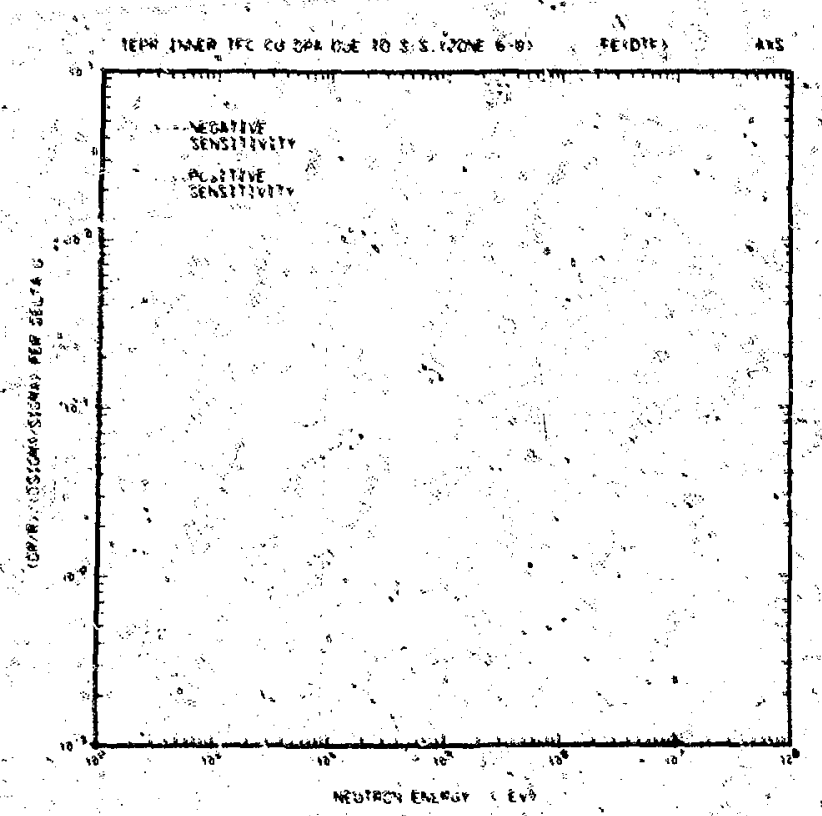

Fig. B-XXVIX. Sensitivity of Inner TFC Cu dpa to Fe in zones 6-8. Neutrou absorption cross secilon, pure loss term.

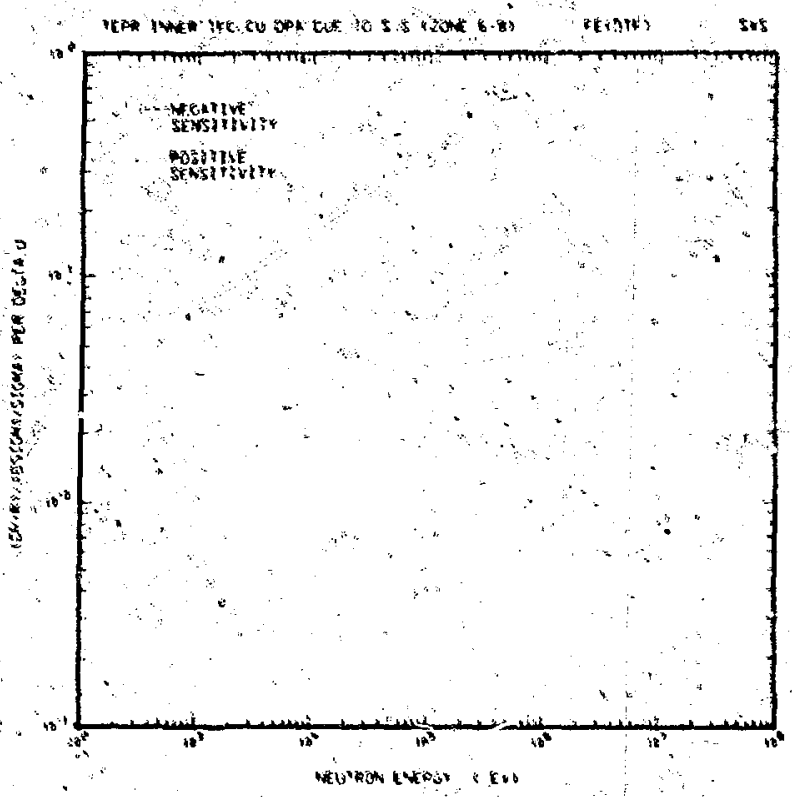

EIg. B-XXVIII. Sensitluicy of inner TrC Ou dpa to Ye in zones $6-8$. Neutrons scattering eross seetion, loss term only.

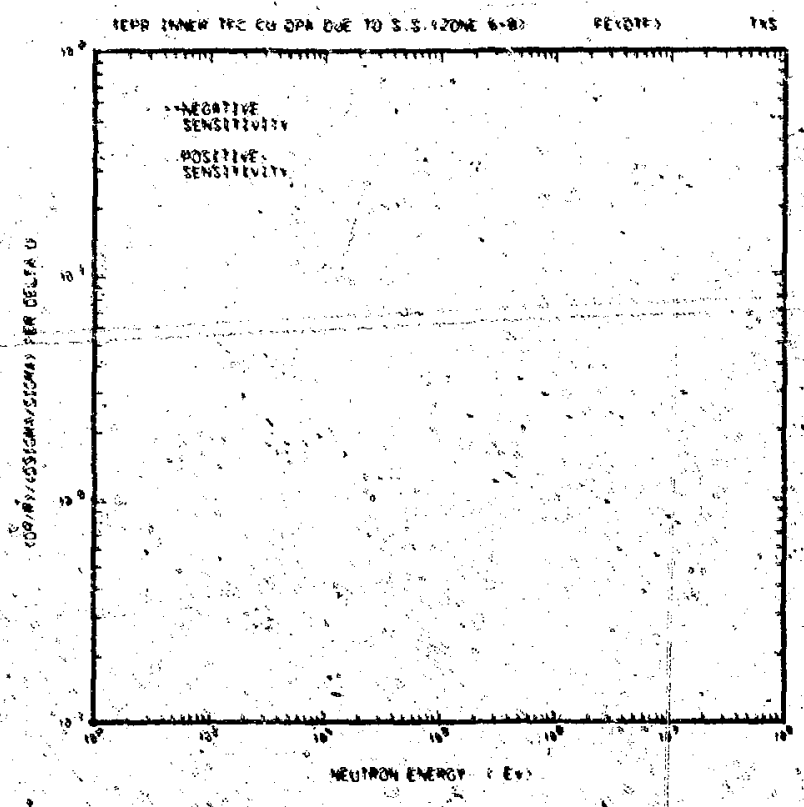

F18. B-XXIX. Sensitivity of Inner TFC Cu dpa to Fe In zones $6-8$. Neutxon total cross section, pure losa, term.

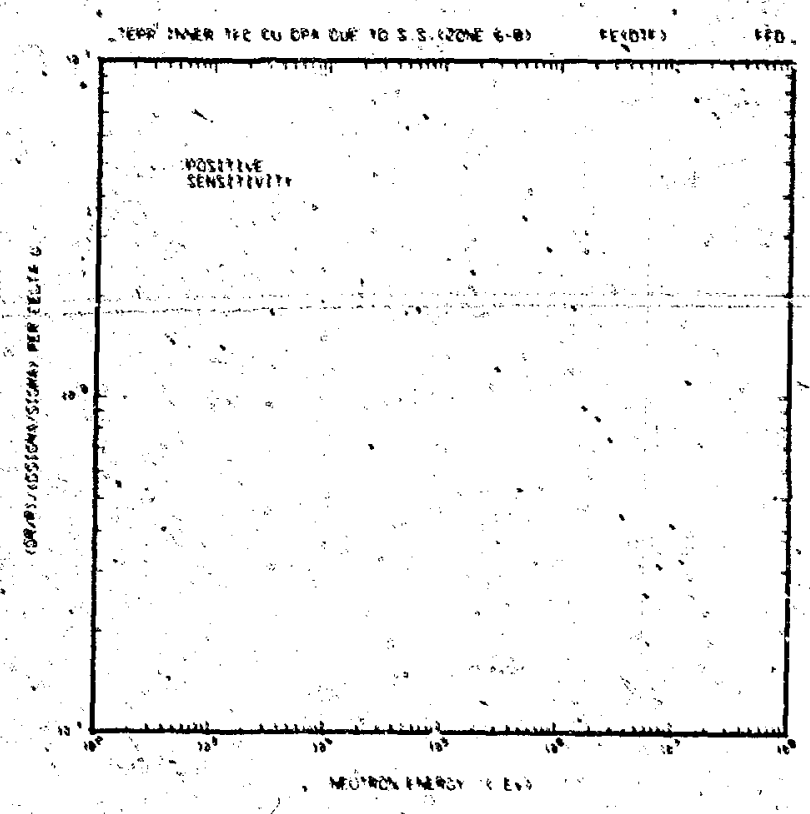

FB. B-xtx. Sunsitivity of Inner TFG Cu dpa to $\mathrm{Fe}$ in zones 6-8. Neutron gatin cow only. 


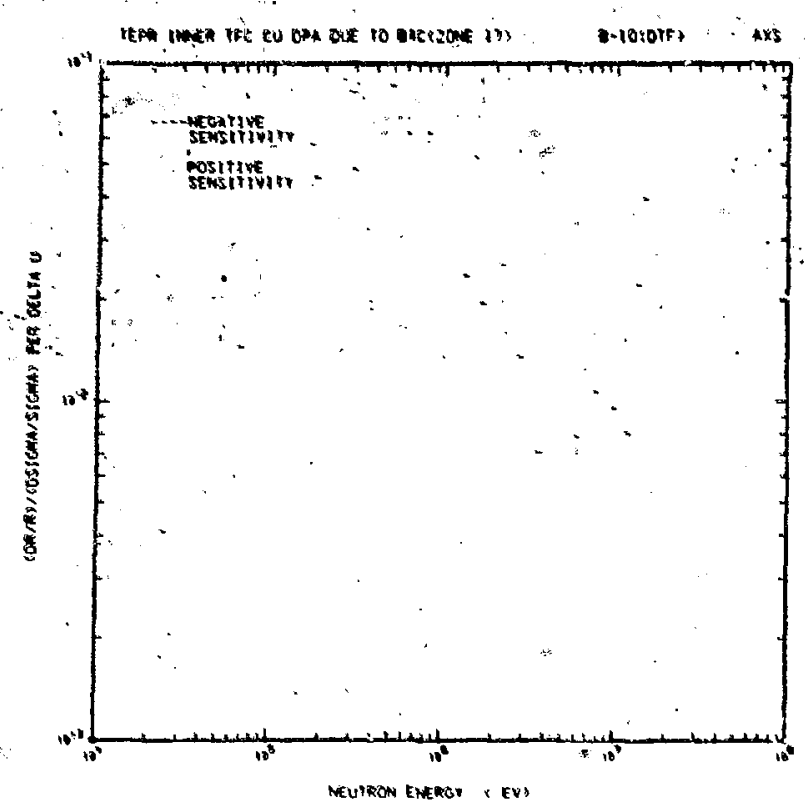

Fig. B- XXXI. Sensitivity of inner TFC Cu dpi to ${ }^{10} \mathrm{~B}$ in zone 17. Neutron absorption cross section, pure loss term.

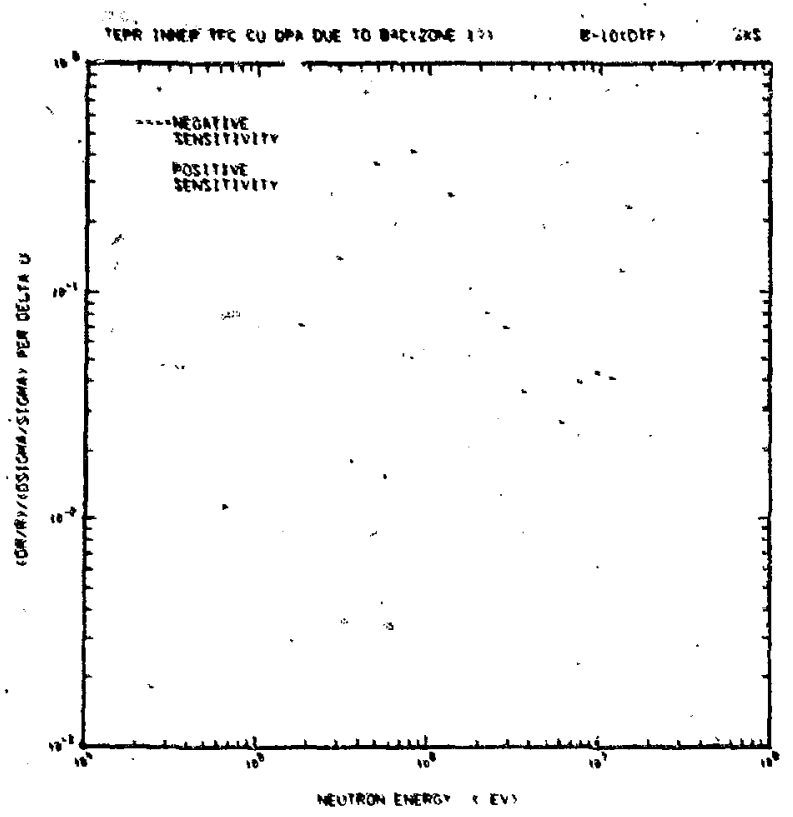

Fig. B-XXXIT. Sensitivity of index TFC Cu dea to ${ }^{10}$ in zone 1\%. Neutron scattering cross section, loss tech only.

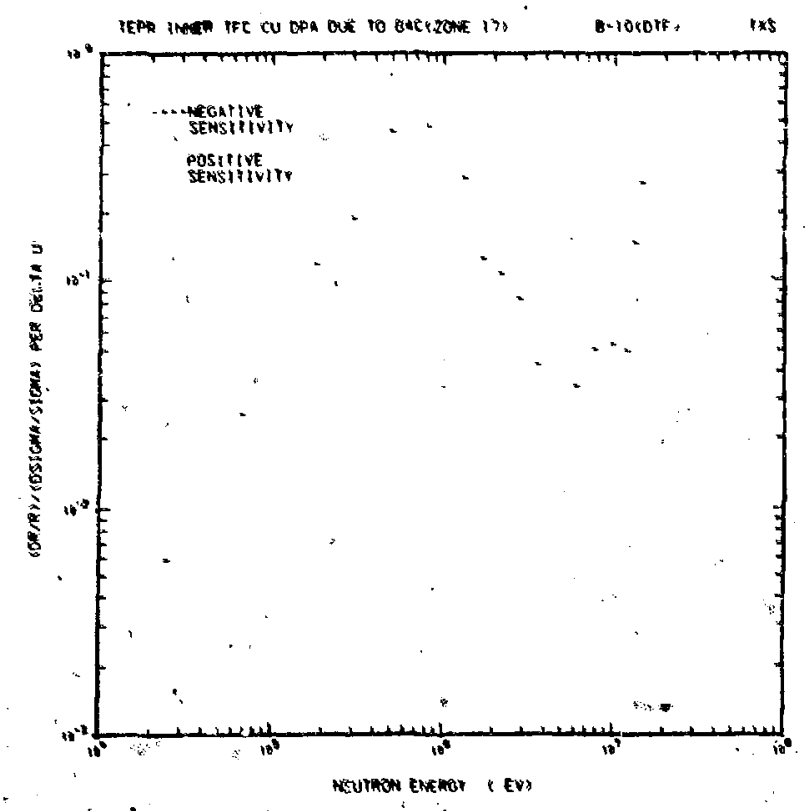

F18. B-XxxIII. Sensitivity of inner TEC Cu dp to $10_{B}$ in zone 17. Neutron t total cross section, pứre loss term.

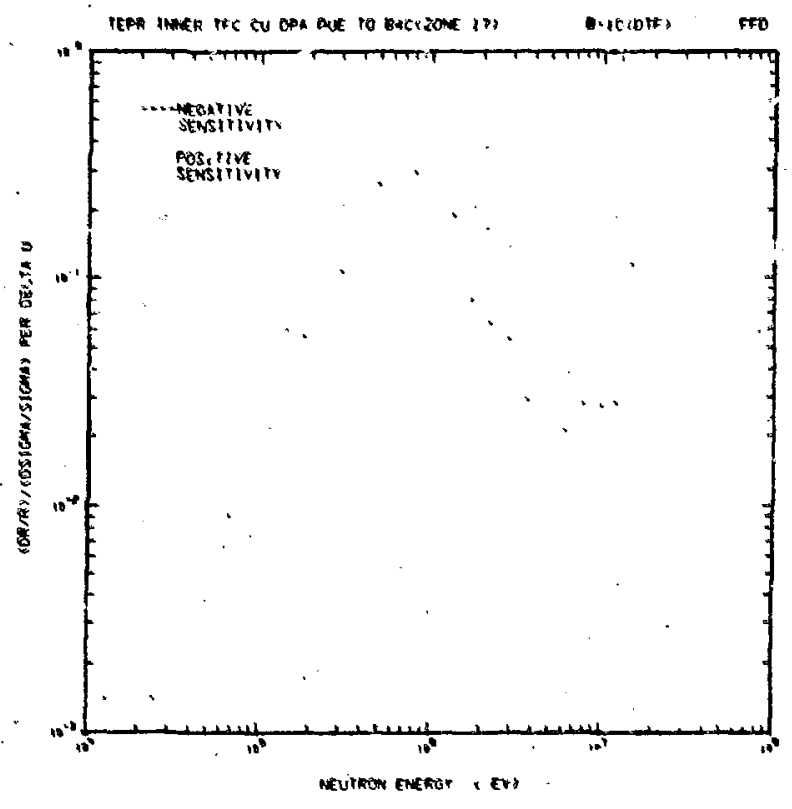

Fig. B-xxiry, Sensitivity of Inner TFC Cu epa to $10_{k}$ in zone $1 \%$. Neutron gain term only.

68 


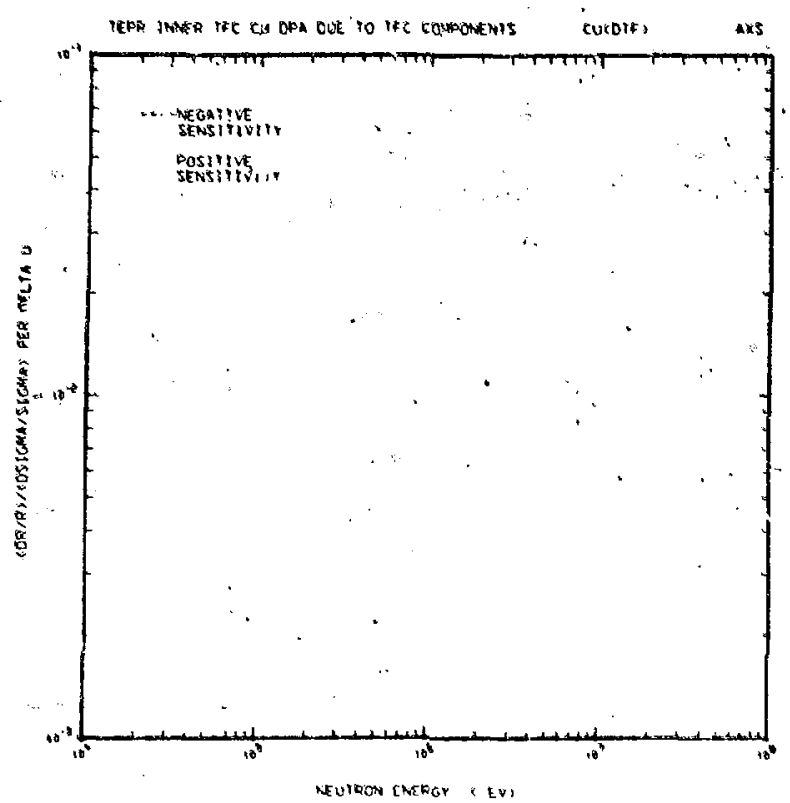

Fig. B-XXXV. Sensteivity of inner TFC Gu dpa to Cu in TFG. . Neutron absorption cross section, pure loss term:

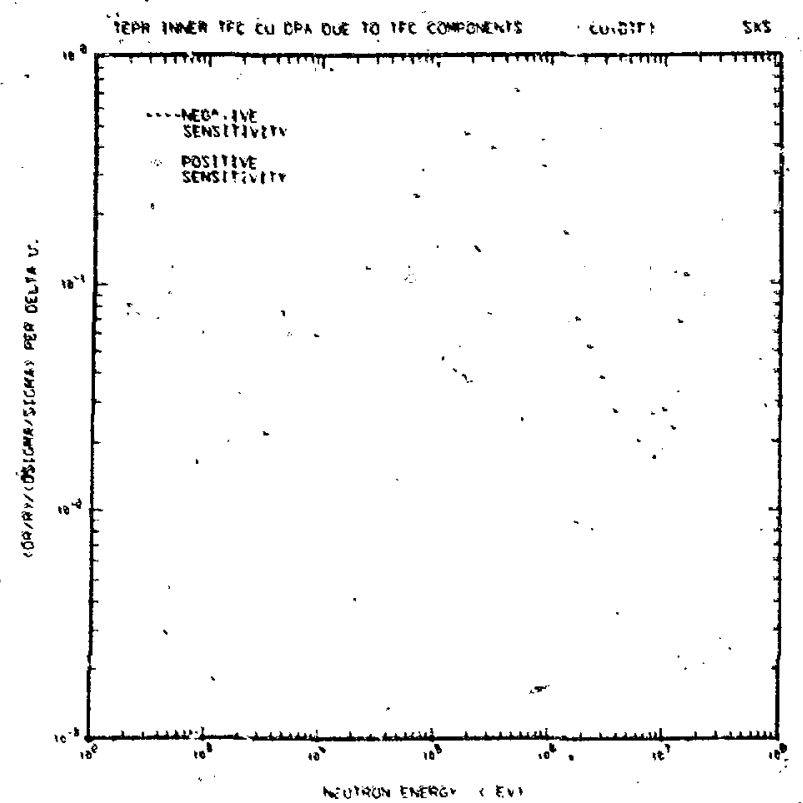

Fig. B-XXXVI. Senilivity of inner TFC Cu dpa to $\mathrm{Cu}$ in TFC. Neutron scattering cross section, loss term ondy.

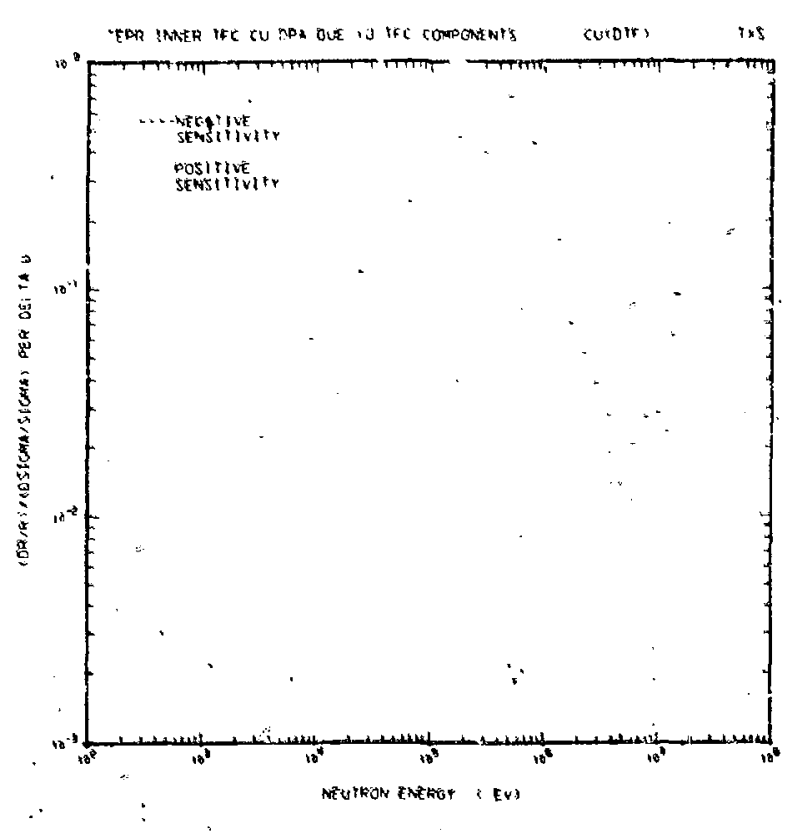

F18. 8-XXXVII. Sensitivity of inner TRC Cu dpa to Cu in TFG. Neutron tocal cross section, pure luss cerm.

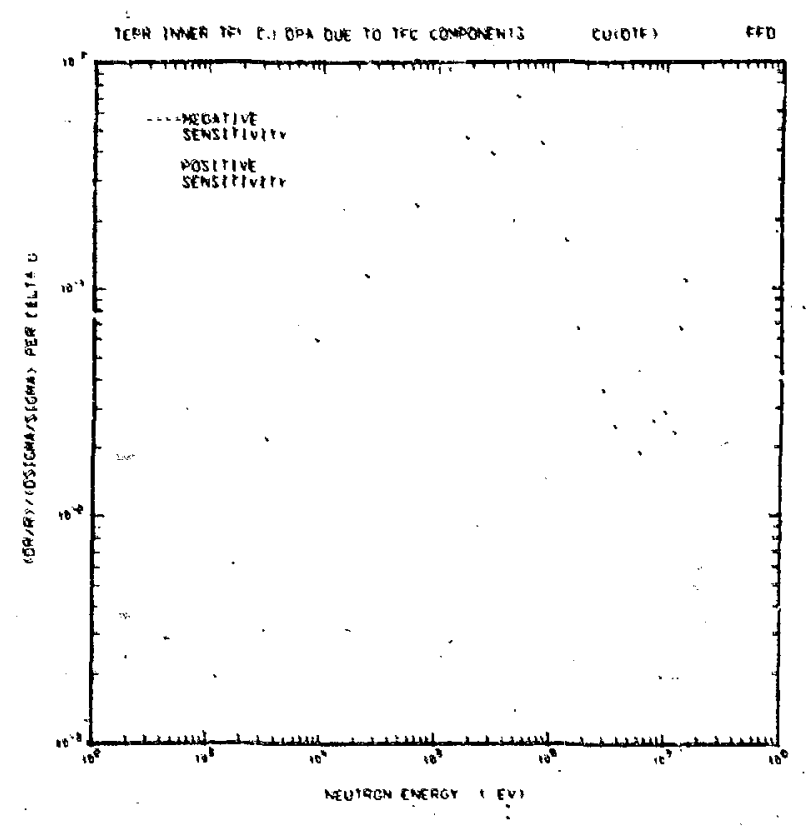

Fig. B-xxxuIII. Sonsitivity of Inner TFC Cu dpa to Cu in TFC. Neutron sain term only. 


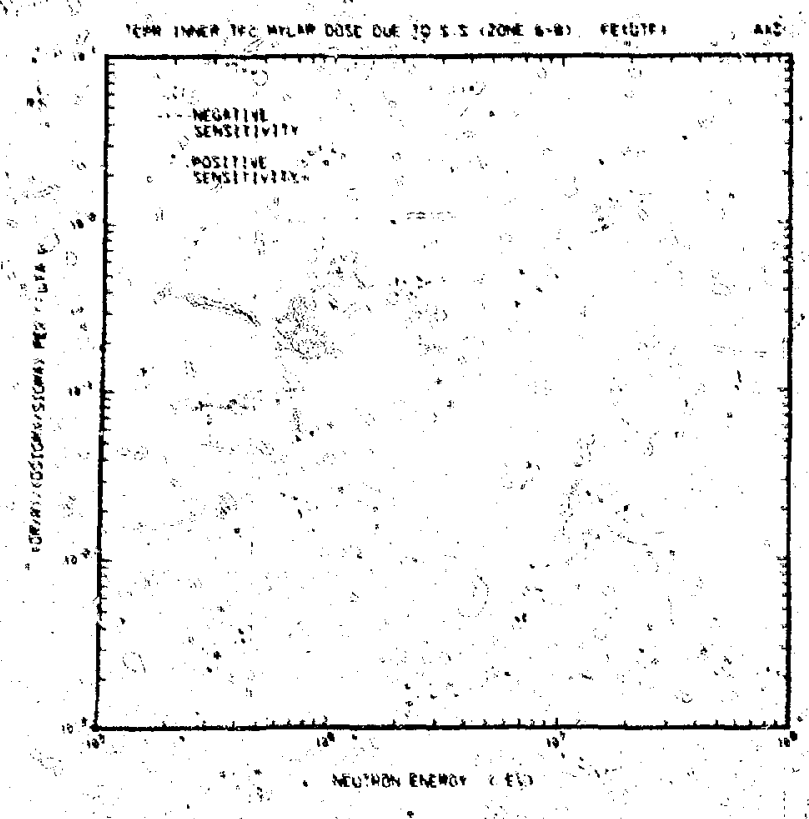

Fig. B-xxxIX. Sensittuity analysis of Inner TFC Aylar dose to Fe in zones 6-8. Neutron absorption eross section, pure lass term.

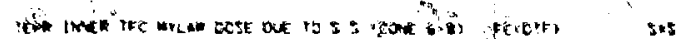

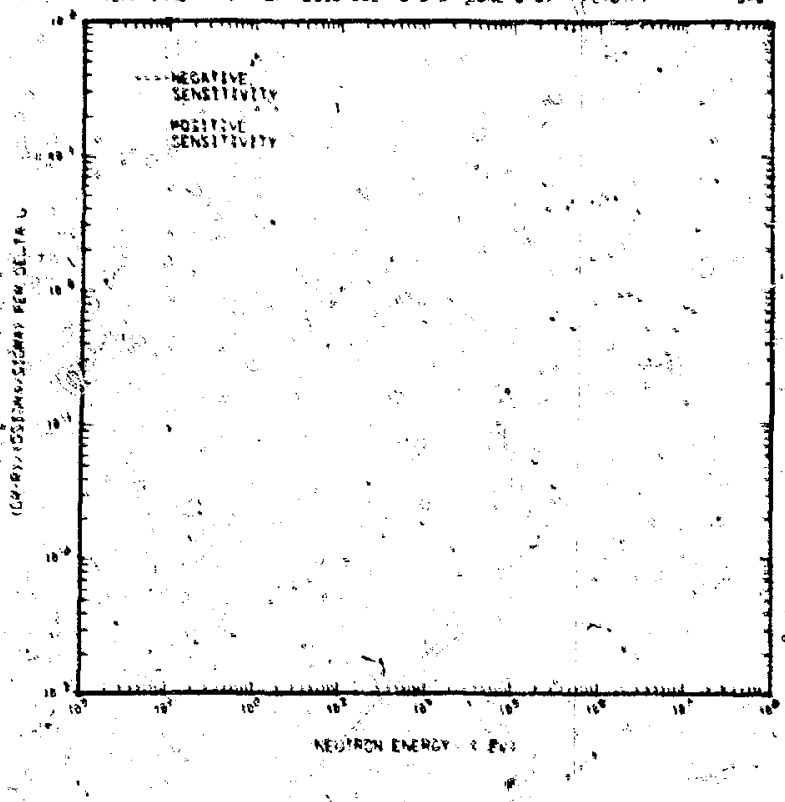

FIB. B-XL. Sengttivity of Inner TFG Mylar dose to Fe in zones 6-8. Neutron 'scattering cross sections, loss term only.

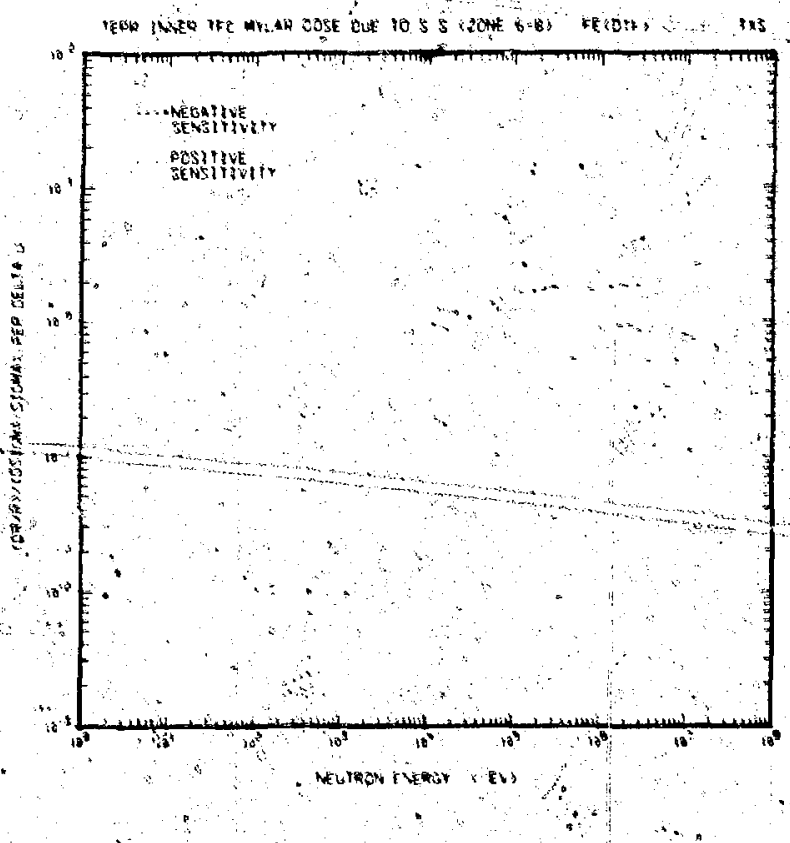

FIg. B-XLI. Sensitivity of Inner TFC Mylar heating to Fe in zones 6-8. Neutron total cross section, pure loss tarm.

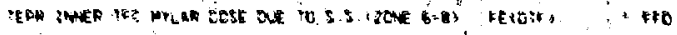

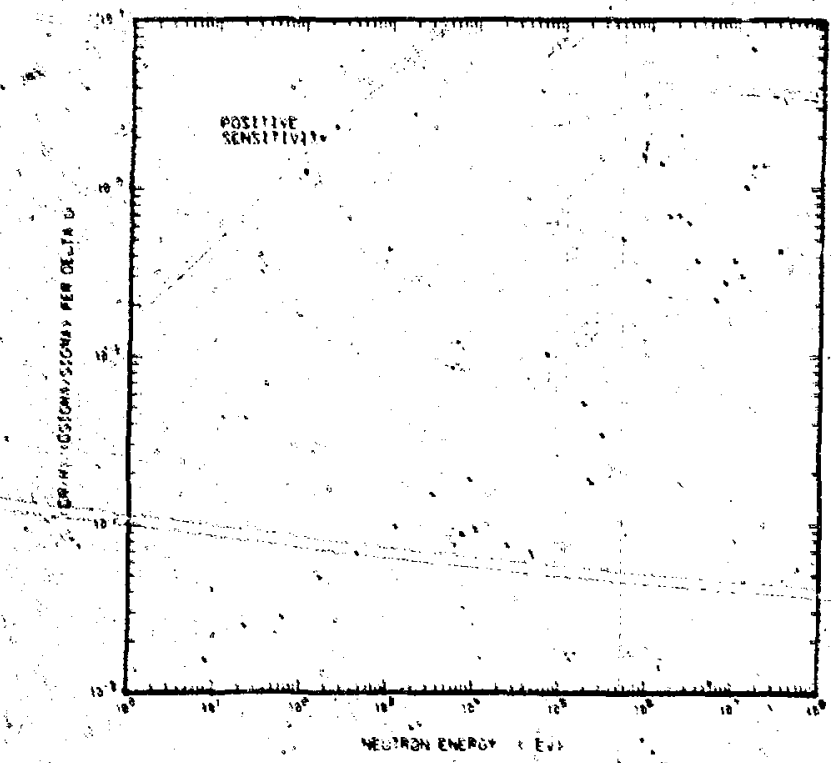

FIB. B-XIII. Sensitivity of inner TFC Mylar dose to Fe in zones 6-8, Meutron gain term only. 


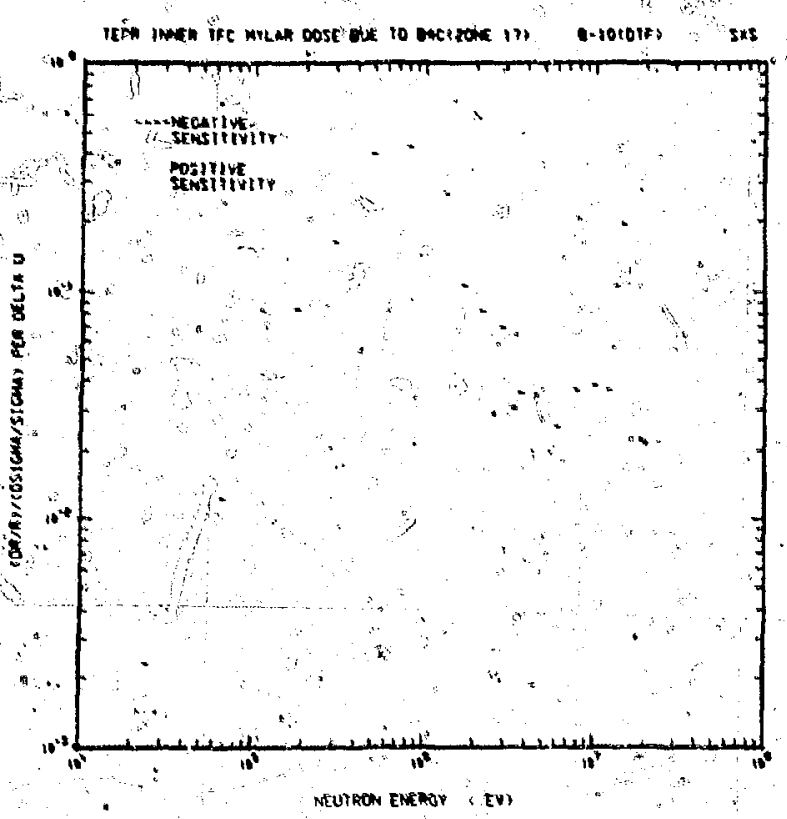

FIE. B-XIVII. Senstetutty of Inner. TFG Mylar dose to $10_{\mathrm{B}}$ in zone 17 . Neutron scatterIng eross section, loss term only.

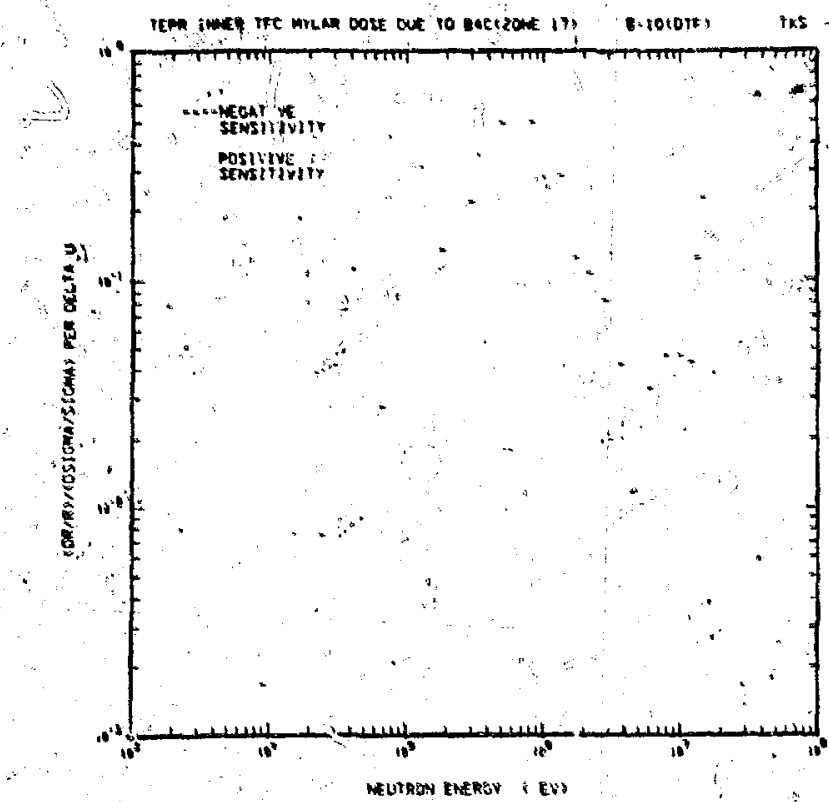

Fig. B-XLVIII. Sensitlyity of Inner TFC Nylar dose to. $10_{B} \cdot$ in zone 17 . Neutron total cross section; pure Ir sis term.

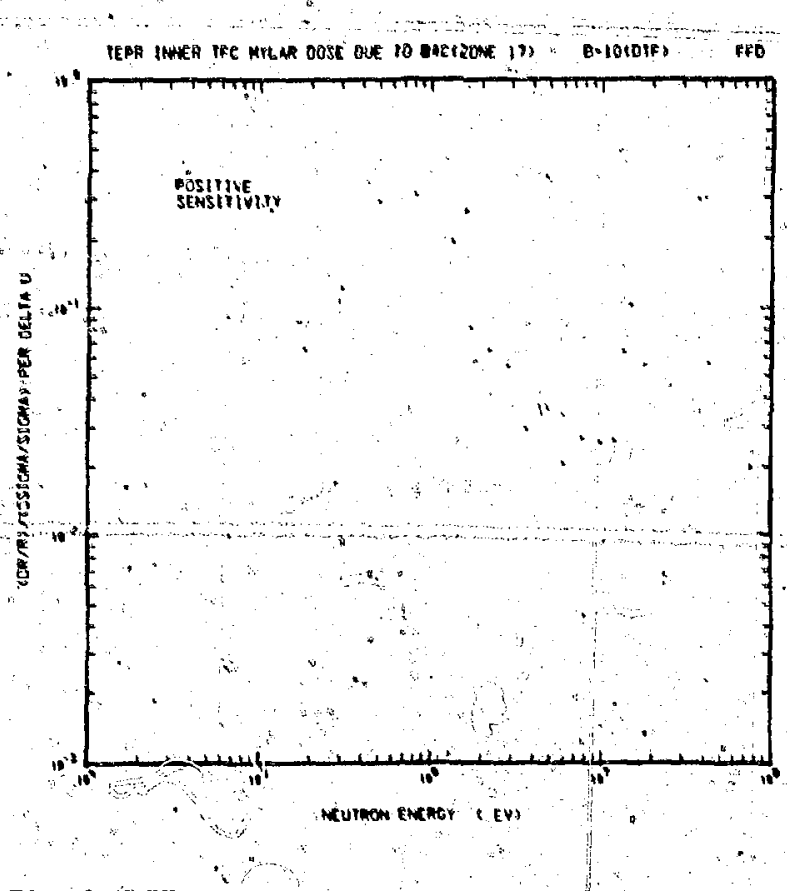

F18. B-XLIX. Sensftivity of Inner TFC Mylar dose to $10_{B}$ in zone 17. Neutron gain term only.

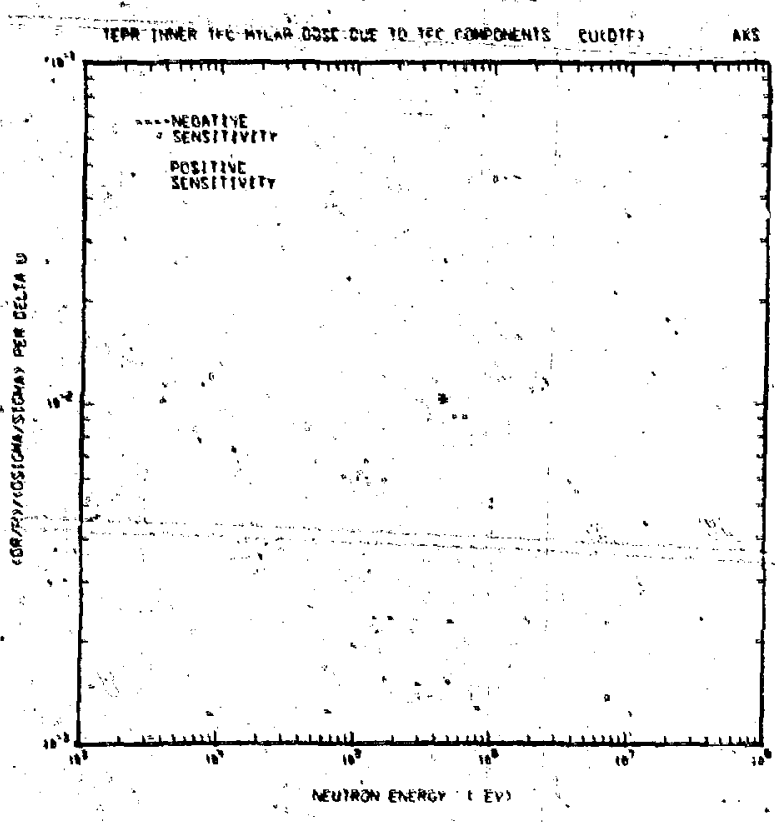

FIg. B-L. Sensitivity of inner TFC Mylar dose to Gu in TFC. Neutron absorption eross section, pure . Loss term. 


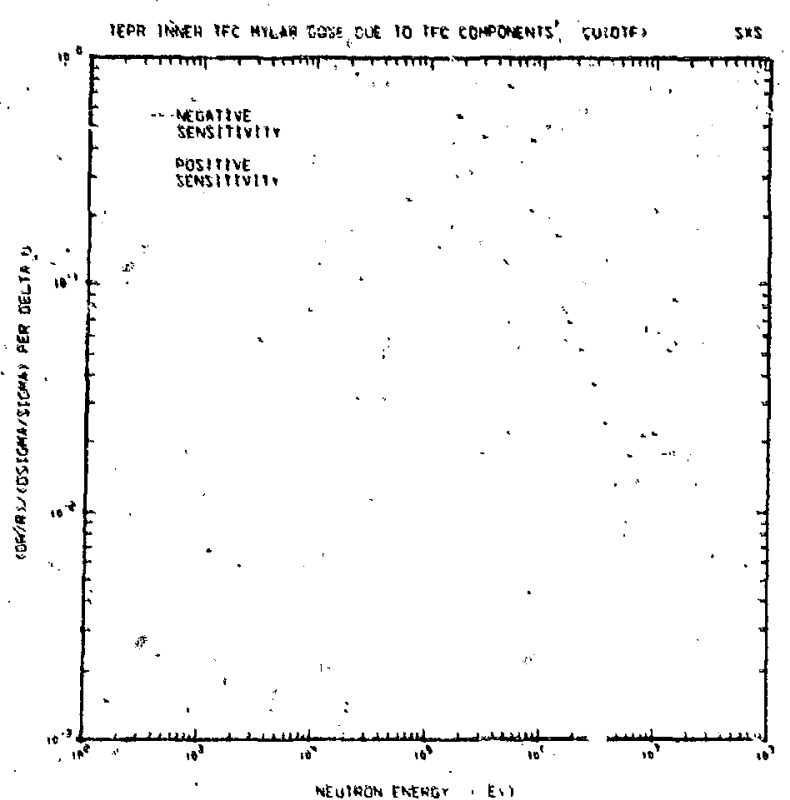

FIg. B-LI. Sensitivity of inner IFC Mylar dose to Cu in TFC. Neutron scaiterting cross section, loss term only.

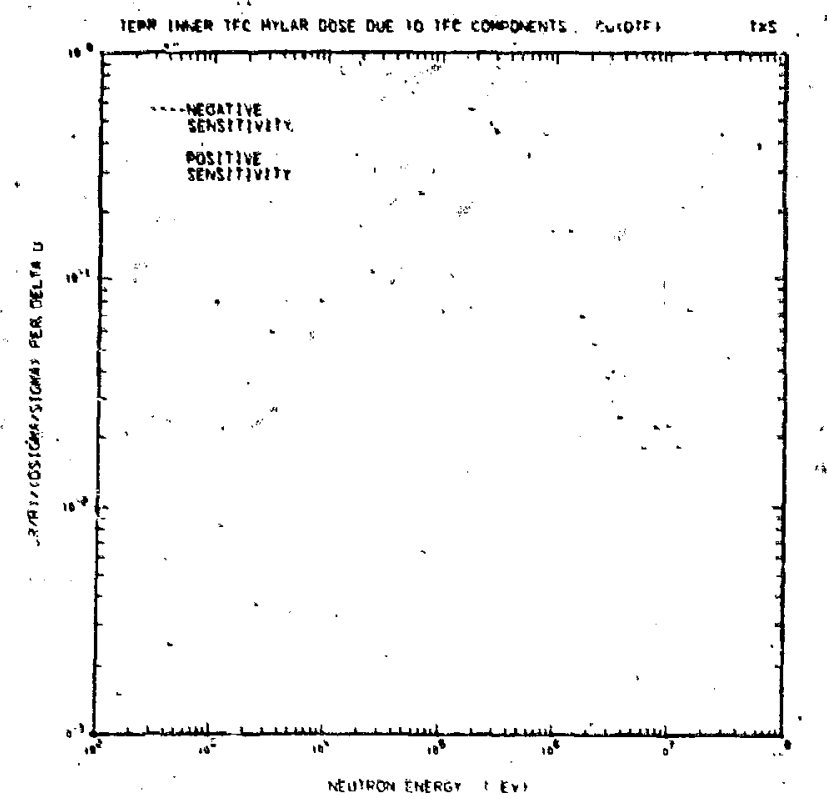

Mig. B-LII. Sensteivity of inner TFC Mylar dose to Gu in TFC. Neutron total cross section. pure loss term.

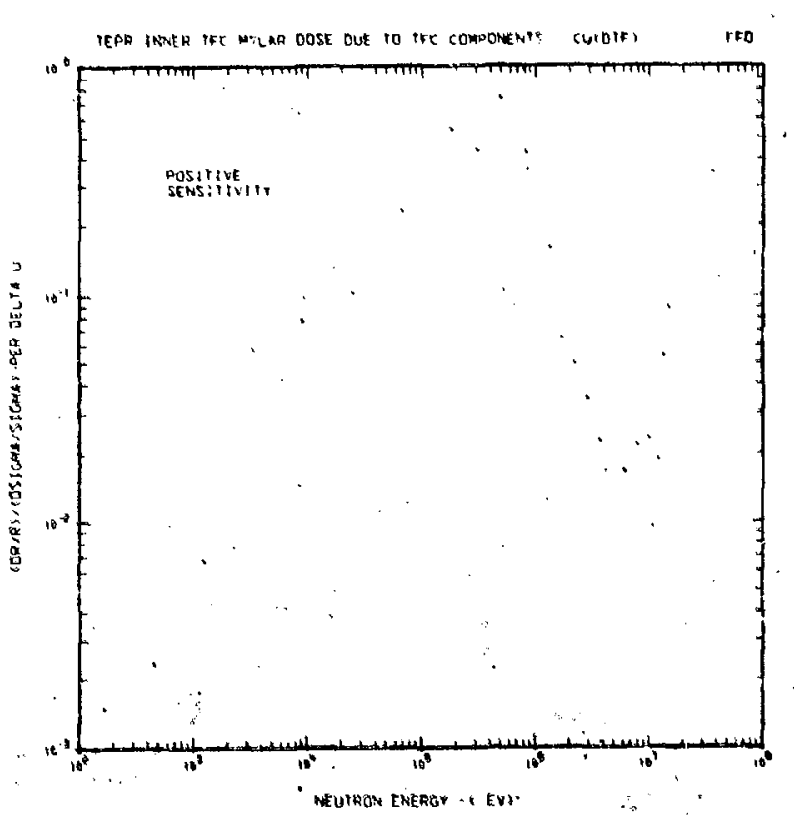

Fig. B-LIII. Senaltivity of tnner TFC Mylar dose to Gu in TFC. Neutron gain terth only.

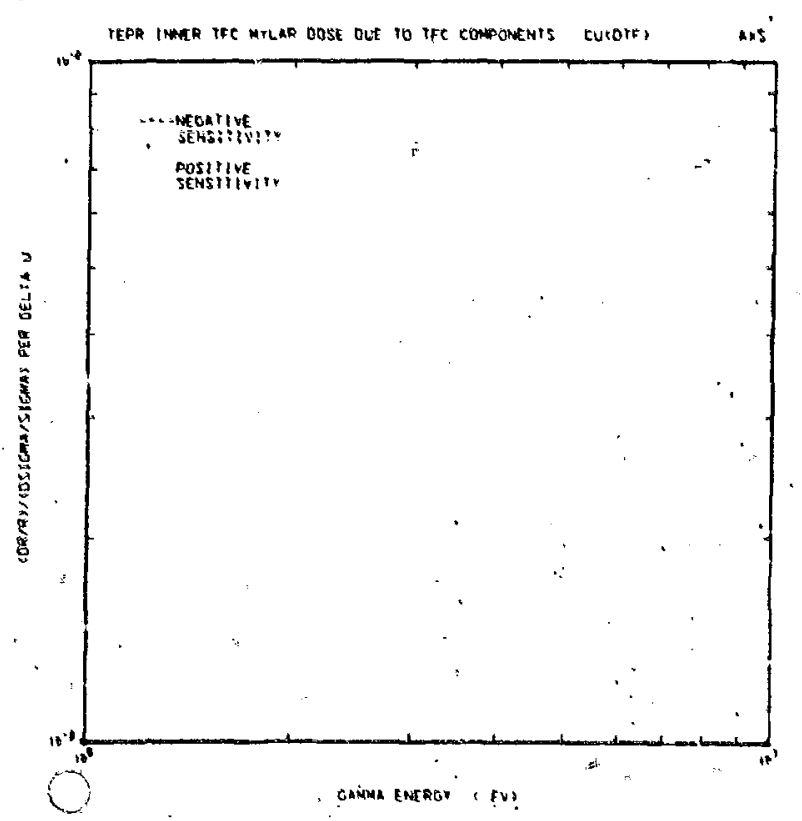

FIg. B-LIV. . Sensitivity of Inner TFr. Mylar dose to Cu In IFC. Gama absorptiot eroso section, pure loss term. 


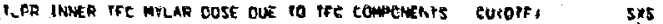

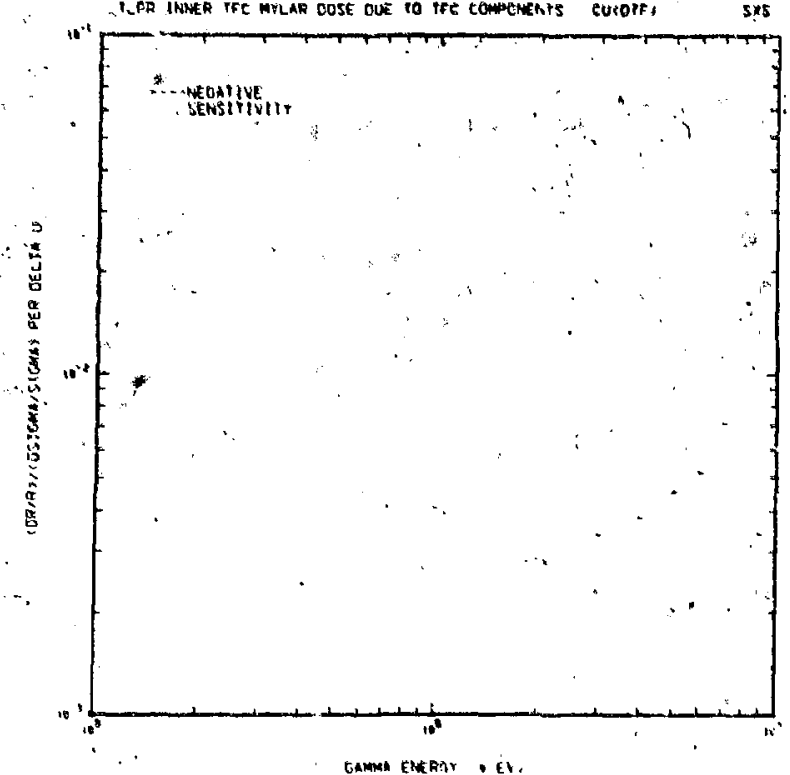

Fig. B-LV. Sensitivity of Inner TFC Mylar Dose to Cu In Trr. Gamma scattering cross section, loss term only.

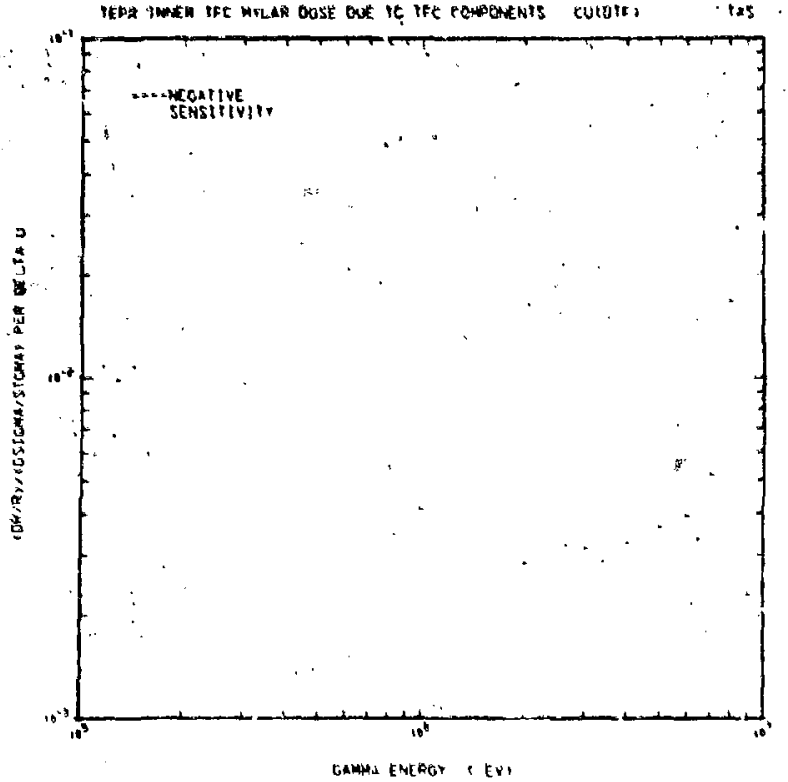

Fig. B-LVI. Sensitivity of tnner TFC Mylar dose to $\mathrm{Cu}$ in TFC. Ganma total cross section, pure lass term.

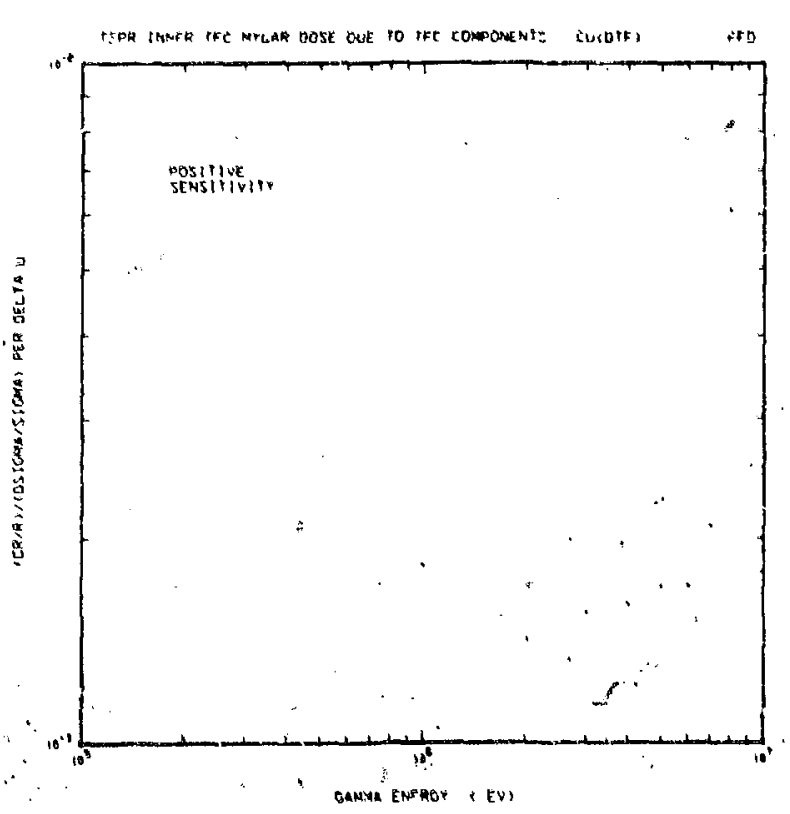

F1g. B-LVII. Sensitivity of Inner TFC Mylar dose to Gu in TFC. Galn terai only.

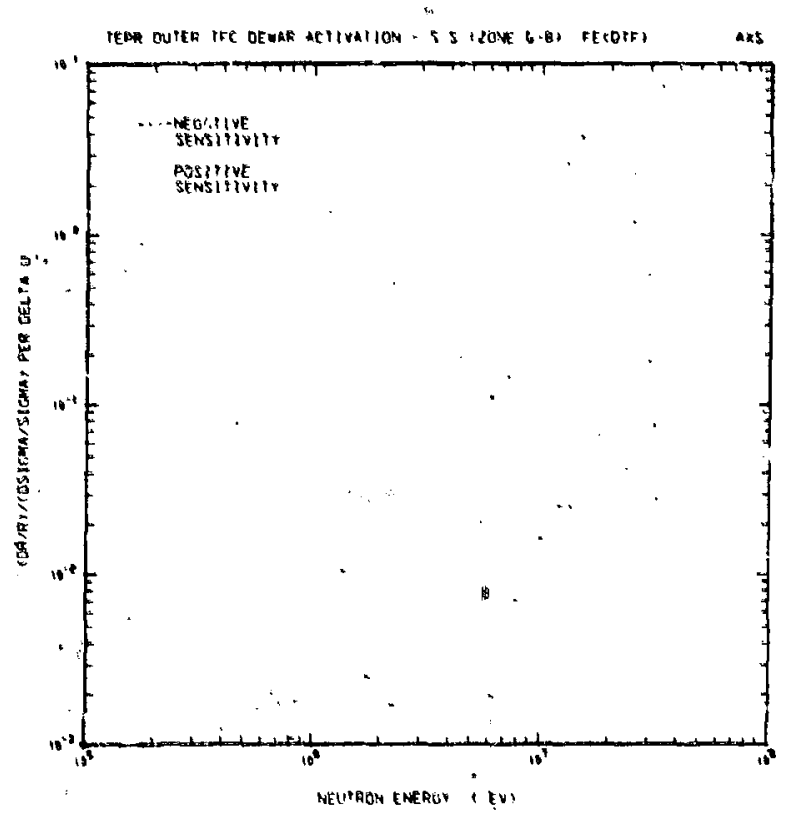

F18. B-LVIII. Sensitfvity of TFC dewar activation to $F e$ in zone 6-8. Neutron absorption cross section, pure loss terto. 


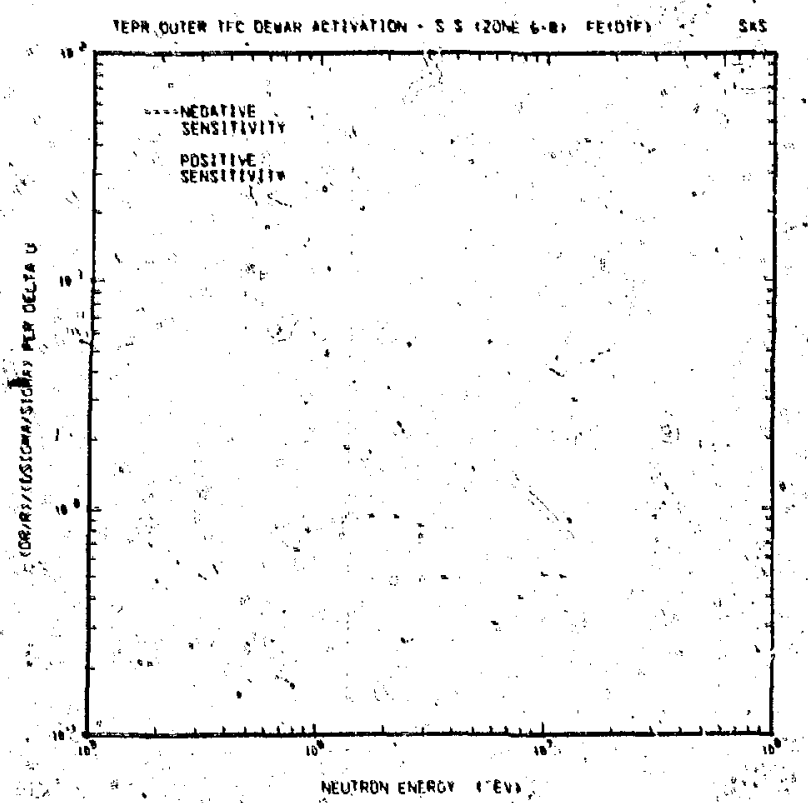

Fig, B-LIX. Sensttivity of, TFC dewar aetivation to Fe in zones 6-8. Neutron seattering. eross seetion, lose term only.

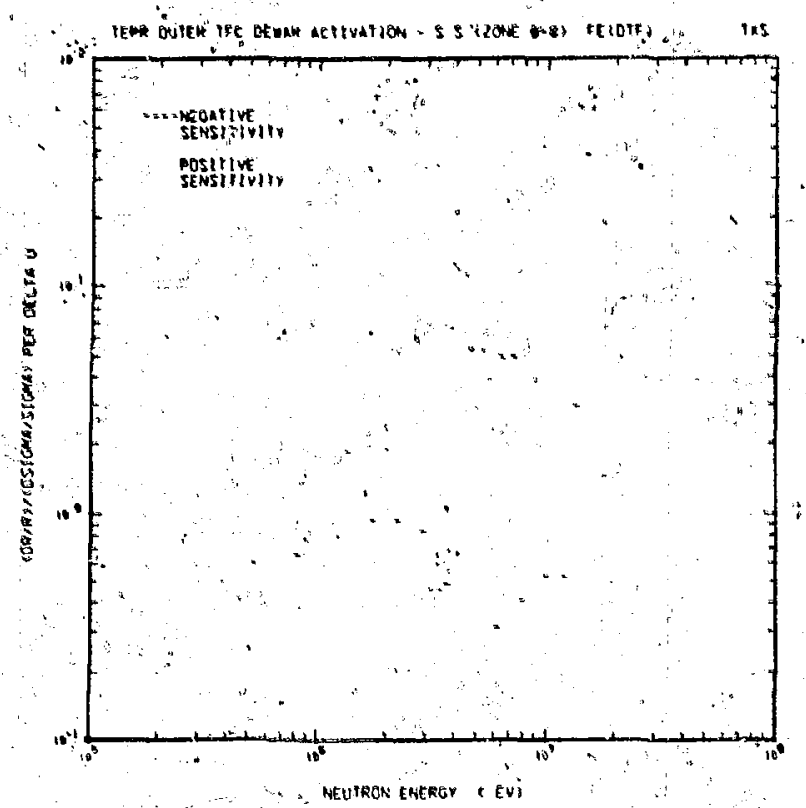

FIB. B-LX. Sensltivity of TFG dewar activation to Fe In zones 6-8. Neutron total cross section, pure loss term.

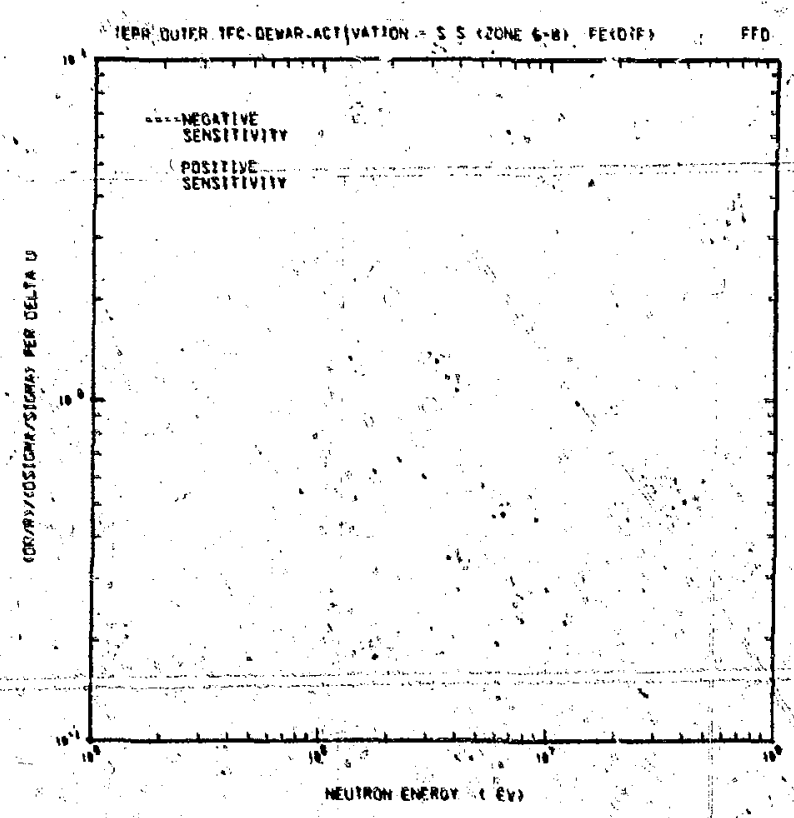

FIg. B-LXI. Sensttivity of TFC dewar activation to Fe in zonea 6-8. Neutron gain teirm only.
Fis. B-LXII. Sensitivity of TFC dewar activacion to $12 \mathrm{C}$ in graphita zones. Neutron absorption cross section, pure loss term. 


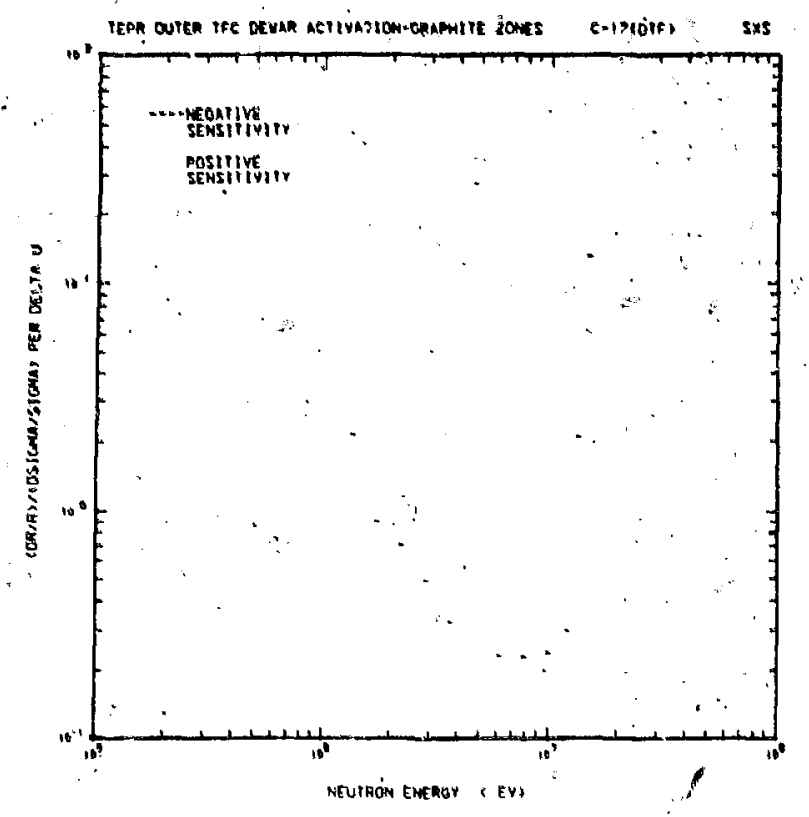

FIg. B-LXIII. Sensitivity of TFC dewar activation to $12_{\mathrm{C}}$ in graphite zones. Neutron scattering cross section, loss term only.

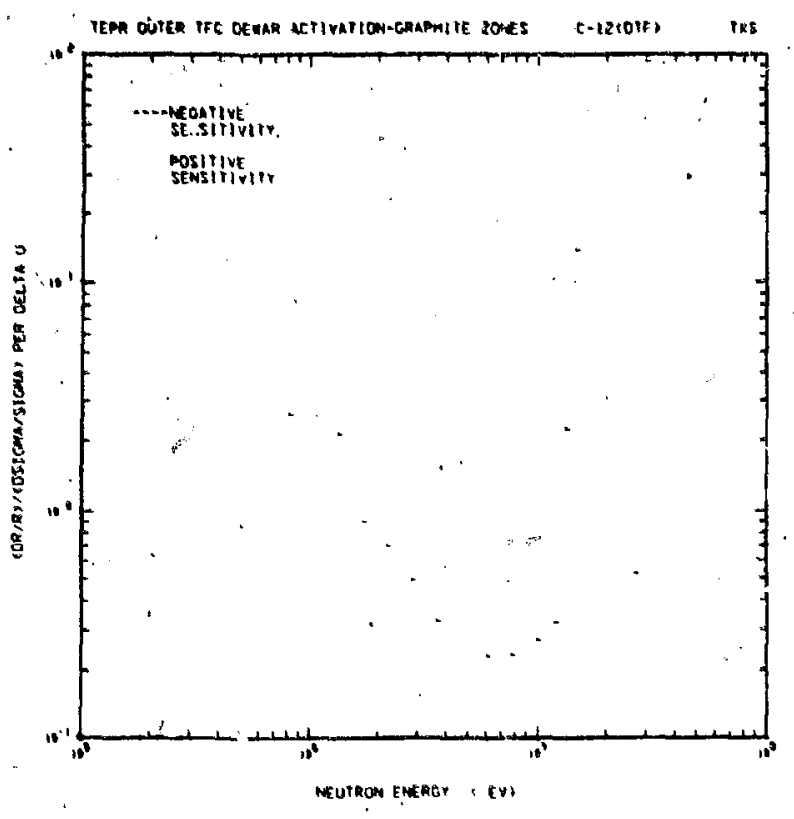

Fig. B-LXIV, Sensitivity of TFC diswar activation to ${ }^{12} \mathrm{C}$ in graphite zones. Neutron total cross section, pure loss term.

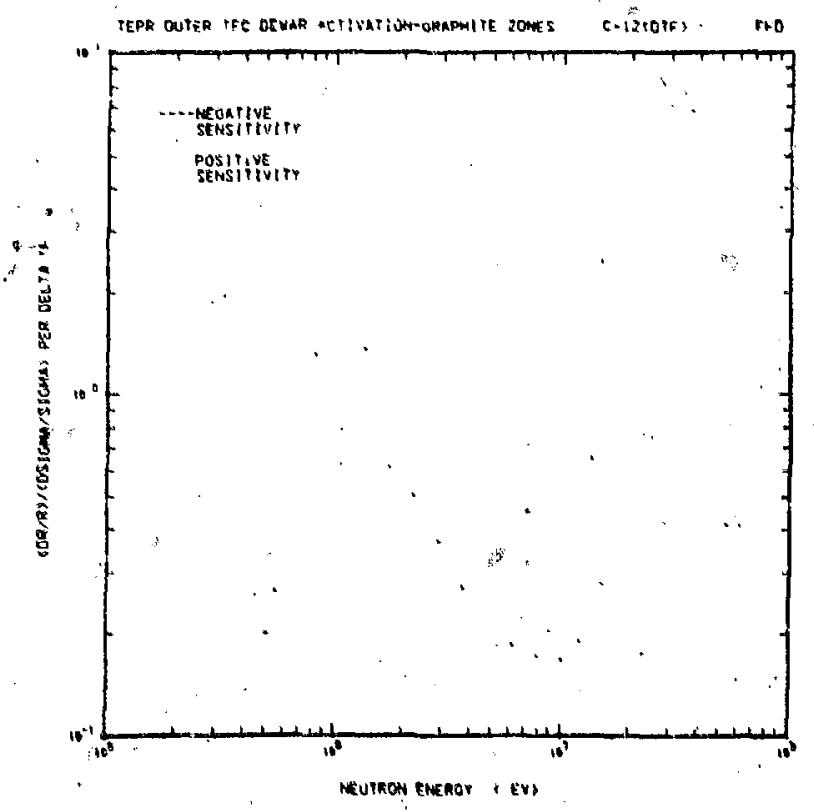

Fig. B-LXV. Sensitivity of TEC dewar activation to ${ }^{12} \mathrm{C}$ in graphite zones. Neutros gain tertio only.

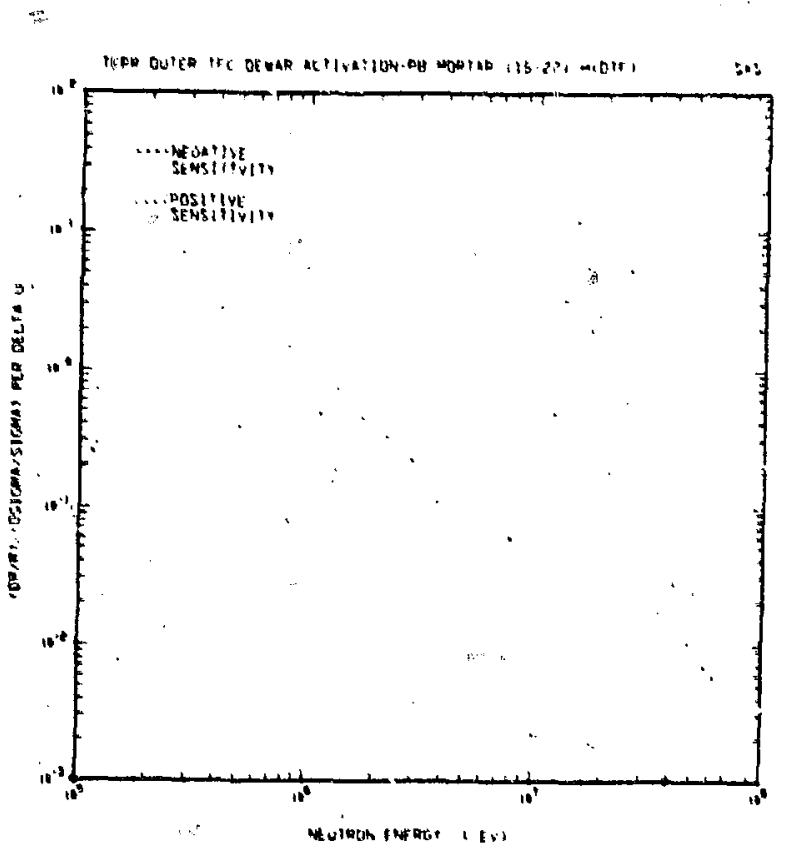

F18. B-LXVI. Sensitivity of TFC dewar activation to 4 in rones 15-22. Neutron scattering. cross section, loss term only. 


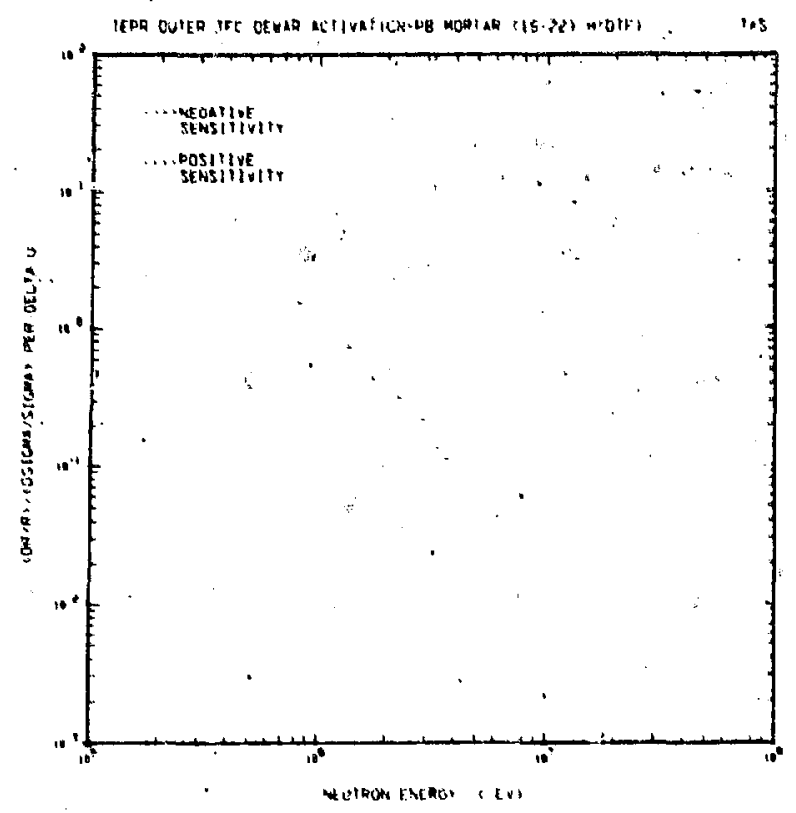

Fig. B-LXVII. Sensitivity of TFC dewar activation to $H$ in zones 15-22. NEutron total cross section, pure lass terms.

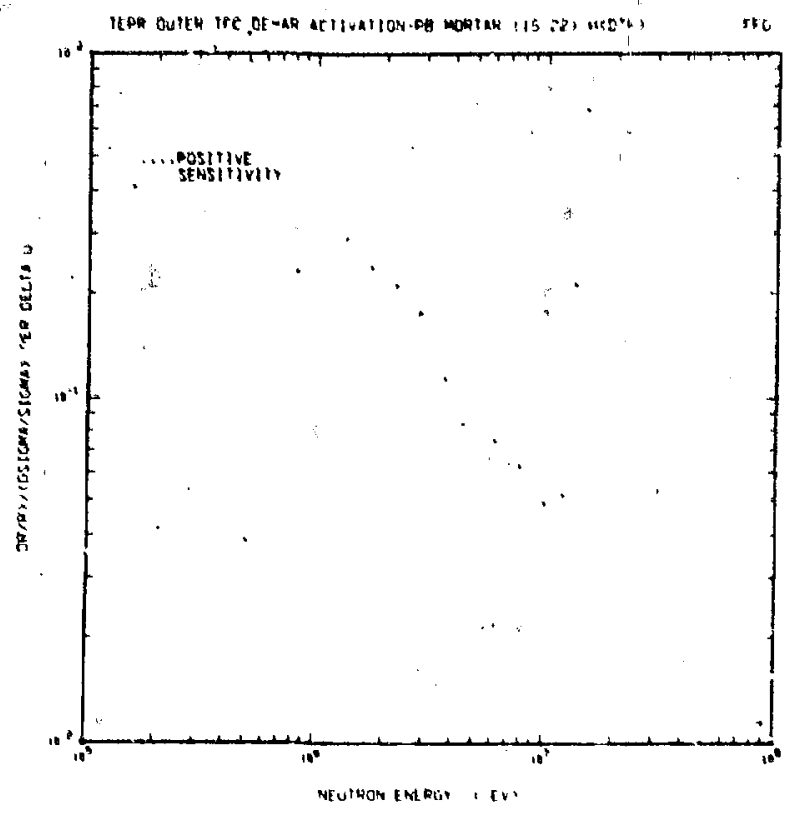

Fig. B-LXVIII. Sensitivity of TFC dewar activation to $H$ in zoncs 15-22. Neutron gain term only.

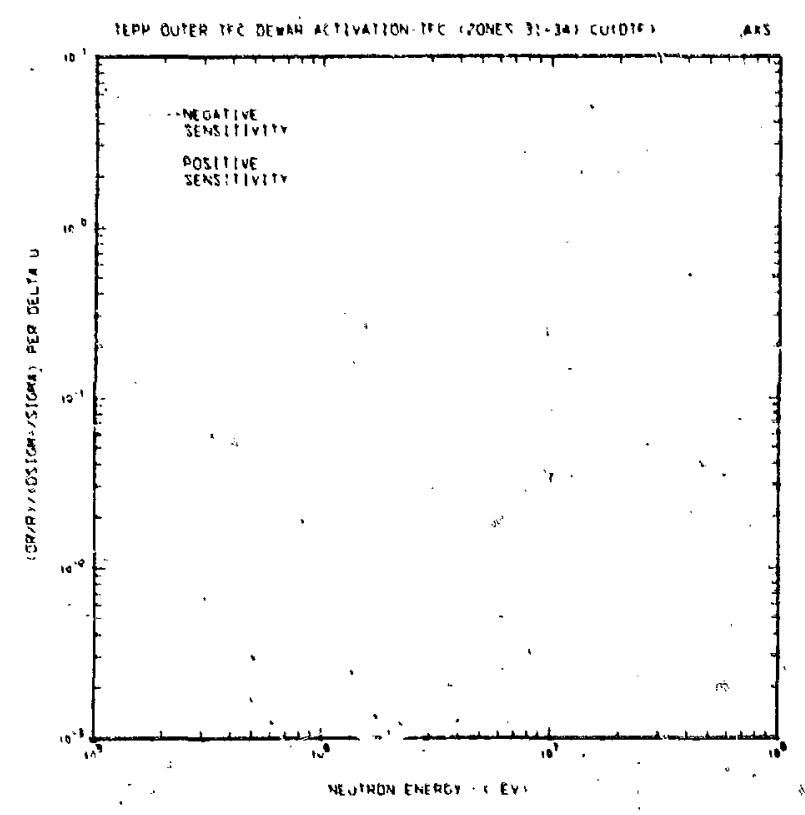

FIg. B-LXIX. Sensitivity of TFC dewer activation : to Gu in sopes 31-34. Neutron absorption cxoss section, pure loss term. 


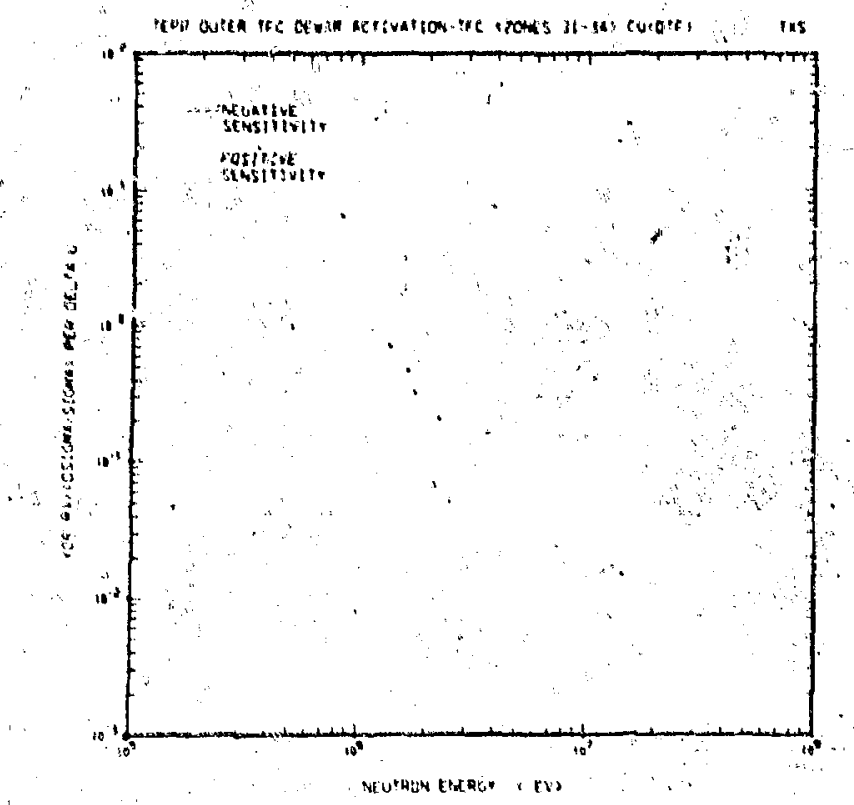

FIg. B-LKXI. Sensitivity of towar activation to Cu in sones 31-34. Neutzon total cross section, pure losa term.

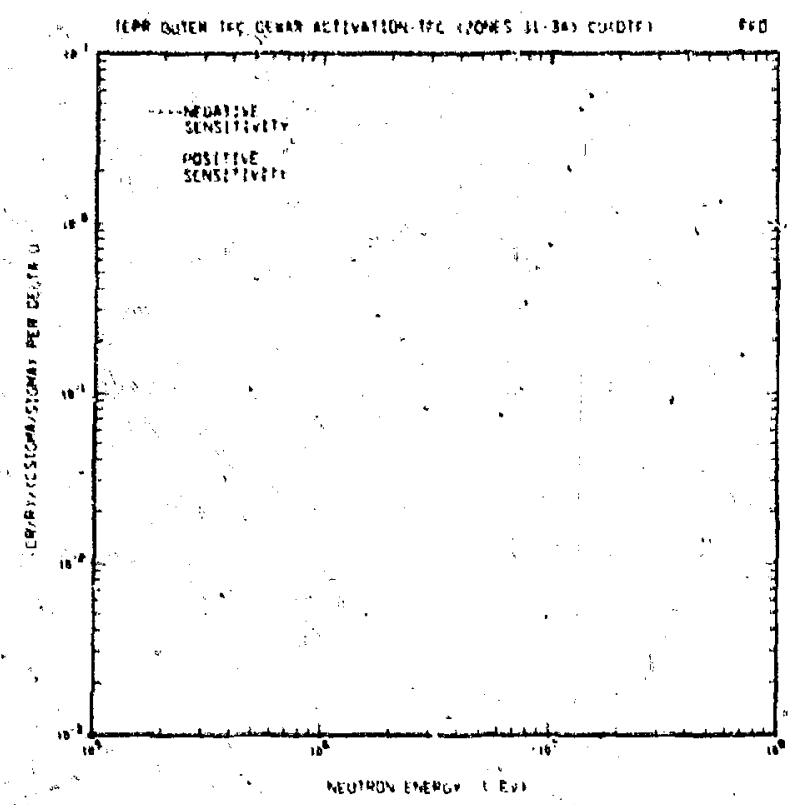

F2B. B-LXXII, Sensitivity of TFC dewar activation. to Gu in zones $32-34$. Neutron gain term only. 